PHYSIOLOGY OF PHOTOTROPHY AND HETEROTROPHY IN ALGAE

WITH CONTRASTING NUTRITIONAL CHARACTERISTICS, PYRENOMONAS SALINA (CRYPTOPHYCEAE)

AND POTERIOOCHROMONAS MALHAMENSIS (CHRYSOPHYCEAE)

\author{
by \\ Alan Jay Lewitus \\ M.S., San Jose State University / \\ Moss Landing Marine Laboratories (1984) \\ B.A., Rutgers University (1975) \\ SUBMITTED IN PARTIAL FULFILLMENT OF THE \\ REQUIREMENTS FOR THE DEGREE OF \\ DOCTOR OF PHILOSOPHY \\ at the \\ MASSACHUSETTS INSTITUTE OF TECHNOLOGY \\ and the \\ WOODS HOLE OCEANOGRAPHIC INSTITUTION
}

August 1990

(c)Alan J. Lewitus 1990

The author hereby grants to MIT and WHOI permission to reproduce and distribute copies of this thesis document in whole or in part.

Signature of Author

Joint Program in Oceanography,

Massachusetts Institute of Technology/Woods Hole

Oceanographic Institution

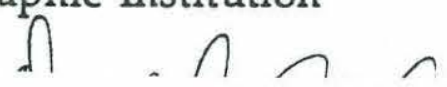

Certified by

David A. Caron, Thesis Supervisor

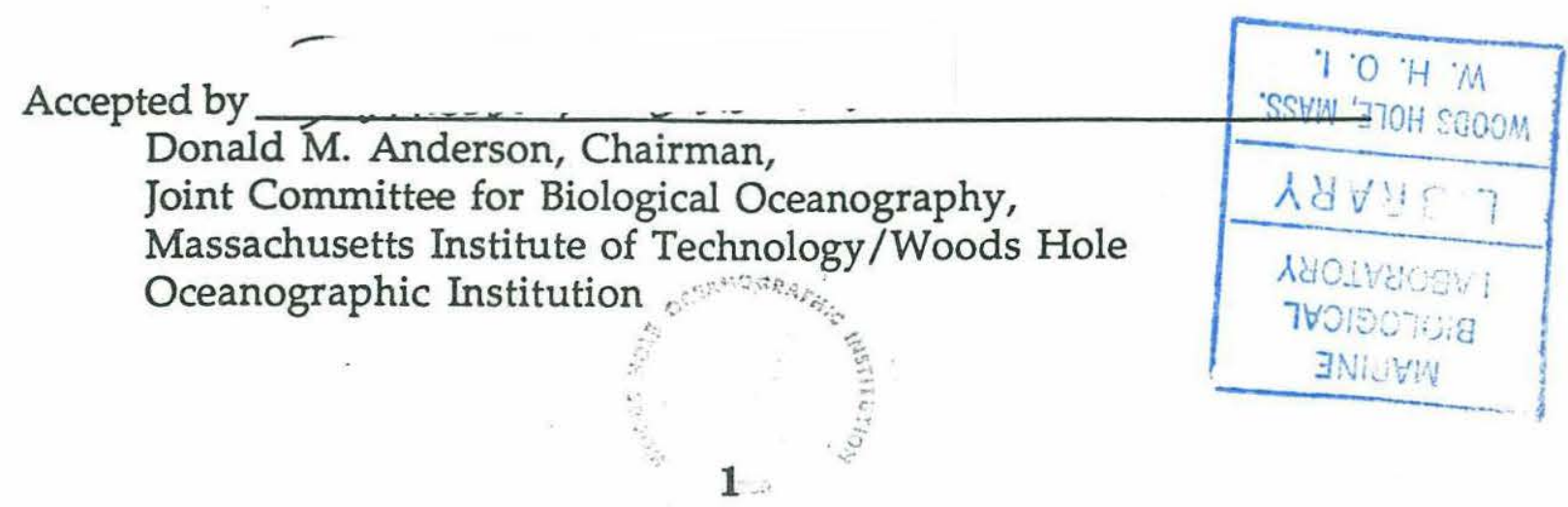


Physiological Studies of Phototrophy and Heterotrophy in Two

Algae with Contrasting Nutritional Characteristics,

Pyrenomonas salina (Cryptophyceae) and

Poterioochromonas malhamensis (Chrysophyceae)

by

Alan Jay Lewitus

Submitted in partial fulfillment of the requirements for the degree of Doctor of Philosophy

\begin{abstract}
The ability of algae to take up dissolved organic compounds is welldocumented for cultured and field populations yet the physiological mechanisms controlling this behavior are largely unknown. The effects of dissolved organic compound additions on the growth and photosynthetic apparatus were examined in two nanophytoplankton with contrasting nutritional characteristics, Pyrenomonas salina (Cryptophyceae) and Poterioochromonas malhamensis (Chrysophyceae). Although both species are capable of chemoheterotrophic nutrition, great differences were found in the relative contribution of heterotrophy to their overall nutrition and the physiological response of their photosynthetic systems to changes in nutritional mode. These differences indicate that the physiological mechanisms involved in integrating autotrophic and heterotrophic nutrition and the environmental control of this integration are distinct in these species.

In comparison to other facultatively heterotrophic algae, $\underline{P}$. malhamensis is exceptional in the dominant contribution of heterotrophy to its overall nutrition. Growth could be significantly enhanced by organic substrate additions to $\underline{P}$. malhamensis at all light intensities and the growth rate on glucose in the dark was equal to the maximum growth rate on glucose in the light. In addition, when organic substrates were available to the alga, chlorophyll a cell ${ }^{-1}$ was reduced and the extent of this reduction varied with the type of organic substrate. These results support the hypothesis that chloroplast development in $\underline{P}$. malhamensis is catabolite-sensitive. The inhibitory effect of organic substrates on chlorophyll production by $\underline{\mathrm{P}}$. malhamensis was only transitory; i. e., after the initial decline in chlorophyll a cell ${ }^{-1}$, chlorophyll production increased and the organic substrate uptake rate cell-1 decreased despite the persistence of a relatively high substrate concentration in the culture
\end{abstract}


medium. These results suggest that the accumulation of substance(s) excreted by $\underline{P}$. malhamensis conditioned the culture medium and led to a relief of the inhibitory effect of organic substrates on chlorophyll production by the alga.

$\underline{P}$. salina is typical of most facultatively heterotrophic algae in culture in that phototrophic growth can be enhanced by organic enrichment only at light intensities limiting for photoautotrophic growth. Contrary to $\underline{P}$. malhamensis, the effect of organic compounds on the growth rate of $\underline{P}$. salina was critically light intensity-dependent under all organic substrate concentrations used in this study. In addition, whereas in $\underline{P}$. malhamensis the addition of organic substrates repressed chloroplast development, only selected elements of the photosynthetic system were inhibited by organic substrate additions to $\underline{P}$. salina, and the uptake rate of inorganic carbon was not affected. These results indicate that these algae have contrasting metabolic strategies for integrating autotrophic and heterotrophic nutrition for growth. When organic substrates are available to $\underline{P}$. malhamensis, the synthesis of the photosynthetic apparatus is repressed and growth and maintenance requirements are met by the catabolism of organic substrates. In contrast, given a sufficient light supply, maximal growth rates can be obtained photoautotrophically by $\underline{P}$. salina, but organic substrates can be used to augment the carbon, energy, and/or reductant supply when photosynthetic rates are light-limited.

The physiological response of $\underline{P}$. salina's photosynthetic system to changes in environmental conditions was further examined by testing two hypotheses. The first hypothesis was that $\underline{P}$. salina responds to nitrogen deprivation by mobilizing phycoerythrin in order to help sustain cellular nitrogen requirements. In response to nitrogen depletion from the culture medium, the phycoerythrin content of $\underline{P}$. salina cells decreased prior to any changes in growth rate, cell volume, or cellular concentrations of chlorophyll $\underline{a}$, carbon, or nitrogen. These results support the hypothesis and suggest that, in addition to its light-harvesting role, phycoerythrin may serve as an important endogenous nitrogen source for this cryptophyte. The second hypothesis was that glycerol uptake selectively inhibits the synthesis of photosynthetic components involved in light-harvesting. Glycerol addition to $\underline{P}$. salina cultures grown at a limiting light intensity reduced the cell phycoerythrin content, phycoerythrin to chlorophyll a ratio, thylakoid width, degree of thylakoid packing, number of thylakoids cell-1, and size of photosystem II complexes. These properties were reduced to a similar extent by increasing the light intensity for growth. These results strongly support the hypothesis and indicate that enhancement of heterotrophic potential occurs at the expense of light-harvesting ability in glycerol-grown $\underline{\mathbf{P}}$. salina.

Thesis Supervisor: David A. Caron, Associate Scientist, WHOI 


\section{ACKNOWLEDGEMENTS}

I am deeply indebted to my thesis advisor, Dave Caron. Dave's guidance was invaluable to my growth as a scientist and his influence will continue with me throughout my career. His encouragement and support provided a solid foundation for my progress at WHOI.

I would like to thank the other members of my thesis committee; Rob Olson, Diane Stoecker, John Waterbury, Penny Chisholm, and Ken Miller, whose ideas, suggestions, and criticisms improved this thesis immensely. I gained valuable experience and knowledge working with Rob Olson during the early portion of my WHOI career for which I am greatly appreciative. Thanks also to Joel Goldman for guidance early on.

My research involved the use of many different instruments and techniques, and I'd like to thank those people who kindly and patiently guided me through these techniques. Erik Zettler helped me learn to use the flow cytometer and was always unselfishly available. Ken Miller opened his laboratory to me and Jules Jacob taught me the freeze-fracture technique. Gene Copeland and the omni-available Louie Kerr taught me thin-sectioning. Mark Dennett guided me through $\mathrm{CHN}$ analysis and was helpful in many other ways. Neil Blough lent the use of his spectrofluorometer and he and Sarah Green were patient instructors of its use. Hovie Clifford helped me collect samples in the early days. Bonnie Woodward graciously did CHN's for me.

Thank you, Jake Peirson, for your support (moral and financial) and Abbie Jackson, Lisa Taylor, and Judy Kleindinst for your kind assistance. 
Special thanks go to my officemate and close friend, Ee Lin Lim (aka Elaine), who provided a never-ending supply of moral support. Her kindness and generosity will always be remembered. I'm also greatly indebted to Celia Marrasé and Linda Amaral, lab-mates/good friends who helped me survive the last "throes" of writing.

Thank you, Mom and Dad, for having confidence in me. You were always there when I needed you and kept my spirits high throughout. This thesis would not exist without your help.

Finally, thank you, Marianne, for your encouragement and love.

This research was funded by the Massachusetts Institute of Technology/Woods Hole Oceanographic Institution Joint Program, Ocean Ventures Fund Grant 25/85.10 of the Woods Hole Oceanographic Institution Education Program, and NSF Grants BSR-8620443 and BSR8919447. 


\section{TABLE OF CONTENTS}

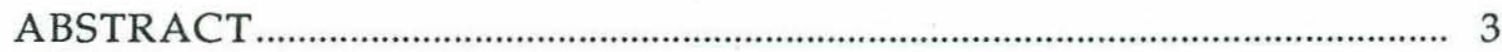

ACKNOWLEDGEMENTS ......................................................................... 5

LIST OF TABLES ........................................................................................ 9

LIST OF FIGURES …………………………………....................................... 10

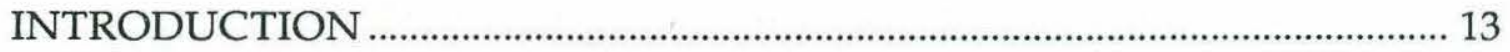

CHAPTER 1. Historical Perspective ...................................................................... 29

Cryptophytes as opportunistic algae ............................................................. 31

Uptake of dissolved organic substrates by Poterioochromonas

malhamensis .................................................................................................. 34

Uptake of dissolved organic substrates by Pyrenomonas

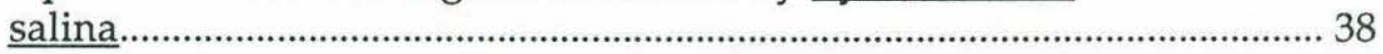

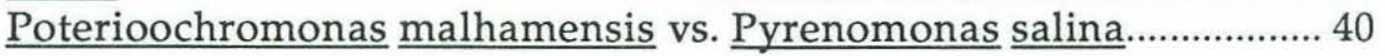

CHAPTER 2. Relative Effects of Nitrogen or Phosphorus Depletion and Light Intensity on the Pigmentation, Chemical Composition, and Volume of Pyrenomonas salina (Cryptophyceae) [Reprint]........................ 53

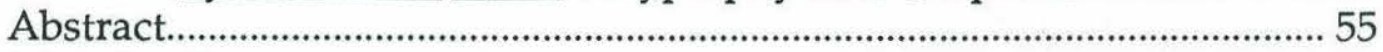

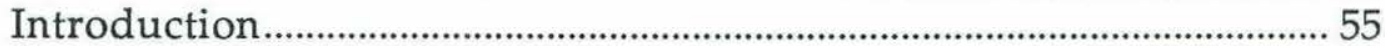

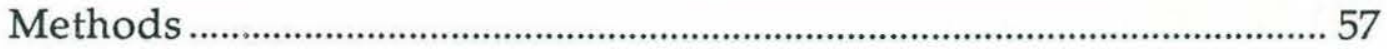

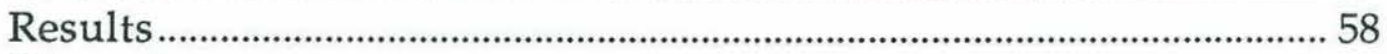

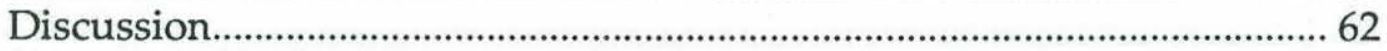

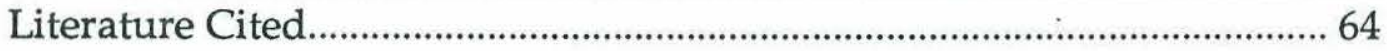

CHAPTER 3. Physiological Responses of Phytoflagellates to Dissolved Organic Substrate Additions. 1. Dominant Role of Heterotrophic Nutrition in Poterioochromonas malhamensis

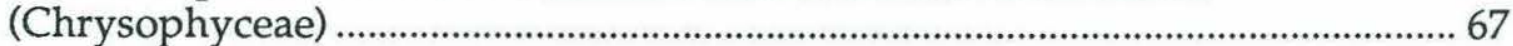

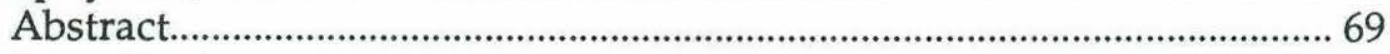

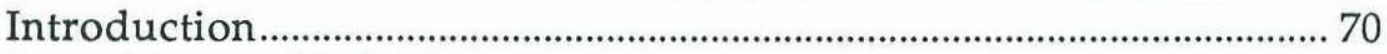

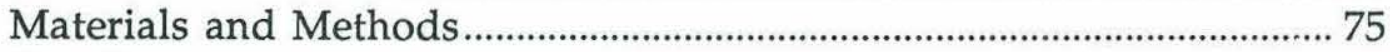

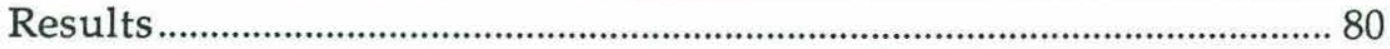

Effect of organic compounds on growth .......................................... 80

Effect of organic compounds on chlorophyll a content................ 91

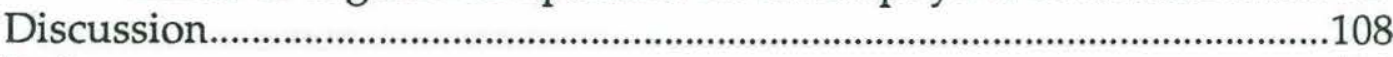

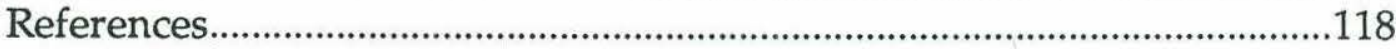


CHAPTER 4. Physiological Responses of Phytoflagellates to Dissolved Organic Substrate Additions. 2. Dominant Role of Autotrophic Nutrition in Pyrenomonas salina (Cryptophyceae).....................127

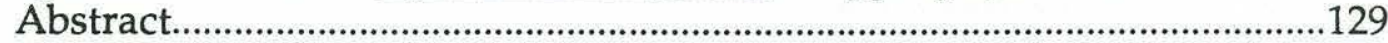

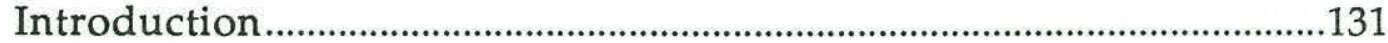

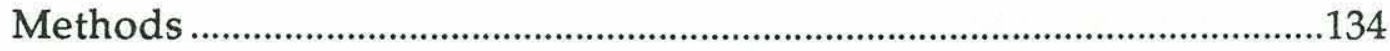

Experiment 1. Growth, size, and pigment patterns.......................134

Results

Experiment 2. [14C]-glycerol vs. [14C]-NaHCO3 uptake.................136

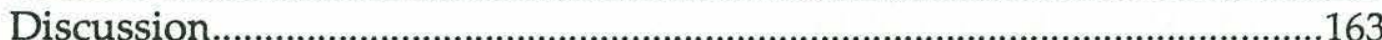

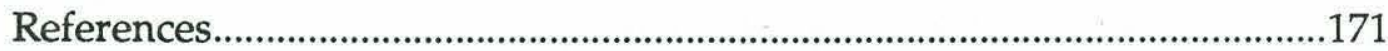

CHAPTER 5. Effects of Light Intensity and Glycerol Addition on the Organization of the Photosynthetic Apparatus in the Facultative Heterotroph, Pyrenomonas salina (Cryptophyceae) .............................................177

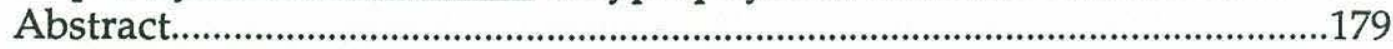

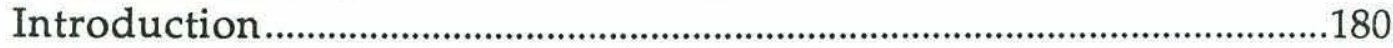

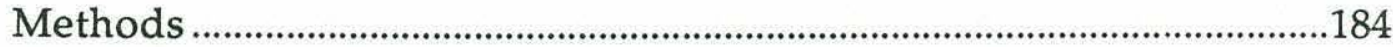

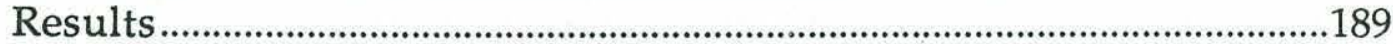

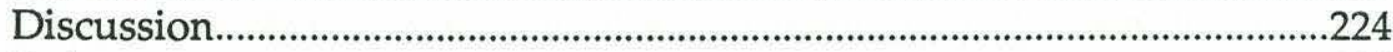

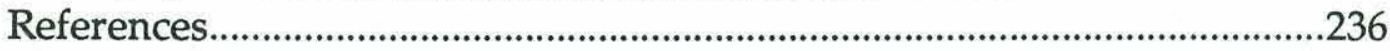

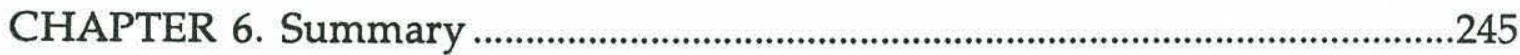




\section{LIST OF TABLES}

\section{CHAPTER 2:}

Table 1: Effect of light intensity and nutrient depletion on

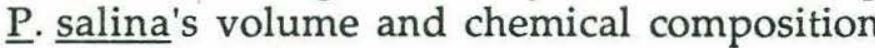

Table 2: Effect of light intensity and nutrient depletion on

P. salina's pigmentation.

Table 3: Effect of light intensity and nutrient depletion on

P. salina's cell nitrogen and phycoerythrin nitrogen

CHAPTER 3:

Table 1: Effect of organic compound additions and light intensity on the growth rate of $\underline{P}$. malhamensis

Table 2: Effect of organic substrates on $\underline{P}$. malhamensis's chlorophyll content.

CHAPTER 4:

Table 1: Effect of organic compound additions and light intensity on the growth rate of $\underline{P}$. salina ......................................141

Table 2: Effect of light intensity and glycerol on $\underline{P}$. salina's volume, chemical composition, and $\mathrm{CO}_{2}$ uptake rate

\section{CHAPTER 5:}

Table 1: Effect of light intensity and glycerol on $\underline{P} . \underline{\text { salina's }}$ pigmentation

Table 2: Effect of light intensity and glycerol on $\underline{P}$. salina's thylakoid membrane system

Table 3: Effect of light intensity and glycerol on the size and density of freeze-fracture particles from $\underline{P}$. salina's thylakoid membranes. 


\section{LIST OF FIGURES}

\section{CHAPTER 2:}

Figure 1: Growth of $\underline{P}$. salina under nitrogen- or phosphorusdepleted conditions ……........................................................................... 57

Figure 2: Growth rate of $\underline{P}$. salina as a function of irradiance ................ 58

Figure 3: Effect of light intensity and nutrient depletion on

$\underline{P}$. salina's growth and cell volume.......................................................... 59

Figure 4: Effect of light intensity and nutrient depletion on

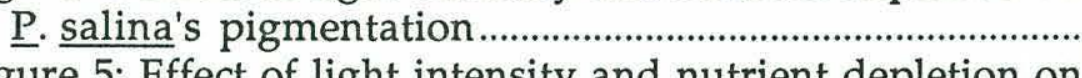

Figure 5: Effect of light intensity and nutrient depletion on

the phycoerythrin to chlorophyll ratio of $\underline{P}$. salina

Figure 6: Effect of nitrogen depletion on $\underline{P}$. salina's nitrogen, phycoerythrin, and chlorophyll contents

\section{CHAPTER 3:}

Figure 1: Effect of glucose on $\underline{P}$. malhamensis's growth under different light conditions

Figure 2: Light vs. dark growth of $\underline{P}$. malhamensis on glucose............. 85

Figure 3: Effect of light intensity and glucose concentration

on $\underline{P}$. malhamensis's growth rate.

Figure 4: Effect of glycerol, ethanol, and glycine on $\underline{P}$. malhamensis's growth rate at different light intensities

Figure 5: Patterns of growth, chlorophyll, glucose concentration, and glucose uptake rate in

P. malhamensis culture

Figure 6: Patterns of growth, chlorophyll, organic substrate concentration, and organic substrate uptake rate in $\underline{P}$. malhamensis cultures grown with glycerol or ethanol

Figure 7: Effect of glucose or glycerol on growth and chlorophyll in serially transferred $\underline{P}$. malhamensis cultures

Figure 8: Effect of $\underline{\mathrm{P}}$. malhamensis population density on $\mathrm{pH}$.............. 103

Figure 9: Effect of $\mathrm{pH}$ on $\underline{\mathrm{P}}$. malhamensis's growth and chlorophyll

Figure 10: Effect of conditioned medium and cyclic AMP

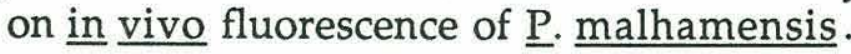

\section{CHAPTER 4:}

Figure 1: Effect of glucose, ethanol, and glycine on $\underline{P}$. salina's growth rate at different light intensities 
Figure 2: Effect of glycerol on $\underline{P}$. salina's growth rate at different light intensities

Figure 3: Effect of light intensity and glycerol concentration on $\underline{\mathrm{P}}$. salina's growth rate. .147

Figure 4: Effect of glycerol on $\underline{P}$. salina's growth under continuous light and a light/dark cycle

Figure 5: Effect of light intensity and glycerol concentration on $\underline{P}$. salina's volume

Figure 6: Effect of organic compounds on $\underline{P}$. salina's pigmentation

Figure 7: Effect of light intensity and glycerol on $\underline{P}$. salina's uptake rate of $\mathrm{CO}_{2}$ and glycerol carbon

Figure 8: Thin-section electron micrographs of $\underline{\underline{P}}$. salina under different light and glycerol conditions

\section{CHAPTER 5:}

Figure 1: Effect of glycerol and light intensity on $\underline{P} . \underline{\text { salina's }}$ growth

Figure 2: Effect of glycerol and light intensity on $\underline{P}$. salina's pigmentation

Figure 3: Thin-section electron micrographs of $\underline{\underline{P}}$. salina grown under different light and glycerol conditions

Figure 4: Thin-section electron micrographs of $\underline{P}$. salina's thylakoid system under different light and and glycerol conditions

Figure 5: Effect of glycerol and light intensity on various properties of $\underline{P}$. salina's thylakoid system

Figure 6: Freeze-fracture electron micrograph showing

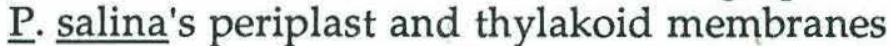

Figure 7: Freeze-fracture electron micrograph showing $\underline{\text { P. salina's nucleus and thylakoid membranes }}$ .211

Figure 8: Freeze-fracture electron micrograph showing $\underline{\mathrm{P}}$. salina's chloroplast envelope and thylakoid membranes

Figure 9: Freeze-fracture electron micrograph showing fracture faces of $\underline{P}$. salina's thylakoid membranes.

Figure 10: Effect of glycerol and light intensity on the size of freeze-fracture particles from $\underline{\underline{P}}$. salina's $\mathrm{EF}$ faces

Figure 11: Normalized plot showing the effect of glycerol and light intensity on the size of $\underline{P}$. salina's EFs freeze-fracture particles

Figure 12: Effect of glycerol and light intensity on the size of freeze-fracture particles from $\underline{\underline{P}}$. salina's $\mathrm{PF}$ faces. 
12 
INTRODUCTION

13 
14 


\section{INTRODUCTION}

A fundamental issue in our understanding of the pathways and rates of nutrient and energy cycling in aquatic environments is knowledge of the nutritional role of phytoplankton within microbial food webs. It is becoming increasingly evident that algae are not strictly primary producers, and can contribute significantly to bacterial ingestion in some aquatic environments (Bird and Kalff, 1986, 1987; Estep et al., 1986; Porter, 1988; Sanders and Porter, 1988; Bockstahler and Coats, 1990; Caron and Lim, unpublished data, 1990). Although considerable interest in the ecological importance of algal phagotrophy has been generated in recent years, few studies in the last decade have examined the potential contribution of algae to the uptake of dissolved organic matter. This is unfortunate because little is known about the heterotrophic capabilities of the smaller nanophytoplankton and picophytoplankton now considered important contributors to energy, carbon, and nutrient cycling in aquatic environments (Pomeroy, 1974; Waterbury et al., 1979; Johnson and Sieburth, 1979, 1982; Shapiro and Guillard, 1987; Stockner, 1988; Hargraves et al., 1989; Sieburth and Johnson, 1989). Given that the availability of dissolved organic material to aquatic microorganisms is greater than previously estimated (Suzuki and Sugimura, 1985; Flynn and Butler, 1986; Sugimura and Suzuki, 1988; Kieber et al., 1989) and the likelihood that the concentrations of dissolved organic compounds within microenvironments are much higher than those estimated based on bottle 
samples, a reassessment of the ecological significance of algal uptake of dissolved organic compounds is clearly needed.

This research examines a basic gap in our knowledge of the role of algae in the cycling of dissolved organic matter in nature; namely, the physiological mechanisms by which algae integrate autotrophic and heterotrophic nutrition and the environmental cues controlling this integration. The research focuses on the physiological responses to changes in light intensity and the availability of dissolved organic substrates of two nanophytoplankton with contrasting nutritional characteristics; Pyrenomonas salina, a marine cryptophyte, and Poterioochromonas malhamensis, a freshwater chrysophyte. Both species are capable of chemoheterotrophic nutrition (e. g., each can grow in the dark) but, as demonstrated in this study, the environmental signals involved in triggering changes in nutritional mode and the structural and biochemical modifications of the photosynthetic apparatus that accompany these changes are very different in these algae.

Given the lack of information on the distributions of these species and their uptake affinities for dissolved organic compounds, it is presently impossible to determine whether the cellular mechanisms demonstrated in this study are laboratory artifacts caused by the addition of unnaturally high concentrations of organic substrates or reflect the adaptive responses of these algae to inputs of organic substrates in nature. $\underline{P}$. malhamensis clone L1297 was isolated from a "red film on a stone" from a mountain

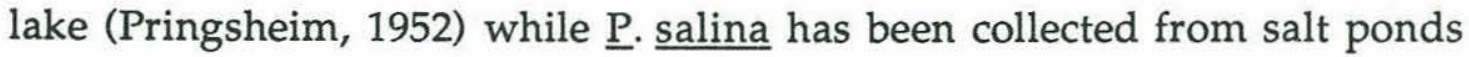
(Wislouch, 1924; Carter, 1937; Hulburt, 1965). Although rock pools and salt 
ponds are environments where relatively high dissolved organic compound concentrations can potentially occur (North and Stephens, 1967; Hellebust, 1970; Lee et al., 1975; Hellebust and Lewin, 1977; Saks and Kahn, 1979; Valiela and Teal, 1979), it is questionable whether phytoplankton in these environments would ever be exposed to organic compound levels comparable to those used in this research. For example, disregarding areas exposed to sewage and other sources of pollution, glucose concentrations in aquatic environments are typically reported in

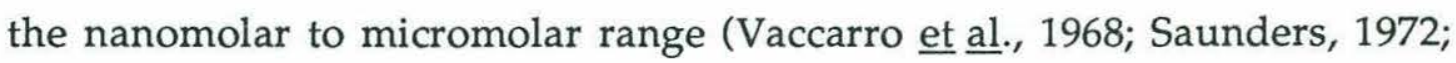
Bollman and Robinson, 1985). Even though these reported concentrations are probably underestimates (Suzuki and Sugimura, 1985; Sugimura and Suzuki, 1988) and might not reflect the concentrations phytoplankton experience 느 situ (White, 1974; Hellebust and Lewin, 1977; Smith, 1982), it is likely that microorganisms in these environments are rarely, if ever, exposed to millimolar or molar levels of dissolved organic compounds as was used in this study.

It is premature, however, to conclude that the cellular mechanisms demonstrated in this study are not ecologically relevant. The lower thresholds of organic substrate concentration needed to elicit the physiological responses observed here were not determined. Wheeler et al. (1974) demonstrated that the growth of several phytoplankton species on relatively high concentrations of amino acids was correlated with the uptake rate of these amino acids at low, natural concentrations. It is therefore at least possible that the physiological responses of cultured algae to the addition of relatively high concentrations of organic substrates are 
the same as those occurring in algae exposed to much lower substrate levels in nature.

Although it is unclear whether $\underline{P}$. malhamensis and $\underline{P}$. salina take up dissolved organic compounds in nature, it is likely that the former species ingests bacteria in the field. $\underline{P}$. malhamensis has a relatively high phagotrophic capability (see Chapter 1) and is capable of growing twice as fast on bacteria than on dissolved organic substrates (Caron et al., 1990; Sanders et al., 1990; this study). It is important therefore to consider that the physiological responses of this alga to dissolved organic substrate additions, as described here, may also occur in response to the uptake of bacteria. In fact, chlorophyll production by $\underline{\underline{P}}$. malhamensis is inhibited in response to the uptake of bacteria (Sanders et al., 1990), similar to its response to dissolved organic substrate uptake (this study). This infers that the critical factor triggering these physiological changes is the intracellular concentration of dissolved organic compounds (e. g., from the metabolic breakdown of bacteria). Given that $\underline{\underline{P}}$. malhamensis can take

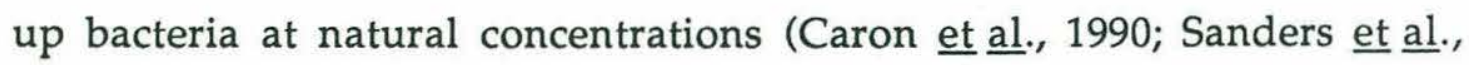
1990), the cellular mechanisms described in this study may be ecologically important as a response to bacterial uptake by this alga.

This is a mechanistic study. Until more is known about the availability of dissolved organic substrates to $\underline{P} . \underline{\text { malhamensis }}$ and $\underline{P}$. salina in nature and their uptake affinities for these substrates, the effects of dissolved organic substrates on their physiology, as observed here, will remain phenomenological. However, a large volume of evidence exists that indicates that algal heterotrophy can occur in nature, including 
laboratory studies demonstrating that the uptake affinities of some photosynthetic plankton for organic compounds is comparable to that of bacteria (Bunt, 1969; Hellebust, 1970; Allen, 1971; Saunders, 1972; Berman et al., 1977; Bollman and Robinson, 1977; Taft et al., 1977; Ellis and Stanford, 1982; Currie and Kalff, 1984a; Bollman and Robinson, 1985; Flynn and Syrett, 1986; Feuillade and Feuillade, 1989; Palenik and Morel, 1990) and field studies showing that a significant proportion of labeled organic compounds introduced into aquatic environments can be taken up by photosynthetic plankton (Allen, 1971; Saunders, 1972; Maeda and Ichimura, 1973; Lee et al., 1975; North, 1975; McKinley, 1977; Taft et al., 1977; Tilzer et al., 1977; Wheeler et $\underline{\text { al., }}$ 1977; Vincent, 1980; Vincent and Goldman, 1980; Currie and Kalff, 1984b; Moll, 1984; Li and Dickie, 1985; Palmisano et al., 1985; Rivkin and Putt, 1987; Feuillade et al., 1988; Bourdier et al., 1989). Exactly how phytoplankton coordinate different modes of carbon acquisition within the cell, however, is poorly understood. This study demonstrates two alternative mechanisms by which the phytoplankton cell is able to integrate autotrophic and heterotrophic nutrition.

This thesis is divided into six chapters. Chapter 1 provides a historical review of the questions addressed in the thesis; i. e., what are the questions, what is currently known about these questions, and how this study will enhance this knowledge.

Chapter 2 examines the effects of light intensity and nutrient depletion on the physiology of $\underline{\underline{P}}$. salina. The key finding of this study was 
that phycoerythrin was preferentially lost from the alga in response to nitrogen depletion, suggesting that $\underline{P}$. salina mobilizes phycoerythrin in order to help sustain cellular nitrogen requirements. This is the first time that this adaptive response has been characterized in a cryptophyte. Although organic substrate effects were not examined here, the study gives insight into the unique photosynthetic system of this cryptophyte and its response to changes in light and nutrient conditions and therefore provides an ideal guide to understanding the effects of organic substrate assimilation on $\underline{P}$. salina's photosynthetic system, as examined in Chapters 4 and 5. This chapter was published in Marine Ecology Progress $\underline{\text { Series }}$ (Lewitus, A. J. and D. A. Caron, 61: 171-181, 1990).

Chapters 3 and 4 are companion papers comparing the effects of light intensity and organic substrate additions on the growth and photosynthetic systems of $\underline{P}$. malhamensis and $\underline{P}$. $\underline{\text { salina. }}$. Striking differences were found in the heterotrophic potential of these algae and the adaptation of their photosynthetic apparati to changes in nutritional mode. These differences indicate species-specific cellular strategies for integrating autotrophic and heterotrophic nutrition and suggest that these algae may occupy distinct ecological niches.

Chapter 5 further characterizes the adaptation of $\underline{P}$. salina's photosynthetic system to glycerol assimilation and changes in light intensity. The results from this study strongly support the hypothesis that enhancement of heterotrophic potential occurs at the expense of lightharvesting ability in $\underline{\mathrm{P}}$. salina.

Chapter 6 summarizes the research. 


\section{REFERENCES}

Allen, H. L. 1971. Dissolved organic carbon utilization in size-fractionated algal and bacterial communities. Int. Rev. Gesamten. Hydrobiol. 56: 731-749.

Berman, T., O. Hadas and B. Kaplan. 1977. Uptake and respiration of organic compounds and heterotrophic growth in Pediastrum duplex (Meyen). Freshwater Biol. 7: 495-502.

Bird, D. F. and J. Kalff. 1986. Bacterial grazing by planktonic lake algae. Science 231: 493-495.

Bird, D. F. and J. Kalff. 1987. Algal phagotrophy: regulating factors and importance relative to photosynthesis in Dinobryon (Chrysophyceae). Limnol. Oceanogr. 32: 277-284.

Bockstahler, K. R. and D. W. Coats. 1990. Mixotophý in Chesapeake Bay dinoflagellates. Abstract 64 presented at $43^{\text {rd }}$ Annual Meeting of the Society of Protozoologists.

Bollman, R. C. and G. G. C. Robinson. 1977. The kinetics of organic acid uptake by three Chlorophyta in axenic culture. J. Phycol. 13: 1-5.

Bollman, R. C. and G. G. C. Robinson. 1985. Heterotrophic potential of the green alga, Ankistrodesmus braunii (Naeg.). Can. J. Microbiol. 31: 549554.

Bourdier, G., J. Bohatier, M. Feuillade and J. Feuillade. 1989. Amino acid incorporation by a natural population of Oscillatoria rubescens. A microautoradiographic study. FEMS Micr. Lett. 62: 185-190. 
Bunt, J. S. 1969. Observations on photoheterotrophy in a marine diatom. J. Phycol. 5: 37-42.

Caron, D. A., K. G. Porter and R. W. Sanders. 1990. Carbon, nitrogen and phosphorus budgets for the mixotrophic phytoflagellate Poterioochromonas malhamensis (Chrysophyceae) during bacterial ingestion. Limnol. Oceanogr. 35: 433-443.

Carter, N. 1937. New or interesting algae from brackish water. Arch. Protistenk. 90: 1-68.

Currie, D. J. and J. Kalff. 1984a. A comparison of the abilities of freshwater algae and bacteria to acquire and retain phosphorus.Limnol. Oceanogr. 29: 298-310.

Currie, D. J. and J. Kalff. 1984b. The relative importance of bacterioplankton and phytoplankton in phosphorus uptake in freshwater. Limnol. Oceanogr. 29: 311-321.

Ellis, B. K. and J. A. Stanford. 1982. Comparative photoheterotrophy, chemoheterotrophy, and photolithotrophy in a eutrophic reservoir and an oligotrophic lake. Limnol. Oceanogr. 27: 440-454.

Estep, K. W., P. G. Davis, M. D. Keller and J. McN. Sieburth. 1986. How important are oceanic algal nanoflagellates in bacterivory? Limnol. Oceanogr. 31: 646-650.

Feuillade, M., J. Bohatier, G. Bourdier, Ph. Dufour, J. Feuillade and H. Krupka. 1988. Amino acid uptake by a natural population of Oscillatoria rubescens in relation to uptake by bacterioplankton. Arch. Hydrobiol. 113: 345-358. 
Feuillade, M. and J. Feuillade. 1989. Heterotrophic capabilities of the bluegreen alga Oscillatoria rubescens. Arch. Hydrobiol. 117: 61-76.

Flynn, K. J. and I. Butler. 1986. Nitrogen sources for the growth of marine microalgae: role of dissolved free amino acids. Mar. Ecol. Prog. Ser. 34: 281-304.

Flynn, K. J. and P. J. Syrett. 1986. Characteristics of the uptake system for Llysine and L-arginine in Phaeodactylum tricornutum. Mar. Biol. 90: 151-158.

Hargraves, P. E., R. D. Vaillancourt and G. A. Jolly. 1989. Autotrophic picoplankton in Narragansett Bay and their interaction with microplankton. In: E. M. Cosper, V. M. Bricelj, and E. J. Carpenter (eds.) Novel Phytoplankton Blooms: Causes and Impacts of Recurrent Brown Tides and Other Unusual Blooms. Lecture Notes on Coastal and Estuarine Studies. Springer-Verlag, Berlin, pp. 23-38.

Hellebust, J. A. 1970. The uptake and utilization of organic substances by marine phytoplankters. In: D. W. Hood (ed.) Organic Matter in Natural Waters. Inst. Mar. Sci. Occas. Publ. No. 1, Univ. of Alaska, Fairbanks, pp. 225-256.

Hellebust, J. A. and J. Lewin. 1977. Heterotrophic nutrition. In: D. Werner (ed.) The Biology of Diatoms. Univ. Calif. Press, Berkeley, pp. 169-197. Hulburt, E. M. 1965. Flagellates from brackish waters in the vicinity of Woods Hole, Massachusetts. J. Phycol. 1: 87-94.

Johnson, P. W. and J. McN. Sieburth. 1979. Chroococcoid cyanobacteria in the sea; a ubiquitous and diverse phototrophic biomass. Limnol. Oceanogr. 24: 928-935. 
Johnson, P. W. and J. McN. Sieburth. 1982. In-situ morphology and occurrence of eukaryotic phototrophs of bacterial size in the picoplankton of estuarine and oceanic waters. J. Phycol. 18: 318-327.

Kieber, D. J., J. McDaniel and K. Mopper. 1989. Photochemical source of biological substrates in sea water: implications for carbon cycling. Nature 341: 637-639.

Lee, J. J., M. E. McEnery, E. M. Kennedy and H. Rubin. 1975. A nutritional analysis of a sublittoral diatom assemblage epiphytic on Enteromorpha from a Long Island salt marsh. J. Phycol. 11: 14-49.

Li, W. K. W. and P. M. Dickie. 1985. Metabolic inhibition of sizefractionated marine plankton radiolabeled with amino acids, glucose, bicarbonate, and phosphate in the light and dark. Microb. Ecol. 11: 1124.

Maeda, O. and S. Ichimura. 1973. On the high density of a phytoplankton population found in a lake under ice. Int. Revue ges. Hydrobiol. 58: 673-685.

McKinley, K. R. 1977. Light-mediated uptake of ${ }^{3} \mathrm{H}$-glucose in a small hard-water lake. Ecology 58: 1356-1365.

Moll, R. 1984. Heterotrophy by phytoplankton and bacteria in Lake Michigan. Verh. Internat. Verein. Limnol. 22: 431-434.

North, B. B. 1975. Primary amines in California coastal waters: Utilization by phytoplankton. Limnol. Oceanogr. 20: 20-27.

North, B. B. and G. C. Stephens. 1967. Uptake and assimilation of amino acids by Platymonas. Biol. Bull. 133: 391-400. 
Palenik, B. and F. M. M. Morel. 1990. Amino acid utilization by marine phytoplankton: a novel mechanism. Limnol. Oceanogr. 35: 260-269.

Palmisano, A. C., S. T. Kottmeier, R. L. Moe and C. W. Sullivan. 1985. Sea ice microbial communities. IV. The effect of light perturbation on microalgae at the ice-seawater interface in McMurdo Sound, Antarctica. Mar. Ecol. Prog. Ser. 21: 37-45.

Pomeroy, L. R. 1974. The ocean's food web, a changing paradigm. Bioscience 24: 499-504.

Porter, K. G. 1988. Phagotrophic phytoflagellates in microbial food webs. Hydrobiologia 159: 89-97.

Pringsheim, E. G. 1952. On the nutrition of Ochromonas. Q. J. Microscop. Sci. 93: 71-96.

Rivkin, R. B. and M. Putt. 1987. Heterotrophy and photoheterotrophy by Antarctic microalgae: light-dependent incorporation of amino acids and glucose. J. Phycol. 23: 442-452.

Saks, N. M. and E. G. Kahn. 1979. Substrate competition between a salt marsh diatom and a bacterial population. J. Phycol. 15: 17-21.

Sanders, R. W. and K. G. Porter. 1988. Phagotrophic phytoflagellates. Adv. Micr. Ecol. 10: 167-192.

Sanders, R. W., K. G. Porter and D. A. Caron. 1990. Relationship between phototrophy and phagotrophy in the mixotrophic chrysophyte Poterioochromonas malhamensis. Microb. Ecol. 19: 97-109.

Saunders, G. W. 1972. Potential heterotrophy in a natural population of Oscillatoria agardhii var. Isothrix Skuja. Limnol. Oceanogr. 17: 704711. 
Shapiro, L. P. and R. R. L. Guillard. 1986. Physiology and ecology of the marine eukaryotic ultraplankton. In: T. Platt and W. K. W. Li (eds.) Photosynthetic picoplankton. Can. Bull. Fish. Aquat. Sci. 214: 371-389.

Sieburth, J. McN. and P. W. Johnson. 1989. Picoplankton ultrastructure: a decade of preparation for the Brown Tide alga, Aureococcus anophagefferens. In: E. M. Cosper, V. M. Bricelj, and E. J. Carpenter (eds.) Novel Phytoplankton Blooms: Causes and Impacts of Recurrent Brown Tides and Other Unusual Blooms. Lecture Notes on Coastal and Estuarine Studies. Springer-Verlag, Berlin, pp. 23-38.

Smith, A. J. 1982. Modes of cyanobacterial carbon metabolism. In: N. G. Carr and B. A. Whitton (eds.) The Biology of Cyanobacteria. Blackwells Scientific Publs., Oxford, pp. 47-85.

Stockner, J. G. 1988. Phototrophic picoplankton: an overview from marine and freshwater ecosystems. Limnol. Oceanogr. 33: 765-775.

Sugimura, Y. and Y. Suzuki. 1988. A high-temperature catalitic oxidation method for the determination of non-volatile dissolved organic carbon in seawater by direct injection of a liquid sample. Mar. Chem. 24: 105-131.

Suzuki, Y. and Y. Sugimura. 1985. A catalitic oxidation method for the determination of total nitrogen dissolved in seawater. Mar. Chem. 16: 83-97.

Taft, J. L., M. E. Loftus and W. R. Taylor. 1977. Phosphate uptake from phosphomonoesters by phytoplankton in the Chesapeake Bay. Limnol. Oceanogr. 22: 1012-1021. 
Tilzer, M. M., H. W. Paerl and C. R. Goldman. 1977. Sustained viability of aphotic phytoplankton in Lake Tahoe (California-Nevada). Limnol. Oceanogr. 22: 84-91.

Vaccarro, R. F., S. E. Hicks, H. W. Jannasch and F. G. Carey. 1968. The occurrence and role of glucose in sea water. Limnol. Oceanogr. 13: 356-360.

Valiela, I. and J. M. Teal. 1979. The nitrogen budget of a salt marsh ecosystem. Nature 280: 652-656.

Vincent, W. F. 1980. The physiological ecology of a Scenedesmus population in the hypolimnion of a hypertrophic pond. II. Heterotrophy. Br. Phycol. J. 15: 35-41.

Vincent, W. F. and C. R. Goldman. 1980. Evidence for algal heterotrophy in Lake Tahoe, California-Nevada. Limnol. Oceanogr. 25: 89-99.

Waterbury, J. B., S. W. Watson, R. R. L. Guillard and L. E. Brand. 1979. Widespread occurrence of a unicellular, marine, planktonic, cyanobacterium. Nature 277: 293-294.

Wheeler, P., B. North, M. Littler and G. Stephens. 1977. Uptake of glycine by natural phytoplankton communities. Limnol. Oceanogr. 22: 900910.

Wheeler, P. A., B. B. North and G. C. Stephens. 1974. Amino acid uptake by marine phytoplankters. Limnol. Oceanogr. 19: 249-259.

White, A. W. 1974. Growth of two facultatively heterotrophic marine centric diatoms. J. Phycol. 10: 292-300.

Wislouch, S. 1924. Beiträge zur Biologie und Entstehung von Heilsclamm der Salinern der Krim. Act. Bot. Polon. 2: 99-129. 
Chapter 1.

Historical Perspective 
Cryptophytes as opportunistic algae

Compared to other algae, cryptophytes are relatively tolerant of wide nutrient (DeNouyelles and O'Brien, 1978), temperature (Ramberg, 1979; Morgan and Kalff, 1979), and light (Brown and Richardson, 1968; Morgan and Kalff, 1979; Ramberg, 1979) regimes. Because of their ability to survive in variable and extreme environments, cryptophytes tend to fill ecological niches unfavorable for other groups (Stewart and Wetzel, 1986). This is reflected by a "pulsing" type of seasonal distribution, where cryptophytes increase in abundance during periods immediately following the decline of previously dominant algal bloom communities (e. g., Stewart and Blinn, 1976; Wojciechowska, 1976; Schwartz et al., 1981). Because these are periods of high algal decomposition, some authors have speculated that a relatively high potential for heterotrophy may help explain cryptophyte abundance in between blooms (Wright, 1964; Stewart and Blinn, 1976; Schwartz et ․‥, 1981).

It's possible that some factor(s) unique to cryptophytes might confer an advantage in exploiting resources for growth and/or survival. This study examined two unusual characteristics of the cryptophyte cell that could potentially contribute to its survival; the gullet and associated trichocysts which might be involved in food capture (i. e., phagotrophy) and the containment of phycobiliproteins, nitrogen-rich light-harvesting pigments that might be mobilized in order to help sustain growth during periods in which the external nitrogen supply is deficient. 
Cryptophytes contain a tubular gullet which is lined with trichocysts in the ventral region. Dischargeable trichocysts are also common around the cell periphery. Two functions of cryptophyte trichocysts have been postulated; as protein storage sources (Schuster, 1968, 1970; Santore, 1985) and in protection (Gantt, 1980). A third possibility is that they function as offensive weapons in food capture. Although scattered anecdotal reports of cryptophyte phagotrophy exist (e. g., Wawrik, 1970; Porter et al., 1985; Pratt and Cairns, 1985), Pyrenomonas salina could not be induced to ingest beads or bacteria under a wide range of light and nutrient conditions (Lewitus, unpubl. data). Chemoheterotrophic growth on glycerol, however, had been demonstrated in $\underline{P}$. salina (Antia et al., 1969). Therefore, if a relatively high potential for heterotrophy contributes to cryptophyte survival in between bloom periods, osmotrophy appeared to be a more likely mechanism (at least in $\underline{\underline{P}}$. salina) for acquiring organic material than phagotrophy. A major focus of this study therefore is on the physiological response of $\underline{P}$. salina to dissolved organic substrate additions (see below).

Phycobiliproteins are nitrogen-rich molecules. Whereas it had been well-established that cyanobacteria and rhodophytes mobilize phycobiliproteins as an endogenous nitrogen source in response to nitrogen deprivation (Allen and Smith, 1969; Foulds and Carr, 1977; Lau et al., 1977; Chapman et al., 1978; Boussiba and Richmond, 1980; Yamanaka and Glazer, 1980; Lapointe, 1981; Stevens et al., 1981; Köst et al., 1984; Grossman et al., 1986; Schenk et al., 1987; Levy and Gantt, 1990), this response had not been examined in cryptophytes. Given the 
immunochemical relatedness between cyanobacteria, rhodophyte, and cryptophyte phycobiliproteins (MacColl et al., 1976; Guard-Friar et al., 1986) and the overwhelming evidence that the cryptophyte chloroplast evolved from a rhodophyte endosymbiont (Greenwood et al., 1977; Dodge, 1979; Gillot and Gibbs, 1980; Whatley, 1981; Ludwig and Gibbs, 1985, 1989; Hansmann et al., 1986; Hansmann, 1988) it seemed likely that, similar to cyanobacteria and rhodophytes, the catabolism of phycobiliproteins may be an early response to nitrogen depletion in cryptophytes. Therefore, this study examined the hypothesis that $\underline{P}$. salina mobilizes phycoerythrin during nitrogen deprivation in order to help supply the biosynthetic demands for cellular growth (see Chapter 2). 
Uptake of dissolved organic substrates by Poterioochromonas malhamensis

Compared to other algae in culture, $\underline{P}$. malhamensis has an exceptionally high heterotrophic capability; e. g., this chrysophyte is capable of ingesting bacteria and other particles at rates comparable to heterotrophic nanoflagellates (Porter, 1988; Sanders and Porter, 1988; Caron et al., 1990; Sanders et al., 1990) and can grow in the dark on several different types of dissolved organic compounds (Pringsheim, 1952; Hutner et al., 1953; Myers and Graham, 1956). The potential for heterotrophic growth by $\underline{\mathrm{P}}$. malhamensis appears to be so much higher than that for autotrophic growth that it's not clear why this alga contains a chloroplast. In fact, Myers and Graham (1956) concluded that, because of the relatively low photoautotrophic growth rate (72 hour doubling time), photosynthetic rate, and chlorophyll $\underline{\text { a }}$ content of $\underline{\mathrm{P}}$. malhamensis, photosynthesis provides only a "marginal" contribution to its nutrition. The role of photosynthesis in this unusual chrysophyte was examined here by measuring the growth rate of batch cultures grown under conditions varying in light intensity and the type and availability of organic substrate (see Chapter 3). Based on the previously reported minor contribution of photosynthesis to $\underline{\mathrm{P}}$. malhamensis's nutrition, the hypothesis was tested that when organic substrates are available to the alga, light intensity has a minor effect on it's growth rate.

The postulated minor role of photosynthesis in $\underline{\underline{P}}$. malhamensis is exemplified by the inhibitory effect of organic substrate assimilation on 
chloroplast development in this alga. Using epifluorescence microscopy, it was observed here qualitatively that the introduction of glucose to batch cultures of $\underline{P}$. malhamensis previously grown photoautotrophically caused a very noticeable reduction in the chloroplast size and chlorophyll fluorescence cell-1. This was consistent with Pringsheim's (1952) observation that growth of $\underline{P}$. malhamensis in an organically enriched medium resulted in a severe reduction in the size of the chloroplast and with Myers and Graham's (1956) demonstration that sucrose addition to $\underline{P}$. malhamensis reduced the cellular chlorophyll content. Thus, $\underline{\mathbf{P}}$. $\underline{\text { malhamensis }}$ resembles Euglena gracilis and certain Chlorella species in that chloroplast development is repressed under conditions supporting heterotrophic growth (App and Jagendorf, 1963; Grenson, 1964; Buetow, 1967; Harris and Kirk, 1969; Shihira-Ishikawa and Hase, 1964, 1965). Although the effects of organic substrates on chloroplast development has been extensively studied in Euglena and Chlorella (Hase, 1971; Osafune and Hase, 1975; Schwelitz et a‥, 1978a, b; Brandt, 1981, 1988; Schuler et $\underline{\text { al., }}$ 1981; James and Schwartzbach, 1982; Schimpf et al., 1982; Schwartzbach and Schiff, 1983; Vannini, 1983; Monroy and Schwartzbach, 1984; Rikin and Schwartzbach, 1989; Schwartzbach, 1990), Handa et al. (1981) was the only study, prior to this research, to examine this phenomenon in $\underline{P}$. malhamensis (discussed below).

Because the addition of certain utilizable nitrogen sources to Euglena and Chlorella can relieve the repression of chloroplast development caused by organic substrates (Shihira-Ishikawa and Hase, 1964; Takashima et al., 1964; Harris and Kirk, 1969; Matsuka et al., 1969; 
Hase, 1971; Schwelitz et. al., 1978a), a critical (and controversial) issue pertaining to the effect of organic substrates on chloroplast development in these chlorophytes is whether this process is controlled by a nutritional factor specific to the organic substrate or the ratio of dissolved organic carbon to nitrogen ( $\mathrm{C} / \mathrm{N}$ ratio) in the environment. Despite earlier conclusions that the nutritional factor regulating chloroplast development in Euglena was the $\mathrm{C} / \mathrm{N}$ ratio of the environment (Harris and Kirk, 1969), it is now well-established (Schwelitz et al., 1978a; Horrum and Schwartzbach, 1980, 1981; Schimpf et al., 1982; Schwartzbach and Schiff, 1983) that chloroplast development in Euglena is independently controlled by the nitrogen concentration in the environment and the specific organic substrate source. Based on the above studies, the hypothesis that chlorophyll production by $\underline{\mathrm{P}}$. malhamensis was controlled specifically by the organic substrate source was tested here by comparing the effects of various organic substrates on the chlorophyll content of $\underline{P}$. malhamensis under conditions where the organic carbon to inorganic nitrogen ratios of the culture medium were comparable (see Chapter 3).

Handa et $\underline{\text { al. }}$ (1981) demonstrated that, in batch cultures of $\underline{P}$. malhamensis, exhaustion of glucose from the culture medium coincided with increased cyclic AMP content cell-1, followed by chlorophyll production. This is consistent with the cyclic AMP-mediated escape from catabolite repression of certain enzyme systems in bacteria and yeast (Peterkofsky and Gazdar, 1971; Prival and Magasanik, 1971; Robison et al., 1971; Pastan and Adhya, 1976; Pall, 1981). That is, a catabolite of glucose induces the synthesis of enzymes required for its metabolism while 
repressing the synthesis of enzymes required for the utilization of an alternative carbon source (in the case of $\underline{P}$. malhamensis, inorganic carbon). The mechanism of repression involves the reduction by glucose of the cellular concentration of cyclic AMP, a molecule required to induce the synthesis of enzymes involved in metabolizing the alternative carbon source. A critical problem with Handa et al.'s (1981) study was that $\underline{P}$. malhamensis cultures were nitrogen-deficient at the beginning of their experiments and, therefore, the effects of glucose and nitrogen deficiency on chlorophyll production by $\underline{P}$. malhamensis could not be differentiated. By using cultures that were initially nitrogen-sufficient, this study examined the effects of organic substrates on chlorophyll production by this alga independent of the effects of nitrogen availability (see Chapter 3 ). 
Uptake of dissolved organic substrates by Pyrenomonas salina

Facultative heterotrophy in $\underline{\mathrm{P}}$. salina had been examined in Antia's laboratory (Antia et al., 1969, 1973, 1974, 1979; Cheng and Antia, 1970; Cheng et al., 1974; Antia, 1980), with a focus on the effect of glycerol assimilation on the alga's growth, starch production, and lipid production. They showed that $\underline{P}$. salina was capable of growing on glycerol in the dark and that glycerol addition to the culture medium could increase the alga's growth rate in the light. However, of a number of organic compounds tested, only glycerol supported growth of this cryptophyte in the dark, and only at relatively high substrate concentrations (Antia et al., 1969). Thus, the heterotrophic capability of $\underline{P}$. salina appeared to be much lower than that of $\underline{P}$. malhamensis. Antia's laboratory also demonstrated that, in the light, glycerol uptake by $\underline{\underline{P}}$. salina stimulated starch production and, in the latter stages of growth, this led to cell gigantism and eventual autolysis. In order to further characterize the interesting physiological response of $\underline{P}$. salina to glycerol addition and to compare the relative contribution of autotrophy and heterotrophy to the alga's nutrition, the interaction of

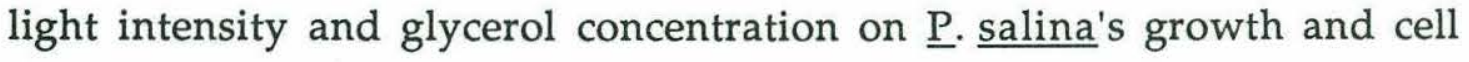
size was examined here (see Chapter 4). Based on the relatively high contribution of autotrophy to $\underline{\underline{P}}$. salina's growth implied by Antia et $\underline{\text { al..'s }}$ (1969) research, this study tested the hypothesis that the effect of glycerol on $\underline{P}$. salina's growth is light intensity-dependent.

Using epifluorescence microscopy, it was observed here that the addition of glycerol to batch cultures of $\underline{P}$. salina reduced the phycoerythrin 
fluorescence cell ${ }^{-1}$ dramatically but did not appear to affect the chlorophyll fluorescence cell-1. This suggested the intriguing possibility that glycerol assimilation by $\underline{P}$. salina reduced the cellular phycoerythrin content and the cellular ratio of phycoerythrin to chlorophyll a. The inhibition of the synthesis of chloroplast components by organic substrate assimilation was not surprising in itself but, whereas in $\underline{P}$. malhamensis, Euglena, and Chlorella, the development of the entire chloroplast was repressed by organic substrates, here was evidence of a selective inhibition of the synthesis of one photosynthetic component (phycoerythrin) over another (chlorophyll a). Because, in cryptophytes, phycobiliproteins have a much greater role in light-harvesting than chlorophyll a (Haxo and Fork, 1959; Lichtlé et al., 1980), it was hypothesized that glycerol addition to $\underline{P}$. salina selectively inhibited the synthesis of those components of the photosynthetic apparatus associated with light-harvesting. The rationale behind this hypothesis was that the ability to harvest light becomes less critical for growth when carbon, energy and/or reductant requirements can be supplied by organic substrate metabolism. The expenditure of biosynthetic energy on light-harvesting components, therefore, may be wasteful to the cell when organic substrates are available. To my knowledge, this hypothesis had not been previously tested. This hypothesis was tested here by combining the use of pigment analyses, thin-section electron microscopy, and freeze-fracture electron microscopy in examining the effects of glycerol addition and light intensity on the photosynthetic system of $\underline{P}$. salina (see Chapter 5). 


\section{$\underline{\text { Poterioochromonas malhamensis vs. Pyrenomonas salina }}$}

It's apparent from the above discussion that $\underline{P}$. malhamensis and $\underline{P}$. salina have contrasting nutritional characteristics. This study aims to compare the relative contributions of autotrophy and heterotrophy to the overall nutrition of these algae and to examine the cellular mechanisms that these algae use to integrate autotrophic and heterotrophic nutrition. The findings from this study indicate that the relative roles of autotrophy and heterotrophy in the growth and survival of these algae differ greatly. The growth of $\underline{\mathrm{P}}$. malhamensis is supported primarily by heterotrophic nutrition while autotrophic nutrition probably provides a means of surviving periods when organic substrates are limiting. On the other hand, carbon acquisition for the growth of $\underline{P}$. salina is derived mainly from autotrophic nutrition while heterotrophic nutrition may provide a means of surviving periods in which light is limiting. These contrasting metabolic strategies are reflected in the distinct cellular mechanisms by which these species combine different modes of carbon acquisition. In $\underline{P}$. malhamensis, the synthesis of the entire chloroplast was repressed by organic substrate additions while, in $\underline{P}$. salina, only the synthesis of selected elements was inhibited. In both species, however, there is a tradeoff within the algal cell between the synthesis of components involved in organic substrate metabolism and those involved in photosynthesis. Organic substrates represent a source of carbon, energy, and/or reductant alternative to that obtained photosynthetically. Therefore, the effect of organic substrate assimilation on the 
photosynthetic systems of these algae can be considered a means of enhancing the metabolism of organic substrates at the expense of those photosynthetic components that, with the acquisition of organic compounds, become less essential for growth. 


\section{REFERENCES}

Allen, M. M. and A. J. Smith. 1969. Nitrogen chlorosis in blue-green algae. Arch. Mikrobiol. 69: 114-120.

Antia, N. J. 1980. Nutritional physiology and biochemistry of marine cryptomonads and chrysomonads. In: M. Levandowsky and S. H. Hutner (eds.) Biochemistry and Physiology of Protozoa, Vol. 3. Academic Press, New York, pp. 67-115.

Antia, N. J., J. Y. Cheng, R. A. J. Foyle and E. Percival. 1979. Marine cryptomonad starch from autolysis of glycerol-grown Chroomonas salina. J. Phycol. 15: 57-62.

Antia, N. J., J. Y. Cheng and F. J. R. Taylor. 1969. The heterotrophic growth of a marine photosynthetic cryptomonad (Chroomonas salina). Proc. Intl. Seaweed Symp. 6: 17-29.

Antia, N. J., J. P. Kalley, J. McDonald and T. Bisalputra. 1973. Ultrastructure of the marine cryptomonad Chroomonas salina cultured under conditions of photoautotrophy and glycerolheterotrophy. J. Protozool. 20: 377-385.

Antia, N. J., R. F. Lee, J. C. Nevenzel and J. Y. Cheng. 1974. Wax ester production by the marine cryptomonad Chroomonas salina grown photoheterotrophically on glycerol. J. Protozool. 21: 768-771.

App, A. A. and A. T. Jagendorf. 1963. Repression of chloroplast development in Euglena gracilis by substrates. J. Protozool. 10: 340343. 
Boussiba, S. and A. E. Richmond. 1980. C-phycocyanin as a storage protein in the blue-green alga Spirulina platensis. Arch. Microbiol. 125: 143147.

Brandt, P. 1981. Evidence for regulative transactions between the nucleocytoplasm and the chloroplasts in Euglena gracilis. Ber. Deutsch. Bot. Ges. 94: 419-433.

Brandt, P. 1988. Strain and stage-specific high-temperature treatment of Euglena gracilis causes permanent apochlorosis. J. Plant Physiol. 133: 281-287.

Brown, T. E. and F. L. Richardson. 1968. The effect of growth environment on the physiology of algae: light intensity. J. Phycol. 4: 38-54.

Buetow, D. E. 1967. Acetate repression of chlorophyll synthesis in Euglena gracilis. Nature 213: 1127-1128.

Caron, D. A., K. G. Porter and R. W. Sanders. 1990. Carbon, nitrogen and phosphorus budgets for the mixotrophic phytoflagellate Poterioochromonas malhamensis (Chrysophyceae) during bacterial ingestion. Limnol. Oceanogr. 35: 433-443.

Chapman, A. R. O., J. W. Markham and K. Lüning. 1978. Effects of nitrogen concentration on the growth and physiology of Laminaria saccharina in culture. J. Phycol. 14: 195-198.

Cheng, J. Y. and N. J. Antia. 1970. Enhancement by glycerol of phototrophic growth of marine planktonic algae and its significance to ecology of glycerol pollution. J. Fish. Res. Bd. Canada 27: 335-346.

Cheng, J. Y., M. Don-Paul and N. J. Antia. 1974. Isolation of an unusually stable cis-isomer of alloxanthin from a bleached autolysed culture of 
Chroomonas salina grown photoheterotrophically on glycerol. Observations on cis-trans isomerization of alloxanthin. J. Protozool. 21: 761-768.

DeNouyelles, F., Jr. and W. J. O'Brien. 1978. Phytoplankton succession in nutrient enriched experimental ponds as related to changing carbon, nitrogen and phosphorus conditions. Arch. Hydrobiol. 84: 137-165.

Dodge, J. D. 1979. The phytoflagellates: fine structure and phylogeny. In: M. Levandowsky and S. H. Hutner (eds.) Biochemistry and Physiology of Protozoa, Vol. 1. Academic Press, New York, pp. 7-57.

Foulds, I. J. and N. G. Carr. 1977. A proteolytic enzyme degrading phycocyanin in the cyanobacterium Anabaena cylindrica. FEMS Microbiol. Lett. 2: 117-119.

Gantt, E. 1980. Photosynthetic cryptophytes. In: E. Cox (ed.) Phytoflagellates. Elsevier, Amsterdam, pp. 381-404.

Gillot, M. A. and S. P. Gibbs. 1980. The cryptomonad nucleomorph: its ultrastructure and evolutionary significance. J. Phycol. 16: 558-568.

Greenwood, A. D., H. B. Griffiths and U. J. Santore. 1977. Chloroplasts and cell compartments in Cryptophyceae. Br. Phycol. J. 12: 119.

Grenson, M. 1964. Physiology and cytology of chloroplast formation and "loss" in Euglena. Int. Rev. Cyt. 16: 37-59.

Grossman, A. R., P. G. Lemaux and P. B. Conley. 1986. Regulated synthesis of phycobilisome components. Photochem. Photobiol. 44: 827-837.

Guard-Friar, D., B. L. Eisenberg, M. R. Edwards, and R. MacColl. 1986. Immunochemistry on cryptomonad biliproteins. Plant Physiol. 80: 3842. 
Handa, A. K., R. A. Bressan, H. Quader and P. Filner. 1981. Association of formation and release of cyclic AMP with glucose depletion and onset of chlorophyll synthesis in Poterioochromonas malhamensis. Plant Physiol. 68: 460-463.

Hansmann, P. 1988. Ultrastructural localization of RNA in cryptomonads. Protoplasma 146: 81-88.

Hansmann, P., H. Falk, U. Scheer and P. Sitte. 1986. Ultrastructural localization of DNA in two Cryptomonas species by use of a monoclonal DNA antibody. Eur. J. Cell Biol. 42: 152-160.

Harris, R. C. and J. T. O. Kirk. 1969. Control of chloroplast formation in Euglena gracilis: antagonism between carbon and nitrogen sources. Biochem. J. 113: 195-205.

Hase, E. 1971. Studies on the metabolism of nucleic acid and protein associated with the processes of de- and re-generation of chloroplasts in Chlorella protothecoides. In: N. K. Boardman, A. W. Linnane, and R. M. Smillie (eds.) Autonomy and Biogenesis of Mitochondria and Chloroplasts. North-Holland, New York, pp. 434-446.

Haxo, F. T. and D. C. Fork. 1959. Photosynthetically active accessory pigments of cryptomonads. Nature 184: 1051-1052.

Horrum, M. A. and S. D. Schwartzbach. 1980. Nutritional regulation of organelle biogenesis in Euglena: repression of chlorophyll and NADP-glyceraldehyde-3-phosphate dehydrogenase synthesis. Plant Physiol. 65: 382-386. 
Horrum, M. A. and S. D. Schwartzbach. 1981. Nutritional regulation of organelle biogenesis in Euglena: induction of microbodies. Plant Physiol. 68: 430-434.

Hutner, S. H., L. Provasoli and J. Filfus. 1953. Nutrition of some phagotrophic fresh-water chrysomonads. Ann. N. Y. Acad. Sci. 56: 852-862.

James, L. and D. D. Schwartzbach. 1982. Differential regulation of phosphoglycolate and phosphoglycerate phosphatases in Euglena. Plant Sci. Lett. 27: 223-232.

Köst, H.-P., M. Senser and G. Wanner. 1984. Effect of nitrate and sulphate starvation on Porphyridium cruentum cells. Z. Pflanzenphysiol. Bd. 113: 231-249.

Lapointe, B. E. 1981. The effects of light and nitrogen on growth, pigment content, and biochemical composition of Gracilaria foliifera v. angustissima (Gigartinales, Rhodophyta). J. Phycol. 17: 90-95.

Lau, R. H., M. M. MacKenzie and W. Ford Doolittle. 1977. Phycocyanin synthesis and degradation in the blue-green bacterium Anacystis nidulans. J. Bact. 132: 771-778.

Levy, I. and E. Gantt. 1990. Development of photosynthetic activity in Porphyridium purpureum (Rhodophyta) following nitrogen starvation. J. Phycol. 26: 62-68.

Lichtle, C., H. Jupin and J. C. Duval. 1980. Energy transfer from Photosystem II to Photosystem I in Cryptomonas rufescens (Cryptophyceae). Biochim. Biophys. Acta 591: 104-112. 
Ludwig, M. and S. G. Gibbs. 1985. DNA is present in the nucleomorph of cryptomonads: further evidence that the chloroplast evolved from a eukaryotic endosymbiont. Protoplasma 127: 9-20.

Ludwig, M. and S. G. Gibbs. 1989. Localization of phycoerythrin at the lumenal surface of the thyloid membrane in Rhodomonas lens. J. Cell Biol. 108: 875-884.

MacColl, R., D. S. Berns and O. Gibbons. 1976. Characterization of cryptomonad phycoerythrin and phycocyanin. Arch. Biochem. Biophys. 177: 265-275.

Matsuka, M., S. Miyachi and E. Hase. 1969. Acetate metabolism in the process of "acetate-bleaching" of Chlorella protothecoides. Plant Cell Physiol. 10: 527-538.

Monroy, A. F. and S. D. Schwartzbach. 1984. Catabolite repression of chloroplast development in Euglena. Proc. Natl. Acad. Sci. U. S. A. 81: 2786-2790.

Morgan, K. C. and J. Kalff. 1979. Effect of light and temperature interactions of Cryptomonas erosa (Cryptophyceae). J. Phycol. 15: 127-134.

Myers, J. and J. Graham. 1956. The role of photosynthesis in the physiology of Ochromonas. J. Cell. Comp. Phys. 47: 397-414.

Öquist, G. 1971. Changes in pigment composition and photosynthesis induced by iron-deficiency in the blue-green alga Anacystis nidulans. Physiol. Plant. 25: 188-191.

Osafune, T. and E. Hase. 1975. Some structural characteristics of the chloroplasts in the "glucose bleaching" and re-greening cells of Chlorella protothecoides. Biochem. Physiol. Pfl. 168: 533-42. 
Pall, M. L. 1981. Adenosine 3', 5'-phosphate in fungi. Microbiol. Rev. 45: $462-480$.

Pastan, I. and S. Adhya. 1976. Cyclic adenosine 5'-monophosphate in Escherichia coli. Bacteriol. Rev. 40: 527-551.

Peterkofsky, A. and C. Gazdar. 1971. Glucose and the metabolism of adenosine 3':5'-cyclic monophosphate in Escherichia coli. Proc. Nat. Acad. Sci. 68: 2794-2798.

Porter, K. G. 1988. Phagotrophic phytoflagellates in microbial food webs. Hydrobiologia 159: 89-97.

Porter, K. G., E. B. Sherr, B. F. Sherr, M. Pace and R. W. Sanders. 1985. Protozoa in planktonic food webs. J. Protozool. 32: 409-415.

Pratt, J. R. and J. Cairns, Jr. 1985. Functional groups in the protozoa: roles in differing ecosystems. J. Protozool. 32: 415-423.

Pringsheim, E. G. 1952. On the nutrition of Ochromonas. Q. J. Microscop. Sci. 93: 71-96.

Prival, M. J. and B. Magasanik. 1971. Resistance to catabolite repression of histidase and proline oxidase during nitrogen-limited growth of Klebsiella aerogenes. J. Biol. Chem. 246: 6288-6296.

Ramberg, L. 1979. Relations between phytoplankton and light climate in two Swedish forest lakes. Int. Revue ges. Hydrobiol. 64: 749-782.

Rikin, A. and S. D. Schwartzbach. 1989. Regulation by light and ethanol of the synthesis of the light-harvesting chlorophyll a/b-binding protein of photosystem II in Euglena. Planta 178: 76-83.

Robison, G. A., R. W. Butcher and E. W. Sutherland. 1971. Cyclic AMP. Academic Press, New York, 531 pp. 
Sanders, R. W. and K. G. Porter. 1988. Phagotrophic phytoflagellates. Adv. Micr. Ecol. 10: 167-192.

Sanders, R. W., K. G. Porter and D. A. Caron. 1990. Relationship between phototrophy and phagotrophy in the mixotrophic chrysophyte Poterioochromonas malhamensis. Microb. Ecol. 19: 97-109.

Santore, U. J. 1985. A cytological survey of the genus Cryptomonas (Cryptophyceae) with comments on its taxonomy. Arch. Protistenk. 130: $1-52$.

Schenk, H. E. A., M. G. Bayer and T. Maier. 1987. Nitrate assimilation and regulation of biosynthesis and disintegration of phycobiliproteids by Cyanophora paradoxa. Indications for a nitrogen store function of the phycobiliproteids. Endocyt. C. Res. 4: 167-176.

Schimpf, Ch., A. G. Govindarajan and B. Pardier. 1982. Influence of preillumination (potentiation) and carbon substrates on plastid aminoacyl-tRNA synthetases in greening Euglena cells. Biochem. Physiol. Pflanzen 177: 777-788.

Schuler, F., P. Brandt and W. Wiessner. 1981. Chloroplastenreduktion in Euglena gracilis durch heterotrophe Ernährung mit Glucose im Licht. Protoplasma 106: 317-327.

Schuster, F. L. 1968. The gullet and trichocysts of Cyathomonas truncata. Exp. Cell Res. 49: 277-284.

Schuster, F. L. 1970. The trichocysts of Chilomonas paramecium. J. Protozool. 17: 521-526. 
Schwartz, S. S., D. W. Blinn and G. Johnson. 1981. The physico-chemical and planktonic response of an algicide-treated shallow mountain lake in Arizona. Int. Revue ges. Hydrobiol. 66: 249-262.

Schwartzbach, S. D. 1990. Photocontrol of organelle biogenesis in Euglena. Photochem. Photobiol. 51: 231-254.

Schwartzbach, S. D. and J. A. Schiff. 1983. Control of plastogenesis in Euglena. In: W. Shropshire, Jr. and H. Mohr (eds.) Encyclopedia of Plant Physiology, New Series Vol. 16A. Springer, Berlin, pp. 312-335.

Schwelitz, F. D., P. L. Cisneros, J. A. Jagielo, J. L. Comer and K. A. Butterfied. 1978a. The relationship of fixed carbon and nitrogen sources to the greening process in Euglena gracilis strain Z. J. Protozool. 25: 257-61.

Schwelitz, F. D., P. L. Cisneros and J. A. Jagielo. 1978b. The effect of glucose on the biochemical and ultrastructural characteristics of developing Euglena chloroplasts. J. Protozool. 25: 398-403.

Shihira-Ishikawa, I. and E. Hase. 1964. Nutritional control of cell pigmentation in Chlorella protothecoides with special reference to the degeneration of the chloroplast induced by glucose. Plant Cell Physiol. 5: 227-240.

Shihira-Ishikawa, I. and E. Hase. 1965. Effects of glucose on the process of chloroplast development in Chlorella protothecoides. Plant Cell Physiol. 6: 101-110.

Stevens, S. E., Jr., D. L. Balkill and D. A. M. Paone. 1981. The effects of nitrogen limitation on the ultrastructure of the cyanobacterium Agmenellum quadruplicatum. Arch. Microbiol. 130: 204-212. 
Stewart, A. J. and D. W. Blinn. 1976. Studies on' Lake Powell, USA: environmental factors influencing phytoplankton success in a high desert warm monomictic lake. Arch. Hydrobiol. 78: 139-164.

Stewart, A. J. and R. G. Wetzel. 1986. Cryptophytes and other microflagellates as couplers in planktonic community dynamics. Arch. Hydrobiol. 106: 1-19.

Takashima, K., I. Shihira-Ishikawa and E. Hase. 1964. Further notes on the growth and chlorophyll formation of Chlorella protothecoides. Plant Cell Physiol. 5: 321-332.

Vannini, G. L. 1983. Degeneration and regeneration of chloroplasts in Euglena gracilis grown in the presence of acetate: ultrastructural evidence. J. Cell Sci. 61: 413-422.

Wawrik, F. 1970. Mixotrophie bei Cryptomonas borealis skuja. Arch. Protistenkd. 112: 312-313.

Whatley, J. M. 1981. Chloroplast evolution-ancient and modern. Ann. N. Y. Acad. Sci. 361: 154-165.

Wojciechowska, W. 1976. Dynamics of phytoplankton biomass in two lakes of a different limnological character. Ekol. Pol. 24: 237-252.

Wright, R. T. 1964. Dynamics of a phytoplankton community in an icecovered lake. Limnol. Oceanogr. 9: 163-178.

Yamanaka, G. and A. N. Glazer. 1980. Dynamic aspects of phycobilisome structure. Arch. Microbiol. 124: 39-47. 


\section{Chapter 2.}

Relative Effects of Nitrogen or Phosphorus Depletion and Light Intensity on the Pigmentation, Chemical Composition, and Volume of Pyrenomonas salina (Cryptophyceae) [Reprint] 
54 


\begin{tabular}{|c|c|c|}
\hline Vol. 61: 171-181, 1990 & $\begin{array}{l}\text { MARINE ECOLOGY PROGRESS SERIES } \\
\text { Mar. Ecol. Prog. Ser. }\end{array}$ & Published March 8 \\
\hline
\end{tabular}

\title{
Relative effects of nitrogen or phosphorus depletion and light intensity on the pigmentation, chemical composition, and volume of Pyrenomonas salina (Cryptophyceae)
}

\author{
Alan J. Lewitus, David A. Caron \\ Biology Department, Woods Hole Oceanographic Institution, Woods Hole, Massachusetts 02543, USA
}

\begin{abstract}
The nitrogen-rich phycobiliproteins are efficient light-harvesting pigments of cryptophytes, cyanobacteria, and rhodophytes. Whereas it is well established that certain cyanobacteria mobilize their phycobiliproteins in response to nitrogen deprivation, the effect of nitrogen stress on cryptophyte physiology has been studied only rarely. We compared the effects of nitrogen and phosphorus depletion on the biovolume, chemical composition, and pigment composition of the marine cryptophyte Pyrenomonas salina, grown in batch cultures under light-limiting and light-saturating conditions. Cellular phycoerythrin content declined during the late exponential growth phase in nitrogen-depleted cultures, and the cells were nearly devoid of phycoerythrin $1<3 \%$ of the phycoerythrin content of nitrogen-replete cells) at the beginning of stationary growth. Phycoerythrin content also decreased during late exponential phase in phosphorus-depleted cultures, but these latter cells contained more than 10 times the phycoerythrin concentration of nitrogen-depleted cells at the same growth stage. Chlorophyll a content declined in nitrogen-depleted cultures, but at a slower rate than the decrease in phycoerythrin, such that the phycoerythrin to chlorophyll a ratio decreased by more than $95 \%$ from the early exponential to early stationary growth phase. In nitrogen-depleted cultures grown at a low light intensity, the decline in phycoerythrin content preceded the decline in chlorophyll $a$ content, and resulted in only slight changes in cellular nitrogen content and biovolume. These data indicate that phycoerythrin is preferentially lost from $P$. salina during nitrogen deficiency, and support the hypothesis that, similar to certain cyanobacteria, $P$. salina responds to nitrogen deprivation by mobilizing phycoerythrin in order to help sustain cellular nitrogen requirements.
\end{abstract}

\section{INTRODUCTION}

Phycobiliproteins are the major light-harvesting pigments in cyanobacteria, rhodophytes, and cryptophytes. Cryptophyte phycobiliproteins are immunochemically related to cyanobacteria and rhodophyte phycobiliproteins (MacColl et al. 1976, Guard-Friar et al. 1986), suggesting a common evolutionary ancestry to the 3 pigment groups. However, the phylogenetic status of cryptophyte phycobiliproteins is complicated by their distinct physical properties and molecular structures (Glazer 1981), and especially by the unique way in which they are organized within the chloroplast (Gantt 1979). Whereas the phycobiliproteins of cyanobacteria and rhodophytes are organized within discrete phycobilisomes located on the outer thylakoid membrane, cryptophytes lack phycobilisomes, and contain

(c) Inter-Research/Printed in F. R. Germany phycobiliproteins within the thylakoid lumen. Cryptophytes also differ from cyanobacteria and rhodophytes in containing 2 light-harvesting pigment complexes, the phycobiliprotein-associated protein complex and a chlorophyll $a / c$ protein complex. The latter is integrally bound to the thylakoid membrane, and transfers energy to either photosystem (Lichtlé et al. 1980).

Cryptophytes resemble cyanobacteria and rhodophytes, however, in that Photosystem II receives excitation energy primarily through the phycobiliprotein light-harvesting protein complex (reviewed in Larkum \& Barrett 1983, MacColl \& Guard-Friar 1987), and this energy transfer is highly efficient (Haxo \& Fork 1959, Holzwarth et al. 1983, Hanzlik et al. 1985, Bruce et al. 1986). Efficient energy transfer in cyanobacteria and rhodophytes can be partly explained by the highly 
ordered juxtapositioning of antenna pigments within the phycobilisome and the close spectral overlap between phycoerythrin, phycocyanin, allophycocyanin, and chlorophyll a (reviewed in Scheer 1981). Efficient energy transfer to Photosystem II is not as thoroughly understood in cryptophytes, where phycobiliprotein complexes are seemingly less efficiently organized, allophycocyanin is absent, and phycoerythrin and phycocyanin have never been demonstrated in the same organism (reviewed in Gantt 1979). However, the presence of multiple forms of phycoerythrin or phycocyanin within a species (Hiller \& Martin 1987 and references therein), and the organization of phycobiliproteins into discrete units closely associated with the thylakoid membrane (Lichtlé et al. 1987, Ludwig \& Gibbs 1989) may partly account for efficient energy conversion in cryptophytes. Clearly, cryptophytes have evolved a unique system for harvesting light, combining strategies of other phycobiliprotein-containing organisms and chromophytes.

One issue that has been extensively studied in cyanobacteria, but not cryptophytes, is the response of the photosynthetic system to changes in nutrient status. In general, cyanobacteria react to nitrogen depletion by decreasing the rate of phycobiliprotein production (reviewed in Grossman et al. 1986). Constant rates of growth and chlorophyll a production were maintained while phycobiliprotein content declined during the initial stages of nitrogen depletion in cultures of Cyanophora paradoxa (Schenk et al. 1987), Spirulina platensis (Boussiba \& Richmond 1980), Anacystis nidulans (Bayer \& Schenk 1986), and Agmenellum quadruplicatum (Stevens et al. 1981a). De novo synthesis of phycocyanin was shown to be selectively depressed by nitrogen-deficient Anacystis nidulans (Lau et al. 1977). This is not surprising given that the light-harvesting machinery associated with phycobiliproteins requires substantial amounts of nitrogen relative to the chlorophyll/protein complexes (Raven 1984), and that photosynthesis can function in the absence of phycobiliproteins (Lemasson et al. 1973, Arnon et al. 1974).

In addition to reducing the rate of phycobiliprotein production, cyanobacteria also appear to be able to degrade phycobiliproteins already present in the cell when organisms become nitrogen-stressed (Allen \& Smith 1969, Foulds \& Carr 1977, Lau et al. 1977, Yamanaka \& Glazer 1980). Phycobiliproteins can, under certain conditions, account for a significant portion of the cellular nitrogen content (Myers \& Kratz 1955, Bennett \& Bogorad 1973, Kana \& Glibert 1987a). Phycobiliprotein degradation is believed to be a mechanism for mobilizing nitrogen for processes required to sustain cellular growth or metabolism during times when the exogenous supply of nitrogen is depleted.
Analogous information on the effects of nitrogen availability on the pigment concentration of cryptophytes is rare, and the relative importance of light intensity and nutrient status to cryptophyte pigment production is unclear. Results from 2 studies indicate that phycobiliproteins may be selectively lost during nitrogen-deficient conditions in cryptophytes. Lichtlé (1979) compared the pigment content and chloroplast ultrastructure of nitrogen-replete Cryptomonas rufescens cultures grown at a relatively high light intensity, nitrogen-replete cultures grown at a relatively low light intensity, and nitrogen-deficient cultures grown at a relatively low light intensity. Cells from the nitrogenreplete cultures grown at the low light intensity and sampled during the exponential growth phase contained higher concentrations of all photosynthetic pigments and a greater proportion of phycoerythrin to total chlorophyll than cells from the nitrogen-deficient cultures grown at the low light intensity. This result is consistent with the selective degradation of phycoerythrin and/or inhibition of phycoerythrin production by C. rufescens in response to nitrogen stress. Pigment determinations from the nitrogen-replete cultures grown at the high light intensity were made at, or just prior to, the stationary growth phase. Because these cultures were grown in media with a dissolved nitrogen to phosphorus ratio of ca 8 , it is possible that the cells were nitrogen-deficient during this growth stage. Therefore, the effects of light intensity and nitrogen availability on the pigment content of C. rufescens cannot be adequately distinguished based on these results.

Similarly, Rhiel et al. $(1985,1986)$ found that nitrogen-deficient Cryptomonas maculata cells, grown under a relatively high light intensity, contained a much lower concentration of phycoerythrin, a lower proportion of phycoerythrin to chlorophyll, and fewer Photosystem II particles than nitrogen-sufficient cells grown at a lower light level. Resupplying the nitrogendeficient cells with nitrate caused a restoration of the red color characteristic of cultures growing exponentially, but the pigment content was not quantified. Therefore, the relative importance of light intensity and nitrogen availability on the cryptophyte photosynthetic apparatus is difficult to differentiate from these results.

The effects of nutrient status (nitrogen depletion, phosphorus depletion) and light intensity on photosynthetic pigment production in the marine cryptophyte Pyrenomonas salina were examined in this study. The physiological response of $P$. salina to nitrogen depletion resembled that of certain cyanobacteria in that, independent of light intensity, cellular phycobiliprotein content declined before cell division stopped or chlorophyll a concentration decreased. Based on patterns of pigment concentration, biovolume, and 
chemical composition, we hypothesize that $P$. salina mobilizes phycoerythrin during nitrogen-stressed growth in order to supply the biosynthetic nitrogen demands for cellular growth.

\section{METHODS}

Pyrenomonas salina Santore (formerly Cryptomonas salina Wislouch; Chroomonas salina Butcher) clone 3C (Culture Collection of Marine Phytoplankton, Bigelow Laboratory for Ocean Sciences) was obtained from Dr Diane Stoecker (Woods Hole Oceanographic Institution). Batch cultures used for inocula in the experimental treatments were grown axenically at $21^{\circ} \mathrm{C}$ in artificial seawater medium (ASPM Base; Table 9 in Guillard [1975], except that $20 \mathrm{mM} \mathrm{CaCl}_{2}, 0.2 \mathrm{mM} \mathrm{H}_{3} \mathrm{BO}_{3}$, and $0.81 \mathrm{mM} \mathrm{KBr}$ were used) with $\mathrm{f}$-mix vitamins and trace metals (Guillard 1975). The nitrogen source was $\mathrm{NaNO}_{3}$ and the phosphorus source was $\mathrm{NaH}_{2} \mathrm{PO}_{4}$. The $\mathrm{pH}$ of the medium was 7.4 and the salinity was $29.5 \%$.

Cultures were grown under 2 different nutrient regimes at each of 2 light intensities. Continuous illumination was provided by cool-white fluorescent lights at intensities of 325 ('High Light') or 15 ('Low Light') $\mu \mathrm{E} \mathrm{m}^{-2} \mathrm{~s}^{-1}$. Irradiance was measured with an integrating $4 \pi$ quantum sensor (Biospherical Instruments, QSL-100P probe). The effects of nitrogen or phosphorus depletion were examined by growing batch cultures of Pyrenomonas salina in media that were nitrogen-depleted or phosphorus-depleted during the stationary growth phase. Data from previous experiments (Fig. 1) indicated that the population density of cultures in the stationary growth phase correlated directly with the initial $\mathrm{NO}_{3}^{-}$concentration in media with initial molar nitrogen to phosphorus ratios between 0.2 and 4 , and correlated with the initial $\mathrm{PO}_{4}^{-3}$ concentration when the initial nitrogen to phosphorus ratio ranged between 50 and 50000 . In this study, cultures were grown in medium with a molar nitrogen to phosphorus ratio of $1\left(5 \mu \mathrm{M} \mathrm{NO}_{3}^{-}\right.$and $\left.5 \mu \mathrm{M} \mathrm{PO}_{4}^{-3}\right)$, and were nitrogen-depleted during the stationary growth phase, or $80\left(25 \mu \mathrm{MNO}_{3}^{-}\right.$and $\left.0.3 \mu \mathrm{M} \mathrm{PO}_{4}^{-3}\right)$, and were phosphorus-depleted during the stationary growth phase.

Cultures were acclimated to high or low light levels (see above) by repeated transfer of cells in the midexponential growth phase. Exponentially growing populations were inoculated into fresh media to begin the experiment (initial population densities of ca $10^{3}$ cells $\mathrm{ml}^{-1}$ ). Cell numbers, biovolumes, and cellular concentrations of phycoerythrin (PE), chlorophyll $a$, carbon, and nitrogen were determined periodically throughout the growth cycle of the alga. Cultures were tested for bacterial contamination throughout the experiment by inoculating tubes containing $0.5 \%$ yeast extract with $1 \mathrm{ml}$ of the culture, and examining these tubes for bacterial growth.

Biovolumes and cell numbers were measured using a Coulter Multisizer particle counter with a $70 \mu \mathrm{m}$ aperture. Cell counts also were determined microscopically from triplicate samples with counting chambers. A Fuchs-Rosenthal Ultra Plane chamber ( $0.2 \mathrm{~mm}$ depth) was used when cell counts were below $2 \times 10^{4}$ cells $\mathrm{ml}^{-1}$, and a Reichert Bright-Line hemacytometer (0.1 mm depth) was used for higher population densities. Counts obtained with the 2 chambers were normalized to each other by performing duplicate counts of a number of samples with both chambers, and normalizing to Reichert Bright-Line estimates.
Fig. 1. Pyrenomonas salina. Growth curves when cultured at $325 \mu \mathrm{E} \mathrm{m}^{-2} \mathrm{~s}^{-1}$ in different nutrient regimes. (A) Cultures grown in media with $\mathrm{NO}_{3}^{-}$as the sole nitrogen source (molar $\mathrm{N}$ : $\mathrm{P}$ ratio ranged from 0.2 to 4). (B) Cultures grown in media with $\mathrm{PO}_{4}^{-3}$ as the sole phosphorus source (molar N: P ratio ranged from 50 to 50000 )

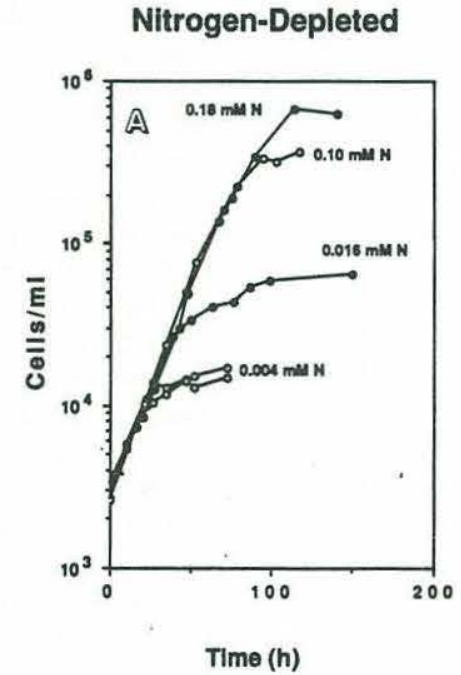

Phosphorus-Depleted

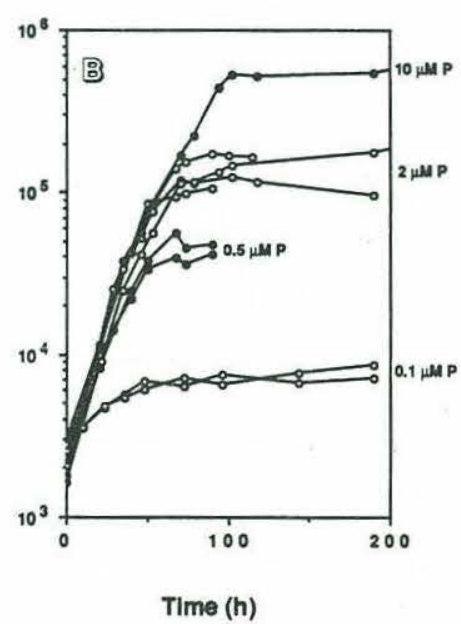


Specific growth rates, $\mu\left(\mathrm{d}^{-1}\right)$, were determined from regressions of the linear portion of the growth curves expressed as the natural log of the population densities versus time (i.e. the exponential growth phase).

$P E$ was extracted by freeze-thawing in $0.05 \mathrm{M}$ phosphate buffer ( $\mathrm{pH}$ 6.8) (Thinh 1983). Cells were harvested by centrifugation, and the pellet was resuspended in buffer. The solution was rapidly frozen in liquid nitrogen and thawed in water at room temperature. One freeze-thaw cycle was sufficient for maximal PE extraction in this species, regardless of population density. Additional cycles did not increase the amount of soluble PE recovered from cultures over a wide range of population densities. After freeze-thawing, the sample was centrifuged at $6800 \times g$ (Sorvall Superspeed RC2-B; Type SS-34 rotor) for $30 \mathrm{~min}$ at $7^{\circ} \mathrm{C}$ to remove particulate material. The concentration of extracted PE in the supernatant was determined fluorometrically, using an SLM Aminco SPF-500C Spectrofluorometer. Dilution series of extracted PE were used to standardize the peak PE fluorescence (550 nm excitation; $585 \mathrm{~nm}$ emission) against peak absorption (549 nm), as measured with a Hewlett Packard 8451A Diode Array Spectrophotometer. PE concentrations were determined based on an extinction coefficient of $12.6 \mathrm{ml} \mathrm{mg}^{-1} \mathrm{~cm}^{-1}$ (R. MacColl pers. comm.).

Chlorophyll was extracted with $100 \%$ acetone, following filtration onto HA Millipore membrane filters (mean pore size $=0.45 \mu \mathrm{m}$ ). Chlorophyll $a$ concentrations were then determined spectrophotometrically (Jeffrey \& Humphrey 1975), using a Shimadzu Spectrophotometer UV-260.

Particulate carbon and nitrogen were measured with a Perkin Elmer 240 elemental analyzer, after filtration onto pre-combusted Whatman GF/F glass-fiber filters. The amount of nitrogen contained in the PE of

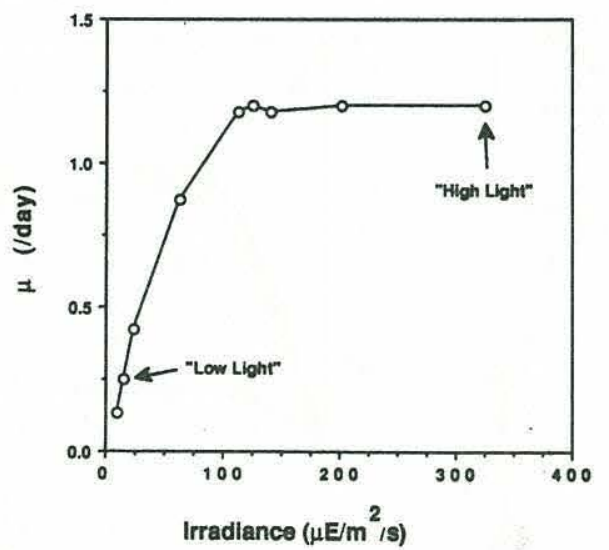

Fig. 2. Pyrenomonas salina. Effect of irradiance on growth rate $(\mu)$. Growth rates at the High Light intensity $\left(325 \mu \mathrm{E} \mathrm{m}^{-2} \mathrm{~s}^{-1}\right)$ and Low Light intensity $\left(15 \mu \mathrm{E} \mathrm{m}^{-2} \mathrm{~s}^{-1}\right)$ used in this study are indicated
Pyrenomonas salina was estimated by assuming that $19 \%$ of the weight of PE from $P$. salina is nitrogen. This value was calculated, based on the amino acid composition of PE from Rhodomonas lens (MacColl et al. 1976), which has the same spectral characteristics as PE from P. salina (R. MacColl pers. comm.).

In a separate experiment, growth rates of Pyrenomonas salina were determined in batch cultures that had been acclimated to $325,200,140,125,110,60,25$, 15 , and $10 \mu \mathrm{E} \mathrm{m}^{-2} \mathrm{~s}^{-1}$ (see Fig. 2). Methods for acclimation to light intensity and determination of growth rates were as previously described. The culture medium for this experiment was identical to that described above except that $\mathrm{NH}_{4} \mathrm{Cl}$ was provided as the nitrogen source.

\section{RESULTS}

Preliminary growth experiments carried out with Pyrenomonas salina demonstrated that the growth rate of this cryptophyte in defined medium is light-saturated at ca $100 \mu \mathrm{E} \mathrm{m}^{-2} \mathrm{~s}^{-1}$ (Fig. 2). The growth rate of $P$. salina at light intensities between 115 and $325 \mu \mathrm{E}$ $\mathrm{m}^{-2} \mathrm{~s}^{-1}$ was constant at $1.2 \mathrm{~d}^{-1}$. The highest light intensity $\left(325 \mu \mathrm{E} \mathrm{m}^{-2} \mathrm{~s}^{-1}\right)$ was the 'High Light' intensity employed in the present study. Below $115 \mu \mathrm{E} \mathrm{m}^{-2} \mathrm{~s}^{-1}$, the growth rate of $P$. salina was proportional to light intensity. The growth rate at $15 \mu \mathrm{E} \mathrm{m}^{-2} \mathrm{~s}^{-1}$ (the Low Light' intensity of this study) was $0.25 \mathrm{~d}^{-1}$.

The average biovolume of Pyrenomonas salina varied with the light level and the growth stage of the alga (Fig. 3; Table 1). Mean biovolume was relatively constant throughout the exponential growth phase in each culture, but was not the same for the various treatments. Differences in biovolumes for cultures grown at the different light intensities were most conspicuous during the exponential growth phase. Biovolume averages for both cultures at High Light were significantly higher (t-test, $p>0.05$ ) than the biovolumes of the cultures at Low Light during exponential growth. Average biovolume decreased during the stationary growth phase at High Light. The initiation of this decline occurred at an earlier growth period in the nitrogen-depleted culture than in the phosphorus-depleted culture (Fig. 3A, C), such that phosphorus-depleted cells were, on average, approximately twice as large as nitrogen-depleted cells $100 \mathrm{~h}$ after the beginning of stationary growth (Table 1). Contrary to the patterns found in cultures grown at High Light, the average biovolume increased during stationary growth in cultures grown at Low Light (Fig. $3 B$, D). However, the increase in volume of phosphorus-depleted cells was greater than that of nitrogen-depleted cells. At the last sampling time, the average volume of nitrogen-depleted cells grown at 
Fig. 3. Pyrenomonas salina. Cell numbers and mean biovolume in: (A) High Light cultures nitrogen-depleted during stationary growth, (B) Low Light cultures nitrogen-depleted during stationary growth, (C) High Light cultures phosphorus-depleted during stationary growth, (D) Low Light cultures phosphorus-depleted during stationary growth
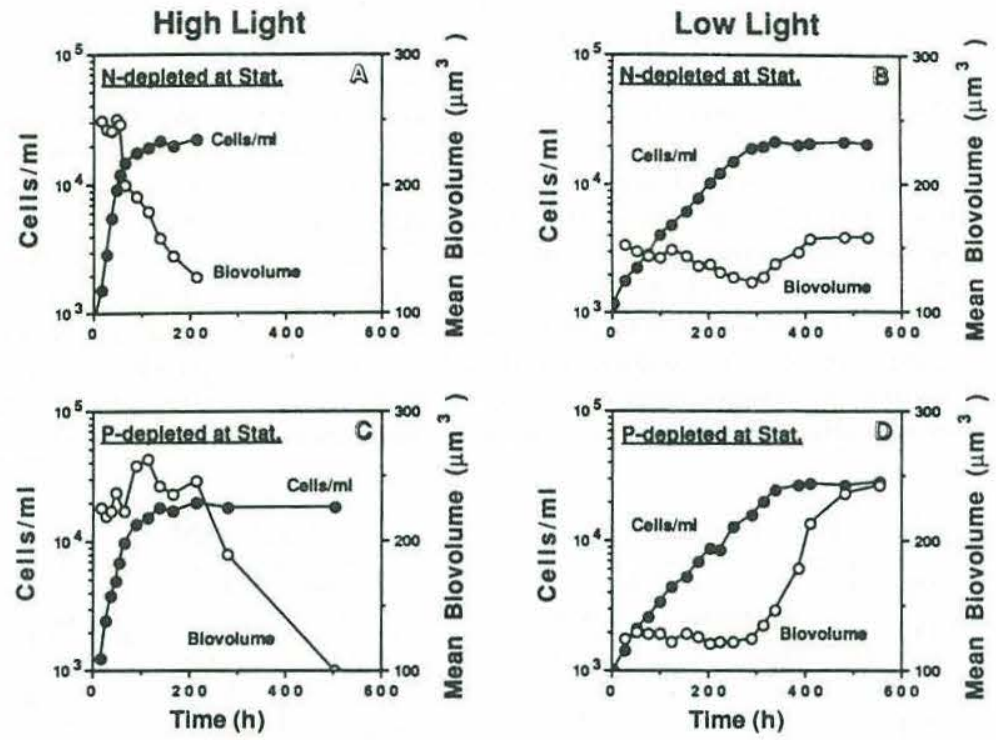

Table 1. Pyrenomonas salina. Mean biovolume (Biovol), carbon, nitrogen, and C:N ratio of cells during the exponential and stationary growth phases. Exponential growth phase data are the mean values obtained from cells in early and middle exponential growth. Means of cell carbon and nitrogen from exponentially growing cultures were calculated from 2 and 3 sampling time points for High Light and Low Light cultures, respectively. Stationary phase data were obtained from cells $100 \mathrm{~h}$ after the beginning of stationary growth, with the exception of the Low Light culture grown at an N:P ratio of 80 . Data from the latter culture were obtained from cells $50 \mathrm{~h}$ after the approximate beginning of stationary phase. The standard deviations for the biovolume distributions, as calculated from cell size histograms, ranged from 7 to $10 \%$ of the mean

\begin{tabular}{|c|c|c|c|c|c|c|c|c|c|c|c|c|}
\hline \multirow[t]{3}{*}{ Treatment } & \multicolumn{6}{|c|}{ Exponential phase } & \multicolumn{6}{|c|}{ Stationary phase } \\
\hline & \multirow{2}{*}{$\begin{array}{l}\text { Biovol. } \\
\left(\mu \mathrm{m}^{3}\right)\end{array}$} & \multicolumn{2}{|c|}{ Carbon } & \multicolumn{2}{|c|}{ Nitrogen } & \multirow[t]{2}{*}{$\mathrm{C}: \mathrm{N}$} & \multirow{2}{*}{$\begin{array}{l}\text { Biovol. } \\
\left(\mu \mathrm{m}^{3}\right)\end{array}$} & \multicolumn{2}{|c|}{ Carbon } & \multicolumn{2}{|c|}{ Nitrogen } & \multirow[t]{2}{*}{$\mathrm{C}: \mathrm{N}$} \\
\hline & & $\begin{array}{l}(\mathrm{pmol} \\
\left.\text { cell }^{-1}\right)\end{array}$ & $\begin{array}{l}(\mathrm{fmol} \\
\left.\mu \mathrm{m}^{-3}\right)\end{array}$ & $\begin{array}{l}\left(\mathrm{pmol}^{-1}\right. \\
\left.\text { cell }^{-1}\right)\end{array}$ & $\begin{array}{l}(\mathrm{fmol} \\
\left.\mu \mathrm{m}^{-3}\right)\end{array}$ & & & $\begin{array}{l}(\mathrm{pmol} \\
\left.\text { cell }^{-1}\right)\end{array}$ & $\begin{array}{l}(\mathrm{fmol} \\
\mu \mathrm{m}^{-3} \text { ) }\end{array}$ & $\begin{array}{l}\left(\mathrm{pmol}^{-1}\right. \\
\left.\text { cell }^{-1}\right)\end{array}$ & $\begin{array}{l}\text { (fmol } \\
\mu \mathrm{m}^{-3} \text { ) }\end{array}$ & \\
\hline \multicolumn{13}{|l|}{ High Light } \\
\hline $\begin{array}{l}\mathrm{N} \text {-depleted } \\
\text { at stat. phase }\end{array}$ & 246 & 5.7 & 23 & 0.89 & 3.6 & 6.5 & 128 & 3.8 & 30 & 0.36 & 2.8 & 10.6 \\
\hline $\begin{array}{l}\text { P-depleted } \\
\text { at stat. phase }\end{array}$ & 226 & 7.9 & 35 & 1.2 & 5.2 & 6.6 & 246 & 9.6 & 39 & 1.1 & 4.5 & 8.7 \\
\hline \multicolumn{13}{|l|}{ Low Light } \\
\hline $\begin{array}{l}\mathrm{N} \text {-depleted } \\
\text { at stat. phase }\end{array}$ & 144 & 4.6 & 32 & 0.69 & 4.8 & 6.7 & 152 & 6.2 & 41 & 0.67 & 4.4 & 9.4 \\
\hline $\begin{array}{l}\text { P-depleted } \\
\text { at stat. phase }\end{array}$ & 126 & 4.9 & 39 & 0.81 & 6.4 & 6.0 & 178 & 5.7 & 32 & 0.61 & 3.4 & 9.5 \\
\hline
\end{tabular}

Low Light was ca $60 \%$ less than that of phosphorusdepleted cells (Fig. 3B, D).

The mean molar carbon to nitrogen $(C: N)$ ratios of exponentially growing Pyrenomonas salina did not differ significantly with light intensity (t-test, $p \cdot>0.05$ ), despite the differences in average biovolumes (Table 1). Cells from the stationary growth phase had significantly greater $\mathrm{C}: \mathrm{N}$ ratios than exponentially growing cells for all treatments.

During the exponential growth phase, PE concen- tration cell ${ }^{-1}$ and PE concentration (cellular carbon) ${ }^{-1}$ were significantly higher (t-test, $p>0.05$ ) in cultures grown at Low Light than at High Light (Fig. 4; Table 2). PE cell ${ }^{-1}$ decreased during late exponential growth in all cultures. However, the extent of the reduction of the PE content during late exponential and early stationary growth was affected by the nutrient regime of the culture medium. When cells were grown in medium that became nitrogen-depleted in the stationary growth phase, PE cell ${ }^{-1}$ decreased to 
near-zero values during early stationary growth (Fig. 4A, B; Table 2). During this growth phase, cells in these cultures contained less than $10 \%$ of the PE concentration of phosphorus-stressed algae. The PE content of Pyrenomonas salina grown in a medium that became phosphorus-depleted declined steadily during stationary growth at the High Light intensity (Fig. 4C). PE concentration also decreased in cells grown in the same medium at Low Light, but remained relatively constant at around $2 \mathrm{pg} \mathrm{PE} \mathrm{cell-1}$ for the duration of the experiment (Fig. 4D).

Unlike PE concentration cell ${ }^{-1}$, there were no significant differences (t-test, $\mathrm{p}>0.05$ ) in the concen- tration of chlorophyll a cell ${ }^{-1}$ at the 2 light levels during exponential growth (Fig. 4; Table 2). This difference between PE and chlorophyll a concentration in the 2 light regimes resulted in a higher cellular ratio of PE to chlorophyll $a$ in cultures grown at Low Light than those grown at High Light during this period (Fig. 5; Table 2). The chlorophyll a content of cells grown in the nitrogen-depleted medium began to decline during late exponential growth, but the rate of decrease was much less than the rate of decrease of PE cell ${ }^{-1}$ (Fig. 4A, B), leading to a sharp decline in the ratio of $\mathrm{PE}$ to chlorophyll a during this period (Fig. 5; Table 2). The chlorophyll a content of cells
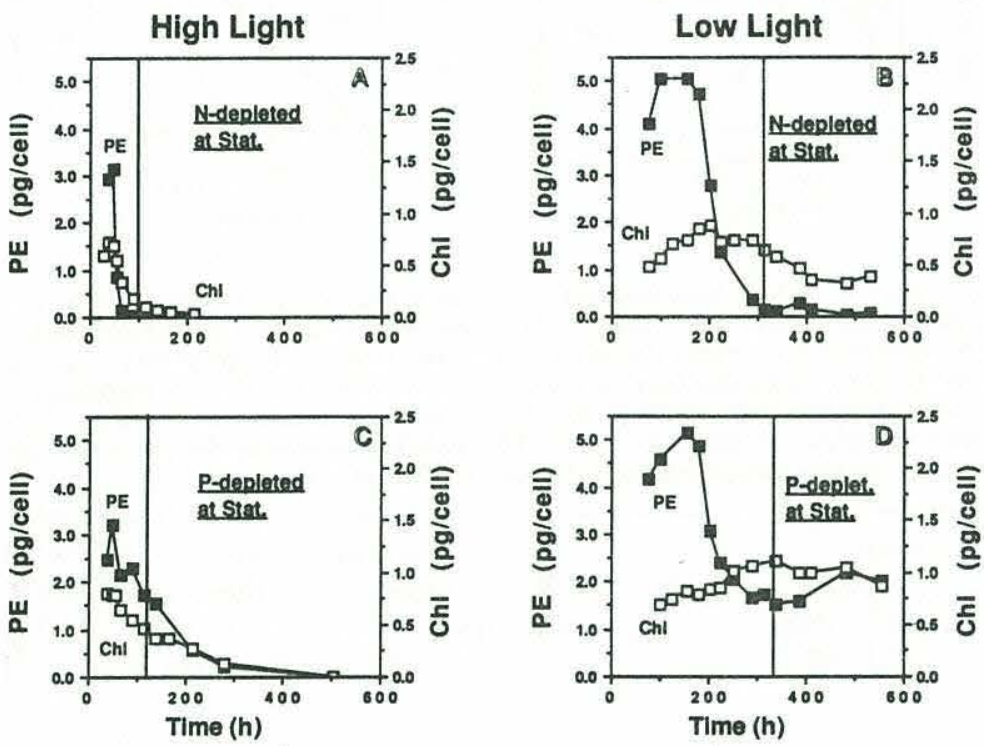

Fig. 4. Pyrenomonas salina. Cellular PE and chlorophyll $a$ in: (A) High Light cultures nitrogen-depleted during stationary growth; (B) Low Light cultures nitrogen-depleted during stationary growth; (C) High Light cultures phosphorus-depleted during stationary growth; (D) Low Light cultures phosphorus-depleted during stationary growth. Vertical lines indicate approximate beginning of stationary growth

Table 2. Pyrenomonas salina. Mean PE content, chlorophyll a content, and PE to chlorophyll a ratio of cells from the early exponential and early stationary growth phases. Data from the early exponential phase are the mean values obtained from cells prior to the time when the decline in PE content began. Data from the early stationary phase were obtained from cells $24 \mathrm{~h}$ after the approximate beginning of stationary phase.

\begin{tabular}{|c|c|c|c|c|c|c|c|c|}
\hline \multirow[t]{3}{*}{ Treatment } & \multicolumn{4}{|c|}{ Early exponential phase } & \multicolumn{4}{|c|}{ Early stationary phase } \\
\hline & \multirow{2}{*}{\multicolumn{2}{|c|}{$\begin{array}{c}\text { PE } \\
\left(\text { pg cell }^{-1}\right)\left(\mathrm{g}\left(\mathrm{mg} \mathrm{cell} \mathrm{C}^{-1}\right)\right.\end{array}$}} & \multirow{2}{*}{\multicolumn{2}{|c|}{$\begin{array}{c}\text { Chl } \\
\left(\text { pg cell }^{-1}\right)\left(\mathrm{g}\left(\mathrm{mg} \mathrm{cell} \mathrm{C}^{-1}\right)\right.\end{array}$}} & \multirow[t]{2}{*}{$\mathrm{PE}: \mathrm{Chl}$} & \multirow{2}{*}{$\begin{array}{c}\text { PE } \\
\left(\mathrm{pg} \mathrm{cell} \text { cel }^{-1}\right)\end{array}$} & \multirow{2}{*}{$\begin{array}{c}\mathrm{Chl} \\
\left(\mathrm{pg} \text { cell }^{-1}\right)\end{array}$} & \multirow[t]{2}{*}{ PE : Chl } \\
\hline & & & & & & & & \\
\hline \multicolumn{9}{|l|}{ High Light } \\
\hline $\begin{array}{l}\mathrm{N} \text {-depleted } \\
\text { at stat. phase }\end{array}$ & 3.0 & 44 & 0.70 & 10 & 4.3 & 0.02 & 0.10 & 0.20 \\
\hline $\begin{array}{l}\text { P-depleted } \\
\text { at stat. phase }\end{array}$ & 2.9 & 31 & 0.75 & 8 & 4.0 & 1.7 & 0.46 & 3.7 \\
\hline Low Light & & & - & & & & & \\
\hline $\begin{array}{l}\mathrm{N} \text {-depleted } \\
\text { at stat. phase }\end{array}$ & 4.9 & 89 & 0.65 & 12 & 7.6 & 0.14 & 0.67 & 0.21 \\
\hline $\begin{array}{l}\text { P-depleted } \\
\text { at stat. phase }\end{array}$ & 4.9 & 83 & 0.77 & 13 & 6.2 & 1.7 & 1.1 & 1.6 \\
\hline
\end{tabular}


High Light

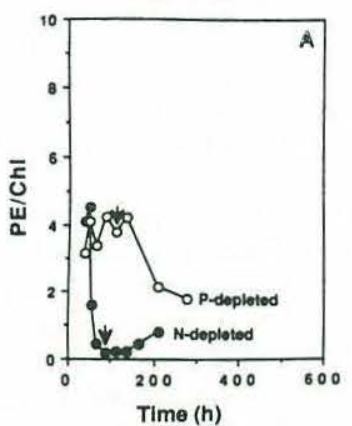

Low Light

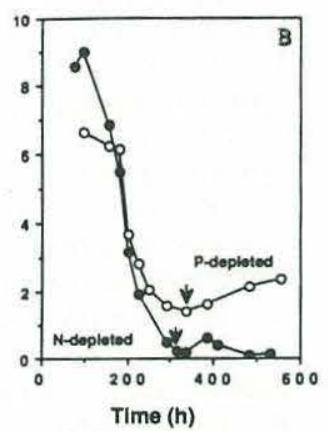

Fig. 5. Pyrenomonas salina. Cellular PE to chlorophyll a ratio in cultures grown under different nutrient regimes at: (A) High Light and (B) Low Light intensities. 'N-depleted' and 'Pdepleted' refer to cultures that were nitrogen- and phosphorus-depleted, respectively, during stationary growth. Arrows indicate approximate beginning of stationary growth

grown in the phosphorus-depleted medium decreased during the late exponential growth phase in High Light and continued to decrease during the stationary growth phase at a rate similar to that of PE cell-1 (Fig. 4C), resulting in comparable PE to chlorophyll a ratios in cells from the exponential and early stationary growth phases (Fig. 5A; Table 2). The chlorophyll a concentration actually increased during the late exponential growth phase in cells grown at Low Light in the phosphorus-depleted medium (Fig. 4D), possibly due to culture self-shading effects. Because PE cell-1 decreased during this same period, the cellular PE to chlorophyll a ratio of this culture decreased by ca $75 \%$ during the transition period from exponential growth to early stationary growth (Fig. 5B; Table 2). These cells maintained a relatively high chlorophyll a content throughout the stationary growth phase (ca $1 \mathrm{pg} \mathrm{cell}{ }^{-1}$ ).

Algae from all cultures experienced a decline in nitrogen content cell ${ }^{-1}$ and PE content cell ${ }^{-1}$ in the stationary growth phase relative to the exponential growth phase (Table 3 ). The decrease in cellular nitrogen during this period, however, was less than the decrease in the amount of nitrogen contained in PE (calculation described in 'Methods'). That is, as the cultures approached the stationary growth phase, a greater percentage of the PE nitrogen was lost from the cells than indicated by the change in total nitrogen. The largest discrepancy was observed for algae grown at the low light intensity in the nitrogendepleted medium. During early stationary growth, these cells contained only $3 \%$ of the PE nitrogen and $87 \%$ of the total cellular nitrogen of the same culture during the exponential growth phase (Fig. 6A; Table 3). In contrast to PE, chlorophyll a cell ${ }^{-1}$ did not change significantly (t-test, $p>0.05$ ) during this same period (Fig. 6A). Nitrogen contained in PE contributed significantly (ca $9 \%$ or ca $4 \%$ in cultures grown at Low Light or High Light, respectively) to total cellular nitrogen of exponentially growing Pyrenomonas salina (Table 3). This contribution decreased dramatically as the cultures reached the stationary growth phase in the nitrogen-depleted medium (e.g. Fig. 6B).

Table 3. Pyrenomonas salina. Mean cell nitrogen and nitrogen contained in cell's PE (PE-N) of cultures from the early exponential and early stationary growth phases. See 'Methods' for procedure for calculating PE-N. Also included are the \% decrease in cell nitrogen and PE-N from the early exponential to early stationary growth phase, and the quotient of these 2 parameters. Early exponential growth phase data are the mean values obtained from cells prior to the time when the decline in PE content began. Means of cell nitrogen from exponentially growing cultures were calculated from 2 and 3 sampling time points for High Light and Low Light cultures, respectively. Early stationary growth phase data were obtained from cells $24 \mathrm{~h}$ after the approximate beginning of stationary phase

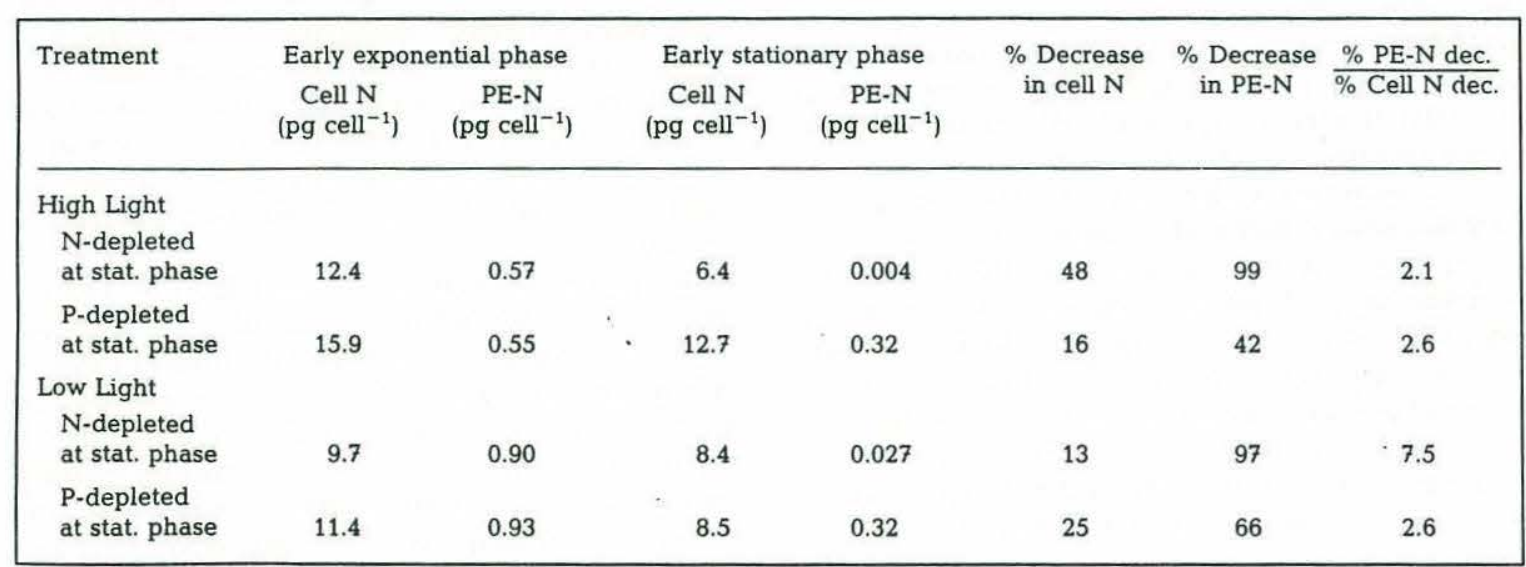




\section{Low Light; N-depleted at Stat. Phase}
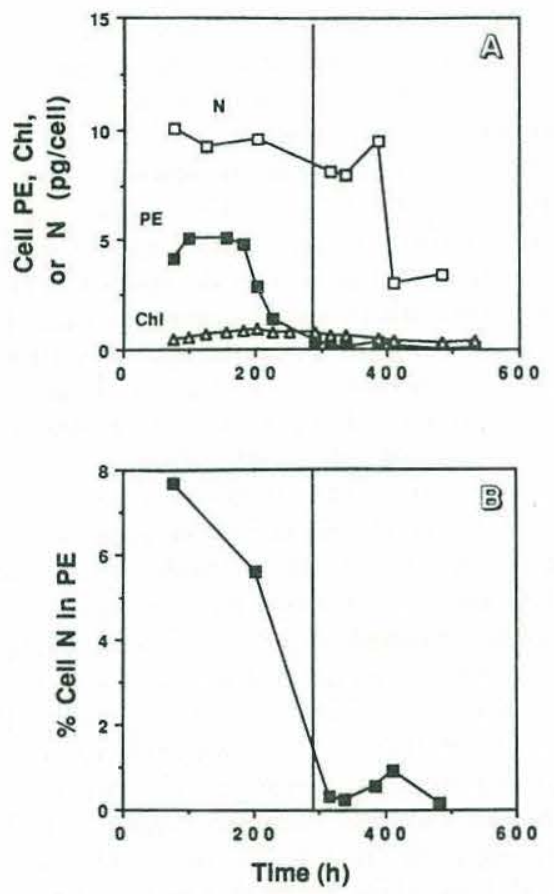

Fig. 6. Pyrenomonas salina. (A) Cellular PE, chlorophyll $a$, and nitrogen contents in the Low Light culture nitrogen-depleted during stationary growth. (B) Fraction of cellular nitrogen contained in PE of this same culture. Vertical lines indicate approximate beginning of stationary growth

\section{DISCUSSION}

A common response of phytoplankton to nitrogen deprivation is the selective loss of proteins associated with the photosynthetic apparatus (e.g. Hipkin \& Syrett 1977, Perry et al. 1981, Coleman et al. 1988a, b). It has been suggested that the mobilization of nitrogen from the photosynthetic components allows continued synthesis of proteins essential for cell maintenance and growth during periods of nitrogen deficiency (Perry et al. 1981). In some species of cyanobacteria, phycobiliprotein content decreases in response to nitrogen stress prior to decreases in chlorophyll a content and growth rate (Boussiba \& Richmond 1980, Stevens et al. 1981a, Bayer \& Schenk 1986, Schenk et al. 1987). Thus, the mobilization of $\mathrm{PE}$ as an endogenous nitrogen source appears to be an adaptive response of these cyanobacteria to early stages of nitrogen deficiency. To our knowledge, this study is the first to compare the relative importance of nitrogen deficiency, phosphorus deficiency, and light intensity on the chemical composition and pigment content of a cryptophyte. The patterns in cellular volume, carbon and nitrogen content, and pigment composition observed in this study indicate that, similar to some cyanobacteria, the mobilization of PE may serve as an important endogenous source of nitrogen in Pyrenomonas salina, but that phosphorus stress and light intensity also have significant effects on PE content.

Analogous to the situation in cyanobacteria, the adaptive significance of mobilizing nitrogen from photosynthetic components by Pyrenomonas salina may lie in the ability of the cell to support growth and/ or maintenance during periods of nitrogen deficiency. Because nitrate concentration of the culture medium was not measured in our study, the precise point of nitrogen exhaustion in the nitrogen-depleted cultures was not determined. However, we can assume that, in cultures grown in the medium with a nitrogen to phosphorus ratio of 1 , nitrogen was depleted no later than at the onset of stationary growth, and that physiological adaptations in response to nitrogen stress were initiated at some point prior to the stationary growth phase. Based on these assumptions, we present evidence supporting the hypothesis that nitrogen mobilization from PE may sustain growth and/or cellular maintenance in nitrogen-stressed $P$. salina.

Nitrogen-depleted cultures reached the stationary growth phase only after the cellular PE content declined considerably (from 3 to $0.03 \mathrm{pg} \mathrm{cell}^{-1}$ at High Light and from 5 to $0.4 \mathrm{pg}$ cell $^{-1}$ at Low Light). Relative to PE, chlorophyll a content decreased only slightly during this period (i.e. the PE to chlorophyll a ratio decreased precipitously), indicating a preferential loss of PE relative to chlorophyll a prior to the cessation of cell division. It is noteworthy that the decline in PE content began during exponential growth. Physiological adaptations to nitrogen depletion in phytoplankton batch cultures are known to occur during exponential growth (Prézelin 1982). The decrease in the PE content of nitrogen-stressed Pyrenomonas salina in this study occurred prior to changes in the growth rate, chlorophyll a content, biovolume, carbon content, or nitrogen content of the alga. This was especially clear for the nitrogen-depleted culture grown at Low Light (Figs. 4B and 6). The latter values did not change significantly until the stationary growth phase was reached (and after PE content decreased to near-zero values).

The probability that PE was mobilized by Pyrenomonas salina for other cellular uses in nitrogendepleted cultures is supported by the relative changes in nitrogen contained in PE and in the total cellular nitrogen of $P$. salina. These patterns are shown for the culture at Low Light in Fig. 6. The cellular nitrogen content of this nitrogen-depleted culture did not change substantially during the late exponential and early stationary growth phases. The PE concentration 
cell ${ }^{-1}$ of this culture, however, decreased dramatically during this same period. It is possible that the mobilization of PE nitrogen allowed the cells to maintain a relatively high nitrogen content during this period, thus delaying the eventual decrease in total cellular nitrogen that occurred in the late stationary growth phase.

Nitrogen depletion had a marked effect on the PE concentration cell ${ }^{-1}$ in Pyrenomonas salina as described above. However, both light and phosphorus depletion also had significant effects on the PE concentration of this alga. The PE content and PE to chlorophyll a ratio of phosphorus-depleted cultures decreased during the late exponential growth phase, similar to the pattern in the nitrogen-depleted cultures. It is incongruous that PE cell ${ }^{-1}$ declined in a phosphorus-stressed culture if PE is mobilized for nitrogen, because the breakdown of PE would not provide a biosynthetic source of phosphorus. However, loss of phycocyanin in response to phosphorus depletion has been observed in the cyanobacterium Agmenellum quadruplicatum concurrent with a decrease in the nitrate uptake rate and total cellular nitrogen content (Stevens et al. 1981b). Given that deficiencies in sulfur (Lawry \& Jensen 1979), carbon dioxide (Miller \& Holt 1977), or iron (Öquist 1971) can also lead to phycobiliprotein loss in cyanobacteria, the decline in cellular PE content in phosphorus-depleted $P$. salina may reflect a more general response to nutrient deprivation. Interestingly, the decrease in PE concentration cell $^{-1}$ in the nitrogen-depleted culture at Low Light was much greater than the decrease in the phosphorus-depleted culture in this light regime (Fig. 4B, D). At High Light, the decrease in the PE concentration cell ${ }^{-1}$ in the phosphorus-depleted culture occurred at a much slower rate than in the nitrogen-depleted culture, although PE concentration cell ${ }^{-1}$ eventually reached very low values in both cultures (Fig. 4A, C).

The possibility that a decline in the PE content of Pyrenomonas salina may be a generalized response to stress is supported by the interaction of phosphorus depletion and the light regime in this study. Although phosphorus depletion resulted in a decrease in the PE concentration cell $^{-1}$, the magnitude of the decrease was different at the 2 light intensities as mentioned in the previous paragraph (Fig. 4). Measurable concentrations of $\mathrm{PE}\left(>1 \mathrm{pg} \mathrm{cell}^{-1}\right)$ were always present in the phosphorus-stressed culture grown at Low Light. The $\mathrm{PE}$ content of the culture grown in the same medium at High Light eventually attained very low values, although the rate of decrease of PE concentration in this culture was much slower than that of the nitrogendepleted culture. The lower concentrations of PE in the phosphorus-depleted culture at High Light (relative to Low Light) are consistent with our expectations if the loss of PE is a generalized response to stress. The additive effects of phosphorus depletion and continuous high light intensity could account for the greater loss of PE. It is perhaps noteworthy that, in this latter culture, chlorophyll a concentration cell ${ }^{-1}$ decreased concomitantly with PE concentration (but did not decrease in the culture grown at Low Light). The interaction of light intensity and PE concentration cell $^{-1}$ was not as evident in the nitrogen-depleted cultures because of the overriding influence of nitrogen deficiency on PE concentrations (Fig. 4A, B).

One consistent effect of the light regime that may have affected PE concentration cell ${ }^{-1}$ was the changes in biovolume of the cryptophyte over the growth cycle (Fig. 3). Increases in cell size during the late exponential and stationary growth phase of batch cultures have been commonly observed in phytoplankton (Fogg 1959, Epstein et al. 1961, Prakash et al. 1973, Lehman 1976). Increased cell size during this period apparently can result both from a decrease in the rate of cell division relative to biomass production and a general shift in cellular metabolism from protein to storage carbohydrate or lipid synthesis (Prakash et al. 1973, Lehman 1976, Ben-Amotz et al. 1985). Pyrenomonas salina in the stationary growth phase was larger and contained a greater proportion of carbon to nitrogen than exponentially growing cells for both cultures grown at Low Light. This result is consistent with a shift from protein to carbohydrate or lipid production. The large decreases in average biovolume of $P$. salina during the stationary growth phase of the cultures at High Light are more problematical to explain, but, at least during early stationary growth, may be related to the expenditure of cellular reserves in response to the high metabolic demands of rapidly growing cells that suddenly encounter nutrient-depleted conditions (Prézelin 1982). The continual decline in mean biovolume through late stationary growth is perhaps indicative of cells becoming severely stressed or even dying as a consequence of the additive effects of high light intensity and nutrient deficiency.

This study was not designed to address whether or not 2 separate pools of PE exist in Pyrenomonas salina, one for light-harvesting and one for nitrogen storage. Such a controversy exists concerning the role of $\mathrm{PE}$ in the cyanobacteria Synechococcus spp. (Wyman et al. 1985, 1986, Yeh et al. 1986, Kana \& Glibert 1987a, b). In Synechococcus WH7803, Kana \& Glibert (1987a) argued against a non-photosynthetically coupled pool of PE based partly on the large differences in PE concentration observed in cyanobacteria grown at different light intensities. Although PE concentration in exponentially growing $P$. salina was affected by light intensity (Fig. 4), these differences in PE cell-1 and PE (cellular carbon $)^{-1}$ were much less than the differences observed for Synechococcus. Given this observation, and the 
finding that much of the PE in another cryptophyte, Rhodomonas lens, was loosely arranged in the thylakoid lumen (Spear-Bernstein \& Miller 1987, but see Ludwig \& Gibbs 1989), it is at least possible that PE in $P$. salina provides a small pool of endogenous nitrogen that can be mobilized under the appropriate circumstances.

In summary, we have presented evidence that supports the hypothesis that mobilization of nitrogen from $\mathrm{PE}$ is an adaptive response of Pyrenomonas salina to nitrogen depletion. In addition, we have demonstrated that phosphorus depletion and the light regime also affected the PE concentration cell ${ }^{-1}$. These results extend the observations of Lichtle (1979) and Rhiel et al. (1985) that in cryptophytes, as in cyanobacteria and rhodophytes, phycobiliproteins may be selectively lost during nutrient stress conditions.

Acknowledgements. The authors are grateful to Dr Neil Blough for valuable discussions and the use of the spectrofluorometer. We also thank Drs Sallie Chisholm, Todd Kana, Robert Olson, Diane Stoecker, and John Waterbury for helpful comments on the manuscript, and Bonnie Woodward who performed the CHN analysis. This work was supported by NSF Grant BSR-8620443, Ocean Ventures Fund Grant 25/ 85.10 of the Woods Hole Oceanographic Institution Education Program, and the Woods Hole Oceanographic Institution Education Program. WHOI Contribution 7191.

\section{LITERATURE CITED}

Allen, M. M., Smith, A. J. (1969). Nitrogen chlorosis in bluegreen algae. Arch. Microbiol. 69: 114-120

Arnon, D. I., McSwain, B. D., Tsujimoto, H. Y., Wada, K. (1974). Photochemical activity and components of membrane preparations from blue-green algae: I. Coexistence of two photosystems in relation to chlorophyll $a$ and removal of phycocyanin. Biochim. Biophys. Acta 357: 231-245

Bayer, M. G., Schenk, H. E. A. (1986). Biosynthesis of proteins in Cyanophora paradoxa. I. Protein import into the endocyanelle analyzed by micro two-dimensional gel-electrophoresis. Endocyt. Cell Res. 3: 197-202

Ben-Amotz, A., Tornabene, T. G., Thomas, W. H. (1985). Chemical profile of selected species of microalgae with emphasis on lipids. J. Phycol. 21: 72-81

Bennett, A., Bogorad, L. (1973). Complimentary chromatic adaptation in a filamentous blue-green alga. J. Cell Biol. 58: $419-435$

Boussiba, S., Richmond, A. E. (1980). C-phycocyanin as a storage protein in the blue-green alga Spirulina platensis. Arch. Microbiol. 125: 143-147

Bruce, D., Biggins, J., Steiner, T., Thewalt, M. (1986). Excitation energy transfer in the cryptophytes. Fluorescence excitation spectra and picosecond time-resolved emission spectra of intact algae at $77 \mathrm{~K}$. Photochem. Photobiol. 44: 519-525

Coleman, L. W., Rosen, B. H., Schwạrtzbach, S. D. (1988a). Environmental control of carbohydrate and lipid synthesis in Euglena. Plant Cell Physiol. 29: 423-432

Coleman, L. W., Rosen, B. H., Schwartzbach, S. D. (1988b). Preferential loss of chloroplast proteins in nitrogen deficient Euglena. Plant Cell Physiol. 29: 1007-1014
Epstein, S. S., Weiss, J. B., Causeley, D., Bush, P. (1961). Influence of vitamin $\mathrm{B}_{12}$ on the size and growth of Euglena gracilis. J. Protozool. 9: 336-339

Fogg, G. E. (1959). Nitrogen nutrition and metabolic patterns in algae. Symp. Soc. exp. Biol. 13: 106-125

Foulds, I. J., Carr, N. G. (1977). A proteolytic enzyme degrading phycocyanin in the cyanobacterium Anabaena cylindrica. FEMS Microbiol. Lett. 2: 117-119

Gantt, E. (1979). Phycobiliproteins of Cryptophyceae. In: Levandowski, M., Hutner, S. H. (eds.) Biochemistry and physiology of protozoa, Vol. 2. Academic Press, New York, p. $121-137$

Glazer, A. N. (1981). Photosynthetic accessory proteins with bilin prosthetic groups. In: Hatch, M. D., Boardman, N. K. (eds.) The biochemistry of plants, Vol. 8. Academic Press, New York, p. 51-96

Grossman, A. R., Lemaux, P. G., Conley, P. B. (1986). Regulated synthesis of phycobilisome components. Photochem. Photobiol. 44: 827-837

Guard-Friar, D., Eisenberg, B. L., Edwards, M. R., MacColl, R. (1986). Immunochemistry on cryptomonad biliproteins. Plant Physiol. 80: 38-42

Guillard, R. R. L. (1975). Culture of phytoplankton for feeding marine invertebrates. In: Smith, W. L., Chanley, M. H. (eds.) Culture of marine invertebrate animals. Plenum Press, New York, p. 29-60

Hanzlik, C., Hancock, L. E., Knox, R. S., Guard-Friar, D., MacColl, R. (1985). Picosecond fluorescence spectroscopy of the biliprotein phycocyanin 612: direct evidence for fast energy transfer. J. Luminescence 34: 99-106

Haxo, F. T., Fork, D. C. (1959). Photosynthetically active accessory pigments of cryptomonads. Nature, Lond. 184: $1051-1052$

Hiller, R. G., Martin, C. D. (1987). Multiple forms of a type I phycoerythrin from a Chroomonas sp. (Cryptophyceae) varying in subunit composition. Biochim. Biophys. Acta 923: 98-102

Hipkin, C. R., Syrett, P. J. (1977). Some effects of nitrogenstarvation on nitrogen and carbohydrate metabolism in Ankistrodesmus braunii. Planta 133: 209-214

Holzwarth, A. R., Wendler, J., Wehrmeyer, W. (1983). Studies on chromophore coupling in isolated phycobiliproteins: I. Picosecond fluorescence kinetics of energy transfer in phycocyanin 645 from Chroomonas sp. Biochim. Biophys. Acta 724: $388-395$

Jeffrey, S. W., Humphrey, G. F. (1975). New spectrophotometric equations for the determination of chlorophylls $a, b$, $c 1$, and $c 2$ in higher plants, algae, and natural populations. Biochem. Physiol. Pflanz. 167: 191-194

Kana, T. M., Glibert, P. M. (1987a). Effect of irradiances up to $2000 \mu \mathrm{E} \mathrm{m}^{-2} \mathrm{sec}^{-1}$ on marine Synechococcus WH7803-I. Growth, pigmentation, and cell composition. Deep Sea Res. 34: 479-495

Kana, T. M., Glibert, P. M. (1987b). Effect of irradiances up to $2000 \mu \mathrm{E} \mathrm{m}^{-2} \mathrm{sec}^{-1}$ on marine Synechococcus WH7803-II. Photosynthetic responses and mechanisms. Deep Sea Res. 34: $497-516$

Larkum, A. W. D., Barrett, J. (1983). Light-harvesting processes in algae. Adv. bot. Res. 10: 1-219

Lau, R. H., MacKenzie, M. M., Doolittle, W., F. (1977). Phycocyanin synthesis and degradation in the blue-green bacterium Anacystis nidulans. J. Bact. 132: 771-778

Lawry, N. H., Jensen, T. E. (1979). Deposition of condensed phosphate as an effect of varying sulfur deficiency in the cyanobacterium Synechococcus sp. (Anacystis nidulans). Arch. Microbiol. 120: 1-7

Lehman, J. T. (1976). Photosynthetic capacity and luxury 
uptake of carbon during phosphate limitation in Pediastrum duplex (Chlorophyceae). J. Phycol. 12: 190-193

Lemasson, C., Tandeau de Marsac, N., Cohen-Bazire, G. (1973). Role of allophycocyanin as a light-harvesting pigment in cyanobacteria. Proc. natn. Acad. Sci. U.S.A. 70: 3130-3133

Lichtlé, C. (1979). Effects of nitrogen deficiency and light of high intensity on Cryptomonas rufescens (Cryptophyceae): I. Cell and photosynthetic apparatus transformations and encystment. Protoplasma 101: 283-299

Lichtlé, C., Duval, J. C., Lemoine, Y. (1987). Comparative biochemical, functional and ultrastructural studies of photosystem particles from a Cryptophycea: Cryptomonas rufescens; isolation of an active phycoerythrin particle. Biochim. Biophys. Acta 894: 76-90

Lichtlé, C., Jupin, H., Duval, J. C. (1980). Energy transfer from Photosystem II to Photosystem I in Cryptomonas rufescens (Cryptophyceae). Biochim. Biophys. Acta 591: 104-112

Ludwig, M., Gibbs, S. P. (1989). Localization of phycoerythrin at the lumenal surface of the thylakoid membrane in Rhodomonas lens. J. Cell Biol. 108: 875-884

MacColl, R., Berns, D. S., Gibbons, O. (1976). Characterization of cryptomonad phycoerythrin and phycocyanin. Arch. Biochem. Biophys. 177: 265-275

MacColl, R., Guard-Friar, D. (1987). Phycobiliproteins. CRC Press, Boca Raton

Miller, L. S., Holt, S. C. (1977). Effect of carbon dioxide on pigment and membrane content in Synechococcus lividus. Arch. Microbiol. 115: 185-198

Myers, J., Kratz, K. A. (1955). Relation between pigment content and photosynthetic characteristics in blue-green algae. J. gen. Physiol. 39: 11-22

Öquist, G. (1971). Changes in pigment composition and photosynthesis induced by iron-deficiency in the bluegreen alga Anacystis nidulans. Physiol. Plant. 25: 188-191

Perry, M. J., Talbot, M. C., Alberte, R. S. (1981). Photoadaptation in marine phytoplankton: response of the photosynthetic unit. Mar. Biol. 62: 91-101

Prakash, A., Skoglund, L., Rystad, B., Jensen, A. (1973). Growth and cell-size distribution of marine planktonic algae in batch and dialysis cultures. J. Fish. Res. Bd Can. 30: $143-155$

Prézelin, B. B. (1982). Effects of light intensity on aging of the dinoflagellate Gonyaulax polyedra. Mar. Biol. 69: 129-135

This article was presented by DrM. Levandowsky, New York, USA
Raven, J. A. (1984). A cost-benefit analysis of photon absorption by photosynthetic unicells. New Phytol. 98: 593-625

Rhiel, E., Krupinska, K., Wehrmeyer, W. (1986). Effects of nitrogen starvation on the function and organization of the photosynthetic membranes in Cryptomonas maculata (Cryptophyceae). Planta 169: 361-369

Rhiel, E., Mörschel, E., Wehrmeyer, W. (1985). Correlation of pigment deprivation and ultrastructural organization of thylakoid membranes in Cryptomonas maculata following nutrient deficiency. Protoplasma 129: 62-73

Scheer, H. (1981). Biliproteins. Angew. Chem. int. edn Engl 20: $241-261$

Schenk, H. E. A., Bayer, M. G., Maier, T. (1987). Nitrate assimilation and regulation of biosynthesis and disintegration of phycobiliproteids by Cyanophora paradoxa. Indications for a nitrogen store function of the phycobiliproteids. Endocyt. Cell Res. 4: 167-176

Spear-Bernstein, L., Miller, K. R. (1987). Immunogold localization of the phycobiliprotein of a cryptophyte alga to the intrathylakoidal space. In: Biggins, J. (ed.) Progress in photosynthetic research, Vol. 2. Martinus Nijhoff Publishing, Dordrecht, p. 309-312

Stevens, S. E. Jr, Balkill, D. L., Paone, D. A. M. (1981a). The effects of nitrogen limitation on the ultrastructure of the cyanobacterium Agmenellum quadruplicatum. Arch. Microbiol. 130: 204-212

Stevens, S. E. Jr, Paone, D. A. M., Balkill, D. L. (1981b) Accumulation of cyanophycin granules as a result of phosphate limitation in Agmenellum quadruplicatum. Plant Physiol. 67: 716-719

Thinh, L.-V. (1983). Effect of irradiance on the physiology and ultrastructure of the marine cryptomonad, Cryptomonas strain Lis (Cryptophyceae). Phycologia 22: 7-11

Wyman, M., Gregory, R. P. F., Carr, N. G. (1985). Novel role for phycoerythrin in a marine cyanobacterium, Synechococcus Strain DC2. Science 230: 818-820

Wyman, M., Gregory, R. P. F., Carr, N. G. (1986). Role of phycoerythrin in marine Synechococcus spp.; response. Science 234: 1423-1424

Yamanaka, G., Glazer, A. N. (1980) Dynamic aspects of phycobilisome structure. Arch. Microbiol. 124: 39-47

Yeh, S. W., Ong, L. J., Glazer, A. N. (1986). Role of phycoerythrin in marine Synechococcus spp. Science 234: $1422-1423$

Manuscript first received: September 1, 1989

Revised version accepted: December 1, 1989 
66 
Chapter 3.

Physiological Responses of Phytoflagellates to Dissolved Organic Substrate Additions. 1. Dominant Role of Heterotrophic Nutrition in Poterioochromonas malhamensis (Chrysophyceae) 
68 


\begin{abstract}
Algal heterotrophy is a potentially important step in the flow of carbon through aquatic food webs. The physiological responses to organic compound additions under various light intensities were examined in Poterioochromonas malhamensis, a freshwater chrysophyte with an exceptionally high heterotrophic capability. $\underline{P}$. malhamensis demonstrated a much greater potential for heterotrophic growth than photoautotrophic growth. Organic substrate uptake and chlorophyll production by the alga, however, were markedly affected by the type of organic substrate. When organic substrates (glucose, glycerol, or ethanol) were added to the culture medium, the growth rate of $\underline{P}$. malhamensis significantly increased while the chlorophyll a content cell-1 decreased, even at light intensities saturating for photoautotrophic growth. After the initial decline in chlorophyll production caused by organic substrate uptake, chlorophyll a cell $^{-1}$ increased and the uptake rate of organic substrates decreased, despite the persistence of a relatively high substrate concentration in the medium. The results are consistent with the production of substance(s) by $\underline{\mathrm{P}}$. malhamensis that conditioned the culture medium, leading to a relief of the inhibitory effect of organic substrates on chlorophyll production.
\end{abstract}




\section{INTRODUCTION}

The ability to assimilate organic matter is well-documented for many species of microalgae grown in culture. This process may help to meet cellular requirements for metabolic energy, reducing power, carbon, nitrogen, phosphorus, or other growth factors (see reviews by Aaronson 1973, Neilson and Lewin 1974, Antia 1980, Bonin and Maestrini 1981). The ecological significance of heterotrophy for the growth and survival of microalgae, however, is poorly understood. The uptake kinetics of algae for dissolved organic substrates have been shown to be adequate in some cases for successful competition with bacteria (Hellebust 1970, Allen 1971, Vincent and Goldman 1980, Bollman and Robinson 1977, 1985) but inadequate in other cases (Hobbie and Wright 1965, Sloan and Strickland 1966, Bennett and Hobbie 1972, Platt et al. 1983). Size-fractionation studies examining the incorporation of radiolabeled organic compounds by photosynthetic organisms have indicated that algal uptake of dissolved organic matter can range from $0 \%$ to greater than $50 \%$ of the total plankton community incorporation (Munro and Brock 1968, Williams 1970, Allen 1971, Paerl and Goldman 1972, Maeda and Ichimura 1973, Berman 1975, Azam and Hodson 1977, McKinley 1977, Vincent 1980, Vincent and Goldman 1980, Moll 1984, Rivkin and Putt 1987). Given the

newfound abundance of picophytoplankton in many aquatic environments (reviewed in Stockner 1988, Hargraves et al. 1989, Sieburth and Johnson 1989), however, assumptions that uptake in the smallest size fractions is strictly due to bacteria must be viewed with caution. Whether 
algal heterotrophy is a laboratory artifact or contributes significantly to $\underline{\text { in }}$ situ trophic interactions is not yet resolved.

Our poor understanding of the role of algal heterotrophy in nature is due, in part, to a lack of information on the physiological mechanisms by which algae integrate autotrophic and heterotrophic nutrition, and the environmental cues controlling this integration. The physiological effects of dissolved organic substrates on algal photosynthetic systems have focused on a few chlorophyll $\underline{b}$-containing species; e. g., Chlamydomonas mundana (Eppley et al. 1963), Chlamydobotrys stellata (Wiessner and French 1970, Brandt et al. 1982), certain Chlorella strains (Shihira-Ishikawa and Hase 1964, Ogawa and Aiba 1981), Euglena gracilis (Harris and Kirk 1969, Monroy and Schwartzbach 1984), and Golenkinia (Ellis et al. 1981). The response of the photosynthetic system to organic substrate uptake differs greatly in these species, ranging from repression of chloroplast development in Chlorella and Euglena to enhancement of chlorophyll production by Golenkinia. In the absence of organic substrates, however, these species contain a well-developed photosynthetic system and are capable of growing at rates comparable to or greater than growth rates in the presence of organic substrates.

In comparison to many other cultured algae, Poterioochromonas malhamensis, a freshwater chrysophyte, has an unusually low capacity for photoautotrophic growth. Despite early reports that $\underline{P}$. malhamensis could not grow without organic carbon sources (Pringsheim 1952, Hutner et al. 1953), Myers and Graham (1956) observed slow growth (72 hour doubling time) in organic-free medium. They concluded that photosynthesis 
provides only a "marginal contribution" to the nutrition of $\underline{P}$. malhamensis, however, because the photoautotrophic growth rate was five times lower than the heterotrophic rate, and because the photosynthetic rate and chlorophyll a content of $\underline{P}$. malhamensis were much lower than those observed in other photosynthetic organisms. Heterotrophy, therefore, appears to be the dominant mode of carbon nutrition in $\underline{P}$. malhamensis, even when grown in the light. This is exemplified by an exceptionally high capacity for heterotrophic growth by P. malhamensis, which, in the presence of a variety of dissolved organic substrate types, can grow in the dark at rates comparable to growth rates in the light (Pringsheim 1952, Myers and Graham 1956). $\underline{\text { P. malhamensis is }}$ also capable of ingesting a range of particle types and sizes at rates comparable to heterotrophic nanoflagellates (Porter 1988, Sanders and Porter 1988, Caron et al. 1990, Sanders et al. 1990).

There is some information available on the physiological response of the photosynthetic system of $\underline{\mathrm{P}}$. malhamensis to organic substrate assimilation. In one of these previous studies, growth of $\underline{P}$. malhamensis in the light and in an organically enriched medium resulted in a severe reduction in the size of the chloroplast. Cultures grown in the dark also contained smaller chloroplasts and appeared paler than those supplied with light (Pringsheim 1952). These results with $\underline{P}$. malhamensis are analogous to studies of Euglena gracilis and some Chlorella species in which it was demonstrated that chloroplast development was repressed under conditions supporting heterotrophic growth (App and Jagendorf 1963, Harris and Kirk 1969, Shihira-Ishikawa and Hase 1964, 1965). Myers 
and Graham (1956) observed a lower chlorophyll a content in $\underline{P}$. malhamensis cells grown with sucrose than without sucrose, consistent with the repression of chloroplast development by organic substrates.

In cultures of $\underline{P}$. malhamensis grown with glucose in the medium, depletion of this carbon source was accompanied by an increased cellular cyclic AMP content, and followed by chlorophyll production (Handa et al. 1981). These patterns are consistent with their hypothesis that glucose is a catabolite repressor of chloroplast development in $\underline{\mathrm{P}}$. malhamensis and that cyclic AMP acts to mediate the escape from this repression. In other words, analogously to the mechanism demonstrated in some bacteria (Robison et al. 1971), a catabolite of glucose induces the synthesis of enzymes required for its metabolism while repressing the synthesis of enzymes involved in the utilization of an alternative carbon source (in the case of $\underline{P}$. malhamensis, inorganic carbon). In bacteria, glucose acts to lower the cellular level of cyclic AMP, a molecule required to induce the synthesis of enzymes involved in the metabolism of the alternative carbon source, and removal of glucose from the medium increases cellular cyclic AMP levels and the activity of these enzymes. Although Handa et al.'s (1981) results suggest that a similar catabolite repression mechanism may be involved in $\underline{\text { P. malhamensis, }}$ one problem with their study was that inocula for their experiments were derived from nitrogen-deficient cultures and, therefore, it's not clear whether the initial inhibition of chlorophyll production by $\underline{\mathrm{P}}$. malhamensis was caused by glucose uptake or nitrogen deficiency (see Horrum and Schwartzbach 1980). 
In order to gain a better understanding of the role and regulation of photosynthesis and heterotrophy in this unusual organism, the physiological response of $\underline{P}$. malhamensis to organic substrate additions to the culture medium was examined. Under nitrogen-sufficient conditions, chlorophyll a concentration cell ${ }^{-1}$ decreased in the presence of organic substrates, and the degree to which the organic substrates inhibited chlorophyll production was substrate-specific. These results support Handa et al.'s (1981) hypothesis that the regulation of chloroplast development in $\underline{P}$. malhamensis is catabolite-sensitive. Evidence is also presented, however, that, even in the presence of high organic substrate concentrations, the repression of chlorophyll production by organic substrates could be relieved by substance(s) produced by $\underline{\mathrm{P}}$. malhamensis. Possible causes for this phenomenon are examined and their implications for the control of autotrophy and heterotrophy in this chrysophyte are discussed. 


\section{MATERIALS AND METHODS}

Poterioochromonas malhamensis Peterfi (formerly Ochromonas malhamensis Pringsheim) Starr L1297 (Culture Center for Algae and Protozoa, Cambridge, England) was obtained from Dr. Karen Porter (University of Georgia). Batch cultures used in the experimental treatments were grown axenically at $21^{\circ} \mathrm{C}$ in Defined Ochromonas Medium (Modification "G", Myers and Graham 1956) except that the trace metal mix consisted of Medium WC metals (Guillard 1975), histidine was omitted, and $16 \mu \mathrm{M} \mathrm{H}_{3} \mathrm{BO}_{3}$ was added. The nitrogen source was $\mathrm{NH}_{4}{ }^{+}$ and the $\mathrm{pH}$ was 4.8 .

Cultures used for inocula were grown photoautotrophically and acclimated to specific light intensities by repeated transfer of cells in the mid-exponential growth phase. Continuous illumination was provided by cool-white fluorescent lights at intensities of $325,265,190,105,25$, and 15 $\mu \mathrm{E} \mathrm{m}^{-2} \mathrm{~s}^{-1}$. Irradiance was measured with an integrating $4 \mu$ quantum sensor (Biospherical Instruments, QSL-100P probe). After acclimation to the light regime, exponentially growing populations were inoculated into media containing various organic compounds. The treatments consisted of Defined Ochromonas Medium, or this Medium supplemented with one of the following organic compounds; glucose, ethanol, glycine, or glycerol. When glycine was present, $\mathrm{NH}_{4}{ }^{+}$was omitted from the experimental culture medium. Inocula for cultures grown in continuous darkness were taken from photoautotrophic cultures acclimated to $15 \mu \mathrm{E}$ $\mathrm{m}^{-2} \mathrm{~s}^{-1}$. 
Cell counts from triplicate samples were determined throughout the growth cycle of the population. A Sedgewick-Rafter counting chamber was used when cell counts were below $5 \times 10^{3}$ cells ml-1. A FuchsRosenthal Ultra Plane chamber was used when cell counts were between 5 $\times 10^{3}$ and $2 \times 10^{4}$ cells ml- $^{-1}$, and a Reichert Bright-Line hemacytometer was used for higher population densities. Counts obtained with the three chambers were normalized to each other by performing dilution series and comparing duplicate counts of a number of samples made with all three chambers, and normalizing to the Reichert Bright-Line estimates.

Specific growth rates, $\mu\left(\right.$ day $\left.^{-1}\right)$, were determined from regressions of the linear portion of the growth curves expressed as the natural log of the population densities versus time (i. e., the exponential growth phase).

All cultures were sampled aseptically throughout the experiments. Cultures were tested periodically for bacterial contamination throughout the experiment by inoculating tubes containing $0.5 \%$ yeast extract with 1 $\mathrm{ml}$ of the culture, and examining these tubes for bacterial growth.

Biovolume, chlorophyll a cell-1, $\mathrm{pH}$ of the medium, and organic compound concentration also were measured in cultures growing at 105 $\mu \mathrm{E} \mathrm{m}^{-2} \mathrm{~s}^{-1}$. Flasks containing the same media but without algae served as controls in order to determine losses of organic compounds not related to algal uptake. Biovolume was measured using a Coulter Multisizer particle counter with a $70 \mu \mathrm{m}$ aperture. Chlorophyll a was extracted with 90\% acetone, following filtration onto HA Millipore membrane filters (mean pore size $=0.45 \mu \mathrm{m}$ ). Chlorophyll $\underline{\mathrm{a}}$ concentrations were then determined fluorometrically (Holm-Hansen et al. 1965), using a G. K. 
Turner III fluorometer. The $\mathrm{pH}$ was determined with an Orion $611 \mathrm{pH}$ meter and a Ross combination electrode.

Following centrifugation, the glucose, glycerol, or ethanol concentrations of the supernatant were determined using enzymatic analysis kits (Boehringer Mannheim Biochemicals Cat. No. 716251 for glucose, 148270 for glycerol, and 176290 for ethanol). The methods are based on the spectrophotometric quantification of NADH or NADPH, stoichiometrically produced from the phosphorylation of glucose or glycerol, or the oxidation of ethanol (Bergmeyer et al. 1974, Eggstein and Kuhlmann 1974, Beutler and Michal 1977). NADH or NADPH absorption (340 $\mathrm{nm}$ ) was detected using a Shimadzu Spectrophotometer UV-260.

The organic substrate uptake rate cell-1 was calculated based on the disappearance of substrate and increase in population density during the incubation period,

$$
\text { Uptake rate (pg substrate cell-1 } \left.\mathrm{h}^{-1}\right)=\left(\mathrm{C}_{1}-\mathrm{C}_{2}\right) \cdot\left(\mathrm{F}^{\prime} \bullet \Delta \mathrm{t}\right)^{-1}
$$

where $C_{1}$ and $C_{2}$ are the substrate concentrations (pg ml-1) at the start and end, respectively, of each time interval $\Delta t(h) ; F^{\prime}$ is the weighted average population density (cells ml-1) over each time interval (Heinbokel 1978),

$$
F^{\prime}=\left(F_{2}-F_{1}\right) \cdot\left(\ln F_{2}-\ln F_{1}\right)^{-1}
$$

where $\mathrm{F}_{1}$ and $\mathrm{F}_{2}$ are the population densities (cells $\mathrm{ml}^{-1}$ ) at the start and end, respectively, of each time interval. 
In order to examine the interaction of $\mathrm{pH}$ and glucose on chlorophyll a production, batch cultures acclimated to $105 \mu \mathrm{E} \mathrm{m}^{-2} \mathrm{~s}^{-1}$ were inoculated into culture medium containing $0.029 \mathrm{M}$ glucose at $\mathrm{pH} 8.0$, 6.4, 4.8, or 3.2. The $\mathrm{pH}$ of each treatment was adjusted with $\mathrm{NaOH}$ or $\mathrm{HCl}$. Cell counts, cell chlorophyll a content, and the $\mathrm{pH}$ of the culture medium were determined throughout the growth cycle of the population.

The effect of cyclic AMP on cellular chlorophyll fluorescence was examined by transferring cultures originally grown at $105 \mu \mathrm{E} \mathrm{m}^{-2} \mathrm{~s}^{-1}$ with $0.029 \mathrm{M}$ glucose in the medium to fresh medium containing glucose and cyclic AMP. Cyclic AMP was sterile-filtered (Costar $0.22 \mu \mathrm{m}$ filter) and added to a final concentration of $1 \mathrm{mM}$ or $10 \mathrm{mM}$. Chlorophyll fluorescence cell-1 was determined based on in vivo fluorescence mesurements using a G. K. Turner III fluorometer fitted with a Corning 560 [348 to $515 \mathrm{~nm}$ ] excitation filter and a Corning 2-64 [high pass filter with $667 \mathrm{~nm}$ half-power] emission filter. The addition of $10 \mathrm{mM}$ cyclic AMP had no detectable effect on the fluorescence of the medium prior to the transfer of $\underline{P}$. malhamensis cultures.

The effect of "conditioned medium" on cellular chlorophyll fluorescence was also examined. Batch cultures were grown at $105 \mu \mathrm{E} \mathrm{m}-2$ $\mathrm{s}^{-1}$ with $0.029 \mathrm{M}$ glucose in the medium and, after reaching a population density of approximately $7 \times 10^{5}$, the cells were centrifuged out and the supernatant (i. e., the so-called "conditioned medium") transferred aseptically into a sterile flask. Microscopical observations and measurements of in vivo fluorescence revealed no evidence of $\underline{P}$. malhamensis cells in the supernatant. The glucose concentration of the 
supernatant was determined as $0.028 \mathrm{M}$. Cultures originally grown at 105 $\mu \mathrm{E} \mathrm{m}^{-2} \mathrm{~s}^{-1}$ with $0.029 \mathrm{M}$ glucose in the medium were transferred into this conditioned medium or into fresh medium with glucose and the in vivo fluorescence cell-1 ${ }^{-1}$ was measured as specified above. 


\section{RESULTS}

\section{Effect of organic compounds on growth:}

In general, Poterioochromonas malhamensis grew slowly in the absence of organic substrates relative to its growth rate with organic substrates in the medium (Table 1, Figs. 1-3). The photoautotrophic growth rate was constant $\left(\sim 0.3\right.$ day $\left.^{-1}\right)$ at light intensities between 105 and $325 \mu \mathrm{E} \mathrm{m}^{-2} \mathrm{~s}^{-1}$, and decreased directly with light intensity below $105 \mu \mathrm{E}$ $\mathrm{m}^{-2} \mathrm{~s}^{-1}$.

When glucose was added to the culture medium at relatively low concentrations $(0.029 \mathrm{M}$ or $0.0025 \mathrm{M})$, the growth rate of the alga was greater than twice that of photoautotrophically grown cultures, regardless of light intensity. The growth rate of $\underline{P}$. malhamensis in the presence of these two lower glucose concentrations varied only slightly with light intensity; e. g., the average growth rate of these cultures was approximately $20 \%$ greater at $325 \mu \mathrm{E} \mathrm{m}^{-2} \mathrm{~s}^{-1}$ than at $15 \mu \mathrm{E} \mathrm{m}^{-2} \mathrm{~s}^{-1}$. In fact, $\underline{\mathrm{P}}$. malhamensis exhibited an exceptional capacity to grow in the dark in the presence of glucose (Fig. 2). The growth rate of the alga grown with 0.029 $\mathrm{M}$ or $0.0025 \mathrm{M}$ glucose was as great in the dark as in any other condition (Table 1, Fig. 3).

The effect of glucose addition on the growth rate of $\underline{P}$. malhamensis in the light, however, was dependent on the concentration of glucose. No difference was found in the growth rates of the alga grown at $0.029 \mathrm{M}$ and $0.0025 \mathrm{M}$ glucose, but growth in the light was always slower in the presence of $0.25 \mathrm{M}$ glucose than at the lower glucose concentrations (Figs. 
1-3). Relative to photoautotrophically grown cultures, the addition of 0.25 $M$ glucose reduced the growth rate at $325 \mu \mathrm{E} \mathrm{m}^{-2} \mathrm{~s}^{-1}$, slightly enhanced the growth rate at light intensities between 25 and $190 \mu \mathrm{E} \mathrm{m}^{-2} \mathrm{~s}^{-1}$, and greatly enhanced growth at $15 \mu \mathrm{E} \mathrm{m} \mathrm{m}^{-2} \mathrm{~s}^{-1}$. Growth at the highest glucose concentration was much faster in the dark than in the light. Although the alga in the light grew more slowly in the presence of $0.25 \mathrm{M}$ glucose than at the lower concentrations, growth in the dark was not affected by glucose concentration.

Similar to the pattern observed in the presence of $0.25 \mathrm{M}$ glucose, the addition of $0.25 \mathrm{M}$ glycerol enhanced the growth rate of the alga at 25 $\mu \mathrm{E} \mathrm{m}^{-2} \mathrm{~s}^{-1}$, had little effect on the growth rate at $105 \mu \mathrm{E} \mathrm{m}^{-2} \mathrm{~s}^{-1}$, and greatly reduced the growth rate at $325 \mu \mathrm{E} \mathrm{m}^{-2} \mathrm{~s}^{-1}$ relative to its growth rate without organic substrates added (Table 1, Fig. 4). The addition of $0.13 \mathrm{M}$ ethanol increased the growth rate of $\underline{P}$. malhamensis grown at 105 and 25 $\mu \mathrm{E} \mathrm{m}^{-2} \mathrm{~s}^{-1}$ but had no effect on the growth rate at $325 \mu \mathrm{E} \mathrm{m}^{-2} \mathrm{~s}^{-1}$ relative to photoautotrophic growth (Fig. 4). The growth rate of $\underline{P}$. malhamensis cultures grown with $0.03 \mathrm{M}$ glycine as the sole nitrogen source was comparable to that of photoautotrophic cultures grown with $\mathrm{NH}_{4}{ }^{+}$at 105 and $25 \mu \mathrm{E} \mathrm{m}^{-2} \mathrm{~s}^{-1}$, but $50 \%$ lower at $325 \mu \mathrm{E} \mathrm{m}^{-2} \mathrm{~s}^{-1}$ (Fig. 4). 
Figure 1. Representative growth curves (see Table 1) showing the effect of $0.029 \mathrm{M}$ (open squares) or $0.25 \mathrm{M}$ glucose addition (closed circles) on the growth of $\underline{\mathrm{P}}$. malhamensis at (A) 325 or (B) $25 \mu \mathrm{E} \mathrm{m}^{-2} \mathrm{~s}^{-1}$, or (C) in continuous darkness. Growth without glucose is shown in the open circles. 


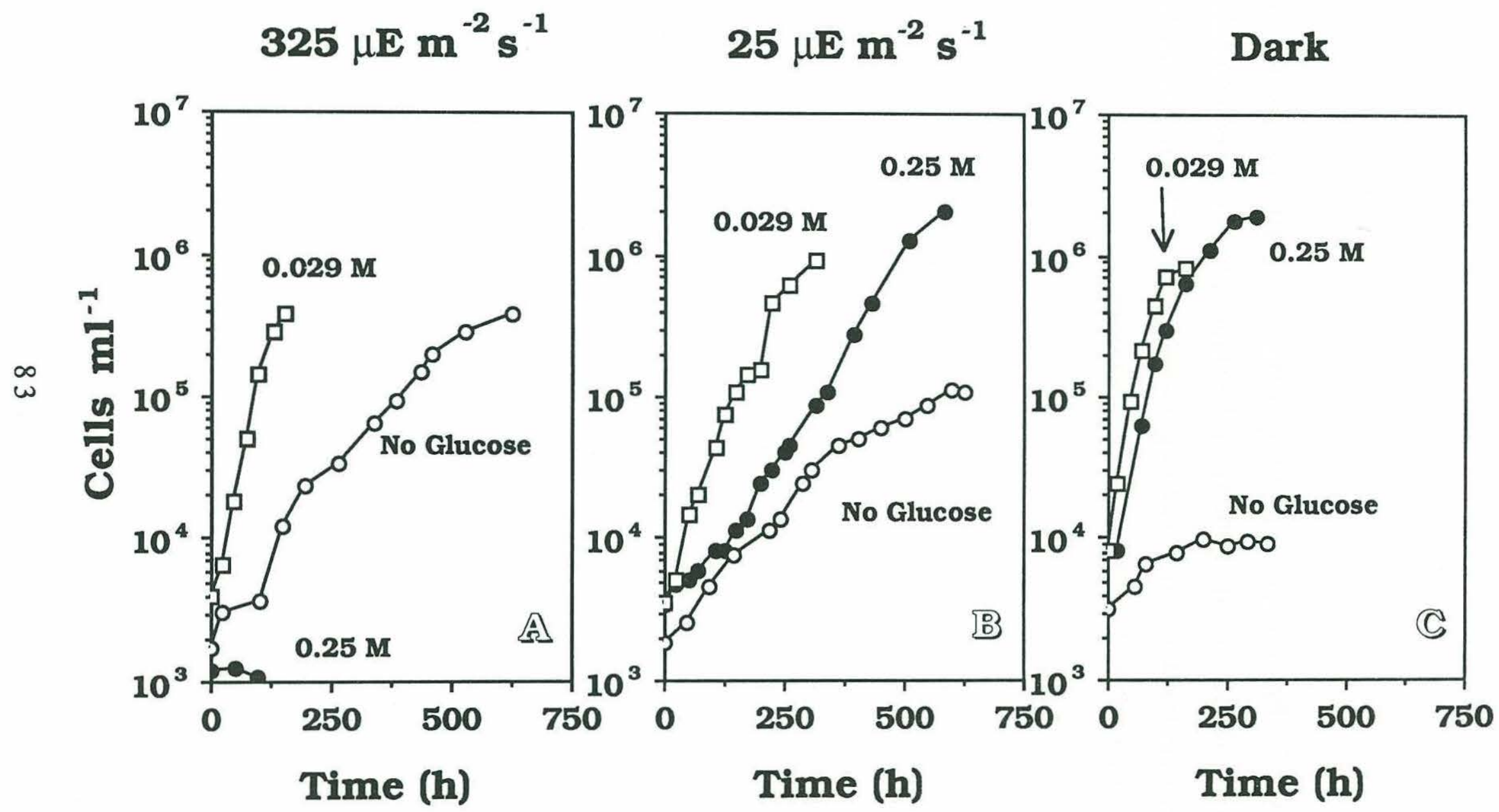


Figure 2. Representative growth curves of $\underline{\mathrm{P}}$. malhamensis (see Table 1) comparing growth at $15 \mu \mathrm{E} \mathrm{m}^{-2} \mathrm{~s}^{-1}$ without glucose (open symbols) with growth in the dark with $0.029 \mathrm{M}$ glucose (closed symbols). Arrows indicate the origin of the inoculum for serial transfers. 


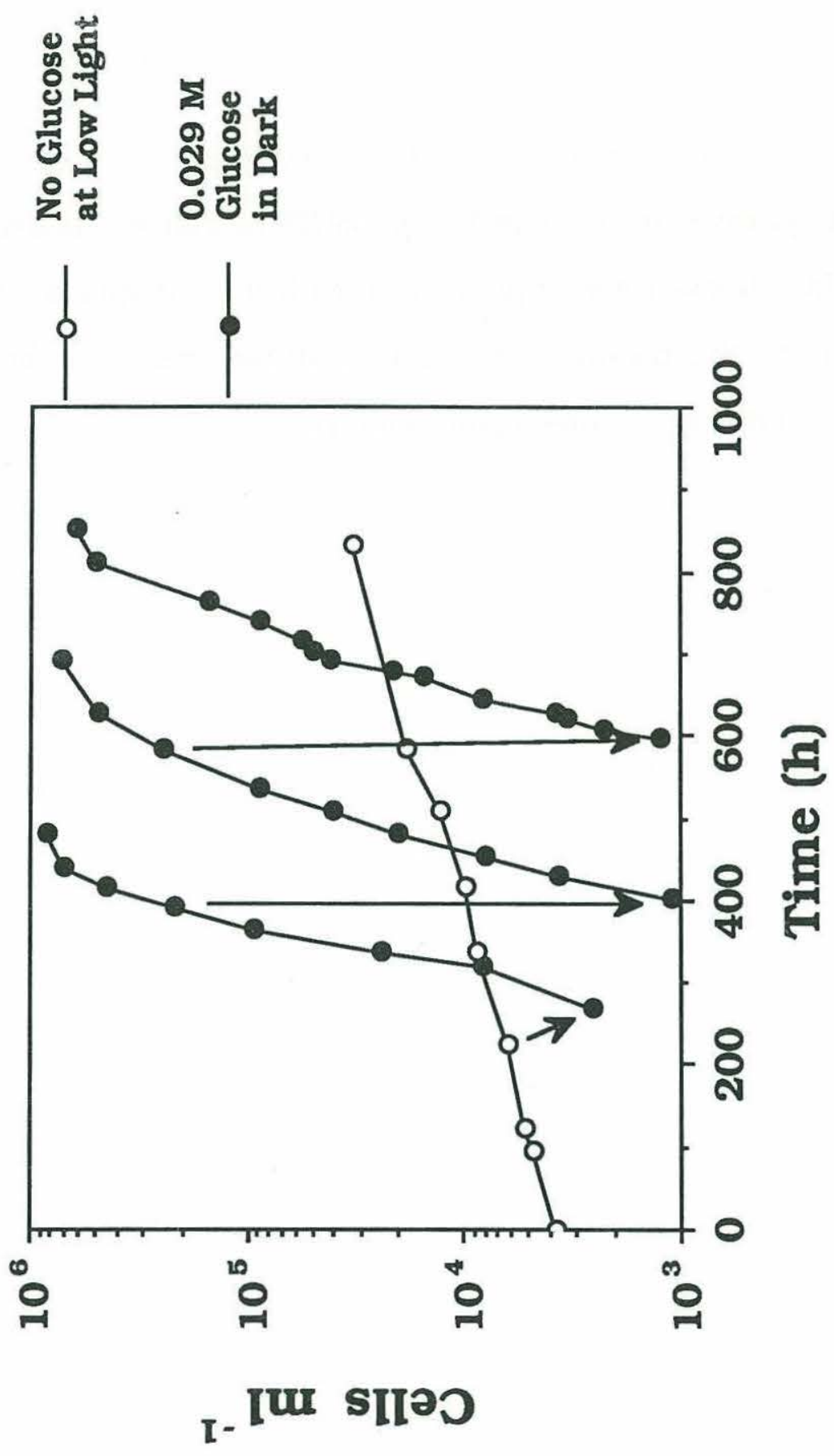


Figure 3. Effect of irradiance on the specific growth rate of $\underline{P}$. malhamensis without glucose (open circles), with $0.0025 \mathrm{M}$ glucose (closed squares), with $0.029 \mathrm{M}$ glucose (open squares), or with $0.25 \mathrm{M}$ glucose (closed circles). Values are the means of replicate cultures and error bars indicate the standard error of the mean (see Table 1). 


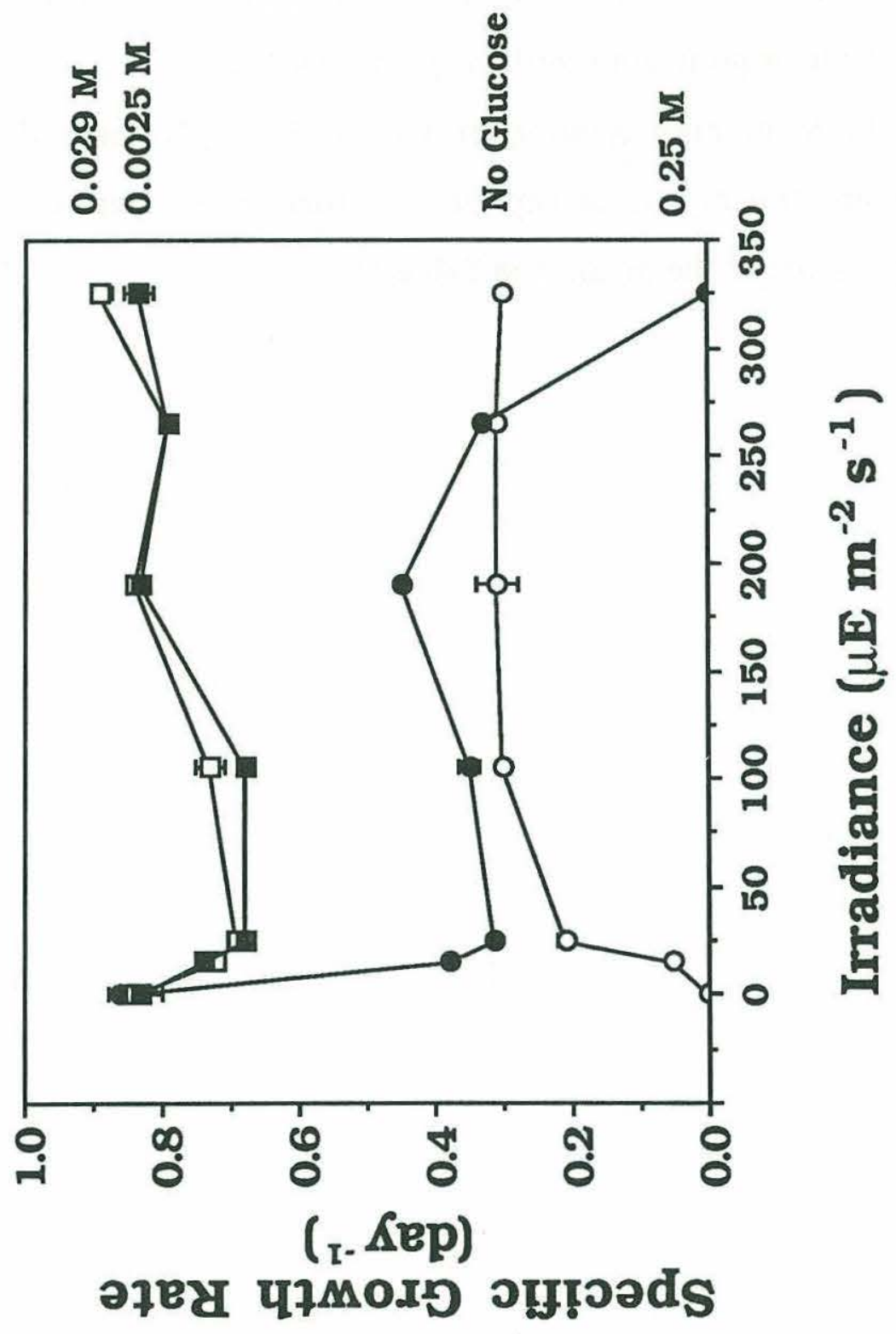


Figure 4. Specific growth rate of $\underline{P}$. malhamensis at 325,105 , or $25 \mu \mathrm{E} \mathrm{m}-2$ $\mathrm{s}^{-1}$ without organic compounds (gray), with $0.25 \mathrm{M}$ glycerol (diagonals), with $0.13 \mathrm{M}$ ethanol (white), or with $0.03 \mathrm{M}$ glycine (horizontal lines). Values are the means of replicate cultures and error bars indicate the standard error of the mean (see Table 1). 


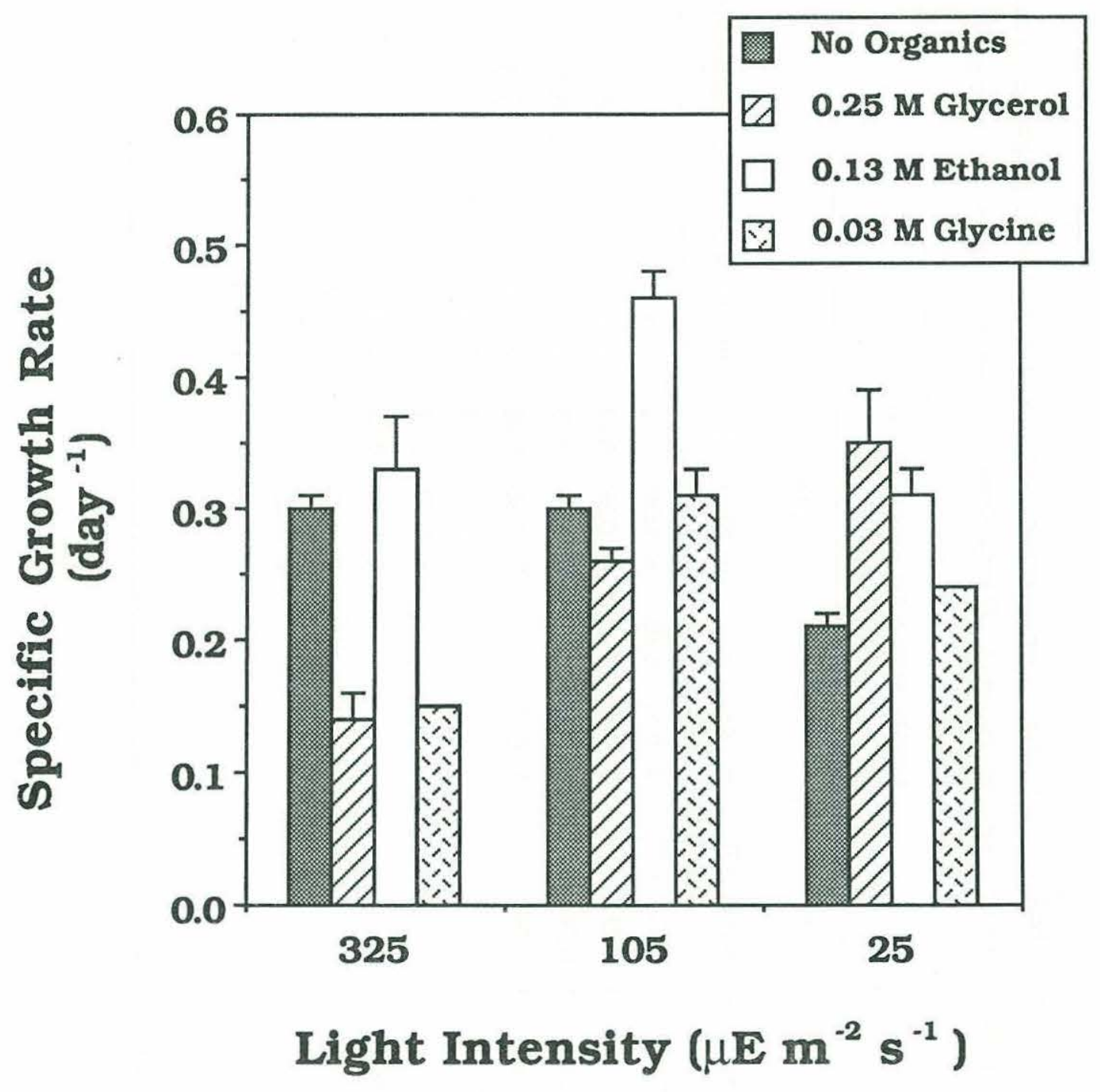


Table 1 Effect of organic compound additions on the mean specific growth rate (day ${ }^{-1}$ ) of replicate $\underline{P}$. malhamensis cultures grown under different light intensities. $\mathrm{N}$ is the number of replicate cultures. SE is the standard error of the mean. NG = no growth.

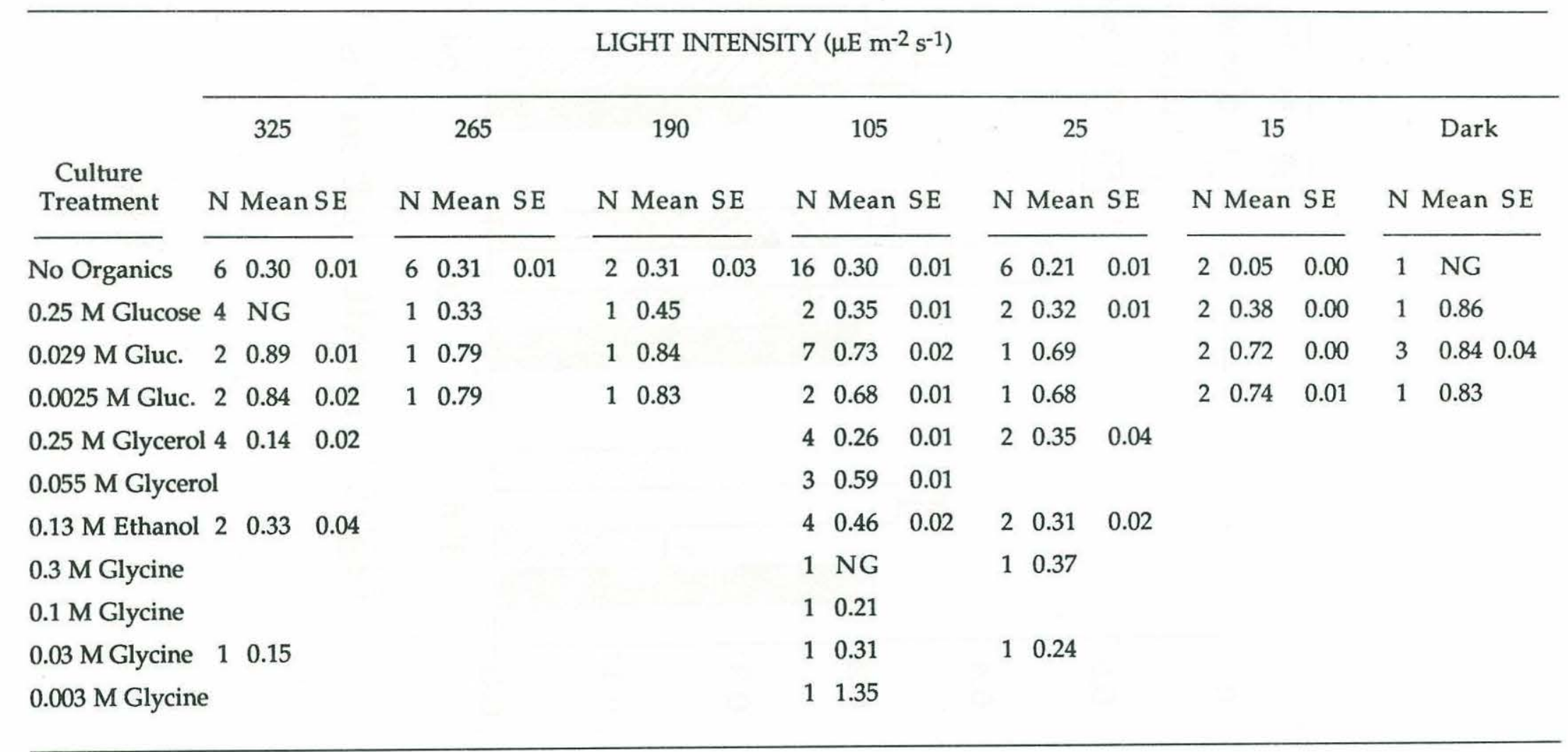




\section{Effect of organic compounds on chlorophyll a content:}

The chlorophyll $\underline{a}$ concentration cell ${ }^{-1}$ of photoautotrophic $\underline{P}$. malhamensis cultures grown at $105 \mu \mathrm{E} \mathrm{m}^{-2} \mathrm{~s}^{-1}$ was relatively constant throughout growth at approximately $0.5 \mathrm{pg}^{\text {cell-1 }}{ }^{-1}$ (Fig. 5A, B). The addition of glucose $(0.029 \mathrm{M})$, glycerol $(0.055 \mathrm{M})$, or ethanol $(0.13 \mathrm{M})$ during early exponential growth resulted in a sudden, rapid, but transient decline in the chlorophyll a content of the alga that extended into at least the middle exponential growth phase (Figs. 5,6). The extent of the decrease in chlorophyll a cell-1 varied with the organic compound (Table 2). The overall decreases in chlorophyll a cell ${ }^{-1}$ relative to photoautotrophically grown cultures were $33 \%, 50 \%$, and $93 \%$ in cultures grown with ethanol, glycerol, and glucose, respectively. Organic substrate additions to photoautotrophic cultures grown at $105 \mu \mathrm{E} \mathrm{m}-2 \mathrm{~s}^{-1}$ increased the average cell size. The average volume of cells growing exponentially with ethanol, glycerol, and glucose in the culture medium were 1.2, 1.4, and 1.8 times, respectively, that of photoautotrophic cells (Table 2).

Because the addition of $0.029 \mathrm{M}$ glucose, $0.055 \mathrm{M}$ glycerol, or $0.13 \mathrm{M}$ ethanol at $105 \mu \mathrm{E} \mathrm{m}^{-2} \mathrm{~s}^{-1}$ resulted in an increase in the growth rate, one possible explanation for the decline and then recovery of chlorophyll $\underline{a}$ cell-1 $^{-1}$ of these cultures is that the cellular chlorophyll production rate lagged behind the increase in the cell division rate, and then increased to restore the chlorophyll a concentration cell $^{-1}$ back to levels present before the addition of organic substrates. When exponentially growing cells from media containing glucose or glycerol were repeatedly transferred into the same culture media, however, the chlorophyll a content of the cells 
growing in the fresh media was maintained at a relatively low concentration during the period when the chlorophyll a content of cells from the source cultures increased (Fig. 7). Recovery of chlorophyll $\underline{a}$ concentration in the cells of the original cultures occurred despite the persistence of high exogenous substrate concentrations at this time. Because the growth rate did not change in either culture during this period, the inhibitory effect of glucose or glycerol addition on chlorophyll a production cannot be explained by a change in cell division rate. The effect of ethanol addition on cell chlorophyll a content in successively transferred cultures was not examined.

After the initial decline, chlorophyll a cell ${ }^{-1}$ increased in cultures grown in the presence of organic substrates (Figs. 5, 6). The initiation of this increase coincided with a decrease in growth rate when glycerol or ethanol was present (Fig. 6) but the chlorophyll a concentration cell-1 in the cultures with glucose started to increase 150 hours before any decrease in growth rate was detected (Fig. 5C, D). The organic substrate concentration of the culture medium at the time when chlorophyll a cell-1 began to increase only slightly decreased in the three treatments (Figs. 5, 6), indicating that the increase in cell chlorophyll a content was not due to a rapid depletion of the organic substrate supply. The organic compound concentration of the control treatments did not change throughout the duration of the experiment.

During the period in which chlorophyll a cell-1 increased, the calculated organic substrate uptake rate cell-1 decreased sharply such that, in cultures grown with glucose or ethanol, the uptake rate at the end of 
the experiment was approximately $10 \%$ of the highest rate measured (Figs. $5,6)$. Concurrent with increases in chlorophyll a cell ${ }^{-1}$ and decreasing glucose or ethanol uptake rate, the $\mathrm{pH}$ of the culture medium decreased precipitously. The decreases in $\mathrm{pH}$ of the media were directly related to population densities of the cultures (Fig. 8). In order to test whether the increase in chlorophyll a cell-1 was related to the $\mathrm{pH}$ of the culture medium, the initial $\mathrm{pH}$ of the culture medium containing glucose was adjusted to $\mathrm{pH} 8.0,6.4,4.8$, and 3.2, and chlorophyll a concentrations cell-1 were measured throughout the growth cycle (Fig. 9). No growth occurred at $\mathrm{pH}$ 8.0, but growth curves were comparable in the latter three treatments (Fig. 9A). The increase in chlorophyll a cell-1 was not directly related to the $\mathrm{pH}$ of the medium. The $\mathrm{pH}$ of the medium at the time when chlorophyll a cell ${ }^{-1}$ began to increase was different in the three treatments, and did not vary substantially from the initial pH (Fig. 9B, C).

In order to test an alternative hypothesis that the recovery of chlorophyll cell ${ }^{-1}$ after the initial decline due to glucose addition was caused by the accumulation of excretory substance(s) produced by $\underline{P}$. malhamensis, the effects of the conditioned medium (see "Materials and Methods") and cyclic AMP (a reported excretory product of $\underline{\mathrm{P}}$. malhamensis, Bressan et al. 1980, Handa et al. 1981) on chlorophyll fluorescence were examined (Fig. 10). In comparison to cultures transferred into fresh media without exogenously added cyclic AMP, cultures transferred into the conditioned medium or into medium containing $1 \mathrm{mM}$ or $10 \mathrm{mM}$ cyclic AMP had a substantially higher chlorophyll fluorescence cell-1 during exponential growth although the 
growth rate was comparable between treatments. The chlorophyll fluorescence cell-1 of cultures growing with $10 \mathrm{mM}$ cyclic AMP in the medium was significantly greater than that of $1 \mathrm{mM}$ cyclic AMP during this same period (Fig. 10B). Because relatively high concentrations of glucose were present in the medium at the time of transfer, these data indicate a stimulatory effect of the conditioned medium and cyclic AMP on chlorophyll production. The increase in chlorophyll fluorescence cell $^{-1}$, however, was much more rapid in the original cultures from which the inocula for these new treatments were derived. These treatments, therefore, could only partially account for the recovery of chlorophyll cell $^{-1}$ observed after the initial inhibition of chlorophyll production caused by glucose addition. 
Table 2 Effect of organic compound addition on average specific growth rate $(\mu)$, biovolume, chlorophyll a cell-1, and chlorophyll a biovolume ${ }^{-1}$ of replicate $\underline{P}$. malhamensis cultures grown at $105 \mu \mathrm{E} \mathrm{m}^{-2} \mathrm{~s}^{-1}$. Chlorophyll a cell-1 decreased and biovolume increased in cultures enriched with organic substrates. Chlorophyll values for these cultures are the minimal values observed (Figs. 5D, 6B, 6D), and biovolume values are the maxima observed during the exponential growth phase. $\mathrm{C}: \mathrm{N}$ Ratio = the organic carbon to inorganic nitrogen ratio of the culture medium; $\mathrm{N}=$ the number of replicate cultures; $\mathrm{SE}=$ the standard error of the mean.

\begin{tabular}{|c|c|c|c|c|c|c|c|c|c|c|c|c|c|}
\hline \multirow{3}{*}{$\begin{array}{l}\text { Organic } \\
\text { Compound } \\
\text { None }\end{array}$} & \multirow[t]{3}{*}{ C:N Ratio } & \multirow{2}{*}{\multicolumn{3}{|c|}{$\begin{array}{c}\mu \\
\left(\text { day }^{-1}\right)\end{array}$}} & \multicolumn{3}{|c|}{$\begin{array}{l}\text { Biovolume } \\
\left(\mu \mathrm{m}^{3} \text { cell }^{-1}\right)\end{array}$} & \multicolumn{3}{|c|}{$\begin{array}{l}\text { Chlorophyll a } \\
(\text { pg cell-1) }\end{array}$} & \multicolumn{3}{|c|}{$\begin{array}{l}\text { Chlorophyll a } \\
\left(\mathrm{fg} \mu \mathrm{m}^{-3}\right)\end{array}$} \\
\hline & & & & & $\mathrm{N}$ & Avera & SE & $\mathrm{N}$ & Averag & SE & $\mathrm{N}$ & Averag & $\mathrm{SE}$ \\
\hline & & 3 & 0.32 & 0.02 & 2 & 269 & 11 & 3 & 0.46 & 0.02 & 2 & 1.77 & 0.00 \\
\hline 0.029 M Glucose & 4.5 & 6 & 0.72 & 0.02 & 3 & 473 & 2 & 6 & 0.03 & 0.00 & 3 & 0.07 & 0.00 \\
\hline 0.055 M Glycerol & 4.3 & 3 & 0.59 & 0.01 & 2 & 369 & 6 & 3 & 0.23 & 0.01 & 2 & 0.62 & 0.03 \\
\hline $0.13 \mathrm{M}$ Ethanol & 4.3 & 1 & 0.49 & & 1 & 311 & & 1 & 0.31 & & 1 & 0.98 & \\
\hline
\end{tabular}


Figure 5. Representative growth curve (closed circles) and chlorophyll a cell $^{-1}$ (closed squares) of $\underline{\mathrm{P}}$. malhamensis grown at $105 \mu \mathrm{E} \mathrm{m}^{-2} \mathrm{~s}^{-1}$ with (A, B) no organic substrates or (C, D) $0.029 \mathrm{M}$ glucose. Included also are the (C) glucose concentrations of the culture medium (open circles) and (D) calculated glucose uptake rate cell-1 (open squares). 

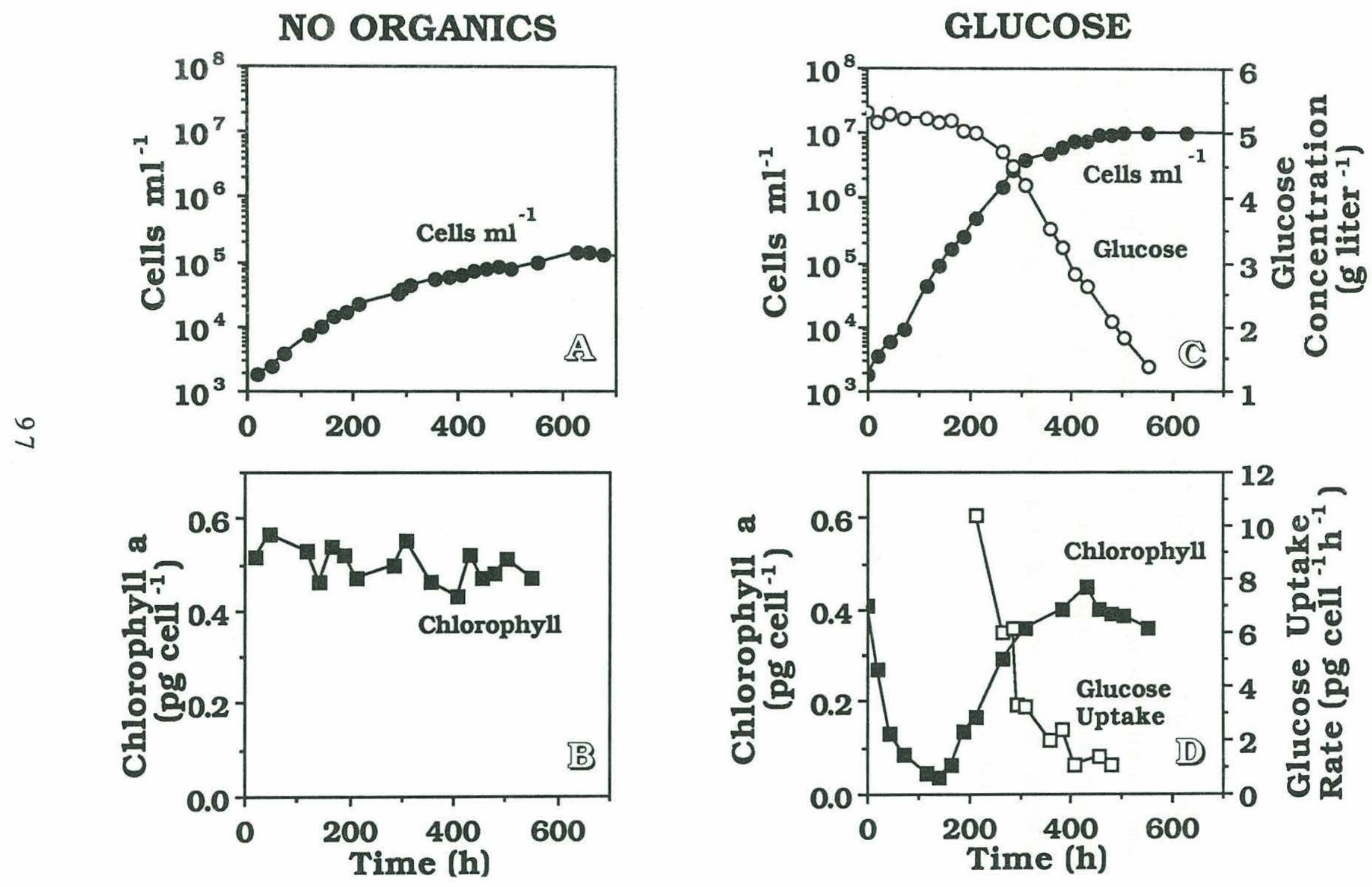
Figure 6. Representative growth curves (closed circles), organic substrate concentration of the culture medium (open circles), chlorophyll a cell-1 (closed squares), and substrate uptake rate cell-1 (open squares) of $\underline{P}$. malhamensis grown at $105 \mu \mathrm{E} \mathrm{m}^{-2} \mathrm{~s}^{-1}$ with (A, B) $0.055 \mathrm{M}$ glycerol or (C, D) $0.13 \mathrm{M}$ ethanol. 


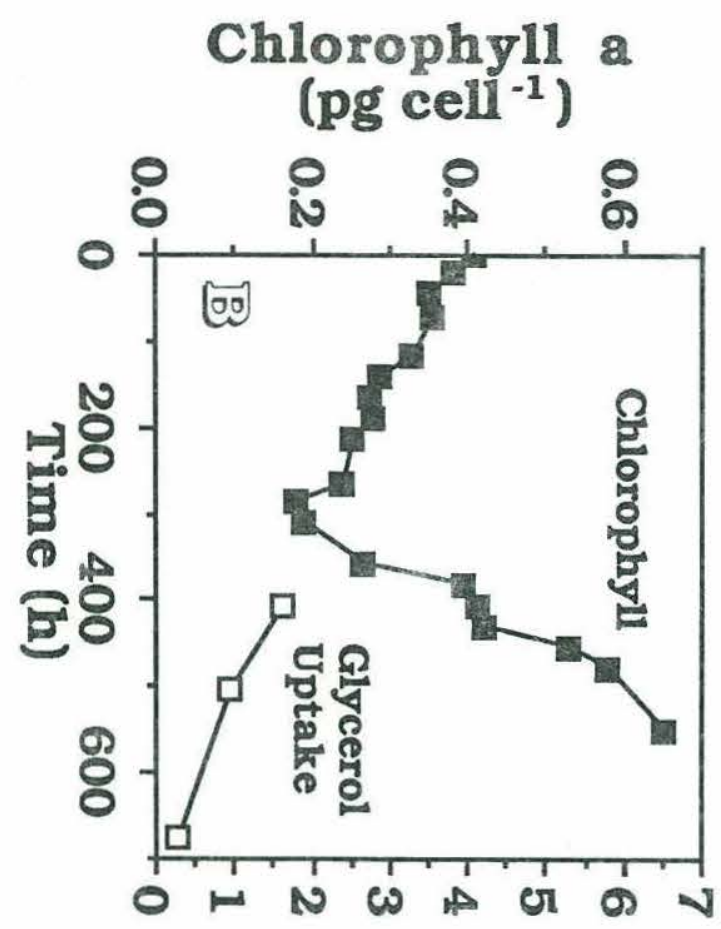

Glycerol Uptake Rate (pg cell ${ }^{-1} \mathbf{h}^{-1}$ )

Chlorophyll a (pg cell ${ }^{-1}$ )

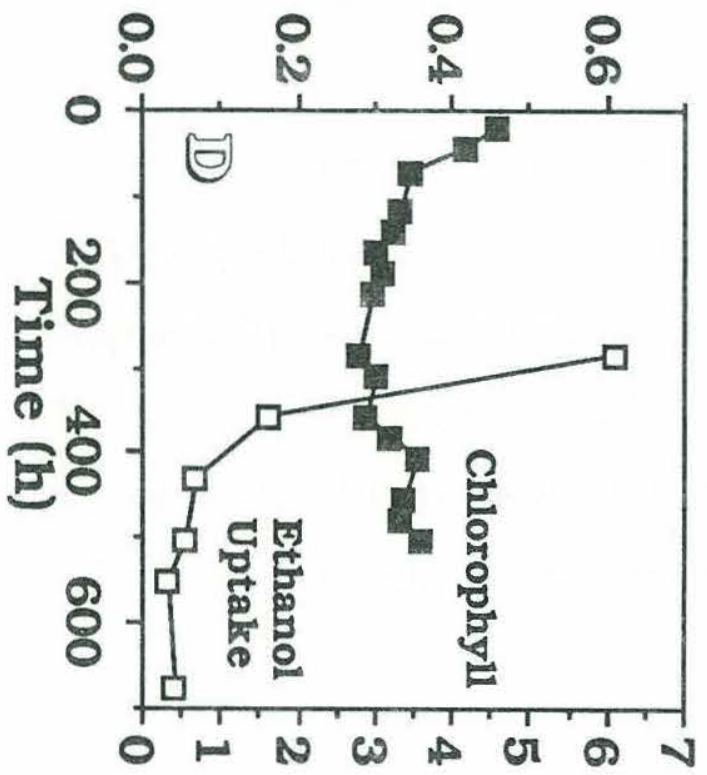

Ethanol Uptake Rate (pg cell ${ }^{-1} \mathbf{h}^{-1}$ )
Cells $\mathrm{ml}^{-1}$

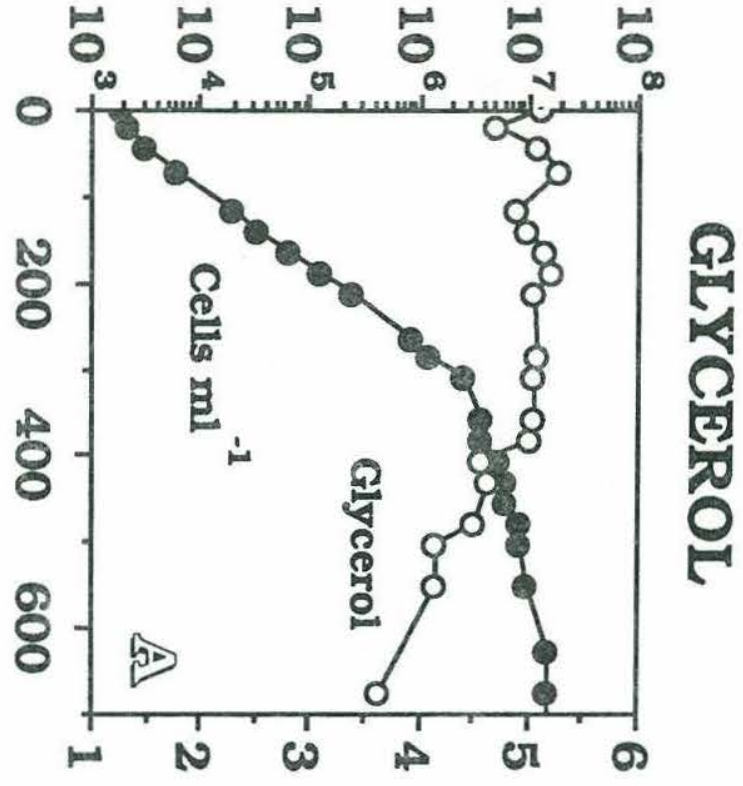

Glycerol Concentration (g liter ${ }^{-1}$ )

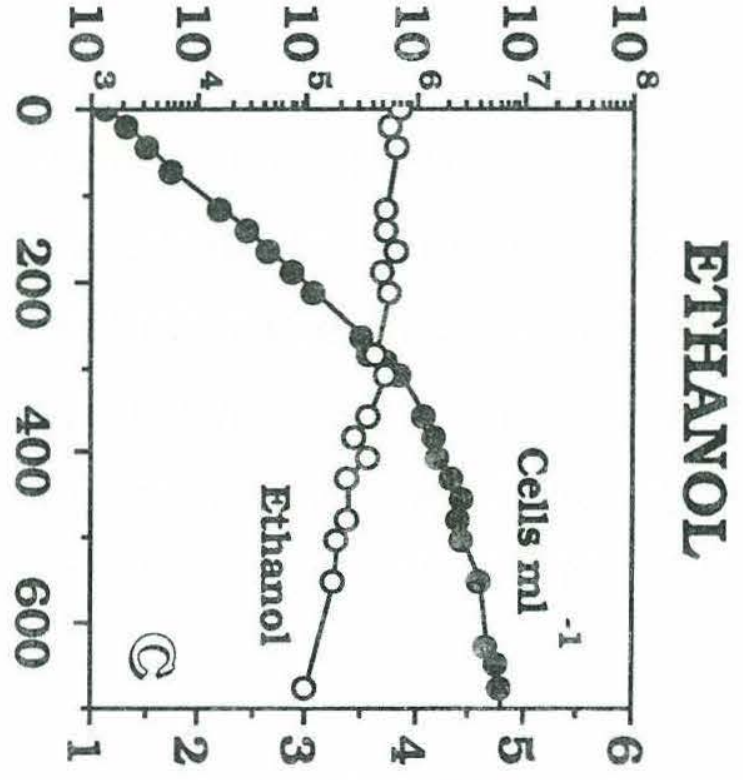

Ethanol Concentration (g liter ${ }^{-1}$ ) 
Figure 7. Growth curves and chlorophyll a cell ${ }^{-1}$ of $\underline{P}$. malhamensis grown at $105 \mu \mathrm{E} \mathrm{m}^{-2} \mathrm{~s}^{-1}$ with (A, B) $0.029 \mathrm{M}$ glucose or (C, D) $0.055 \mathrm{M}$ glycerol. Data are shown for populations serially transferred from cultures represented by the open circles to cultures represented by the closed circles and, in the glucose treatment, to cultures represented by the open squares. Arrows indicate the origin of the inoculum for serial transfers. 

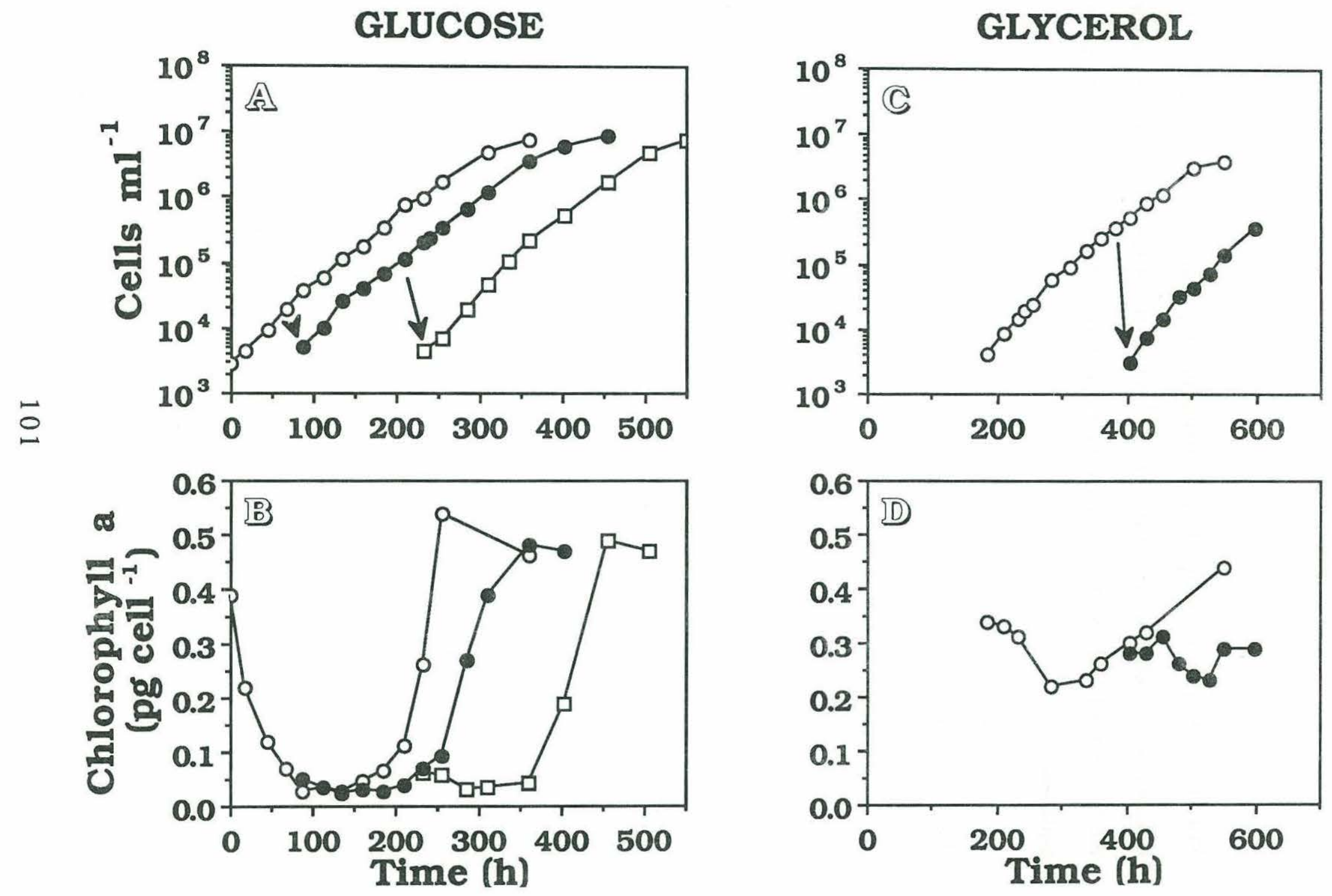
Figure 8. Effect of population density on the culture medium $\mathrm{pH}$ of $\underline{\mathrm{P}}$. malhamensis grown at $105 \mu \mathrm{E} \mathrm{m}^{-2} \mathrm{~s}^{-1}$ without organic substrates (open circles), with $0.029 \mathrm{M}$ glucose (closed circles), or with $0.13 \mathrm{M}$ ethanol (open squares). 


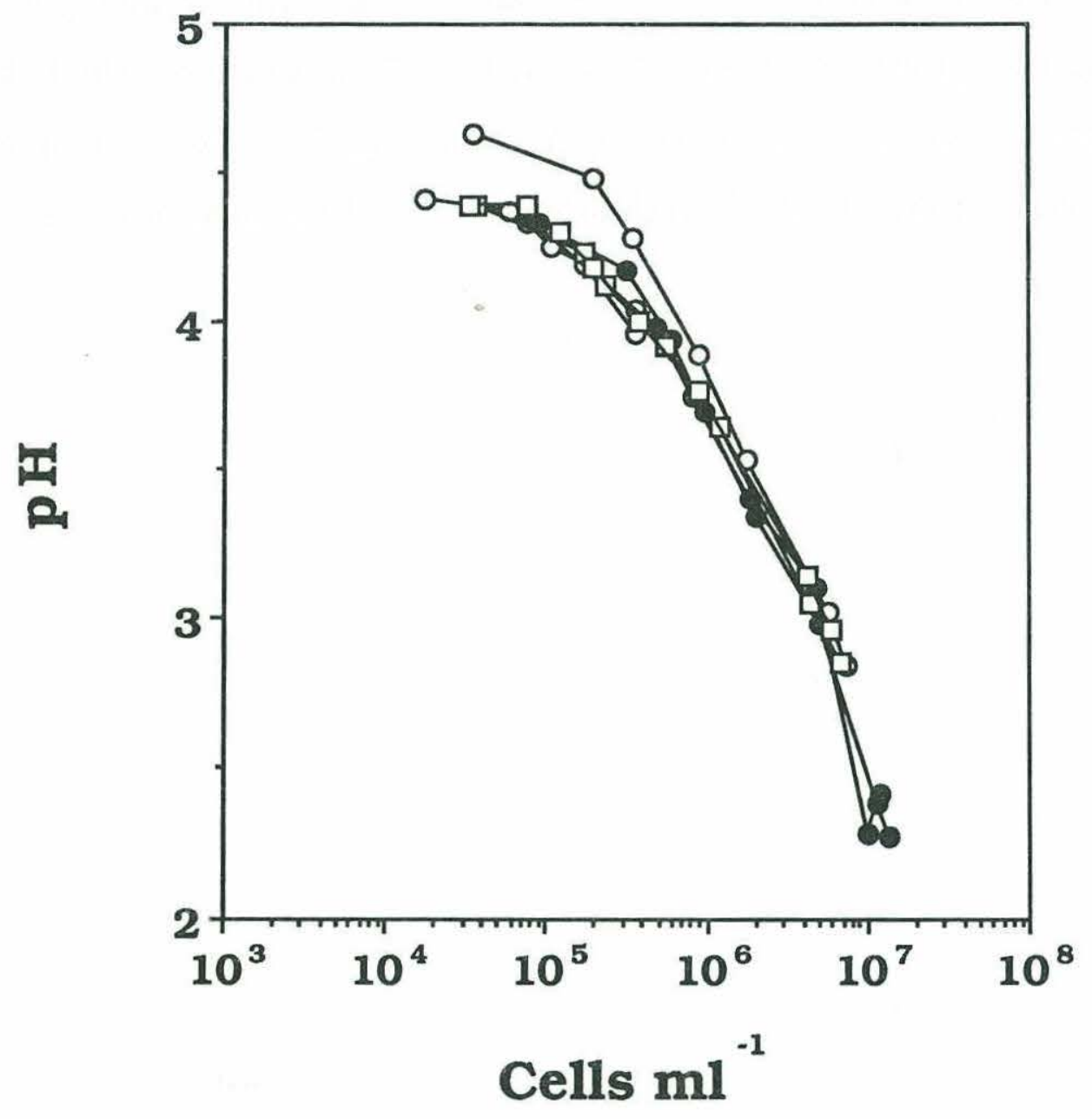

103 
Figure 9. Effect of initial $\mathrm{pH}$ of the culture medium on (A) growth curves, (B) chlorophyll $\underline{\mathrm{a}}$ cell-1 versus time, and (C) $\mathrm{pH}$ versus time for $\underline{\mathrm{P}}$. malhamensis grown at $105 \mu \mathrm{E} \mathrm{m}^{-2} \mathrm{~s}^{-1}$ with $0.029 \mathrm{M}$ glucose. The initial pHs were 6.4 (closed circles), 4.8 (open circles), or 3.2 (closed triangles). Arrows indicate the $\mathrm{pH}$ at which chlorophyll a cell-1 began to increase. 

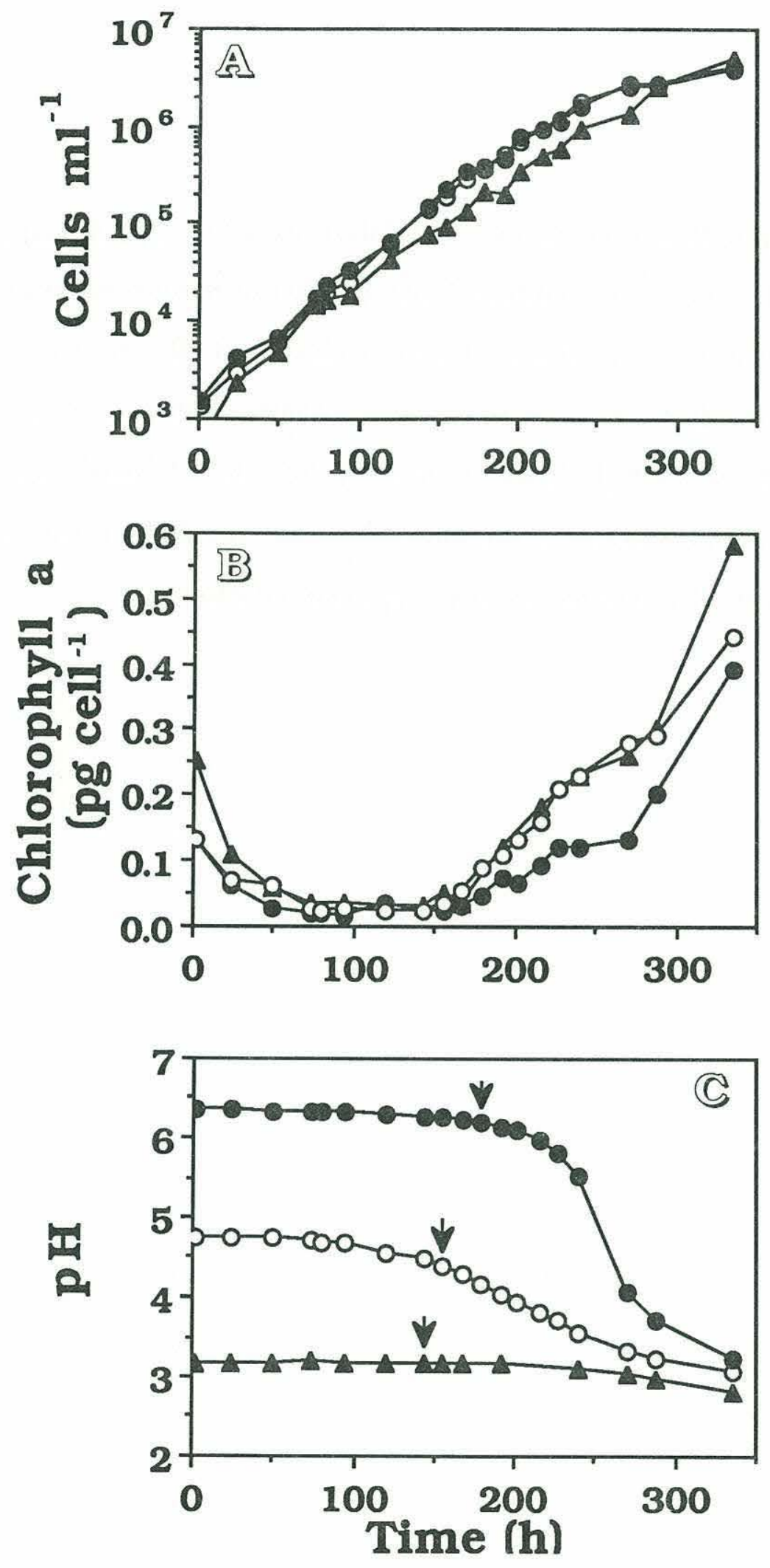
Figure 10. In vivo fluorescence cell-1 (relative units) of $\underline{P}$. malhamensis transferred (A) from a source culture (open circles) to fresh medium (open squares) or conditioned medium (closed circles) and (B) from a source culture to fresh medium containing no cyclic AMP (open squares), $1 \mathrm{mM}$ cyclic AMP (closed triangles), or $10 \mathrm{mM}$ cyclic AMP (closed squares). Arrows indicate the origin of the inoculum. Error bars indicate the standard deviation of the mean of three replicate cultures. 

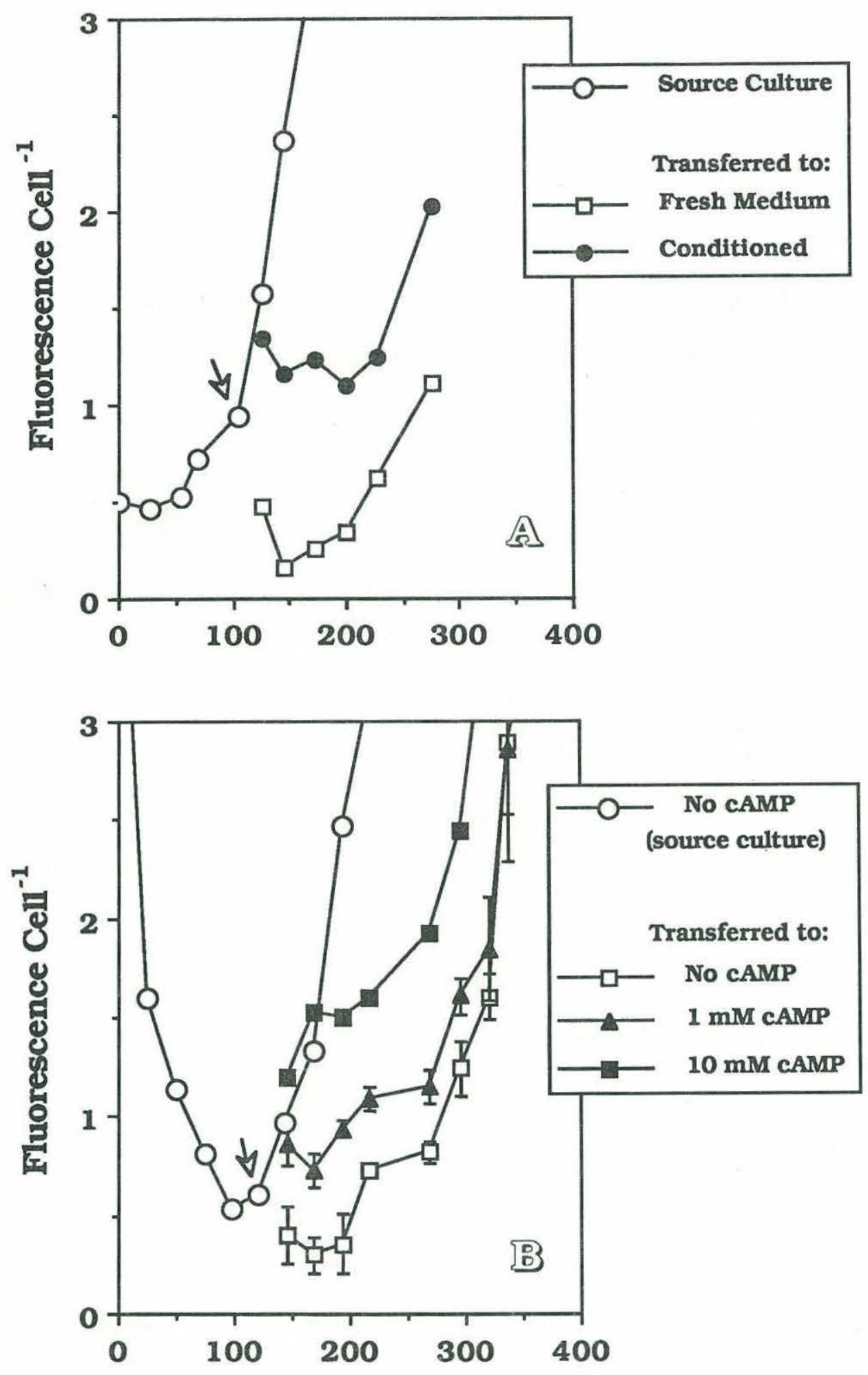

Time (h) 


\section{DISCUSSION}

This study demonstrated a much greater potential for heterotrophic growth than photoautotrophic growth in $\underline{\mathrm{P}}$. malhamensis. The addition of $0.029 \mathrm{M}$ glucose to batch cultures of $\underline{\mathrm{P}}$. malhamensis growing photoautotrophically at a saturating light level increased the alga's growth rate even though this addition resulted in a reduction of chlorophyll a cell-1 $^{-1}$ to near-zero values. This result indicates that, when glucose is available to the alga, the synthesis of photosynthetic components in the cell is repressed and growth and maintenance requirements are met by the catabolism of glucose. The decrease in chlorophyll a cell-1 caused by glucose addition was only transient, however; chlorophyll a cell-1 recovered during the exponential growth phase despite a high ambient glucose concentration. Apparently, chlorophyll production by $\underline{P}$. malhamensis grown in batch cultures was controlled by more than simply the glucose concentration of the medium.

It is particularly noteworthy that the recovery of the chlorophyll $\underline{a}$ cell $^{-1}$ could be retarded (or at least delayed) by the repeated transfer of $\underline{P}$. malhamensis to fresh medium (Fig. 7). This retardation did not occur in the cultures from which the inocula were taken (chlorophyll recovery in those cultures followed the patterns depicted in Figs. 5, 6), even though the concentrations of organic substrates in these cultures remained very high; high enough to cause the chlorophyll $\underline{\text { a }}$ cell $^{-1}$ to decrease in the first place (Figs. 5, 6). In addition, the transfer of the alga to "conditioned medium" substantially increased the chlorophyll fluorescence cell-1 over 
that of cultures transferred to fresh media (Fig. 10A). These patterns of chlorophyll cell-1 support the contention that the ability of $\underline{P}$. malhamensis to resume chlorophyll synthesis in the presence of dissolved organic compounds was not solely the result of an internal physiological change in the alga. Instead, this pattern is consistent with the release of some dissolved substance(s) by the alga which somehow conditioned the culture medium, allowing chlorophyll synthesis to recommence. Upon transfer to fresh medium this conditioning was no longer present and inhibition of chlorophyll synthesis continued until the new medium was conditioned.

Although the identity of this causative substance responsible for conditioning the medium is unknown, the reported activity of cyclic AMP would be consistent with these observed patterns. The uptake rate of the organic substrate by $\underline{\underline{P}}$. malhamensis decreased during the period of increasing chlorophyll a concentration cell-1. Cyclic AMP, an excretory product of $\underline{\underline{P}}$. malhamensis, is an important regulatory compound in the control of chlorophyll synthesis and organic substrate uptake by some photosynthetic organisms (reviewed in Francko 1983, Francko 1989). Batch cultures of $\underline{P}$. malhamensis have been shown to release cyclic AMP into the culture medium (Bressan et al. 1980), and glucose addition in particular has been shown to stimulate this release (Handa et al. 1981). Furthermore, addition of cyclic AMP to batch cultures grown with glucose stimulated chlorophyll production in Chlorella fusca (Berchtold and Bachofen 1977), depressed glucose assimilation in Anabaena flos-aquae (Francko 1984), and prevented or reversed the glucose-mediated 
repression of the synthesis of several inducible enzymes in a number of bacteria (reviewed in Robison et al. 1971). The observations in this study that the addition of cyclic AMP significantly enhanced chlorophyll fluorescence by $\underline{P}$. malhamensis and that this stimulatory effect was dependent on the concentration of cyclic AMP (Fig. 10B) are consistent with the hypothesis that the release of cyclic AMP during exponential growth may at least partly explain the observations of decreased organic substrate uptake and increased chlorophyll a production by $\underline{P}$. malhamensis cells in the presence of high exogenous substrate concentrations.

The $\mathrm{pH}$ of the culture medium declined rapidly throughout growth (Fig. 8). Reazin (1954) has previously demonstrated that oxygen uptake by $\underline{\mathbf{P}}$. malhamensis in the presence of glucose was $\mathrm{pH}$-dependent. Oxygen uptake rates in that study were optimal at pH 5 and decreased sharply below this $\mathrm{pH}$, indicating that respiration rates were near zero at $\mathrm{pH} 3.5$. An alternative hypothesis, therefore, for the increase in chlorophyll $\underline{a}$ cell $^{-1}$ in the presence of high organic substrate concentration observed in this study is that the uptake of organic substrates by $\underline{P}$. malhamensis was inhibited when the $\mathrm{pH}$ decreased below some threshold value, thereby leading to an increase in chlorophyll a production. The results of the $\mathrm{pH}$ experiment, however, refuted this hypothesis. The patterns of chlorophyll a cell ${ }^{-1}$ prior to the time at which chlorophyll a cell-1 increased were similar in cultures grown in media with initial pHs of 3.2, 4.8, and 6.4 (Fig. 9B). Also, the $\mathrm{pH}$ of the medium at the time that chlorophyll a cell-1 began to increase was different in the three treatments, and did not vary 
substantially from the initial $\mathrm{pH}$ (see arrows in Fig. 9C). These results indicate that the recovery from substrate inhibition of chlorophyll $\underline{\text { a }}$ synthesis by $\underline{\mathrm{P}}$. malhamensis can not be explained by changes in the $\mathrm{pH}$ of the culture medium alone.

Another alternative explanation for the recovery of chlorophyll $\underline{a}$ cell $^{-1}$ in $\underline{\text { P. malhamensis }}$ is that the cells were responding to a decrease in light availability caused by self-shading effects in the cultures. The chlorophyll a content cell ${ }^{-1}$ of cultures grown without organic substrates, however, was relatively constant throughout the experiment, even in one culture where the population density reached greater than $5 \times 10^{6}$ cells $\mathrm{ml}^{-1}$. Also, the in vivo fluorescence cell-1 of exponentially growing cells was nearly twice as high at $25 \mu \mathrm{E} \mathrm{m}^{-2} \mathrm{~s}^{-1}$ as at $105 \mu \mathrm{E} \mathrm{m}^{-2} \mathrm{~s}^{-1}$, data not shown (measured with a G. K. Turner III fluorometer fitted with a Corning 5-60 [348 to $515 \mathrm{~nm}$ ] excitation filter and a Corning 2-64 [high pass filter with $667 \mathrm{~nm}$ half-power] emission filter). These results indicate that self-shading effects in the batch cultures in this study probably were not significant at population densities less than $5 \times 10^{6}$ cells ml-1. $^{-1}$.

The effect of organic substrate addition on the chlorophyll a content of $\underline{\mathrm{P}}$. malhamensis cells growing at $105 \mu \mathrm{E} \mathrm{m} \mathrm{m}^{-2} \mathrm{~s}^{-1}$ varied with the organic substrate, even though the organic carbon to inorganic nitrogen ratios of the culture media were similar (Table 2). Chlorophyll production by $\underline{\mathrm{P}}$. malhamensis, therefore, was not controlled by the organic carbon to inorganic nitrogen ratio of the medium, as had been previously hypothesized for Euglena gracilis (Harris and Kirk 1969). Thus, the present results for $\underline{P}$. malhamensis are in accordance with results from previous 
studies of Euglena in which the inhibition of chlorophyll production varied with different organic substrates and was independent of the organic carbon to inorganic nitrogen ratio of the medium (Horrum and Schwartzbach 1980, Monroy and Schwartzbach 1984).

The finding here that the control of chlorophyll synthesis in $\underline{P}$. malhamensis is a substrate-specific process is consistent with the hypothesis of Handa et al. (1981) that glucose is a catabolite repressor of chloroplast formation in $\underline{\mathrm{P}}$. malhamensis. They demonstrated that, in $\underline{\mathrm{P}}$. malhamensis, glucose depletion from the culture medium was accompanied by increased cellular cyclic AMP concentration, and then chlorophyll production. This finding is consistent with the cyclic AMPmediated escape from catabolite repression of certain enzyme systems in bacteria (Pastan and Adhya 1976) and yeast (Pall 1981). Because the cultures used in Handa et al.'s (1981) experiments were initially nitrogendeficient, however, it is possible that the inhibition of chlorophyll production observed in their study was at least partially a result of nitrogen deficiency (e. g. as found in Euglena, Horrum and Schwartzbach 1980). Because inocula were derived from exponentially growing (i. e., nitrogen-sufficient) cultures in the present study, the inhibitory effect of organic substrates on chlorophyll production could be distinguished from that of nitrogen deficiency. These results, therefore, extend Handa et al.'s (1981) findings by showing that glucose specifically inhibits chlorophyll synthesis independently of nitrogen availability in $\underline{P}$. malhamensis. These results are also consistent with the hypothesis that glycerol and ethanol are catabolite repressors of chloroplast development in $\underline{P}$. malhamensis. 
Handa et al. (1981) found that the onset of cyclic AMP production and, subsequently, chlorophyll production by $\underline{\mathrm{P}}$. malhamensis required the depletion of an "appreciable" proportion of glucose from the medium. In contrast, in this study, after the initial decline in cell chlorophyll a content caused by organic substrate addition, chlorophyll a cell ${ }^{-1}$ increased despite only nominal changes in organic substrate concentration. Because the initial population densities in the batch cultures of $\underline{P}$. malhamensis grown in these experiments were much lower than in cultures grown in Handa et al.'s (1981) study, the duration of exponential growth of cultures in this study was more than twice as long. One possible reason, therefore, that chlorophyll $\underline{\text { a cell }}{ }^{-1}$ began to increase prior to the depletion of organic substrates in this study but not in Handa et al. (1981) was that the longer duration of exponential growth in these experiments allowed the buildup of excretory product(s) to concentrations sufficient to condition the medium and allow chlorophyll production, as hypothesized above.

Although the regulation of organic substrate uptake and chlorophyll synthesis by $\underline{\underline{P}}$. malhamensis is complex, the potential contribution of photosynthesis to the nutrition of this alga is minor relative to that of heterotrophy. The maximum photoautotrophic growth rate observed in this study, 0.3 day $^{-1}$, is uncharacteristically low for phytoplankton (e. g., Droop 1974, Glover et al. 1987). Moreover, the growth rate of the alga could be enhanced significantly by organic substrate addition to cultures growing at light levels saturating for photoautotrophic growth. Typically, the growth rate of facultatively heterotrophic algae at saturating light intensities is unaffected by organic 
substrate enrichment (Van Baalan and Pulich 1973, Ukeles and Rose 1976). Further evidence for the dominant role of heterotrophy in $\underline{P}$. malhamensis is the finding that the growth rate of the alga in the dark was equal to or greater than the maximum growth rate in the light at all glucose concentrations. The ability of $\underline{\underline{P}}$. malhamensis to grow as fast in the dark as in the light is unusual among phytoplankton (Van Baalan and Pulich 1973, Droop 1974, Ukeles and Rose 1976, Hellebust and Lewin 1977, Antia 1980). This exceptional heterotrophic capability of $\underline{\underline{P}}$. malhamensis also is reflected by the lack of a lag period when adjusting to dark conditions. Phytoplankton typically require an adaptation period when switching from photoautotrophic to chemoheterotrophic growth (Lewin 1963, Van Baalan and Pulich 1973), but the growth rate of $\underline{P}$. malhamensis increased immediately when exponentially growing cultures were transferred into the dark and supplemented with glucose (e. g., Fig. 3).

Although the growth rate of $\underline{P}$. malhamensis cultures grown with $0.029 \mathrm{M}$ or $0.0025 \mathrm{M}$ glucose in the medium was relatively unaffected by changes in light intensity, the effect of $0.25 \mathrm{M}$ glucose, $0.25 \mathrm{M}$ glycerol, or $0.03 \mathrm{M}$ glycine on growth rate was light intensity-dependent. According to Pringsheim (1952), glucose concentrations between $0.003 \mathrm{M}$ and $0.01 \mathrm{M}$ were optimal for the growth of $\underline{P}$. malhamensis, and growth rate decreased with increasing glucose concentration above $0.01 \mathrm{M}$. The light regime, however, was not specified for that portion of his study, clearly an important consideration based on the results of the present study. The results from this study indicate that, analogous to Pringsheim (1952), 0.25 $\mathrm{M}$ glucose was less favorable for growth than $0.029 \mathrm{M}$ and $0.0025 \mathrm{M}$ in the 
light. It is noteworthy, however, that the growth rate of $\underline{P}$. malhamensis in the dark was equal at all three glucose concentrations. Also, whereas the growth of $\underline{P}$. malhamensis at low light intensities was unaffected or enhanced by the addition of $0.25 \mathrm{M}$ glucose, $0.25 \mathrm{M}$ glycerol, or $0.03 \mathrm{M}$ glycine, the growth rate in these treatments was markedly inhibited at a high light intensity (325 $\left.\mu \mathrm{E} \mathrm{m}^{-2} \mathrm{~s}^{-1}\right)$. Thus, although it is clear that $\underline{\mathrm{P}}$. malhamensis has a limited capacity for photoautotrophic growth, heterotrophic growth can be profoundly influenced by light intensity under some culture conditions. This complex interaction of organic substrate type, concentration, and light intensity is poorly understood and requires further study.

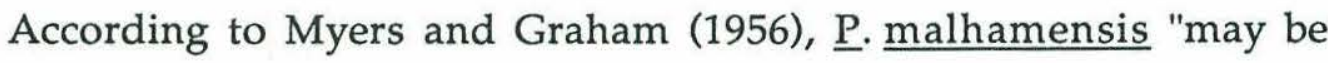
considered a very primitive animal which has retained only enough of its photosynthetic apparatus to sustain it between bites". The results of this study and those of Caron et al. (1990) and Sanders et al. (1990) support this thesis by demonstrating a much greater potential for heterotrophic growth than photoautotrophic growth in $\underline{P}$. malhamensis. In fact, the growth rates of $\underline{\underline{P}}$. malhamensis with bacteria as a substrate (Caron et al. 1990, Sanders et al. 1990) are approximately twice as great as the maximum growth rate on dissolved organic substrates observed in this study. Although the potential for photoautotrophic growth is relatively low, the observations presented here that light conditions dramatically affected growth in the presence of relatively high substrate concentrations, that the extent of organic substrate inhibition of chlorophyll a synthesis varied with the substrate, and that chlorophyll a synthesis could take place after 
"acclimation" to the presence of organic substrates, indicate that the relative contribution of photosynthesis to overall nutrition in $\underline{P}$. malhamensis is controlled by a complex interaction of environmental conditions and algal physiology. 


\section{ACKNOWLEDGEMENTS}

This work was supported by NSF Grants BSR-8620443, BSR-8919447, Ocean Ventures Fund Grant 25/85.10 of the Woods Hole Oceanographic

Institution Education Program, and the Woods Hole Oceanographic Institution Education Program. 


\section{REFERENCES}

Aaronson, S. (1973) Digestion in phytoflagellates. In Lysosomes in Biology and Pathology. Edited by Dingle, J. T. pp. 18-37. North-Holland, Amsterdam.

Allen, H. L. (1971) Dissolved organic carbon utilization in size-fractionated algal and bacterial communities. Int. Rev. Gesamten. Hydrobiol. 56: 731-749.

Antia, N. J. (1980) Nutritional physiology and biochemistry of marine cryptomonads and chrysomonads. In Biochemistry and Physiology of Protozoa Vol. 3. Edited by Levandowsky, M. and Hutner, S. H. pp. 67115. Academic Press, New York.

Antia, N. J., Cheng, J. Y. and Taylor, F. J. R. (1969) The heterotrophic growth of a marine photosynthetic cryptomonad (Chroomonas salina). Proc. Intl. Seaweed Symp. 6: 17-29.

App, A. A. and Jagendorf, A. T. (1963) Repression of chloroplast development in Euglena gracilis by substrates. I. Protozool. 10: 340343.

Azam, F. and Hodson, R. E. (1977) Size distribution and activity of marine microheterotrophs. Limnol. Oceanogr. 22: 492-501.

Bennett, M. E. and Hobbie, J. E. (1972) The uptake of glucose by Chlamydomonas sp. I. Phycol. 8: 392-398.

Bergmeyer, H. U., Bernt, E., Schmidt, F. and Stork, H. (1974) D-Glucose. Determination with hexokinase and glucose-6-phosphate dehydrogenase. In Methods of Enzymatic Analysis Vol. 3. Edited by 
Bergmeyer, H. U. pp. 1196-1201. Verlag Chemie, Weinheim, Academic Press, New York.

Berchtold, M. and Bachofen, R. (1977) Possible role of cyclic AMP in the synthesis of chlorophyll in Chlorella fusca. Arch. Microbiol. 112: 173177.

Berman, T. (1975) Size fractionation of natural aquatic populations associated with autotrophic and heterotrophic carbon uptake. Mar. Biol. 33: 215-220.

Beutler, H-O. and Michal, G. (1977) Neue Methode zur enzymatischen Bestimmung von Äthanol in Lebensmitteln. ‥ Anal. Chem. 284: 113-117.

Bollman, R. C. and Robinson, G. G. C. (1977) The kinetics of organic acid uptake by three Chlorophyta in axenic culture. I. Phycol. 13: 1-5.

Bollman, R. C. and Robinson, G. G. C. (1985) Heterotrophic potential of the green alga, Ankistrodesmus braunii (Naeg.). Can. I. Microbiol. 31: 549-554.

Bonin, D. J. and Maestrini, S. Y. (1981) Importance of organic nutrients for phytoplankton growth in natural environments: implications for

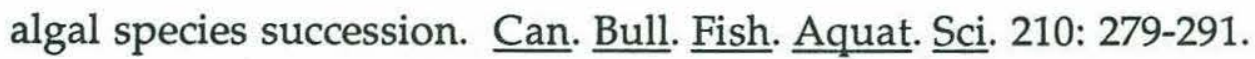

Brandt, P., Kaiser-Jarry, K. and Wiessner, W. (1982) Chlorophyll-protein complexes. Variability of CPI, and the existence of two distinct forms of LHCP and one low-molecular-weight chlorophyll a protein. Biochim. Biophys. Acta 679: 404-409. 
Bressan, R. A., Handa, A. K., Quader, H. and Filner, P. (1980) Synthesis and release of cyclic adenosine $3^{\prime}: 5^{\prime}$-monophosphate by Ochromonas malhamensis. Plant Physiol. 65: 165-170.

Caron, D. A., Porter, K. G. and Sanders, R. W. (1990) Carbon, nitrogen and phosphorus budgets for the mixotrophic phytoflagellate Poterioochromonas malhamensis (Chrysophyceae) during bacterial ingestion. Limn. Oceanogr. 35: 433-443.

Droop, M. R. (1974) Heterotrophy of carbon. In Algal Physiology and Biochemistry. Edited by Stewart, W. D. P. pp. 530-559. Blackwell Scientific, Oxford.

Eggstein, M. and Kuhlmann, E. (1974) Triglycerides and glycerol. Determination after alkaline hydrolysis. In Methods of Enzymatic Analysis Vol. 4. Edited by Bergmeyer, H. U. pp. 1825-1831. Verlag Chemie, Weinheim, Academic Press, New York.

Ellis, R., Moore, D. and Shure, R. (1981) Characteristics of chlorophyll formation in the green alga Golenkinia. Plant Cell Physiol. 22: 9991009.

Eppley, R. W., Gee, R. and Saltman, P. (1963) Photometabolism of acetate by Chlamydomonas mundana. Physiol. Plant. 16: 777-792.

Francko, D. A. (1983) Cyclic AMP in photosynthetic organisms: Recent developments. In Advances in Cyclic Nucleotide Research Vol. 15. Edited by Greengard, P. and Robison, G. A. pp. 97-117. Raven Press, New York. 
Francko, D. A. (1984) The significance of cyclic nucleotides in phytoplanktonic carbon metabolism: A current view. Verh. Internat. Verein. Limnol. 22: 612-619.

Francko, D. A. (1989) Modulation of photosynthetic carbon assimilation in Selenastrum capricornutum (Chlorophyceae) by cAMP: An electrogenic mechanism? I. Phycol. 25: 305-313.

Glover, H. E., Keller, M. D. and Spinrad, R. W. (1987) The effects of light quality and intensity on photosynthesis and growth of marine eukaryotic and prokaryotic phytoplankton clones. I. Exp. $\underline{\text { Mar. }} . \underline{\text { Biol. }}$ Ecol. 105: 137-159.

Guillard, R. R. L. (1975) Culture of phytoplankton for feeding marine invertebrates. In Culture of Marine Invertebrate Animals. Edited by Smith, W. L. and Chanley, M. H. pp. 29-60. Plenum, New York.

Handa, A. K., Bressan, R. A., Quader, H. and Filner, P. (1981) Association of formation and release of cyclic AMP with glucose depletion and onset of chlorophyll synthesis in Poterioochromonas malhamensis. Plant Physiol. 68: 460-463.

Hargraves, P. E., Vaillancourt, R. D. and Jolly, G. A. (1989) Autotrophic picoplankton in Narragansett Bay and their interaction with microplankton. In Novel Phytoplankton Blooms: Causes and Impacts of Recurrent Brown Tides and Other Unusual Blooms. Lecture Notes on Coastal and Estuarine Studies. Edited by Cosper, E. M., Bricelj, V. M. and Carpenter, E. J. pp. 23-38. Springer-Verlag, Berlin. 
Harris, R. C. and Kirk, J. T. O. (1969) Control of chloroplast formation in Euglena gracilis: antagonism between carbon and nitrogen sources. Biochem. I. 113: 195-205.

Heinbokel, J. F. (1978) Studies on the functional role of tintinnids in the Southern California Bight. I. Grazing and growth rates in laboratory cultures. Mar. Biol. 47: 177-189.

Hellebust, J. A. (1970) The uptake and utilization of organic substances by marine phytoplankters. In Organic Matter in Natural Waters. Inst. Mar. Sci. Occas. Publ. No. 1. Edited by Hood, D. W. pp. 225-256. Univ. of Alaska, Fairbanks.

Hellebust, J. A. and Lewin, J. (1977) Heterotrophic nutrition. In The Biology of Diatoms. Edited by Werner, D. pp. 169-197. Univ. Calif. Press, Berkeley.

Hobbie, J. E. and Wright, R. T. (1965) Competition between planktonic bacteria and algae for organic solutes. In Primary Productivity in Aquatic Environments. Mem. 1st Ital. Idrobiol. 18 supplement. Edited by Goldman, C. R. pp. 175-185. Univ. Calif. Press, Berkeley.

Holm-Hansen, O., Lorenzen, C. J., Holmes, R. W. and Strickland, J. D. H. (1965) Fluorometric determination of chlorophyll. I. Cons., Cons. Perm. Int. Explor. Mer. 30: 3-15.

Horrum, M. A. and Schwartzbach, S. D. (1980) Nutritional regulation of organelle biogenesis in Euglena: repression of chlorophyll and NADP-glyceraldehyde-3-phosphate dehydrogenase synthesis. Plant Physiol. 65: 382-386. 
Hutner, S. H., Provasoli, L. and Filfus, J. (1953) Nutrition of some phagotrophic fresh-water chrysomonads. $\underline{\text { Ann }} . \underline{\text { N. }} \underline{\underline{Y}} . \underline{\text { Acad. }} \underline{\text { Sci. }}$ 56: 852-862.

Lewin, J. C. (1963) Heterotrophy in marine diatoms. In Symposium on Marine Microbiology. Edited by Oppenheimer, C. H. pp. 229-235. C. C. Thomas, Springfield, Mass.

Maeda, O. and Ichimura, S. (1973) On the high density of a phytoplankton population found in a lake under ice. Int. Revue ges. Hydrobiol. 58: 673-685.

McKinley, K. R. (1977) Light-mediated uptake of ${ }^{3} \mathrm{H}$-glucose in a small hard-water lake. Ecology 58: 1356-1365.

Moll, R. (1984) Heterotrophy by phytoplankton and bacteria in Lake Michigan. Verh. Internat. Verein. Limnol. 22: 431-434.

Monroy, A. F. and Schwartzbach, S. D. (1984) Catabolite repression of chloroplast development in Euglena. Proc. Natl. Acad. Sci. $\underline{\text { U. }} . \underline{\text { S. }} . \underline{\text { A. }}$ 81: $2786-2790$.

Munro, A. L. S. and Brock, T. D. (1968) Distinction between bacterial and algal utilization of soluble substances in the sea. I. Gen. Microbiol. 51: $35-42$.

Myers, J. and Graham, J. (1956) The role of photosynthesis in the physiology of Ochromonas. I. Cell. Comp. Phys. 47: 397-414.

Neilson, A. H. and Lewin, R. A. (1974) The uptake and utilization of organic carbon by algae: an essay in comparative biochemistry. Phycologia 13: 227-264. 
Ogawa, T. and Aiba, S. (1981) Bioenergetic analysis of mixotrophic growth in Chlorella vulgaris and Scenedesmus acutus. Biotech. Bioenerg. 23: $1121-1132$.

Paerl, H. W. and Goldman, C. R. (1972) Heterotrophic assays in the detection of water masses at Lake Tahoe, California. Limnol. Oceanogr. 17: 145-148.

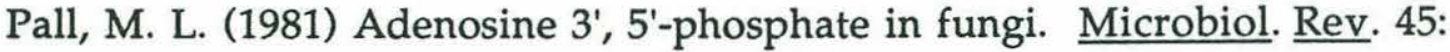
$462-480$.

Pastan, I. and Adhya, S. (1976) Cyclic adenosine 5'-monophosphate in Escherichia coli. Bacteriol. Rev. 40: 527-551.

Platt, T., Subba Rao, D. V., Smith, J. C., Li, W. K. W., Irwin, B., Horne, R. P. W. and Sameoto, D. D. (1983) Photosynthetically-competent phytoplankton from the aphotic zone of the deep ocean. Mar. Ecol.Progr. Ser. 10: 105-110.

Porter, K. G. (1988) Phagotrophic phytoflagellates in microbial food webs. Hydrobiologia 159: 89-97.

Pringsheim, E. G. (1952) On the nutrition of Ochromonas. ㅇ. I. Microscop. Sci. 93: 71-96.

Reazin, G. H., Jr. (1954) On the dark metabolism of a golden-brown alga, Ochromonas malhamensis. Am. I. Bot. 41: 771-777.

Rivkin, R. B. and Putt, M. (1987) Heterotrophy and photoheterotrophy by Antarctic microalgae: light-dependent incorporation of amino acids and glucose. I. Phycol. 23: 442-452.

Robison, G. A., Butcher, R. W. and Sutherland, E. W. (1971) Cyclic AMP. 531 pp. Academic Press, New York. 
Sanders, R. W. and Porter, K. G. (1988) Phagotrophic phytoflagellates. In Advances in Microbial Ecology Vol. 10. Edited by Marshall, K. C. pp. 167-192. Plenum Press, New York.

Sanders, R. W., Porter, K. G. and Caron, D. A. (1990) Relationship between phototrophy and phagotrophy in the mixotrophic chrysophyte Poterioochromonas malhamensis. Microb. Ecol. 19: 97-109.

Shihira-Ishikawa, I. and Hase, E. (1964) Nutritional control of cell pigmentation in Chlorella protothecoides with special reference to the degeneration of the chloroplast induced by glucose. Plant Cell Physiol. 5: 227-240.

Shihira-Ishikawa, I. and Hase, E. (1965) Effects of glucose on the process of chloroplast development in Chlorella protothecoides. Plant Cell Physiol. 6: 101-110.

Sieburth, J. McN. and Johnson, P. W. (1989) Picoplankton ultrastructure: a decade of preparation for the brown tide alga, Aureococcus anophagefferens. In Novel Phytoplankton Blooms: Causes and Impacts of Recurrent Brown Tides and Other Unusual Blooms. Lecture Notes on Coastal and Estuarine Studies. Edited by Cosper, E. M., Bricelj, V. M. and Carpenter, E. J. pp. 1-21. Springer-Verlag, Berlin.

Sloan, O. R. and Strickland, J. D. H. (1966) Heterotrophy of four marine phytoplankters at low substrate concentrations. I. Phycol. 2: 29-32.

Stockner, J. G. (1988) Phototrophic picoplankton: an overview from marine and freshwater ecosystems. Limnol. Oceanogr. 33: 765-775. 
Ukeles, R. and Rose, W. E. (1976) Observations on organic carbon utilization by photosynthetic marine microalgae. Mar. Biol. 37: 11-28.

Van Baalan, C. and Pulich, W. M. (1973) Heterotrophic growth of the microalgae. CRC Crit. Rev. Microbiol. 2: 229-255.

Vincent, W. F (1980) The physiological ecology of a Scenedesmus population in the hypolimnion of a hypertrophic pond. II. Heterotrophy. Br. Phycol. I. 15: 35-41.

Vincent, W. F. and Goldman, C. R. (1980) Evidence for algal heterotrophy in Lake Tahoe, California-Nevada. Limnol. Oceanogr. 25: 89-99.

Wiessner, W. and French, C. S. (1970) The forms of native chlorophyll in Chlamydobotris stellata and their changes during adaptation from photo-heterotrophic to autotrophic growth. Planta (Berl) 94: 78-90.

Williams, P. J. LeB. (1970) Heterotrophic utilization of dissolved organic compounds in the sea. I. Size distribution of population and relationship between respiration and incorporation of growth substrates. I. Mar. Biol. Assoc. ‥ ‥ ‥ 50: 859-870. 


\section{Chapter 4.}

Physiological Responses of Phytoflagellates to Dissolved Organic

Substrate Additions. 2. Dominant Role of Autotrophic Nutrition in Pyrenomonas salina (Cryptophyceae) 


\begin{abstract}
The enhancement of algal growth by organic substrate assimilation is a common laboratory observation, yet few studies have addressed the interaction of dissolved organic compounds and environmental factors for controlling the relative contribution of heterotrophy and autotrophy to the nutrition of these algae. The effects of light intensity and organic compound additions on the growth, cell volume, pigmentation, and carbon uptake of the facultative heterotroph, Pyrenomonas salina Santore were examined. Growth rate in the presence of high concentrations of dissolved organic substrates was critically dependent on light intensity, and the enhancement of growth by organic substrate assimilation occurred only in cultures grown at light levels limiting for photoautotrophic growth. The addition of high organic substrate concentrations to cultures grown at a very high light intensity inhibited the growth of the alga. Glycerol addition to cultures growing at a limiting light intensity increased the growth rate, increased the average cell volume and cellular starch content, decreased the cellular phycoerythrin to chlorophyll a ratio, and had no effect on the $\mathrm{CO}_{2}$ uptake rate cell-1. Glycerol addition to cultures growing at a moderate light intensity that was saturating for photoautotrophic growth increased the average cell volume and cellular starch content but had no effect on the $\mathrm{CO}_{2}$ uptake rate cell-1. The results indicate that autotrophy was the major process for carbon acquisition during the growth of $\underline{\mathrm{P}}$. salina, but that carbon acquisition from glycerol catabolism also was used to partially support growth of the alga at the
\end{abstract}


limiting light intensity. In addition, glycerol presumably was used to fulfill the energy and/or reductant requirements of the alga, and to increase the reserve carbohydrate (starch) in the organism. 


\section{INTRODUCTION}

The physiological mechanisms controlling organic substrate uptake and metabolism by algae are largely unknown. Besides providing a source of energy for photosynthesis, light can play a key role in the regulation of organic substrate utilization by algae. The relative contribution of heterotrophy to algal growth is characteristically dependent on light intensity (Van Baalan and Pulich 1973, Ukeles and Rose 1976). Depending on the species studied, however, both stimulation and inhibition of substrate assimilation have been documented (reviewed in Neilson and Lewin 1974). Whereas, in most species examined, supplementation of the mineral medium with metabolizable organic substrates can enhance algal growth at light intensities limiting for photoautotrophic growth (Pintner and Provasoli 1968, Van Baalan and Pulich 1973), the enhancement of growth by the addition of organic substrates at saturating light levels has been reported only rarely (e. g., Endo et al. 1977, Ogawa and Aiba 1981, Lewitus and Caron subm.). These results imply that most algae are capable of attaining maximal growth rates photoautotrophically, but that organic substrate assimilation can augment the carbon and/or energy supply to the algal cell when photosynthetic rates are light-limited.

The metabolism of organic substrates by algae is regulated by the nature of the organic compound as well as by light. Some organic compounds can stimulate their utilization by inducing the synthesis of cellular components (e. g., enzymes, organelles) required for organic substrate metabolism (Horrum and Schwartzbach 1981, Komor et al. 1988). 
Organic substrates that stimulate their own use may also inhibit the synthesis of chloroplast components and lead to reductions in photosynthetic activity; e. g., ethanol addition to Euglena induced the development of glyoxysomes, organelles involved in ethanol metabolism, and repressed chloroplast formation (Monroy and Schwartzbach 1984).

Because light and the type of organic substrate are each important regulatory factors controlling the metabolism of organic substrates, there is a potential for a rather complex interaction between these two factors for controlling the relative importance of phototrophy and heterotrophy in algal species. It has previously been demonstrated (Lewitus and Caron subm.) that these two variables strongly interacted to influence the growth of the freshwater chrysophyte, Poterioochromonas malhamensis. Even at high light intensities, however, the addition of organic substrates (glucose, glycerol, or ethanol) to the culture medium increased the growth rate of this alga in nearly all cases, and caused transient decreases in the amount of chlorophyll a cell-1. Contrary to the situation for some species in which light intensity controls substrate utilization, these results imply that light has a minor role in controlling organic substrate uptake and metabolism in $\underline{P}$. malhamensis.

Like $\underline{P}$ malhamensis, organic substrate addition to the culture medium can enhance the phototrophic growth of the marine cryptophyte, Pyrenomonas salina (Antia et al. 1969). The relative capabilities for photoautotrophic and heterotrophic growth, however, differ greatly in these two species. In contrast to $\underline{P}$. malhamensis, $\underline{\underline{P}}$. $\underline{\text { salina grows readily }}$ photoautotrophically, but apparently has a limited heterotrophic 
capability. Although the assimilation of various organic substrates enhanced its growth under light-limiting conditions, the growth of $\underline{P}$. salina in the dark has been obtained only with high concentrations of glycerol (Antia et al. 1969, Cheng and Antia 1970). The response of the photosynthetic system to organic substrate assimilation is also very different for these two algae. Whereas organic substrates can repress chloroplast development in $\underline{P}$. malhamensis (Pringsheim 1952), glycerol addition to $\underline{P}$. salina caused a selective inhibition of the synthesis of photosynthetic components that appeared to be specific towards the lightharvesting function of the algal cell (Lewitus et al. subm.).

In the present study, the effects of light intensity and organic substrates on the growth, cell pigment composition, cell volume, heterotrophic carbon uptake, and photosynthetic carbon uptake of $\underline{P}$. salina cultures were examined. These results for $\underline{P}$. salina resembled previous results obtained with $\underline{\mathrm{P}}$. malhamensis (Lewitus and Caron subm.) in that growth was critically dependent on an interaction between light intensity and organic substrate concentration. In contrast to the results obtained with $\underline{P}$. malhamensis, however, the growth rate of $\underline{P}$. $\underline{\text { salina }}$ was light intensity-dependent under all conditions used in this study. That is, unlike $\underline{P}$. malhamensis, autotrophic nutrition contributed to the overall growth rate of the cryptophyte in all situations. Thus, $\underline{P}$. salina and $\underline{P}$. malhamensis have contrasting metabolic strategies for combining heterotrophic and autotrophic nutrition for growth. 


\section{METHODS}

Pyrenomonas salina Santore (formerly Cryptomonas salina Wislouch; Chroomonas salina Butcher) clone 3C (Culture Collection of Marine Phytoplankton, Bigelow Laboratory for Ocean Sciences) was obtained from Dr. Diane Stoecker (Woods Hole Oceanographic Institution). Batch cultures used for inocula in the experimental treatments were grown axenically in artificial seawater medium with fmix vitamins and trace metals (ASPM Base; Table 9 in Guillard (1975), except that $20 \mathrm{mM} \mathrm{CaCl}_{2}$ and $0.2 \mathrm{mM} \mathrm{H}_{3} \mathrm{BO}_{3}$ were substituted for $10 \mathrm{mM}$ $\mathrm{CaCl}_{2}$ and $0.4 \mathrm{mM} \mathrm{H}_{3} \mathrm{BO}_{3}$, respectively, and $0.81 \mathrm{mM} \mathrm{KBr}$ was added). The nitrogen source was $0.1 \mathrm{mM} \mathrm{NH}_{4} \mathrm{Cl}$ and the phosphorus source was 0.1 $\mathrm{mM} \mathrm{NaH} \mathrm{PO}_{4}$. The $\mathrm{pH}$ of the medium was 7.4 and the salinity was 29.5\%. The growth temperature for all cultures used in this study was $21^{\circ} \mathrm{C}$.

Experiment 1: Growth, $\underline{\text { size }}$ and pigment patterns

The effects of light intensity and the addition of organic compounds on the growth rate, cell volume, and cell pigment content and composition of $\underline{P}$. salina were examined in batch cultures. Cultures used for inocula were acclimated to specific light intensities by repeated transfer of cells in the mid-exponential growth phase. Continuous illumination was provided by cool-white fluorescent lights at intensities of 325, 265, 190, 105,25 , or $15 \mu \mathrm{E} \mathrm{m}^{-2} \mathrm{~s}^{-1}$. Irradiance was measured with an integrating $4 \mu$ 
quantum sensor (Biospherical Instruments, QSL-100P probe). After acclimation to the light regime, exponentially growing populations were inoculated into media that varied in the organic compound composition. Four organic compounds were used; glucose, ethanol, glycine, and glycerol. $\mathrm{NH}_{4} \mathrm{Cl}$ was omitted from the experimental culture medium with glycine.

Cell numbers, volumes, and, in selected cultures, phycoerythrin (PE) and chlorophyll a concentrations were determined periodically throughout the growth cycle of the alga. Cultures were tested for bacterial contamination periodically during the experiment by inoculating tubes containing sterile $0.5 \%$ yeast extract in artificial seawater medium with 1 $\mathrm{ml}$ of the culture, and examining these tubes for bacterial growth.

Cell counts were determined from triplicate samples with counting chambers. A Sedgewick-Rafter counting chamber was used when cell counts were below $5 \times 10^{3}$ cells $\mathrm{ml}^{-1}$. A Fuchs-Rosenthal Ultra Plane chamber was used when cell counts were between $5 \times 10^{3}$ and $2 \times 10^{4}$ cells $\mathrm{ml}^{-1}$, and a Reichert Bright-Line hemacytometer was used for higher population densities. Counts obtained with the three chambers were normalized to each other by performing dilution series and comparing duplicate counts of a number of samples made with all three chambers, and normalizing to the Reichert Bright-Line estimates. Specific growth rates, $\mu$ (day $\left.{ }^{-1}\right)$, were determined from regressions of the linear portion of the growth curves expressed as the natural log of the population densities versus time (i. e., the exponential growth phase). 
Cell size was measured using a Coulter Multisizer particle counter with a $70 \mu \mathrm{m}$ aperture. PE was extracted by freeze-thawing in $0.05 \mathrm{M}$ phosphate buffer ( $\mathrm{pH}$ 6.8) (Thinh 1983, modified by Lewitus and Caron 1990). The concentration of PE was determined fluorometrically, using an SLM Aminco SPF-500C Spectrofluorometer (Lewitus and Caron 1990). For chlorophyll analyses, samples were filtered onto HA Millipore membrane filters (mean pore size $=0.45 \mu \mathrm{m}$ ) and then extracted with $90 \%$ acetone. Chlorophyll a concentrations were determined fluorometrically (HolmHansen et al. 1965) using a G. K. Turner III fluorometer.

Experiment 2: $\left[{ }^{14} \underline{\mathrm{C}] \text {-glycerol vs. }}\left[{ }^{14} \underline{\mathrm{C}]-\mathrm{NaHCO}} 3\right.\right.$ uptake

The uptake of $\left[{ }^{14} \mathrm{C}\right]-\mathrm{NaHCO}_{3}$ and $\left[{ }^{14} \mathrm{C}\right]$-glycerol (Sigma, uniformlylabeled, sterile filtered aqueous solution, $17.3 \mathrm{mCi} \mathrm{mmol}^{-1}$ ) was examined at 265 or $25 \mu \mathrm{E} \mathrm{m}^{-2} \mathrm{~s}^{-1}$. These two intensities are saturating or limiting, respectively, to photoautotrophic growth of $\underline{P}$ salina. After reaching a

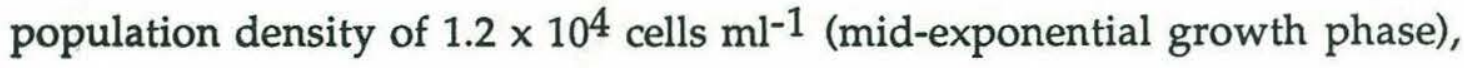
the cultures were divided into several $125-\mathrm{ml}$ glass erlenmeyer flasks. Replicate flasks were enriched with unlabeled glycerol (final concentration $=0.2 \mathrm{M}$ ), and these cultures were used for measuring the uptake of $\left[{ }^{14} \mathrm{C}\right]$ glycerol (final radioisotope concentration of $0.1 \mu \mathrm{Ci} \mathrm{m}-1$ ) or $\left[{ }^{14} \mathrm{C}\right]-\mathrm{NaHCO}_{3}$ (final radioisotope concentration of $1.0 \mu \mathrm{Ci} \mathrm{ml}-1$ ). Changes in population density and cell volume of the experimental treatments were estimated from "cold" replicates of these cultures (i. e., cultures with the same glycerol concentration but no radioactivity). $\left[{ }^{14} \mathrm{C}\right]-\mathrm{NaHCO}_{3}$ uptake, 
population density, and cell volumes also were measured in replicate flasks containing no glycerol $\left(\mathrm{CO}_{2}\right.$ fixation in the absence of organic substrates). Radiolabel uptake by cultures preserved with $1 \%$ glutaraldehyde were used as controls.

The time-course uptake of $\left[{ }^{14} \mathrm{C}\right]$ was determined from triplicate samples collected throughout the exponential growth phase of the algae. Radiolabeled cells were collected by gentle filtration ( $<5$ psi) onto $0.2 \mu \mathrm{m}$ Nuclepore membrane filters and rinsed three times with filtered seawater. After fuming the filters with concentrated $\mathrm{HCl}$, scintillation fluid (Biofluor) was added and the radioactivity measured by liquid scintillation counting on a Beckman LS 1801 instrument. The $\left[{ }^{14} \mathrm{C}\right]$ uptake rates were calculated based on the formula of Parsons et al. (1984), and using a weighted average of population density (Heinbokel 1978).

The cellular carbon and nitrogen content of cultures grown under identical conditions at a later time were determined from cells harvested during the mid-exponential growth phase. Particulate carbon and nitrogen were measured with a Perkin Elmer 240 elemental analyzer, after filtration onto pre-combusted Whatman GF/F glass-fiber filters.

In order to demonstrate the high potential for starch accumulation in $\underline{P}$ salina thin-section electron micrographs were compared between cells grown at $265 \mu \mathrm{E} \mathrm{m}^{-2} \mathrm{~s}^{-1}$ with $0.2 \mathrm{M}$ glycerol in the medium and at 25 $\mu \mathrm{E} \mathrm{m} \mathrm{m}^{-2} \mathrm{sec}^{-1}$ without glycerol. Cells harvested during the midexponential growth phase were fixed with glutaraldehyde (3\% final concentration) in cacodylate buffer ( $\mathrm{pH}$ 7.2) for 15 minutes. After repeated washes in buffer, cells were pelleted and resuspended in 3\% agar. Samples 
were postfixed in $1 \% \mathrm{OsO}_{4}$ in agar blocks for one hour, stained en bloc with uranyl acetate, dehydrated in a graded ethanol series, and embedded in Spurr's low-viscosity resin (Spurr 1969). Ultrathin sections were cut with a Sorvall MT-2B microtome. Electron microscopy was performed on a Zeiss 10 Electron Microscope operated at $80 \mathrm{kV}$. 


\section{RESULTS}

The growth of $\underline{P}$. salina in the absence of organic compounds was light-saturated at $105 \mu \mathrm{E} \mathrm{m}^{-2} \mathrm{~s}^{-1}\left(\mu \sim 1.2\right.$ day $\left.^{-1}\right)$, and decreased directly with light intensity below $105 \mu \mathrm{E} \mathrm{m}^{-2} \mathrm{~s}^{-1}$ (Table 1; Lewitus and Caron 1990). The addition of glucose to the culture medium did not significantly affect the growth rate of the alga at the light intensities tested (Table 1, Fig. 1). The growth rate in the presence of glycine was approximately equal to the rate of photoautotrophic cultures at two low light intensities, but was $46 \%$ lower at a high light intensity of $325 \mu \mathrm{E} \mathrm{m}^{-2} \mathrm{~s}^{-1}$ (Fig. 1). Ethanol also showed a marked inhibitory effect on growth rate at high light intensity (41\% decrease relative to photoautotrophic cultures). A mild inhibition of growth occurred at $105 \mu \mathrm{E} \mathrm{m}^{-2} \mathrm{~s}^{-1}$ for this organic substrate (Fig. 1). The inhibitory effect of ethanol or glycine on growth rate at $325 \mu \mathrm{E} \mathrm{m}^{-2} \mathrm{~s}^{-1}$ also was apparent in the growth yield. At this light intensity, the population density of stationary phase cultures grown with ethanol or glycine was approximately 10 -fold or 30 -fold less, respectively, than that of photoautotrophic cultures (data not shown).

Glycerol was the only organic compound used in this study to enhance the growth rate relative to photoautotrophic cultures, but this effect was light intensity-dependent. The growth rate of $\underline{P}$. salina at $15 \mu \mathrm{E}$ $\mathrm{m}^{-2} \mathrm{~s}^{-1}$, for example, was 2 times the rate with $0.2 \mathrm{M}$ or $0.5 \mathrm{M}$ glycerol in the culture medium than at the same light intensity without glycerol (Table 1, Fig. 2) These concentrations completely inhibited growth at 325 
$\mu \mathrm{E} \mathrm{m} \mathrm{m}^{-2} \mathrm{~s}^{-1}$. Intermediate light intensities had intermediate effects on growth rate (Fig. 2).

The degree to which glycerol addition inhibited the growth of $\underline{P}$. salina was dependent on the glycerol concentration of the medium. The growth rates of cultures grown with $0.2 \mathrm{M}$ or $0.5 \mathrm{M}$ glycerol, as stated above, decreased with increasing light intensity above $105 \mu \mathrm{E} \mathrm{m}^{-2} \mathrm{~s}^{-1}$ (Fig. $3 \mathrm{~A})$. The growth rates of cultures grown with $0.005 \mathrm{M}$ or $0.055 \mathrm{M}$ glycerol were relatively unchanged at intensities greater than $105 \mu \mathrm{E} \mathrm{m}^{-2} \mathrm{~s}^{-1}$, and were only slightly less than the growth rates of photoautotrophic cultures at these light levels. Glycerol addition to cultures grown at low light intensities ( 25 or $15 \mu \mathrm{E} \mathrm{m}^{-2} \mathrm{~s}^{-1}$ ) enhanced growth in almost all treatments relative to photoautotrophic growth (Fig. 3B).

A separate experiment was conducted in order to examine whether the inhibitory effect of $0.2 \mathrm{M}$ glycerol and high light intensity could be relieved by growing the cultures under a 12 hour light/12 hour dark cycle. After acclimation to continuous light or light/dark conditions, photoautotrophically growing cultures in the exponential growth phase were transferred to fresh media with or without $0.2 \mathrm{M}$ glycerol. Glycerol addition was equally inhibitory to growth under continuous light and light/dark conditions (Fig. 4).

The average cell volume of exponentially growing $\underline{P}$. salina was directly related to light intensity (Fig. 5). The average volumes of all cultures grown at $265 \mu \mathrm{E} \mathrm{m}^{-2} \mathrm{~s}^{-1}$ were greater than 1.5 times that of cultures grown at $15 \mu \mathrm{E} \mathrm{m}^{-2} \mathrm{~s}^{-1}$, regardless of the glycerol concentration of 
Table 1 Effect of organic compound additions on the mean specific growth rate (day $\left.{ }^{-1}\right)$ of $\underline{P}$. salina cultures grown under different light intensities. $\mathrm{N}$ is the number of replicate cultures. SE is the standard error of the mean. NG $=$ no growth.

\section{LIGHT INTENSITY $\left(\mu \mathrm{E} \mathrm{m-2} \mathrm{s}^{-1}\right)$}

\begin{tabular}{llllll}
\hline 325 & 265 & 190 & 105 & 25 & 15
\end{tabular}

\begin{tabular}{|c|c|c|c|c|c|c|c|c|c|c|c|c|c|c|c|c|c|c|}
\hline $\begin{array}{c}\text { Culture } \\
\text { Treatment }\end{array}$ & $\mathrm{N}$ & Mear & SE & $\mathrm{N}$ & Mean & SE & $\mathrm{N}$ & Mean & SE & $\mathrm{N}$ & Mean & SE & $\mathrm{N}$ & Mean & SE & $\mathrm{N}$ & Mea & $\mathrm{SE}$ \\
\hline Jo Organics & 15 & 1.23 & 0.03 & 12 & 1.20 & 0.03 & 3 & 1.20 & 0.06 & 23 & 1.24 & 0.02 & 5 & 0.35 & 0.01 & 6 & 0.15 & 0.01 \\
\hline 0.5 M Glycerol & 1 & NG & & 1 & 0.34 & & 2 & 0.48 & 0.02 & 1 & 0.50 & & 1 & 0.40 & & 2 & 0.30 & 0.00 \\
\hline 0.2 M Glycerol & 4 & NG & & 2 & 0.42 & 0.03 & 1 & 0.67 & & 4 & 1.06 & 0.04 & 5 & 0.55 & 0.02 & 3 & 0.35 & 0.02 \\
\hline .055 M Glycer. & 2 & 1.02 & 0.05 & 4 & 1.13 & 0.08 & 4 & 1.01 & 0.03 & 4 & 1.04 & 0.04 & 2 & 0.66 & 0.01 & 2 & 0.31 & 0.03 \\
\hline 0.005 M Glycer. & 2 & 1.06 & 0.01 & 4 & 1.09 & 0.06 & 4 & 1.13 & 0.07 & 4 & 1.18 & 0.05 & 2 & 0.49 & 0.01 & 2 & 0.17 & 0.01 \\
\hline 0.25 M Glucose & 3 & 1.23 & 0.07 & & & & & & & 3 & 1.20 & 0.08 & 3 & 0.32 & 0.02 & 1 & 0.21 & \\
\hline $13 \mathrm{M}$ Ethanol & 2 & 0.73 & 0.06 & & & & & & & 2 & 0.84 & 0.01 & 2 & 0.31 & 0.01 & 1 & 0.12 & \\
\hline 0.3 M Glycine & 1 & 0.66 & & & & & & & & 2 & 1.25 & 0.05 & 1 & 0.37 & & & & \\
\hline 0.1 M Glycine & & & & & & & & & & 1 & 1.10 & & & & & & & \\
\hline 0.03 M Glycine & & & & & & & & & & 1 & 1.18 & & & & & & & \\
\hline .003 M Glycine & & & & & & & & & & 1 & 1.35 & & & & & & & \\
\hline
\end{tabular}


Figure 1. Specific growth rate of $\underline{P}$. salina at 325,105 , or $25 \mu \mathrm{E} \mathrm{m}^{-2} \mathrm{~s}^{-1}$ without organic compounds (gray), with $0.2 \mathrm{M}$ glucose (diagonals), with $0.13 \mathrm{M}$ ethanol (white), or with $0.03 \mathrm{M}$ glycine (horizontal lines). Values are the means of replicate cultures and error bars indicate the standard error of the mean (see Table 1). 


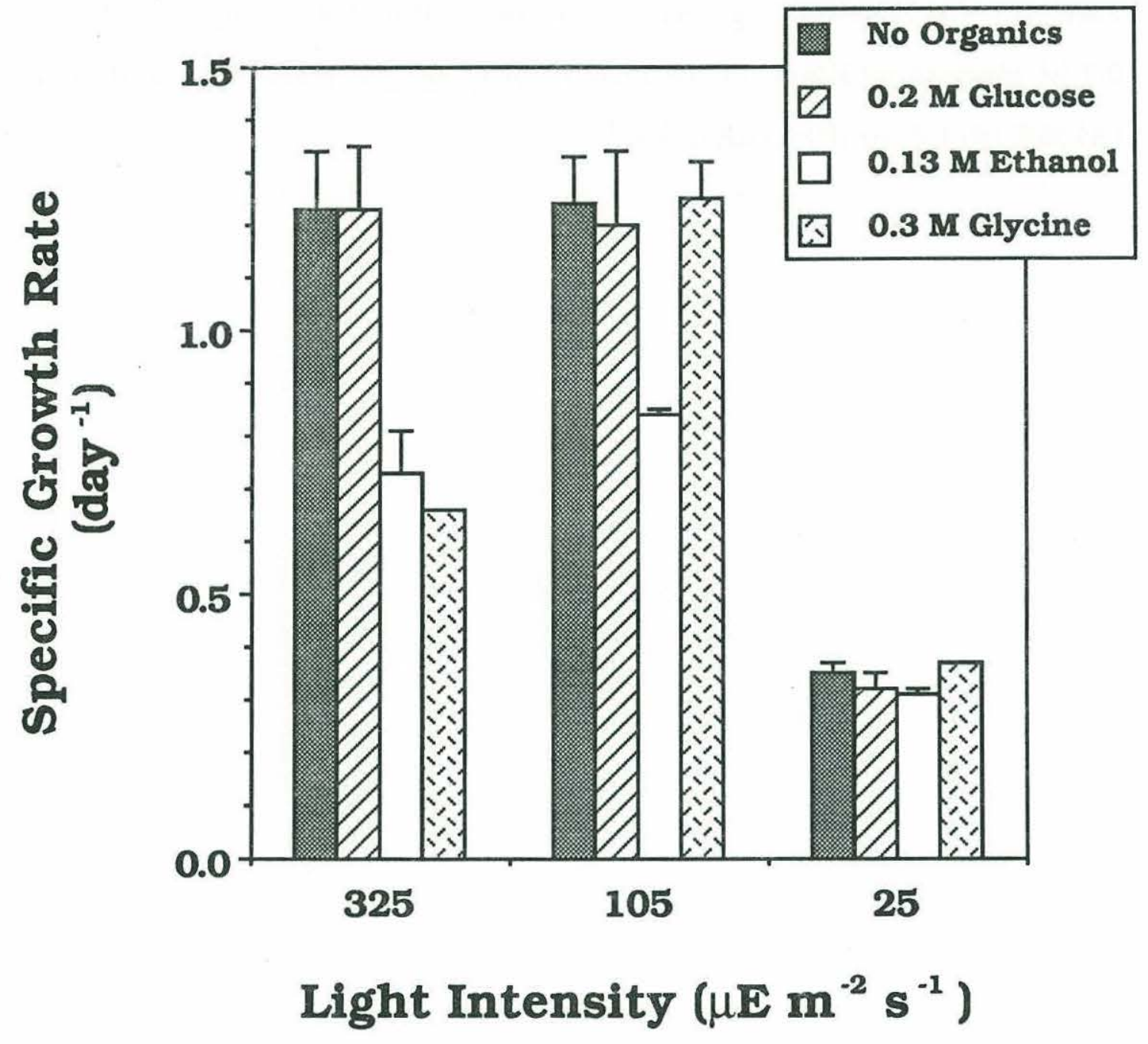


Figure 2. Representative growth curves (see Table 1) showing the effect of $0.2 \mathrm{M}$ glycerol addition on the growth of $\underline{\mathrm{P}}$. salina in continuous light at (A) 325 , (B) 105 , or (C) $15 \mu \mathrm{E} \mathrm{m}^{-2} \mathrm{~s}^{-1}$. 


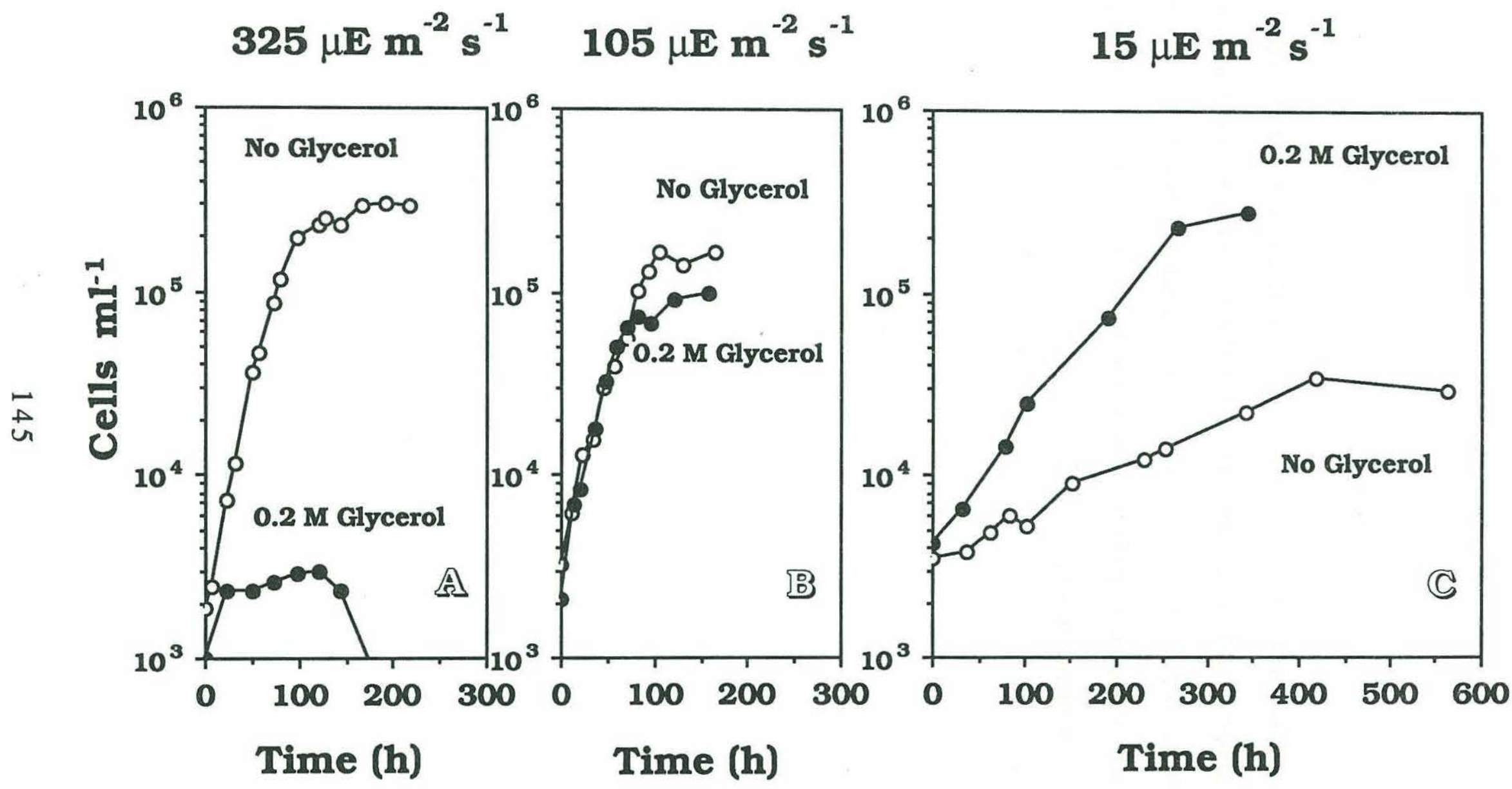


Figure 3. Effect of irradiance on the specific growth rate of $\underline{P}$. salina at different glycerol concentrations. Data are shown (A) from all irradiances or (B) from 15 and $25 \mu \mathrm{E} \mathrm{m}^{-2} \mathrm{~s}^{-1}$ on expanded scales. Values are, in most cases, means of replicate cultures (see Table 1) and error bars indicate the standard error of the mean. 


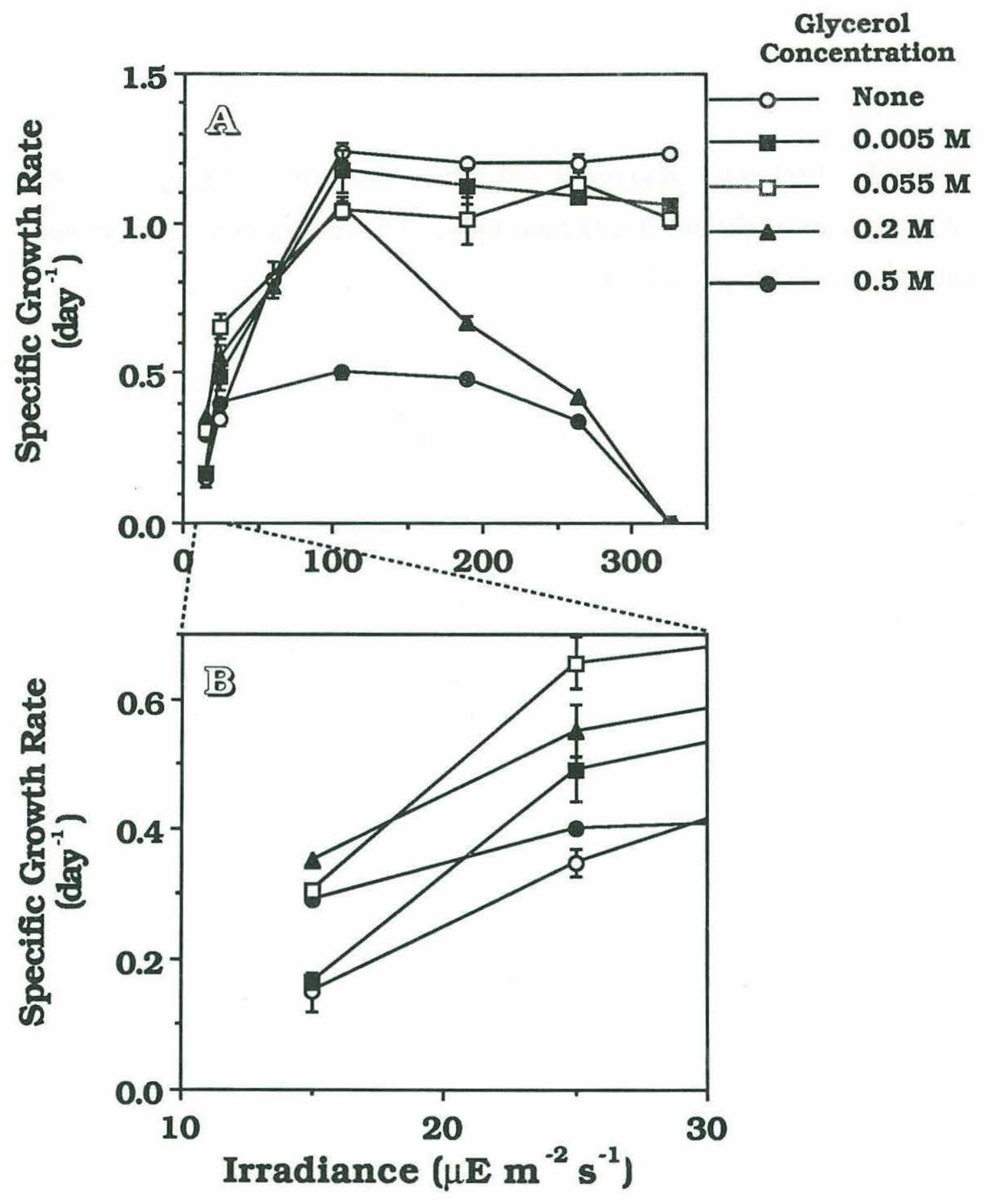


Figure 4. Effect of $0.2 \mathrm{M}$ glycerol addition on the growth of $\underline{P}$. salina under (A) continuous light or (B) a 12 hour light/12 hour dark cycle. The growth irradiance was $325 \mu \mathrm{E} \mathrm{m}^{-2} \mathrm{~s}^{-1}$. 
Continuous Light

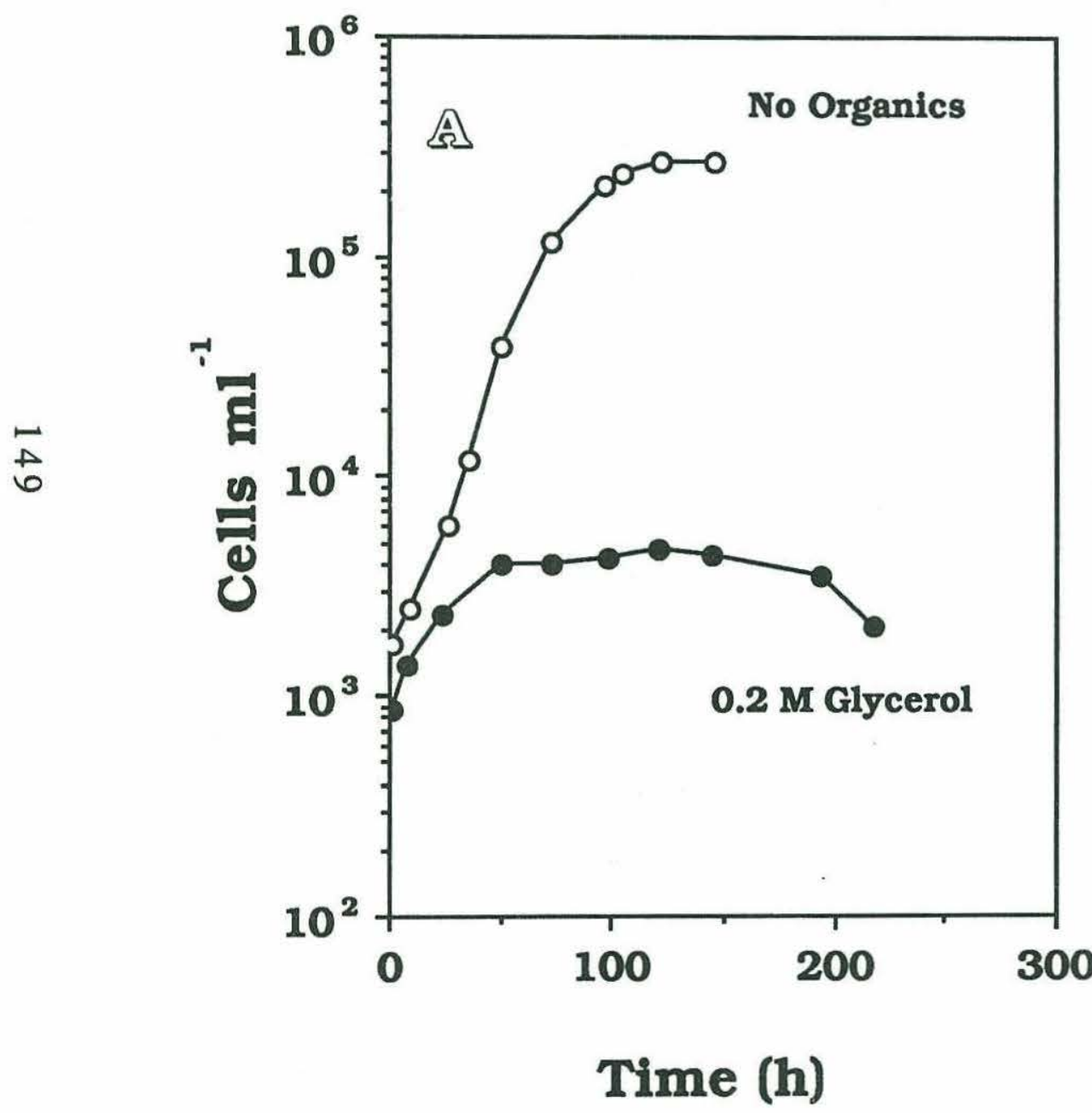

Light/Dark Cycle

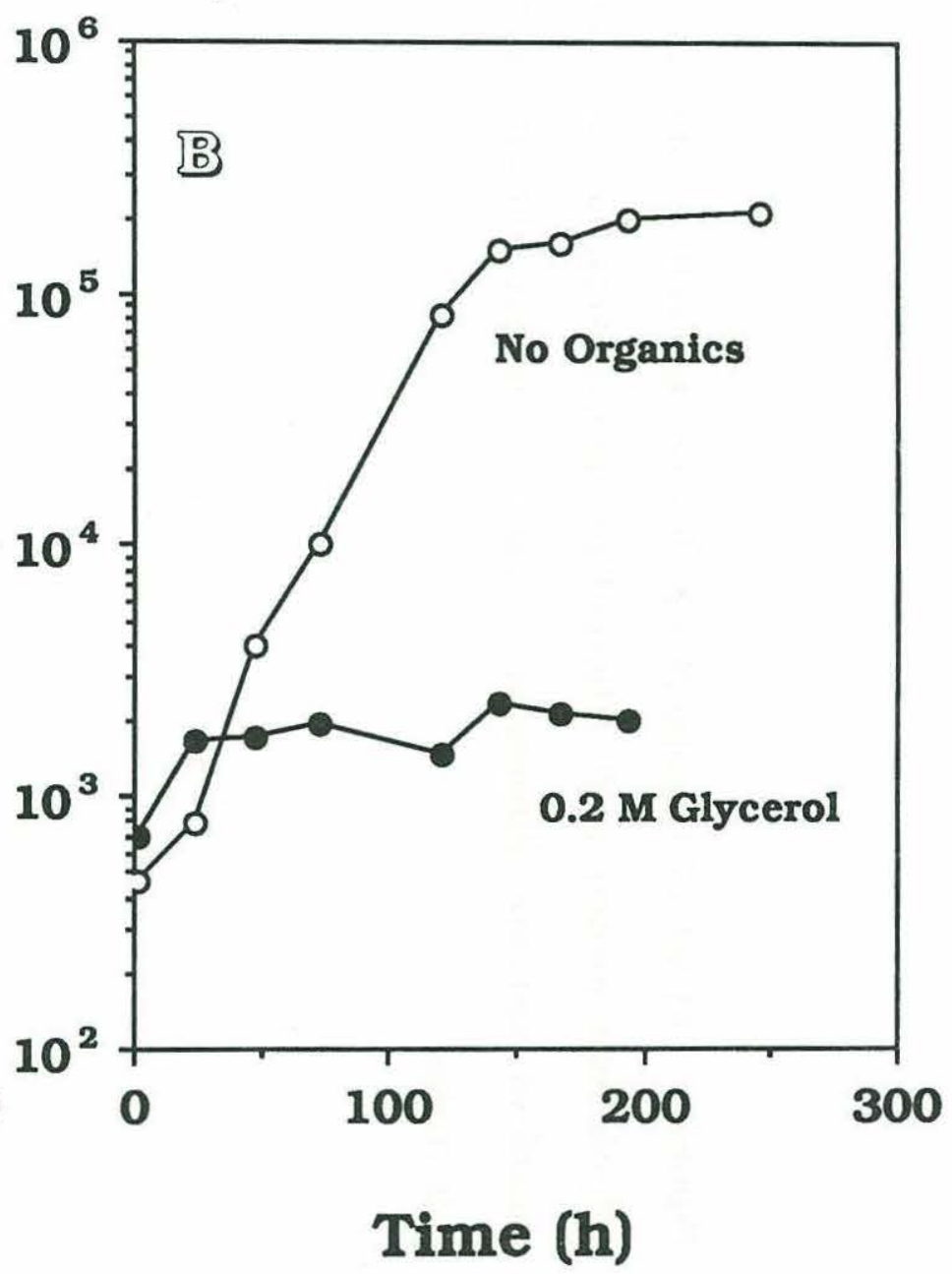


Figure 5. Effect of irradiance on the average cell volume of $\underline{P} \cdot \underline{\text { salina }}$ populations grown with different glycerol concentrations. Values are means of replicate cultures and error bars indicate the standard error of this mean. 


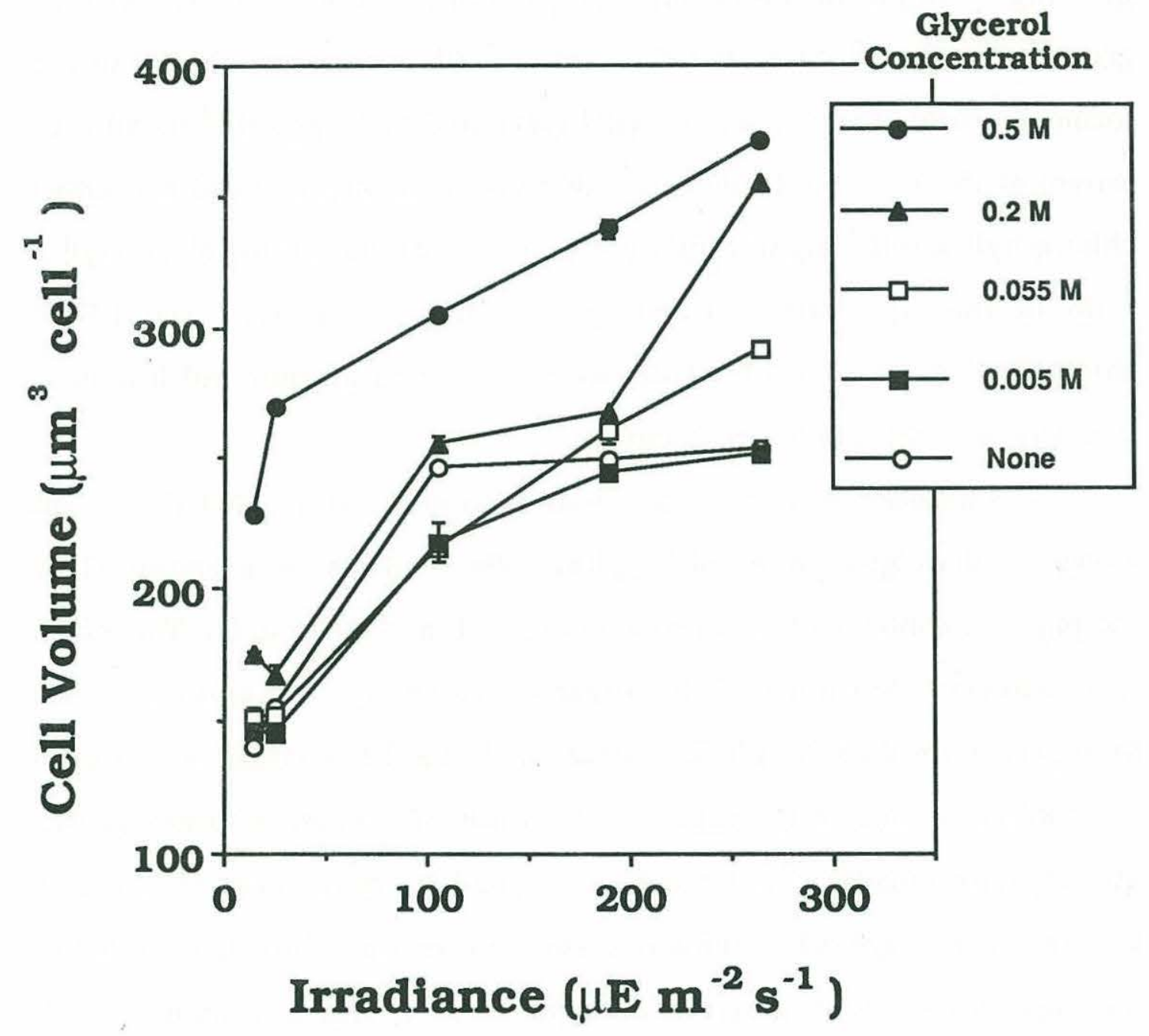


the medium. Cell size also increased with glycerol concentration, but the effect was most pronounced for the $0.5 \mathrm{M}$ treatment.

The phycoerythrin concentration cell-1 of photoautotrophically growing $\underline{P}$. salina in the exponential growth phase was nearly twice as great at $25 \mu \mathrm{E} \mathrm{m}^{-2} \mathrm{~s}^{-1}$ as at $325 \mu \mathrm{E} \mathrm{m}^{-2} \mathrm{~s}^{-1}$ (data not shown). PE in the former cultures averaged $4.9 \mathrm{pg}^{\text {cell }}{ }^{-1}$ compared to $2.7 \mathrm{pg}^{-1 \mathrm{l}^{-1}}$ in cultures grown at the high light intensity. Because light intensity did not affect chlorophyll $\underline{\text { a cell }}{ }^{-1}$ significantly (t-test, $\left.\underline{\mathrm{P}}<0.05\right)$, the PE to chlorophyll $\underline{\mathrm{a}}$ ratio in the alga varied inversely with light intensity. The PE to chlorophyll a ratios of photoautotrophic $\underline{\mathrm{P}}$. salina at high and low light intensity were 4.1 and 6.7 , respectively.

The addition of organic compounds to the medium had significant effects on the pigmentation of $\underline{P}$. salina. These effects are exemplified by the pigment contents of cells growing at $25 \mu \mathrm{E} \mathrm{m}^{-2} \mathrm{~s}^{-1}$ (Fig. 6). This effect was somewhat dependent on the organic compound. The addition of 0.2 $\mathrm{M}$ glycerol or $0.25 \mathrm{M}$ glucose decreased the PE content and PE to chlorophyll $\underline{\text { a }}$ ratio of $\underline{P} . \underline{\text { salina. }}$. The greater PE content of algae grown photoautotrophically could not be explained by differences in cell size because the average cell volume in these cultures was equivalent to that of the algae grown with glucose (data not shown) and less than the cell volume of algae grown with glycerol (Fig. 5). The cell PE to chlorophyll a ratio of the glucose-enriched culture was approximately one half the ratio for the glycerol-enriched cultures and one third the ratio for photoautotrophically grown cultures. The addition of $0.13 \mathrm{M}$ ethanol resulted in increases in PE and chlorophyll a concentrations cell-1 but, 
because the average cell volume of this culture was $20 \%$ higher than that of photoautotrophically grown cells, there was only a slight difference in pigment concentrations cell volume-1 between the treatments. Nevertheless, ethanol addition resulted in a $25 \%$ decrease in the PE to chlorophyll a ratio of the cells.

Light intensity dramatically affected the rate of uptake of $\mathrm{CO}_{2}$ by the alga, but not the rate of uptake of glycerol carbon (Fig. 7). The $\mathrm{CO}_{2}$ uptake rate of cells grown at $265 \mu \mathrm{E} \mathrm{m}^{-2} \mathrm{~s}^{-1}$ was more than 4 times the rate of cells grown at $25 \mu \mathrm{E} \mathrm{m}^{-2} \mathrm{~s}^{-1}$. The addition of glycerol had no effect on the $\mathrm{CO}_{2}$ uptake rate cell-1 at either light intensity.

The incorporation of glycerol carbon greatly exceeded $\mathrm{CO}_{2}$ incorporation in $\underline{P}$ salina cultures grown at the low light intensity (Fig. 7B) and greatly exceeded the calculated carbon requirements of the alga. Although glycerol addition increased the growth rate and slightly increased the average cell volume of cultures at this light level (Table 2), changes in these latter parameters could not account for the large amount of glycerol carbon incorporated in this treatment. The carbon content of

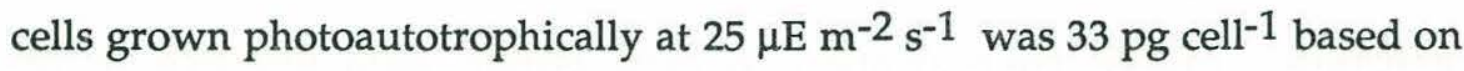
the particulate carbon and nitrogen measurements of the cultures. Assuming that the 1.1-fold increase in average cell volume that resulted from glycerol addition was strictly related to the incorporation of carbon, the calculated carbon content of cells grown with glycerol at the low light intensity would have been $37 \mathrm{pg}$ cell- ${ }^{-1}$. Based on the rate of $\left[{ }^{14} \mathrm{C}\right]-\mathrm{CO}_{2}$ incorporation by $\underline{\underline{P}}$ salina in this treatment, $\mathrm{CO}_{2}$ uptake can account for the acquisition of $18 \mathrm{pg} \mathrm{C}^{-1}$ in one population doubling time (Table 2). 
The amount of glycerol carbon taken up at this light level, $185 \mathrm{pg}^{\mathrm{p}} \mathrm{cell}^{-1}$ doubling time -1 , far exceeded the carbon required to produce the remaining $19 \mathrm{pg} \mathrm{cell}^{-1}$.

These $\left[{ }^{14} \mathrm{C}\right]$ incorporation measurements and estimated carbon requirements of the alga imply that tremendous changes in the chemical composition of the cells took place in cultures grown with glycerol. These changes were apparent visually by the presence of large accumulations of storage products in the cells cultured with glycerol (Fig. 8), and in the extremely high carbon-to-nitrogen (C:N) ratios of the algae grown with glycerol relative to the C:N ratios of cells cultured photoautotrophically (Table 2). The increase in the cellular C:N ratio that resulted from glycerol addition to cultures grown at the low light intensity was related not only to a tremendous (963\%) increase in carbon content cell-1 but to a $45 \%$ decrease in nitrogen content cell-1 ${ }^{-1}$ (Table 2).

Although the cellular carbon content (as calculated based on measurements from the elemental analyzer) of $\underline{P}$. salina grown photoautotrophically could be accounted for by the uptake of $\mathrm{CO}_{2}$, the calculated carbon concentration of cells grown with glycerol in the medium was much greater than the combined uptake of inorganic and glycerol carbon in one generation time (Table 2). It's possible that a portion of the particulate carbon measured in this study was derived from starch bodies liberated from the alga and retained by the glass-fiber filter. The production of starch bodies by $\underline{\underline{P}}$. salina and subsequent release of these particles by autolysis has been observed in cultures grown in the light with glycerol (Antia et al. 1979, this study) but the release of starch 
particles has not been observed in exponentially growing photoautotrophic cells. It is possible, therefore, that the calculated carbon contents of cells grown with glycerol in the medium are overestimates. Nevertheless, that the cellular C:N ratio increased substantially after glycerol addition is indicated by the relatively high cellular starch content (Fig. 8), the relatively low cellular nitrogen content (Table 2), and the high rate of glycerol carbon uptake cell-1 (Table 2) in the cultures grown with glycerol.

Glycerol addition to the cultures growing at the high light intensity caused a slight increase in the average cell volume of the algae but did not affect the growth rate (Table 2). The rate of $\mathrm{CO}_{2}$ incorporation by cells grown at this light level accounted for the calculated cellular carbon requirement of the algae. Similar to the patterns found in the cultures grown at the low light intensity, glycerol addition to cultures grown at the high light intensity resulted in substantial increases in the cellular C:N ratio and carbon content cell-1 and a decrease in the nitrogen content cell-1 (Table 2). 
Figure 6. Effects of organic compound additions on the cellular (A) phycoerythrin content, (B) chlorophyll a content, or (C) phycoerythrin to

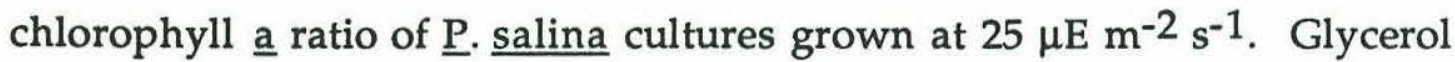
was added at $0.2 \mathrm{M}$, glucose at $0.25 \mathrm{M}$, and ethanol at $0.13 \mathrm{M}$. Error bars indicate the standard error of means from replicate cultures. 

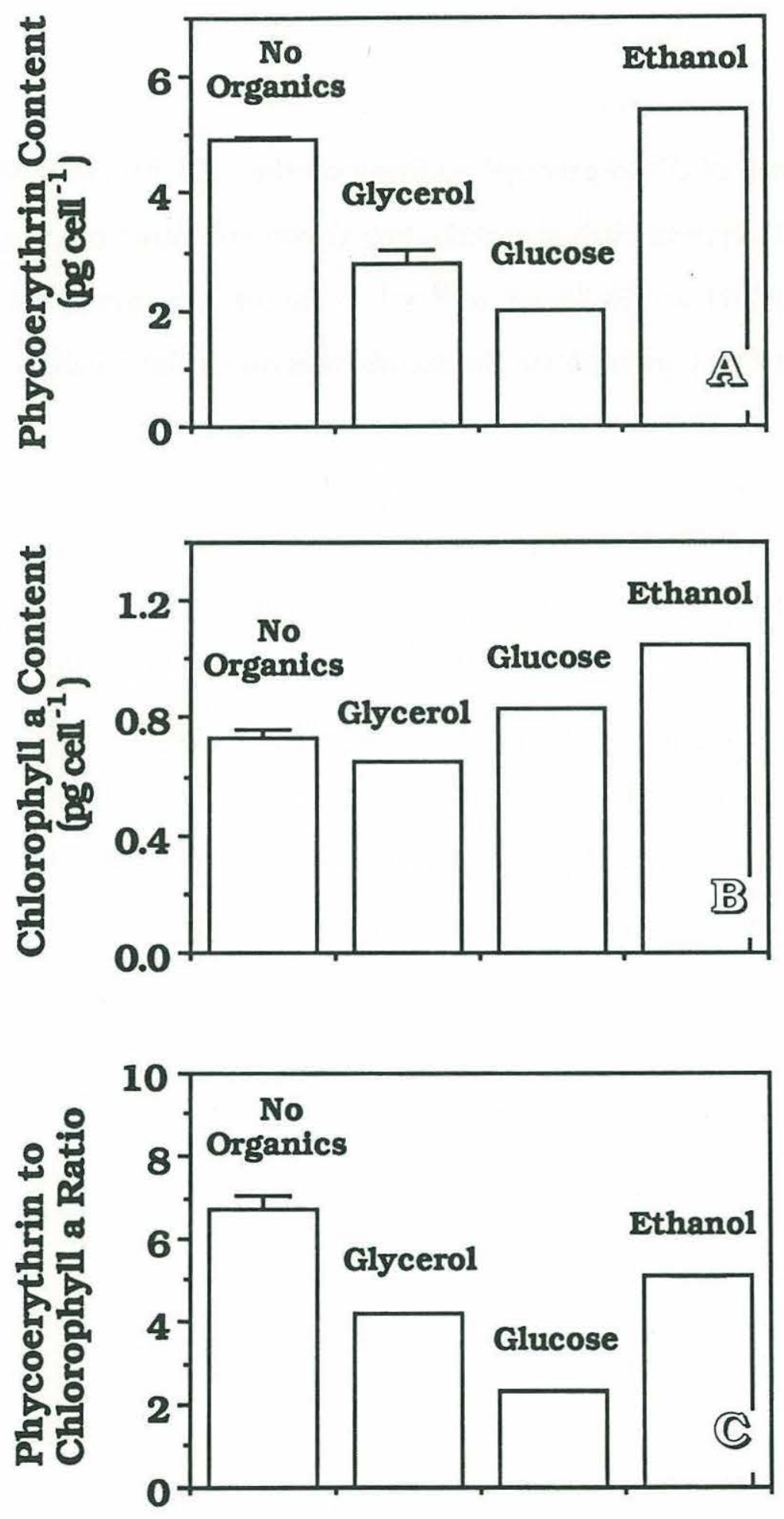
Figure 7. Effect of $0.2 \mathrm{M}$ glycerol addition on the $\mathrm{CO}_{2}$ uptake rate (shaded columns) and glycerol carbon uptake rate (open columns) of $\underline{P}$. $\underline{\text { salina }}$ cells grown at (A) 265 or (B) $25 \mu \mathrm{E} \mathrm{m}^{-2} \mathrm{~s}^{-1}$. Values are means of replicate cultures and error bars indicate the standard error of the mean. 

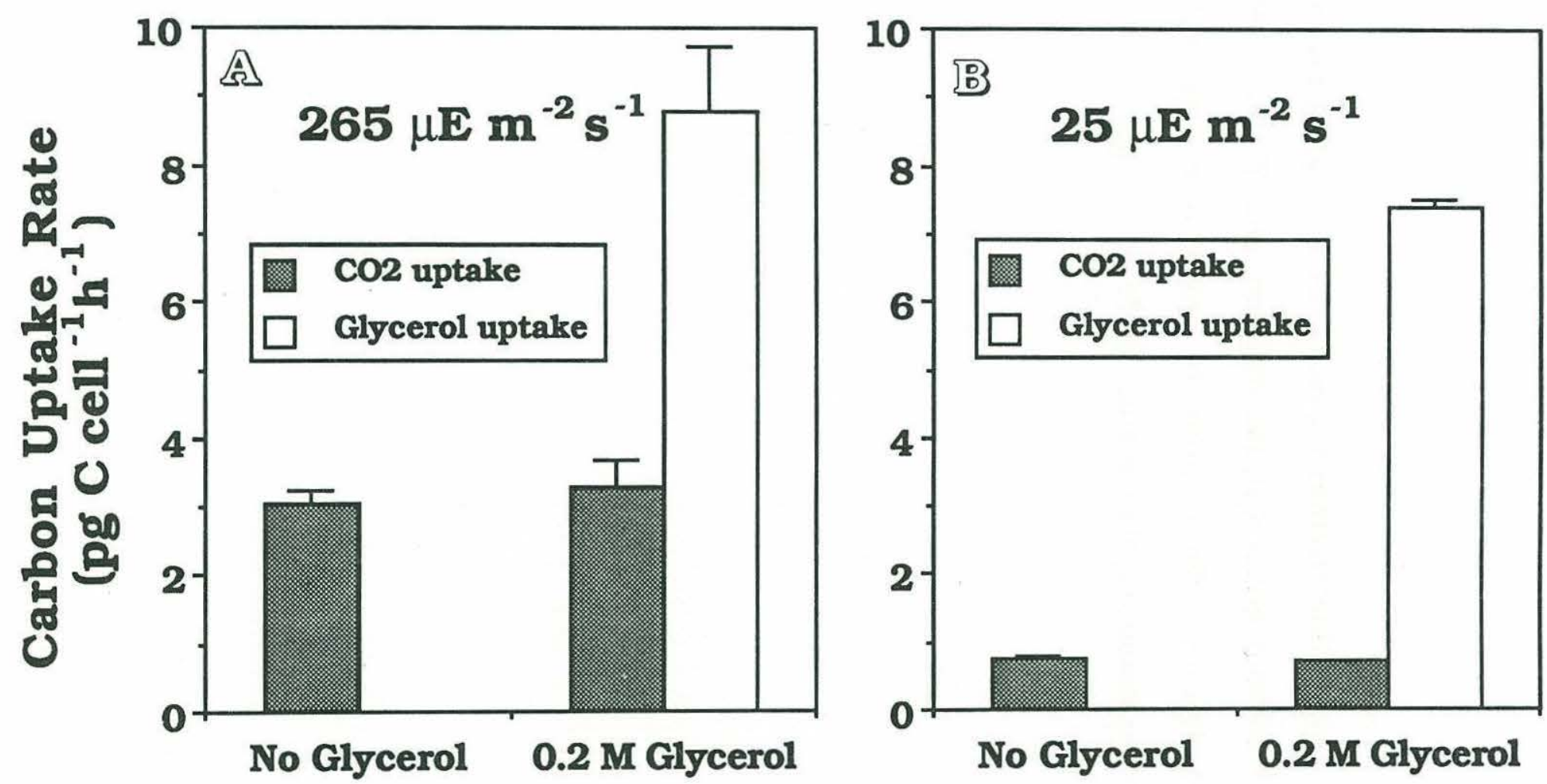
Figure 8. Thin-section electron micrographs of $\underline{P}$. salina grown $(A, B)$ at 25 $\mu \mathrm{E} \mathrm{m}^{-2} \mathrm{~s}^{-1}$ without glycerol in the medium, and (C, D) at $265 \mu \mathrm{E} \mathrm{m}^{-2} \mathrm{~s}^{-1}$ with $0.2 \mathrm{M}$ glycerol in the medium. $\mathrm{N}=$ nucleus; $\mathrm{P}=$ pyrenoid; $\mathrm{S}=$ starch bodies; $\mathrm{T}=$ thylakoid membrane area. Scale bar $=1 \mu \mathrm{m}$. 

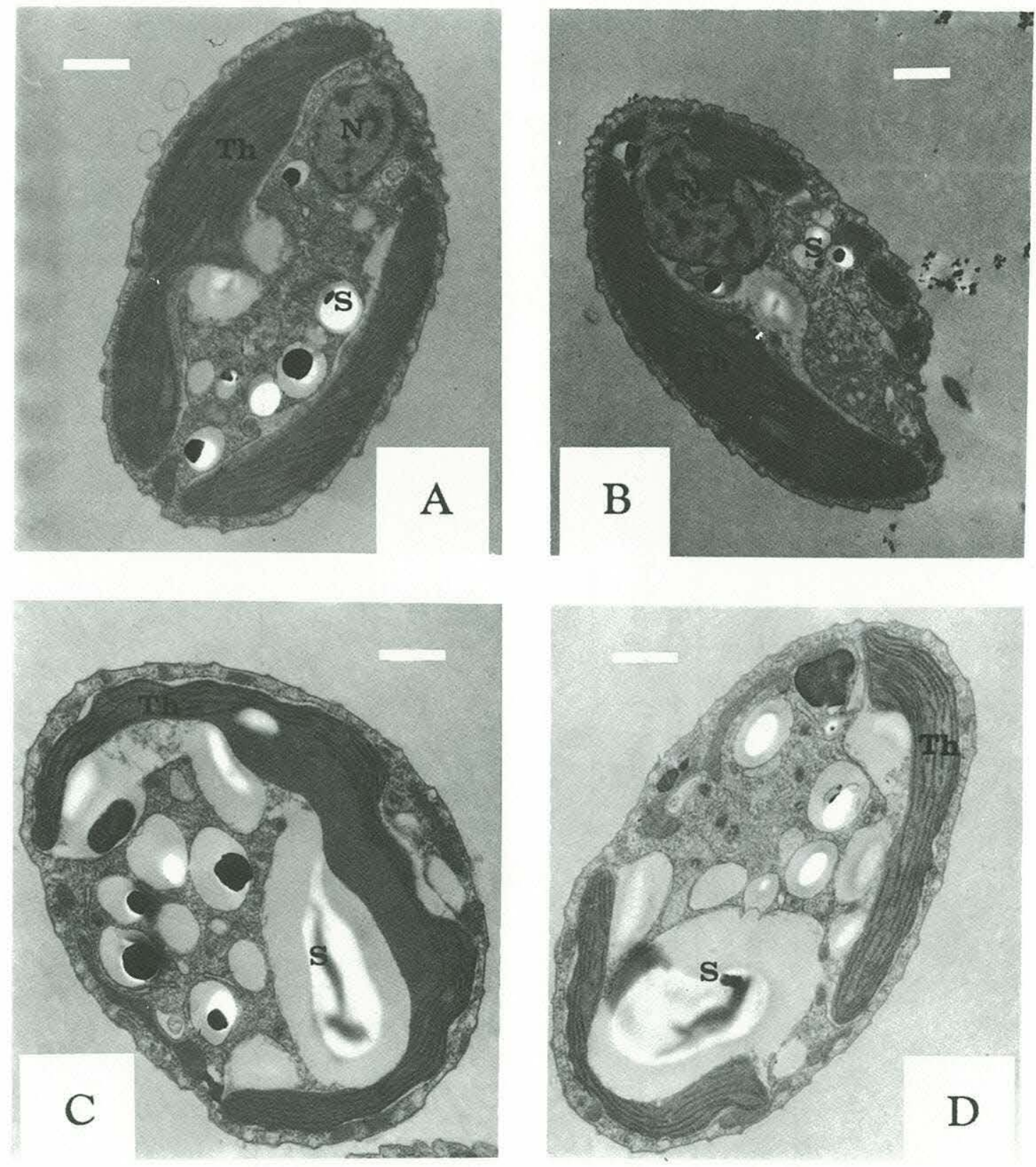
Table 2 Effects of light intensity and $0.2 \mathrm{M}$ glycerol addition on the population doubling time, average cell volume, carbon content cell-1, nitrogen content cell ${ }^{-1}$, cellular carbon to nitrogen ratio, and carbon uptake cell-1 $\left(\mathrm{CO}_{2}\right.$, glycerol, or total) in one population doubling time. High and Low Light intensities were 265 and $25 \mu \mathrm{E} \mathrm{m}^{-2} \mathrm{~s}^{-1}$, respectively.

\begin{tabular}{|c|c|c|c|c|c|c|c|c|}
\hline \multirow[t]{2}{*}{ Treatment } & \multirow[t]{2}{*}{$\begin{array}{l}\text { Doubling } \\
\text { Time (h) }\end{array}$} & \multirow[t]{2}{*}{$\begin{array}{l}\text { Cell volume } \\
\left(\mu \mathrm{m}^{3} \text { cell }^{-1}\right)\end{array}$} & \multirow[t]{2}{*}{$\begin{array}{l}\text { Carbon } \\
\left(\mathrm{pg} \text { cell- }^{-1}\right)\end{array}$} & \multirow[t]{2}{*}{$\begin{array}{l}\text { Nitrogen } \\
\left(\mathrm{pg} \text { cell}^{-1}\right)\end{array}$} & \multirow[t]{2}{*}{$\begin{array}{l}\text { Carbon to } \\
\text { Nitrogen }\end{array}$} & \multicolumn{3}{|c|}{$\begin{array}{c}\text { Carbon Uptake Cell-1 } \\
\text { Doubling Time }{ }^{-1} \text { (pg C cell-1) }\end{array}$} \\
\hline & & & & & & $\mathrm{CO}_{2}$ & Glycerol & Total \\
\hline High Light & 15 & 250 & 47 & 11.4 & 4 & 45 & & 45 \\
\hline High Light + Glycerol & 15 & 264 & 315 & 10.0 & 32 & 49 & 132 & 181 \\
\hline Low Light & 38 & 133 & 33 & 8.1 & 4 & 28 & & 28 \\
\hline Low Light + Glycerol & 125 & 151 & 351 & 4.4 & 80 & 18 & 185 & 203 \\
\hline
\end{tabular}




\section{DISCUSSION}

Based on the patterns of $\mathrm{CO}_{2}$ and glycerol carbon uptake observed in this study, it's hypothesized that $\underline{P}$. salina cells utilized glycerol for at least two purposes; 1) as a source of energy and/or reductant at low light intensity to maintain $\mathrm{CO}_{2}$ fixation rates and increase cell division rates, and 2) as a source of carbon to partially fulfill the cellular carbon requirement for growth at the low light intensity and increase the production of reserve carbohydrate (starch) at both high and low light intensities. The addition of $0.2 \mathrm{M}$ glycerol (as well as $0.13 \mathrm{M}$ ethanol and $0.25 \mathrm{M}$ glucose) to $\underline{\mathrm{P}}$. salina cultures growing at $25 \mu \mathrm{E} \mathrm{m}^{-2} \mathrm{~s}^{-1}$ caused significant decreases in the mean cell PE to chlorophyll a ratio (Fig. 6). This is consistent with the earlier observations that glycerol assimilation by $\underline{P}$. salina caused a selective inhibition of the synthesis of lightharvesting components (Lewitus et al. subm.), and implies that ethanol and glucose may have a similar effect. Because glycerol addition did not affect the cellular $\left[{ }^{14} \mathrm{C}\right]-\mathrm{NaHCO}_{3}$ uptake rate at $25 \mu \mathrm{E} \mathrm{m}^{-2} \mathrm{~s}^{-1}$, however, a reduction in light-harvesting components apparently did not affect the cryptophyte's ability to fix $\mathrm{CO}_{2}$ under light-limiting conditions (Table 2;

Figs. 6, 7). The growth of nutrient-replete photoautotrophic cells at subsaturating light levels presumably is limited by the cell's ability to absorb and photochemically convert light to ATP and reductant, and not by the carbon substrate availability (Larkum and Barrett 1983). Glycerol increased the growth rate of $\underline{P}$. salina cultures growing at $25 \mu \mathrm{E} \mathrm{m}^{-2} \mathrm{~s}^{-1}$ and did not affect the cellular $\mathrm{CO}_{2}$ uptake rate, despite reducing the cellular 
light-harvesting potential. From these results it's concluded that, at this light intensity, glycerol catabolism somehow compensated for the reduction in pigment concentration and it's speculated that perhaps this was accomplished by fulfilling ATP and reductant requirements for growth and $\mathrm{CO}_{2}$ fixation.

Glycerol addition to cultures grown at the saturating light intensity of $265 \mu \mathrm{E} \mathrm{m}^{-2} \mathrm{~s}^{-1}$ did not increase the growth rate in Experiment 2. At saturating light intensities, photosynthesis presumably is limited by the turnover of Calvin cycle enzymes (e. g. ribulose 1,5-bisphosphate carboxylase), and not by the rate of ATP and reductant production (Farquhar and Von Caemmerer 1982). Based on this reasoning, augmenting the cellular supply of ATP or reducing compounds by glycerol catabolism should not have affected $\underline{P}$. salina's growth at the saturating light intensity. This situation was observed for $\underline{P}$. salina.

The addition of some organic compounds to cultures growing at saturating light levels actually inhibited the growth of $\underline{P}$. salina. This growth inhibition caused by the interaction of high light intensity and high organic substrate concentration is difficult to explain, but may be related to an enhanced susceptibility to photoinhibition caused by organic substrate assimilation. Organic substrates can inhibit the synthesis of proteins directly involved in photoprotection (e. g. carotenoids, Harris and Kirk 1969), proteins involved in $\mathrm{CO}_{2}$ fixation (e. g. ribulose 1,5bisphosphate carboxylase, Hase 1971), or proteins involved in photorespiration (e. g. phosphoglycolate phosphatase, James and Schwartzbach 1982). If protein synthesis was inhibited, reduced cellular 
concentrations of proteins in the latter two classes may have limited the cell's ability to remove excess oxygen and/or ATP, thus increasing the potential for photooxidative damage (Heber and Krause 1980).

The growth and cell volume of $\underline{P}$. salina in $0.2 \mathrm{M}$ glycerol and grown at $265 \mu \mathrm{E} \mathrm{m}^{-2} \mathrm{~s}^{-1}$ were not dramatically affected in Experiment 2 as they were in Experiment 1. The magnitude of growth inhibition caused by the combination of high light and high glycerol concentration appears to be related to the population density of the cultures at the time of glycerol addition. In Experiment 1, cultures were transferred into fresh media containing glycerol to give initial population densities of approximately $10^{3}$ cells $\mathrm{ml}^{-1}$. In Experiment 2, glycerol was added to cultures with population densities of approximately $1.2 \times 10^{4}$ cells ml-1. The presence of $0.2 \mathrm{M}$ glycerol in the culture medium inhibited the growth and caused a 1.4-fold increase in the average cell volume of $\underline{P}$. salina in Experiment 1 (Table 1, Fig. 5) but did not change the growth rate and only slightly increased the average cell volume of the alga in Experiment 2 (Table 2). A possible explanation for these different physiological responses is that culture self-shading effects may have limited the amount of light available to the algae grown at high light intensity in Experiment 2. This reasoning is consistent with the hypothesis that the addition of organic substrates acts to increase the susceptibility of $\underline{P}$. salina to photooxidative damage, and may explain the complex effects of substrate concentration and light intensity on the growth of this alga (Fig. 3).

Glycerol addition to $\underline{P}$. salina cultures at high light intensity was associated with distinct changes in cellular morphology and composition. 
Glycerol addition was always accompanied by enhanced cell starch production. This effect was clear from electron micrographs (Fig. 8, Lewitus et al. subm.) and from the higher C:N ratios of the alga grown in the presence of glycerol. Starch production resulted in a slightly larger cell size and a much greater percentage of the cytoplasm filled by starch. The C:N ratio of $\underline{P}$. salina increased substantially when glycerol was added to the medium, and this was related to both an increase in cellular carbon content and decrease in cellular nitrogen content (Table 2). This dramatic change in the chemical composition of $\underline{P}$. salina in response to glycerol assimilation is in agreement with the results of previous studies. Rodríguez-López (1965) noted that the weight ratio of protein to carbohydrate content of Chlorella pyrenoidosa decreased by an order of magnitude due to both a 3.7-fold increase in carbohydrate content and 3.6fold decrease in protein content when the alga was grown in the presence of assimilable organic compounds. Antia et al. (1973) observed that $\underline{P}$. salina grown in the light with $0.25 \mathrm{M}$ glycerol accumulated starch and lipid which led to gigantism, rapid degeneration of the cytoplasm, and eventual autolysis. The overproduction of starch suggests that an imbalance between carbohydrate and protein synthesis occurred in $\underline{P}$. salina. This behavior was attributed to nutrient depletion in previous work, because gigantism occurred in the later stages of exponential growth and readdition of nitrogen to the culture medium restored growth and pigment production by $\underline{\underline{P}}$. salina (Antia et al. 1973, Antia 1980). The results of the present study, however, indicate that at light intensities greater than 
intensities used by Antia et al.'s (1973), cell gigantism appeared at a very early growth stage (i. e., under nutient-replete conditions).

The interactive effect of high light intensity and glycerol concentration on growth and starch accumulation by $\underline{P}$. salina was particularly striking. This interaction must have a biochemical basis. It's suggested here that these two processes act together to force the alga into the production of storage carbohydrate, at the expense of other cellular processes. The principal route of glycerol assimilation by $\underline{P}$. salina is probably via phosphorylation to glycerol-3-phosphate, followed by conversion to dihydroxyacetone phosphate, an intermediate in the glycolytic and gluconeogenic pathways (Antia 1980). Glycerol assimilation, therefore, not only provides a substrate for cellular starch production but leads to the sequestration of phosphate. The sequestration of cytoplasmic orthophosphate by the phosphorylation of organic compounds can lead to starch accumulation in higher plants (Chen-She et al. 1975, Herold and Lewis 1977). Furthermore, ATP and reductant produced by photosynthesis are important regulatory factors of phytoplankton carbon metabolism that inhibit glycolysis and stimulate gluconeogenesis (Turner and Turner 1980). Thus, starch overproduction caused by the interaction of relatively high light intensity and glycerol concentration may be explained as an additive stimulatory effect on starch production by both autotrophic and heterotrophic processes.

The results reported for $\underline{P}$. salina in this study and the previous investigation of the phytoflagellate $\underline{\underline{P}}$. malhamensis (Lewitus and Caron subm.) present some interesting similarities and striking dissimilarities in 
the effects of light and dissolved organic substrates for the growth and biochemistry of these algae. The contrasting nutritional characteristics of $\underline{\text { P. salina }}$ and $\underline{\mathrm{P}}$. malhamensis are apparent not only in their respective abilities to grow photoautotrophically and in the presence of organic compounds, but also in the physiological response of the photosynthetic system of each alga to organic substrate assimilation. Photoautotrophic cultures of $\underline{\underline{P}}$. salina grew faster than those of $\underline{P}$. malhamensis at all light levels, and the maximum photoautotrophic growth rate of $\underline{P} \cdot \underline{\text { salina }}$ exceeded that of $\underline{P}$. malhamensis by four-fold. In contrast, $\underline{\underline{P}}$. malhamensis exhibited a more pronounced ability than $\underline{P}$. salina to utilize dissolved organic compounds for growth (except at high irradiances and organic compound concentrations). Under certain conditions, the addition of organic substrates to the culture medium inhibited the synthesis of photosynthetic components in both algae. Whereas chloroplast development was repressed in $\underline{P}$. malhamensis by the addition of organic compounds to the medium, however, only selected elements of the photosynthetic system were inhibited by organic substrates in $\underline{P}$. salina. Furthermore, glycerol addition to $\underline{P}$. salina did not affect the rate of inorganic carbon uptake. The maintenance of a fully functional photosynthetic system during organic substrate incorporation by $\underline{P}$. salina, but not $\underline{P}$ malhamensis, indicates a greater relative dependency on autotrophic nutrition for growth in the former alga. In $\underline{P}$. malhamensis, photoautotrophic carbon fixation has been considered a mechanism to allow survival during times when the organic substrate concentration or the particulate food supply is limiting (Caron et al. 1990, Sanders et al. 
1990, Lewitus and Caron subm.). In contrast, because glycerol addition enhanced the growth rate of $\underline{P}$. salina only at limiting light intensities, and because glycerol carbon was incorporated largely into starch under all conditions, heterotrophic carbon assimilation by $\underline{P}$. salina may be considered a mechanism to allow survival during times when light is limiting to photosynthesis. 


\section{ACKNOWLEDGEMENTS}

This work was supported by NSF Grants BSR-8620443 and BSR8919447, Ocean Ventures Fund Grant 25/85.10 of the Woods Hole Oceanographic Institution Education Program, and the Woods Hole Oceanographic Institution Education Program. 


\section{REFERENCES}

Antia, N. J. (1980) Nutritional physiology and biochemistry of marine cryptomonads and chrysomonads. In Biochemistry and Physiology of Protozoa Vol. 3. Edited by Levandowsky, M. and Hutner, S. H. pp. 67115. Academic Press, New York.

Antia, N. J., Cheng, J. Y. and Taylor, F. J. R. (1969) The heterotrophic growth of a marine photosynthetic cryptomonad (Chroomonas salina). Proc. Intl. Seaweed Symp. 6: 17-29.

Antia, N. J., J. Y. Cheng, R. A. J. Foyle and Percival, E. (1979) Marine cryptomonad starch from autolysis of glycerol-grown Chroomonas salina. I. Phycol. 15: 57-62.

Antia, N. J., Kalley, J. P., McDonald, J. and Bisalputra, T. (1973) Ultrastructure of the marine cryptomonad Chroomonas salina cultured under conditions of photoautotrophy and glycerolheterotrophy. I. Protozool. 20: 377-385.

Caron, D. A., Porter, K. G. and Sanders, R. W. (1990) Carbon, nitrogen and phosphorus budgets for the mixotrophic phytoflagellate Poterioochromonas malhamensis (Chrysophyceae) during bacterial ingestion. Limnol. Oceanogr. 35: 433-443.

Cheng, J. Y. and Antia, N. J. (1970) Enhancement by glycerol of phototrophic growth of marine planktonic algae and its significance to ecology of glycerol pollution. I. Fish. es. Bd. Canada 27: 335-346. 
Chen-She, S.-H., Lewis, D. H. and Walker, D. A. (1975). Stimulation of photosynthetic starch formation by sequestration of cytoplasmic orthophosphate. New Phytol. 74: 383-392.

Endo, H., Sansawa, H. and Nakajima, K. (1977) Studies on Chlorella regularis, heterotrophic fast-growing strain II. Mixotrophic growth in relation to light intensity and acetate concentration. Plant $\underline{\text { Cell }}$ Physiol. 18: 199-205.

Farquhar, G.D. and von Caemmerer, S. (1982) Modelling of photosynthetic responses to environmental conditions. In Encyclopedia of Plant Physiology (New Series) Vol. 12B. Edited by Lange, O.L., Nobel, P.S., Osmond, C.B. and Ziegler, H. pp. 549-587. Springer Verlag, Berlin.

Guillard, R. R. L. (1975) Culture of phytoplankton for feeding marine invertebrates. In Culture of Marine Invertebrate Animals. Edited by Smith, W. L. and Chanley, M. H. pp. 29-60. Plenum, New York.

Harris, R. C. and Kirk, J. T. O. (1969) Control of chloroplast formation in Euglena gracilis: antagonism between carbon and nitrogen sources. Biochem. I. 113: 195-205.

Hase, E. (1971) Studies on the metabolism of nucleic acid and protein associated with the processes of de- and re-generation of chloroplasts in Chlorella protothecoides. In Autonomy and Biogenesis of Mitochondria and Chloroplasts. Edited by Boardman, N. K., Linnane, A. W. and Smillie, R. M. pp. 434-446. North-Holland, New York.

Heber, U. and Krause, G. H. (1980) What is the physiological role of photorespiration? Trends Biochem. Sci. 5: 32-34. 
Heinbokel, J. F. (1978) Studies on the functional role of tintinnids in the Southern California Bight. I. Grazing and growth rates in laboratory cultures. Mar. Biol. 47: 177-189.

Herold, A. and Lewis, D. H. (1977) Mannose and green plants: occurrence, physiology and metabolism, and use as a tool to study the role of orthophosphate. New Phytol. 79: 1-40.

Holm-Hansen, O., Lorenzen, C. J., Holmes, R. W. and Strickland, J. D. H. (1965) Fluorometric determination of chlorophyll. I. Cons., Cons. Perm. Int. Explor. Mer. 30: 3-15.

Horrum, M. A. and Schwartzbach, S. D. (1981) Nutritional regulation of organelle biogenesis in Euglena: induction of microbodies. Plant Physiol. 68: 430-434.

James, L. and Schwartzbach, S.D. (1982) Differential regulation of phosphoglycolate and phosphoglycerate phosphatases in Euglena. Plant Sci. Lett. 27: 223-232.

Komor, E., Cho, B.-H. and Kraus, M. (1988) The occurrence of the glucoseinducible transport systems for glucose, proline, and arginine in different species of Chlorella. Bot. Acta 101: 321-326.

Larkum, A.W.D. and Barrett, J. (1983) Light-harvesting processes in algae. Adv. Bot. Res. 10: 1-219.

Lewitus, A.J. and Caron, D.A. (1990) Relative effects of nitrogen or phosphorus depletion and light intensity on the pigmentation, chemical composition, and volume of Pyrenomonas salina (Cryptophyceae). Mar. Ecol. Prog. Ser. 61: 171-181. 
Monroy, A. F. and Schwartzbach, S. D. (1984) Catabolite repression of chloroplast development in Euglena. Proc. Natl. Acad. $\underline{\text { Sci. }}$ U. $\underline{\text { S. }}$ A. 81: 2786-2790.

Neilson, A. H. and Lewin, R. A. (1974) The uptake and utilization of organic carbon by algae: an essay in comparative biochemistry. Phycologia 13: 227-264.

Ogawa, T. and Aiba, S. (1981) Bioenergetic analysis of mixotrophic growth in Chlorella vulgaris and Scenedesmus acutus. Biotech. Bioenerg. 23: 1121-1132.

Parsons, T.R., Maita, Y. and Lalli, C.M. (1984) A Manual of Chemical and Biological Methods for Seawater Analysis. 174 pp. Pergamon Press, Oxford.

Pintner, I.J. and Provasoli, L. (1968) Heterotrophy in subdued light of 3 Chrysochromulina species. Bull. Misaki Mar. Biol. Inst., Kyoto Univ. 12: 25-31.

Pringsheim, E. G. (1952) On the nutrition of Ochromonas. ‥ I. Microscop. Sci. 93: 71-96.

Rodríguez-López, M. (1965) Morphological and structural changes produced in Chlorella pyrenoidosa by assimilable sugars. Arch. Mikrob. 52: 319-324.

Sanders, R. W., Porter, K. G. and Caron, D. A. (1990) Relationship between phototrophy and phagotrophy in the mixotrophic chrysophyte Poterioochromonas malhamensis. Microb. Ecol. 19: 97-109.

Spurr, A. R. (1969) A low-viscosity epoxy resin embedding medium for electron microscopy. I. Ultrastruct. $\underline{\text { Res. } 26: 31-42 .}$ 
Thinh, L. (1983) Effect of irradiance on the physiology and ultrastructure of the marine cryptomonad, Cryptomonas strain Lis (Cryptophyceae). Phycologia 22: 7-11.

Turner, J.F. and Turner, D.H. (1980) The regulation of glycolysis and the pentose phosphate pathway. In The Biochemistry of Plants Vol. 2. Edited by Davies, D.D. pp. 279-316. Academic Press, New York.

Ukeles, R. and Rose, W. E. (1976) Observations on organic carbon utilization by photosynthetic marine microalgae. Mar. Biol. 37: 11-28.

Van Baalan, C. and Pulich, W. M. (1973) Heterotrophic growth of the microalgae. CRC Crit. Rev. Microbiol. 2: 229-255. 


\section{Chapter 5.}

Effects of Light Intensity and Glycerol Addition on the Organization of the Photosynthetic Apparatus in the Facultative Heterotroph, Pyrenomonas salina (Cryptophyceae) 
178 


\begin{abstract}
The marine cryptophyte, Pyrenomonas salina Santore, is capable of autotrophic and heterotrophic nutrition. This study examines the physiological and ultrastructural changes that accompany the shift between these nutritional modes. The addition of glycerol to batch cultures of $\underline{P}$ salina, grown at a light intensity limiting for photoautotrophic growth, increased its growth rate and induced specific biochemical and structural changes in its photosynthetic system. Results from extracted pigment analyses, thin-section electron microscopy, and freeze-fracture electron microscopy indicated that glycerol addition reduced the cell phycoerythrin content, phycoerythrin to chlorophyll $\underline{\mathrm{a}}$ ratio, thylakoid width, degree of thylakoid packing, number of thylakoids per cell, and PSII particle size. These properties also were reduced to a similar extent in cells grown photoautotrophically under a light intensity saturating for growth. These results are consistent with the hypothesis that enhancement of heterotrophic potential occurs at the expense of lightharvesting ability in glycerol-grown $\underline{\underline{P}} \underline{\text { salina. }}$.
\end{abstract}




\section{INTRODUCTION}

The photosynthetic system of cryptophytes uniquely combines lightharvesting strategies of other phycobiliprotein-containing organisms and other chromophytes. Cryptophytes are the only group to contain both phycobiliprotein and chlorophyll $\underline{a} / \underline{c}$ light-harvesting antennae. In addition, although the phycobiliproteins of cryptophytes, cyanobacteria, and rhodophytes are evolutionarily closely related (MacColl et al. 1976, Guard-Friar et al. 1986), contrary to cyanobacteria and rhodophytes, the cryptophytes contain only one phycobiliprotein type per species (phycocyanin or phycoerythrin), lack allophycocyanin, do not aggregate their phycobiliproteins in phycobilisomes, and organize their phycobiliproteins within the thylakoid lumen (Gantt 1979, SpearBernstein and Miller 1987, 1989). The thylakoids typically are grouped into bands of two or more in cryptophytes and other chromophytes but not in

cyanobacteria and rhodophytes (Gibbs 1970, Bisalputra 1974). Partly because of the unique pigment composition and thylakoid organization, the cryptophyte photosynthetic system is considered evolutionarily intermediate between that of other phycobiliprotein- and chlorophyll $\underline{\mathrm{c}}-$ containing organisms (Dodge 1979, Gibbs 1981). This intermediate status is exemplified by the structural organization of photosynthetic components in the cryptophyte, Cryptomonas rufescens, which combines features of the cyanobacterial, rhodophyte and chromophyte photosynthetic systems (Lichtlé et al. 1986). 
The physiological response of the photosynthetic system to changes in environmental conditions has been studied in few cryptophyte species. The effect of light intensity on pigment content and composition in cryptophytes is typical of most photoautotrophs in that the total pigment content of the cell and the ratio of the major light-harvesting pigments (in this case, phycobiliproteins) to chlorophyll a vary inversely with light intensity (Brown and Richardson 1968, Faust and Gantt 1973, Lichtlé et al. 1986, Thinh 1983, 1988, Lewitus and Caron 1990). Responses of at least some pigments, however, appear to be species-specific in cryptophytes. For example, even though an inverse relationship between light intensity and chlorophyll $\underline{c}$ content was demonstrated in Cryptomonas strain Lis (Thinh 1983, 1988), light intensity had a relatively minor effect on chlorophyll $\underline{c}$ production by Chroomonas sp. (Faust and Gantt 1973) or Cryptomonas rufescens (Lichtlé et al. 1986). The effect of light intensity on chloroplast area and the degree of thylakoid packing also appears to be species-specific in cryptophytes (Brown and Richardson 1968, Faust and Gantt 1973, Thinh 1983).

Freeze-fracture techniques have been used to characterize the structure of the cryptophyte photosynthetic system in several species (e. g., Lichtlé and Thomas 1976, Dwarte and Vesk 1982, 1983, Rhiel et al. 1985, 1987, Spear-Bernstein and Miller 1985; Lichtlé et al. 1986). A few studies have examined the effect of environmental variables on the molecular organization of the photosynthetic system. Lichtlé et al. (1986) used pigment analyses and fluorescence induction curves to demonstrate that increasing the light intensity caused a decrease in the phycoerythrin 
content, chlorophyll a content, and number of PSII centers in Cryptomonas rufescens, while the size and efficiency of PSII antennae remained unaffected. Results from freeze-fracture electron microscopy indicated that the areal density of PSII complexes varied inversely with light intensity, consistent with the above results. Contrary to expectations, however, the average size of the PSII complexes increased under the higher light level examined, and the authors speculated that this increase was due to the buildup of a non-pigmented protein. Based on the freezefracture results, the authors also concluded that light intensity had no apparent effect on the size or number of PSI complexes in $\underline{\text { C. }} \underline{\text { rufescens }}$ cells.

To my knowledge, Faust and Gantt (1973) is the only study to quantify the effect of organic substrates on pigment production by a cryptophyte. They found that the assimilation of $1 \mathrm{M}$ glycerol did not enhance growth and had no significant effect on the chlorophyll or phycocyanin content of the marine cryptophyte, Chroomonas sp., grown under a continuous light intensity of $1800 \mu \mathrm{W} \mathrm{cm}-2$ (approximately 90 $\mu$ Einsteins $\mathrm{m}^{-2} \mathrm{~s}^{-1}$ using the conversion factor of Richardson et al. 1983). Based on the color of batch cultures, Antia et al. $(1969,1973)$ reported that Pyrenomonas salina cultures grown with glycerol maintained phycoerythrin production after repeated transfers in the dark. The effect of glycerol addition on pigment production in exponentially growing phototrophic cultures of $\underline{P} . \underline{\text { salina }}$ was not determined.

The purpose of this study was to examine the physiological response of $\underline{P}$. salina's photosynthetic system to changes in light intensity 
and nutritional mode. It has been demonstrated previously that glycerol addition can increase the growth rate of $\underline{P}$. $\underline{\text { salina }}$ under light intensities limiting for photoautotrophic growth (Antia et al. 1969, Lewitus and Caron subm.). It's suggested here that, in order to enhance glycerol utilization under light-limiting conditions, it may be advantageous for $\underline{\mathrm{P}}$. salina to spend more biosynthetic energy on cell components involved in glycerol metabolism at the expense of those photosynthetic components superfluous for growth. Because the ability to harvest light becomes less critical when shifting from autotrophic to heterotrophic nutrition, it's hypothesized that glycerol assimilation by $\underline{P}$. salina selectively inhibits the synthesis of those components of the photosynthetic apparatus associated with light-harvesting. The results from pigment analyses, thin-section electron microscopy, and freeze-fracture electron microscopy support this hypothesis and indicate that enhancement of heterotrophic potential occurs at the expense of light-harvesting ability in $\underline{P} . \underline{\text { salina. }}$. 


\section{METHODS}

Pyrenomonas salina Santore (formerly Cryptomonas salina Wislouch; Chroomonas salina Butcher) clone 3C (Culture Collection of Marine Phytoplankton, Bigelow Laboratory for Ocean Sciences) was obtained from Dr. Diane Stoecker (Woods Hole Oceanographic Institution). Batch cultures used for inocula in the experimental treatments were grown axenically at $21^{\circ} \mathrm{C}$ in artificial seawater medium (ASPM Base; Table 9 in Guillard 1975, except that $20 \mathrm{mM} \mathrm{CaCl}_{2}$ and 0.2 $\mathrm{mM} \mathrm{H}_{3} \mathrm{BO}_{3}$ were substituted for $10 \mathrm{mM} \mathrm{CaCl}_{2}$ and $0.4 \mathrm{mM} \mathrm{H}_{3} \mathrm{BO}_{3}$, respectively, and $0.81 \mathrm{mM} \mathrm{KBr}$ was added) with $\mathrm{f}$-mix vitamins and trace metals (Guillard 1975). The nitrogen source was $0.1 \mathrm{mM} \mathrm{NH}_{4} \mathrm{Cl}$ and the phosphorus source was $0.1 \mathrm{mM} \mathrm{NaH}_{2} \mathrm{PO}_{4}$. The $\mathrm{pH}$ of the medium was 7.4 and the salinity was $29.5 \%$.

Cultures used for inocula were acclimated to specific light intensities by repeated transfer of cells in the mid-exponential growth phase into fresh medium. Continuous illumination was provided by cool-white fluorescent lights at intensities of 325 and $25 \mu$ Einsteins $\mathrm{m}^{-2} \mathrm{~s}^{-1}$. Irradiance was measured with an integrating $4 \mu$ quantum sensor (Biospherical Instruments, QSL-100P probe). After acclimation to the light regime, exponentially growing populations were inoculated into fresh media to start the experiment. Two cultures were used at the low light intensity that differed by the addition of $0.2 \mathrm{M}$ glycerol to one of the cultures. Therefore, three experimental treatments were compared; high 
light intensity without glycerol, and low light intensity with and without glycerol.

Cultures were tested for bacterial contamination throughout the experiment by inoculating tubes containing $0.5 \%$ yeast extract with $1 \mathrm{ml}$ of the culture, and examining these tubes for bacterial growth.

Cryptophyte densities were determined periodically throughout the exponential growth phase. Cell counts were determined from triplicate samples with counting chambers. A Fuchs-Rosenthal Ultra Plane chamber was used when cell counts were below $2 \times 10^{4}$ cells ml-1, and a Reichert Bright-Line hemacytometer was used for higher population densities. Counts obtained with the two chambers were normalized to each other by performing dilution series and comparing duplicate counts of a number of samples made with both chambers, and normalizing to the Reichert Bright-Line estimates. Specific growth rates, $\mu\left(\right.$ day $\left.^{-1}\right)$, were determined from regressions of the linear portion of the growth curves expressed as the natural log of the population densities versus time.

Cultures were grown to mid-exponential growth phase and all samples removed prior to the time during late exponential growth when changes in cell volume and pigment content occur (Lewitus and Caron 1990, Lewitus and Caron subm.). At this time, cell cross-sectional areas and concentrations of phycoerythrin (PE), chlorophyll $\underline{a}$, and chlorophyll $\underline{c}$ were determined and cells were preserved for thin-section electron microscopy (TEM) and freeze-fracture electron microscopy.

Cell cross-sectional areas were measured using a Coulter Multisizer particle counter with a $70 \mu \mathrm{m}$ aperture. PE was extracted by freeze-thawing 
in $0.05 \mathrm{M}$ phosphate buffer ( $\mathrm{pH}$ 6.8) (Thinh 1983, modified by Lewitus and Caron 1990). The concentration of PE was determined fluorometrically, using an SLM Aminco SPF-500C Spectrofluorometer (Lewitus and Caron 1990). Chlorophylls $\underline{a}$ and $\underline{c}$ were extracted with $90 \%$ acetone, following filtration onto HA Millipore membrane filters (mean pore size $=0.45 \mu \mathrm{m}$ ). Chlorophyll a concentrations were then determined fluorometrically (Holm-Hansen et al. 1965) using a G. K. Turner III fluorometer, and chlorophyll a and $\underline{c}$ concentrations were determined spectrophotometrically (Humphrey 1979) using a Shimadzu Spectrophotometer UV-260.

Cells prepared for TEM and freeze-fracture electron microscopy were harvested by centrifugation and fixed with glutaraldehyde (3\% final concentration) in cacodylate buffer for 15 minutes. After repeated washes in cacodylate buffer ( $\mathrm{pH}$ 7.2), cells were pelleted and either resuspended in cacodylate buffer (for freeze-fracture analysis) or in 3\% agar (for TEM).

The suspensions to be used for freeze-fracture analysis were infiltrated with glycerol as a cryoprotectant to a final concentration of $20 \%$ $(\mathrm{v} / \mathrm{v})$, pelleted, frozen on copper supports in liquid freon, and cooled in liquid nitrogen. Freeze-fracture was performed with a Balzers 400 freezeetching device. Replicas were shadowed with platinum and carbon, and cleaned in bleach.

Samples used for TEM were postfixed in $1 \% \mathrm{OsO}_{4}$ in agar blocks for one hour, stained en bloc with uranyl acetate, dehydrated in a graded ethanol series, and embedded in Spurr's low-viscosity resin (Spurr 1969). Ultrathin sections were cut with a Sorvall MT-2B microtome. 
Electron microscopy for thin-sections and freeze-fracture replicas was performed on a Zeiss 10 Electron Microscope operated at $60 \mathrm{kV}$. Data analysis for both methods was conducted by examining micrograph negatives on an Olympus dissecting scope connected to an Olympus CUE-2 Image Analyzer. Freeze-fracture particle diameters and areal densities were computed from the replica micrograph negatives. Particle diameters were computed from measurements made perpendicular to the direction of shadowing. The terms, protoplasmic face $(\mathrm{PF})$ and exoplasmic face $(\mathrm{EF})$, are used to designate the fracture faces closest to the chloroplast stroma and intrathylakoid lumen, respectively (Branton et al. 1975). Two types of EF faces and two types of PF faces could be differentiated based on the relationship between particle size and areal density. These faces could be further differentiated by their trans-membrane location; i. e., some faces were observed in regions where membranes were closely aligned while other faces were found in areas where membranes were farther apart. In keeping with the terminology used in previous studies with cryptophytes (Lichtlé and Thomas 1976, Dwarte and Vesk 1983, Spear-Bernstein and Miller 1985, Lichtlé et al. 1986), the subscripts, "s" and "u", will be used to designate faces located in closely aligned and distantly aligned membrane regions, respectively. These subscripts indicate the "stacked" and "unstacked" thylakoid regions, respectively, as originally applied to freezefracture faces observed in higher plants (Staehelin, 1976). Although thylakoid organization differs greatly between cryptophytes and higher plants, it's now evident that thylakoid stacking also occurs in cryptophytes (Dwarte and Vesk 1983, Spear-Bernstein and Miller 1985, Lichtlé et al. 
1986). Therefore the subscripts " $\mathrm{s}$ " and " $\mathrm{u}$ " as used here also represent fracture faces associated with stacked and unstacked regions, respectively.

Thin-section micrograph negatives were analyzed for total cell cross-sectional area, cell cross-sectional area containing thylakoids, cell cross-sectional area containing starch, thylakoid widths, and number of thylakoid pairs per $\mu \mathrm{m}$ chloroplast. Because these measurements are strongly dependent on the orientation of the sectional plane, only those cells sectioned longitudinally and approximately equatorially (as estimated by examining serial sections) were measured. Thylakoid area was determined as the cross-sectional area within the chloroplast envelope but excluding the pyrenoidal region. Thylakoid width was measured as the distance between the inner edges of the thylakoid membrane (i. e., the distance across the thylakoid lumen). The number of thylakoid pairs per $\mu \mathrm{m}$ chloroplast was determined by drawing transects across the widest section of thylakoid area and counting the number of thylakoid pairs that intersected the transect. 


\section{RESULTS}

The high and low light intensities used in this study were chosen based on previous experiments that demonstrated that these intensities were saturating and limiting, respectively, for photoautotrophic growth of

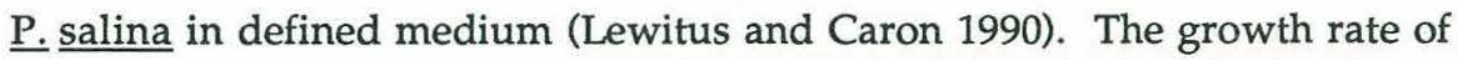

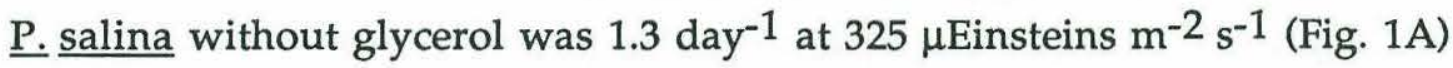
and 0.3 day $^{-1}$ at $25 \mu$ Einsteins $\mathrm{m}^{-2} \mathrm{~s}^{-1}$ (Fig. 1B). The addition of glycerol to the culture medium at the low light intensity resulted in a growth rate of 0.7 day $^{-1}$, more than double the growth rate without glycerol at this light intensity (Fig. 1B).

Cells grown at the low light intensity without glycerol had significantly higher concentrations of PE and chlorophyll a than cells grown at the high light intensity (t $\underline{t}$-test, $\underline{\mathrm{P}}<0.05$, Table 1 , Fig. $2 \mathrm{~A}$ ). The difference in cell PE content between these treatments, however, was greater than the difference in the content of chlorophyll $\underline{a}$, resulting in a significantly higher $\mathrm{PE} /$ chlorophyll a ratio in cells grown at the low light intensity ( $\underline{\mathrm{t}}$-test, $\underline{\mathrm{P}}<0.05$, Fig. $2 \mathrm{~B}$ ). The difference in chlorophyll $\underline{\mathrm{c}}$ concentration cell ${ }^{-1}$ between cultures grown at the high and low light intensities was not significant at the 95\% level (Fig. 2C).

Glycerol addition to cultures grown at the low light intensity resulted in significant decreases in cell PE and chlorophyll a concentrations, but had no effect on chlorophyll $\underline{c}$ concentration cell-1 ${ }^{-1}$ t-test, $\underline{\mathrm{P}}<0.05$, Table 1 , Fig. 2A, C). Similar to the effect that high light intensity had, glycerol addition caused a greater reduction in $\mathrm{PE}$ cell-1 than 
Figure 1. Growth curves of $\underline{P}$. salina grown at (A) high light intensity (325 $\mu$ Einsteins $\left.\mathrm{m}^{-2} \mathrm{~s}^{-1}\right)$ or (B) low light intensity $\left(25 \mu\right.$ Einsteins $\left.\mathrm{m}^{-2} \mathrm{~s}^{-1}\right)$ with and without $0.2 \mathrm{M}$ glycerol in the medium. 

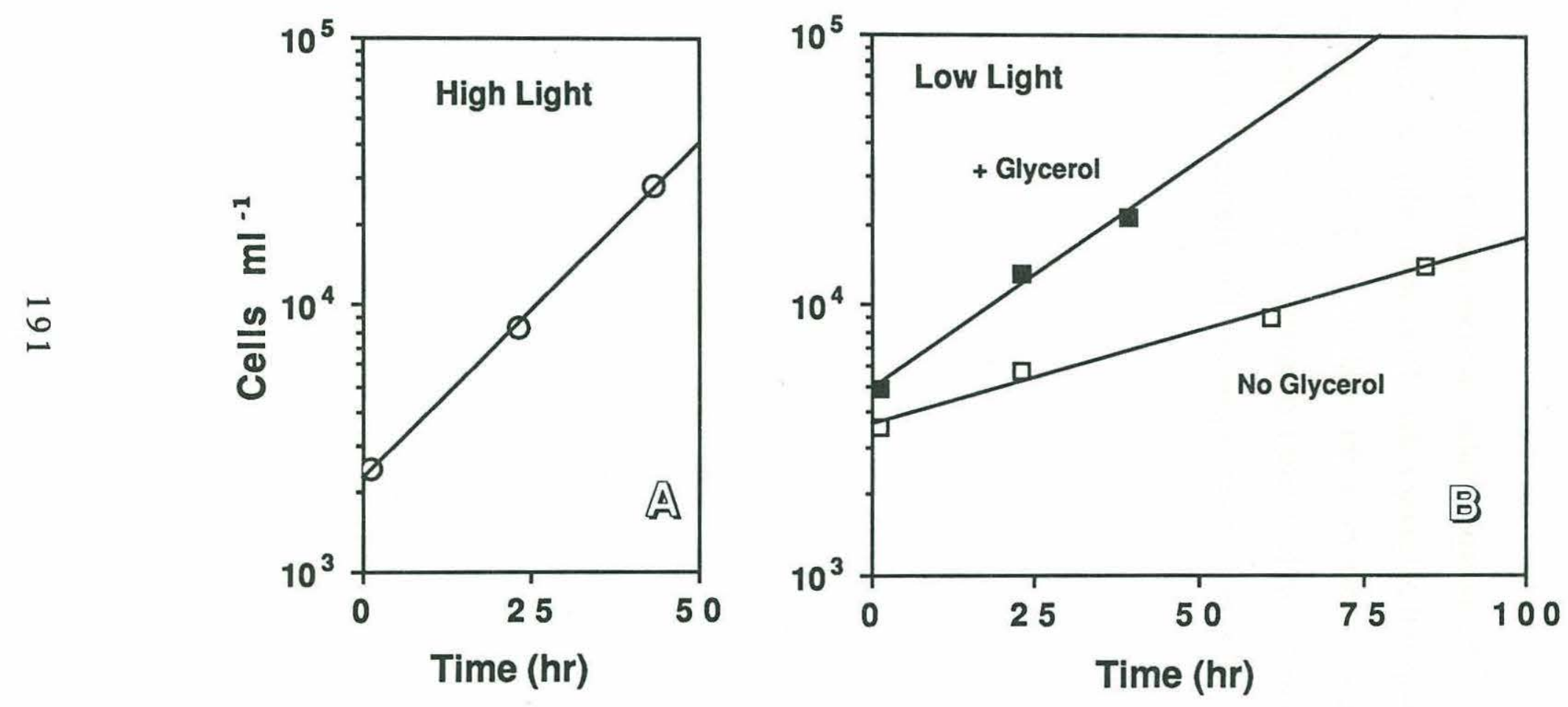
Figure 2. The mean cellular (A) concentration of phycoerythrin (white) and chlorophyll $\underline{\text { a }(d i a g o n a l s),(B) ~ r a t i o ~ o f ~ p h y c o e r y t h r i n ~ t o ~ c h l o r o p h y l l ~} \underline{a}$, and (C) concentration of chlorophyll $\underline{\mathrm{c}}$ in $\underline{\mathrm{P}}$. salina cultures grown at high light intensity or low light intensity with and without glycerol in the medium. The error bars represent the standard error of the mean (see Table 1). 

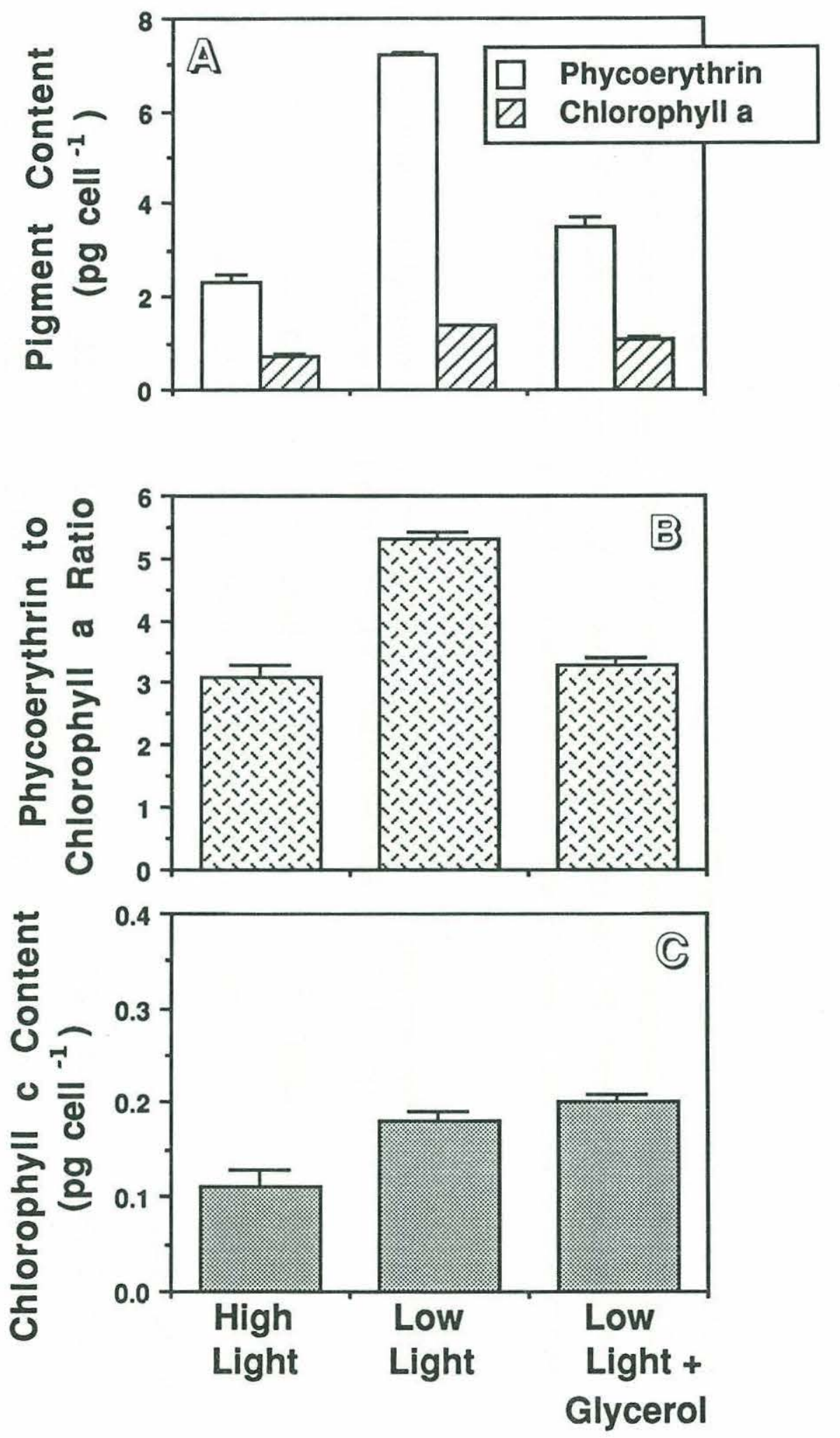
Table 1. Means and standard errors (SE) of cell phycoerythrin, chlorophyll $\underline{a}$, and chlorophyll $\underline{\underline{c}}$ contents, and phycoerythrin to chlorophyll $\underline{\text { a }}$ ratio of replicate samples from $\underline{P} . \underline{\text { salina cultures. Chlorophyll } \underline{\text { a }} \text { was }}$ measured fluorometrically $[\mathrm{Fl}]$ and spectrophotometrically [Sp]. The phycoerythrin to chlorophyll a ratio was calculated using chlorophyll a measurements determined spectrophotometrically.

\begin{tabular}{|c|c|c|c|c|c|c|c|c|c|c|}
\hline \multirow[t]{2}{*}{ TREATMENT } & \multicolumn{2}{|c|}{$\begin{array}{l}\text { Phycoerythrin } \\
\text { (pg cell-1) }\end{array}$} & \multicolumn{2}{|c|}{$\begin{array}{l}\text { Chlorophyll a } \\
(\mathrm{pg} \text { cell-1) [Fl] }\end{array}$} & \multicolumn{2}{|c|}{$\begin{array}{l}\text { Chlorophyll a } \\
\text { (pg cell-1) [Sp] }\end{array}$} & \multicolumn{2}{|c|}{$\begin{array}{l}\text { Chlorophyll c } \subseteq \\
\quad(\text { pg cell }-1)\end{array}$} & \multicolumn{2}{|c|}{$\begin{array}{l}\text { Phycoerythrin } \\
\text { chlorophyll } \underline{a}^{-1}\end{array}$} \\
\hline & mean & $\underline{\mathrm{SE}}$ & mean & $\underline{\mathrm{SE}}$ & mean & $\underline{\mathrm{SE}}$ & mean & $\underline{\mathrm{SE}}$ & mean & $\underline{\mathrm{SE}}$ \\
\hline HIGH LIGHT & 2.3 & 0.2 & 0.64 & 0.01 & 0.74 & 0.01 & 0.11 & 0.02 & 3.1 & 0.2 \\
\hline LOW LIGHT & & & & & & & & & & \\
\hline No Glycerol & 7.2 & 0.1 & 1.32 & 0.07 & 1.38 & 0.02 & 0.18 & 0.01 & 5.3 & 0.1 \\
\hline + Glycerol & 3.5 & 0.2 & $1.07^{a}$ & & 1.10 & 0.02 & 0.20 & 0.01 & 3.3 & 0.1 \\
\hline
\end{tabular}


chlorophyll a cell-1, resulting in a significantly lower cellular $\mathrm{PE} /$ chlorophyll a ratio (t-test, $\underline{\mathrm{P}}<0.05$, Fig. $2 \mathrm{~B}$ ).

Qualitative examinations of thin sections revealed obvious ultrastructural differences between the three treatments (Figs. 3, 4). Cells grown at the high light intensity contained less chloroplastic area and more starch area than cells grown at the low light intensity (Fig. 3A, C). Large accumulations of starch within the perichloroplastic space were common in cells grown at the high light intensity, and, in comparison to cells grown at the low light intensity, the chloroplast cross-sectional area containing thylakoids was more restricted to the cell periphery. The tylakoids predominantly were arranged in pairs, and there was a strong tendency for thylakoid pairs to run parallel to each other. In general, thylakoid pairs were more tightly packed in cells grown at the low light intensity without glycerol than in those grown under the other conditions (Fig. 4).

Differences in cell and thylakoid properties between the treatments were quantified by coulter counter and image analyses (Table 2, Fig. 5). The mean cross-sectional area of cells grown at the high light intensity was 1.4 times that of cells grown at the low light intensity without glycerol (Fig. 5A). The greater size at the high light level coincided with a higher starch content such that starch granules encompassed, on average, $30 \%$ and $7 \%$ of the total cell cross-sectional area in cultures grown at the high and low light intensities, respectively. Thus, cells grown under the higher light level had over six times the starch area of those grown at the low light level. The thylakoid system of cells grown at the high light level was 
poorly developed relative to that of cells grown at the low light intensity without glycerol. Thylakoids were, on average, $60 \%$ thinner in cells grown at the higher irradiance (Fig. 5B), and thylakoid pairs were significantly farther apart (t-test, $\underline{P}<0.05$, Fig. 5 C). Also, the proportion of cell cross-sectional area containing thylakoids was approximately three times higher and the mean thylakoid area per cell twice as high in cultures grown at the lower light level (Fig. 5A).

Cells grown at the low light intensity with glycerol added had a significantly greater mean cell cross-sectional area than cells at this light intensity without glycerol, and a larger proportion of the area of the former cells contained starch (Table 2, Fig. 5A). These values, however, were $80 \%$ and $40 \%$, respectively, of those measured in cells grown at the high light intensity without glycerol added ( $\mathrm{t}$-test, $\underline{\mathrm{P}}<0.05)$. Like the effect of higher light intensity, the increased starch content caused by glycerol addition coincided with a significantly lower mean thylakoid width, number of thylakoid pairs per chloroplast distance, and proportion of cell cross-sectional area containing thylakoids (t-test, $\underline{\mathrm{P}}<0.05$, Table 2, Fig. 5). Glycerol addition did not affect the mean thylakoid area per cell, however,

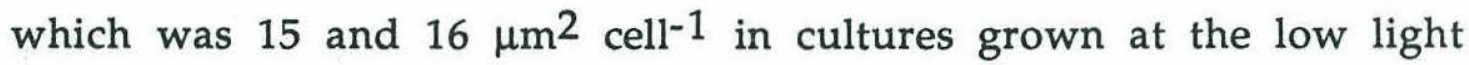
intensity with and without glycerol, respectively (Fig. 5A). While the mean cell thylakoid width and thylakoid area were significantly greater ( $\underline{\mathrm{t}}-$ test, $\underline{\mathrm{P}}<0.05)$ in cells grown at the low light level with glycerol than in cells grown at the high light level, the distance between thylakoid pairs was, on average, comparable in the two treatments (Fig. 5C). 
Figure 3. Thin-section electron micrographs of $\underline{P}$ salina grown at (A) low light intensity without glycerol, (B) low light intensity with glycerol, or (C) high light intensity. $\mathrm{N}=$ nucleus; $\mathrm{Th}=$ thylakoid area; $\mathrm{P}=$ pyrenoid; $\mathrm{S}=$ starch bodies. 

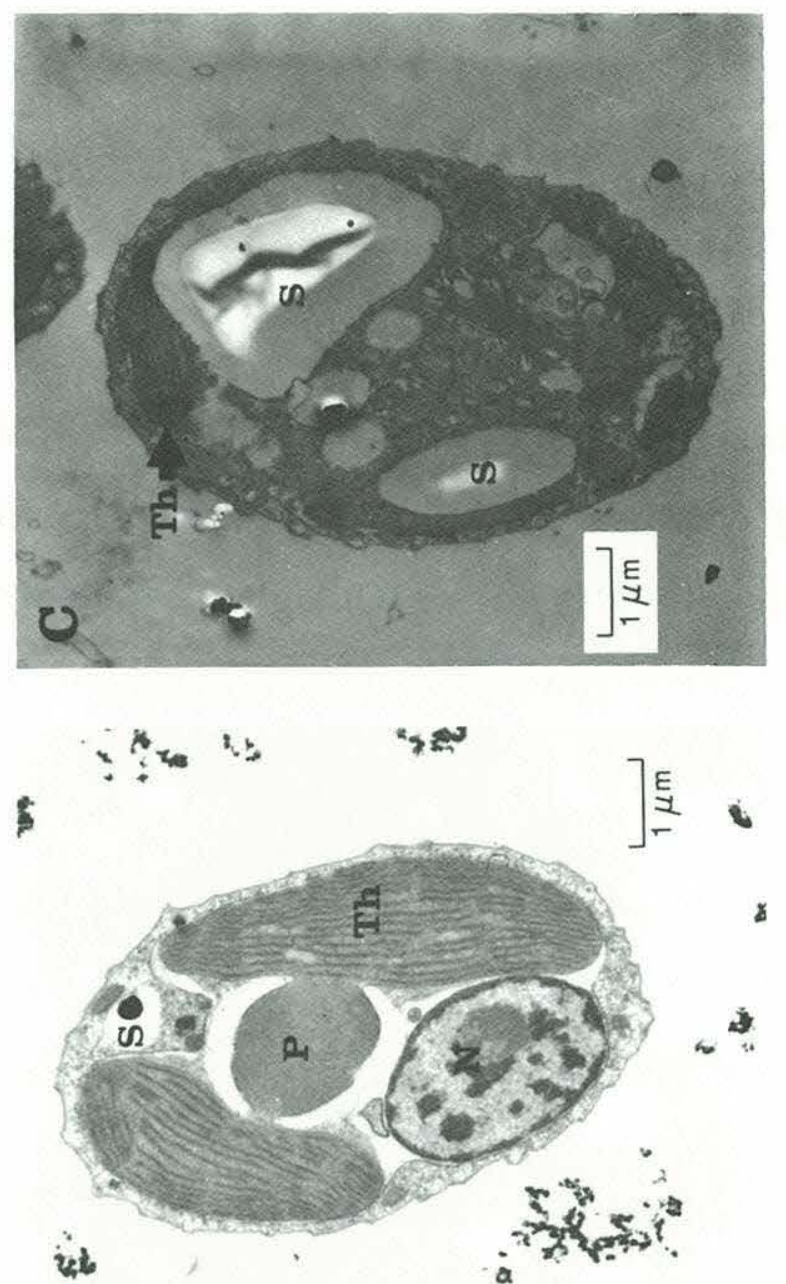

e : is is

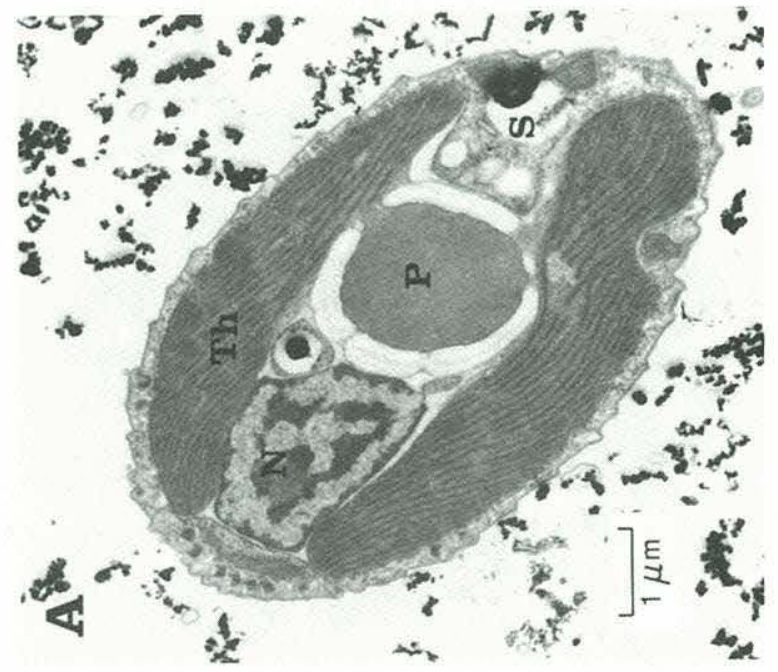


Figure 4. Thin-section electron micrographs showing the thylakoid

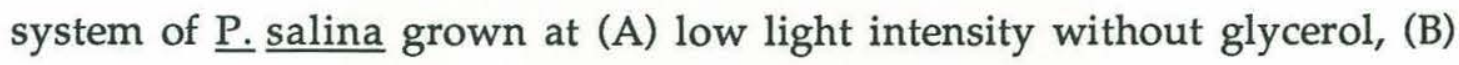
low light intensity with glycerol, or (C) high light intensity. 

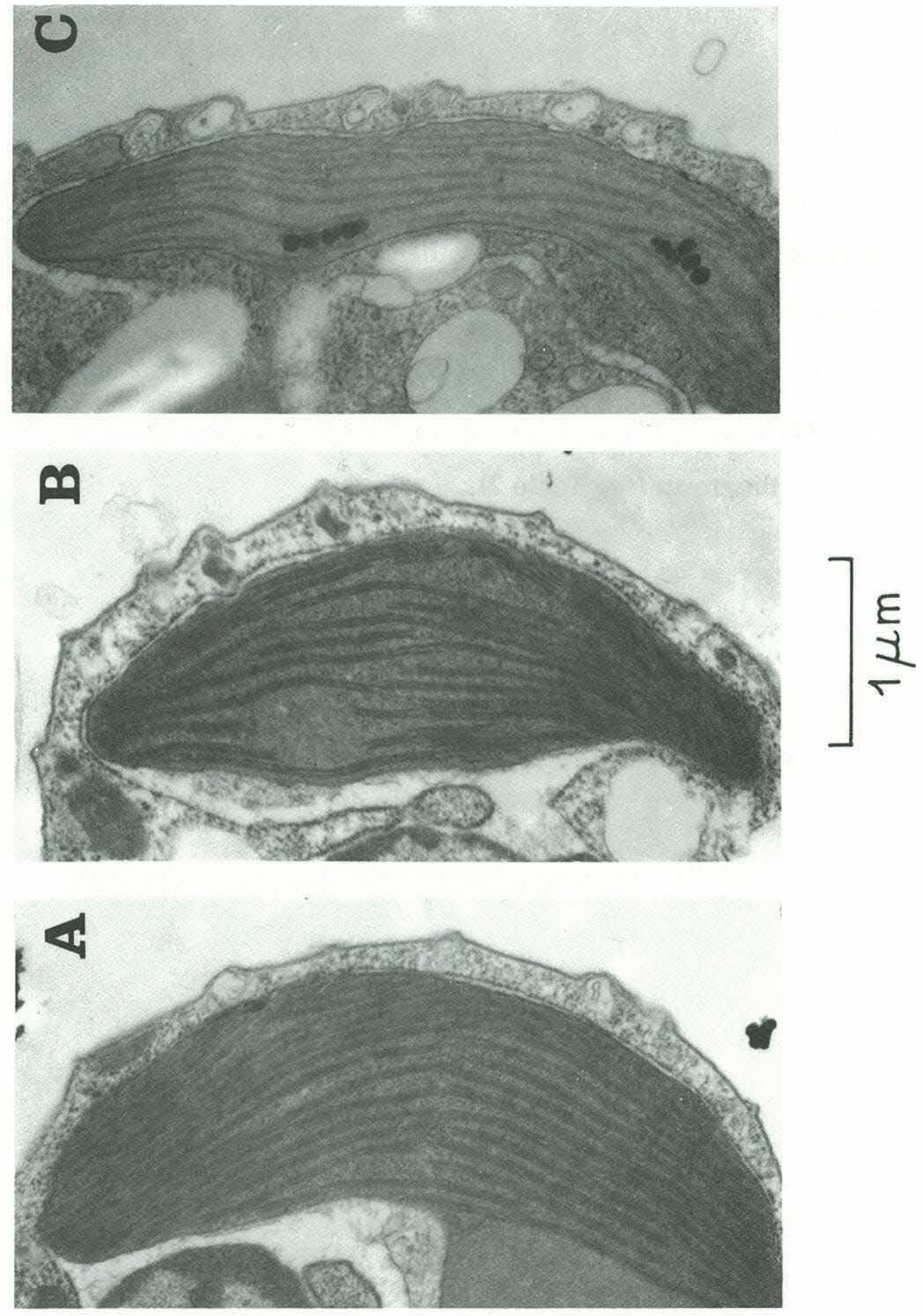
Figure 5. Results from thin-section electron micrographs of $\underline{P} . \underline{\text { salina }}$ showing (A) the mean cell cross-sectional area containing thylakoids (diagonals), starch (white) and other cellular components (shaded), (B) the mean thylakoid width, and $(C)$ the mean number of thylakoid pairs per $\mu \mathrm{m}$ of chloroplast in cells grown at high light intensity or low light intensity with and without glycerol. The error bars represent the standard error of the mean (see Table 2). 

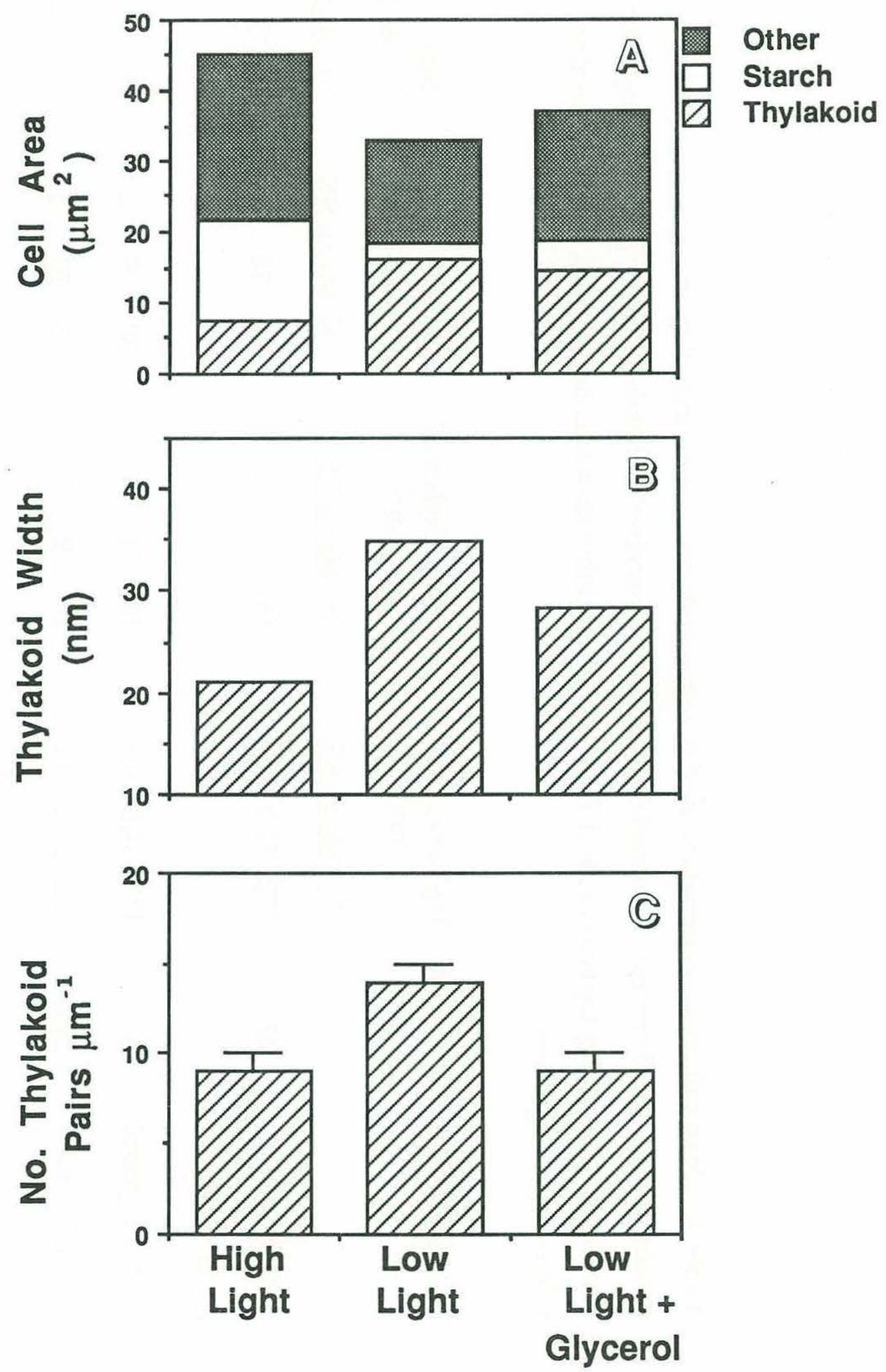
Table 2. Mean cell cross-sectional areas of $\underline{P}$. salina cultures as determined from a coulter counter, and means and standard errors (SE) of thylakoidal widths, number of thylakoid pairs ( $\mu \mathrm{m}$ of chloroplast)- 1 , $\%$ cell area containing thylakoids, and \% cell area containing starch as determined from thin-section micrograph negatives.

D
N

\begin{tabular}{|c|c|c|c|c|c|c|c|c|c|c|c|c|c|}
\hline \multirow[t]{2}{*}{ TREATMENT } & \multirow[t]{2}{*}{$\begin{array}{c}\text { Cell Area } \\
\left(\mu \mathrm{m}^{2}\right)\end{array}$} & \multicolumn{3}{|c|}{$\begin{array}{l}\text { Thylakoid Width } \\
\text { (nm) }\end{array}$} & \multicolumn{3}{|c|}{$\begin{array}{l}\text { Number Thylakoid } \\
\text { Pairs } \mu \mathrm{m}^{-1}\end{array}$} & \multicolumn{3}{|c|}{$\begin{array}{c}\text { Thylakoid Area } \\
\text { (\% cell area) }\end{array}$} & \multicolumn{3}{|c|}{$\begin{array}{l}\text { Starch Area } \\
\text { (\% cell area) }\end{array}$} \\
\hline & & $\underline{\mathrm{N}}$ & Mear & $\underline{\mathrm{SE}}$ & $\underline{\mathrm{N}}$ & Mea & $\underline{\mathrm{SE}}$ & $\underline{\mathrm{N}}$ & Mea & $\underline{\mathrm{SE}}$ & & $\mathrm{Mec}$ & $\underline{\mathrm{SE}}$ \\
\hline HIGH LIGHT & 47 & 172 & 21.0 & 0.1 & 15 & 9 & 1 & 21 & 16 & 1 & 21 & 30 & 2 \\
\hline \multicolumn{14}{|l|}{ LOW LIGHT } \\
\hline No Glycerol & 33 & 150 & 34.8 & 0.1 & 19 & 14 & 1 & 30 & 49 & 2 & 29 & 7 & 1 \\
\hline + Glycerol & 37 & 152 & 28.2 & 0.1 & 17 & 9 & 1 & 16 & 39 & 3 & 16 & 12 & 1 \\
\hline
\end{tabular}


Examination of freeze-fracture replica micrographs (Figs. 6-9) revealed four freeze-fracture faces, $\mathrm{EFu}, \mathrm{EFs}, \mathrm{PFu}$, and PFs; e. g., the EFs and PFs faces shown in Fig. 9 (see "Methods" for the basis for terminology). The areal densities of EFu and EFs particles did not vary significantly with culture treatment ( $\underline{\mathrm{t}}$-test, $\underline{\mathrm{P}}<0.05$, Table 3 ). In each treatment, the density of EFs particles was greater than twice that of EFu particles.

The average EFu particle size did not change significantly with culture treatment ( $\underline{t}$-test, $\underline{\mathrm{P}}<0.05$, Table 3 ). It is apparent from the size histograms, however, that EFu particles in the higher diameter classes, 11 through $15 \mathrm{~nm}$, were lacking in cells grown at the low light intensity with glycerol (Fig. 10A-C). Although the average particle densities on the EFs faces were not significantly different, the mean EFs particle size varied significantly with culture condition (t-test, $\underline{\mathrm{P}}<0.05)$. Cells grown at the low light intensity without glycerol were characterized by a greater mean EFs particle diameter than cells grown under the other two culture conditions (Table 3). The size distributions of EFs particles from cultures grown at the high light level and low light level with glycerol were skewed to low size classes relative to that of the culture grown under the low light level without glycerol (Figs. 10D-F and 11). Growth with glycerol at the low light intensity resulted in very few EFs particles with diameters greater $10 \mathrm{~nm}$ (Fig. 10F). In fact, only $6 \%$ of the EFs particles in cells from this treatment were included in the $11 \mathrm{~nm}$ diameter class, the modal particle size of cells grown at the low light level without glycerol. Only 6\% of the EFs particles from cells grown under the low light level without 
glycerol had diameters in the $9 \mathrm{~nm}$ category, the modal particle size of cells grown with glycerol.

The mean density of PFu particles was slightly, but significantly ( $t-$ test, $\underline{P}<0.05)$, greater than the PFs particle density in cells grown at the low light intensity without glycerol while, in cells grown at the high light level or with glycerol, PFs particles were more tightly spaced than PFu particles (Table 3). Cells grown at the low light intensity without glycerol had a significantly higher mean PFu particle density than in cells grown with glycerol, and a significantly lower mean PFs particle density than in cells grown at the high light intensity (t-test, $\underline{\mathrm{P}}<0.05$ ).

The mean PFu and PFs particle diameters of cells grown at the high light level did not differ significantly from those of cells grown at the low light level without glycerol ( $\underline{t}$-test, $\underline{\mathrm{P}}<0.05$, Table 3 ), and this fact was reflected in the comparable PF particle size distributions in these culture treatments (Fig. 12). Glycerol addition, however, caused a shift in PF particle size distributions to lower diameters (Fig. 12C, F), resulting in significantly smaller mean PF particle diameters (Table 3 ). 
Figure 6. Freeze-fracture electron micrograph of $\underline{P}$. salina showing the periplast $(\mathrm{Pe})$ and thylakoid membranes $(\mathrm{Th})$. Scale bar $=1 \mu \mathrm{m}$. 


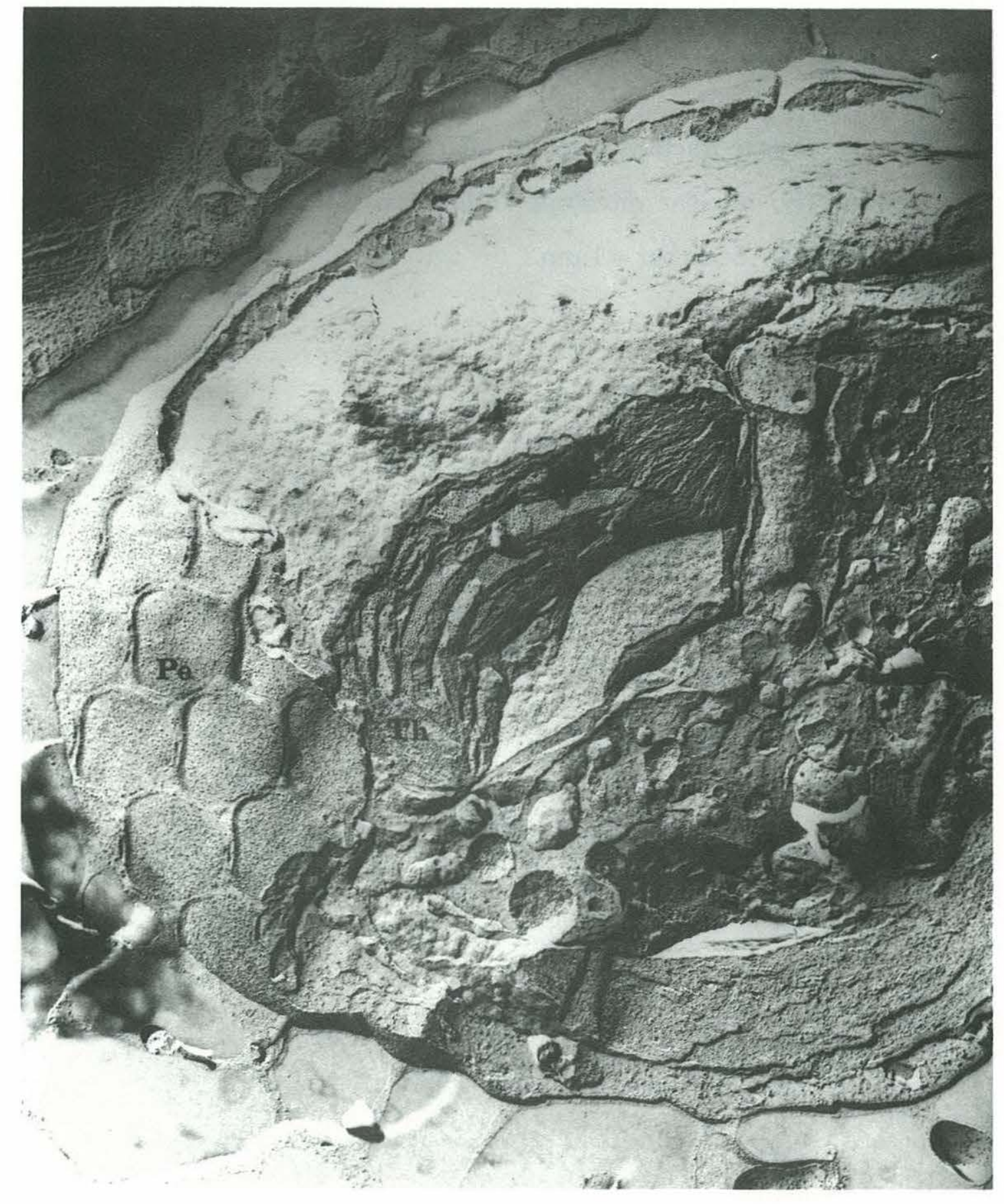


Figure 7. Freeze-fracture electron micrograph of $\underline{P}$ salina showing the flagellum (F), nuclear envelope (N), thylakoid membranes (Th), and trichocysts $(\mathrm{Tr})$. Scale bar $=1 \mu \mathrm{m}$. 


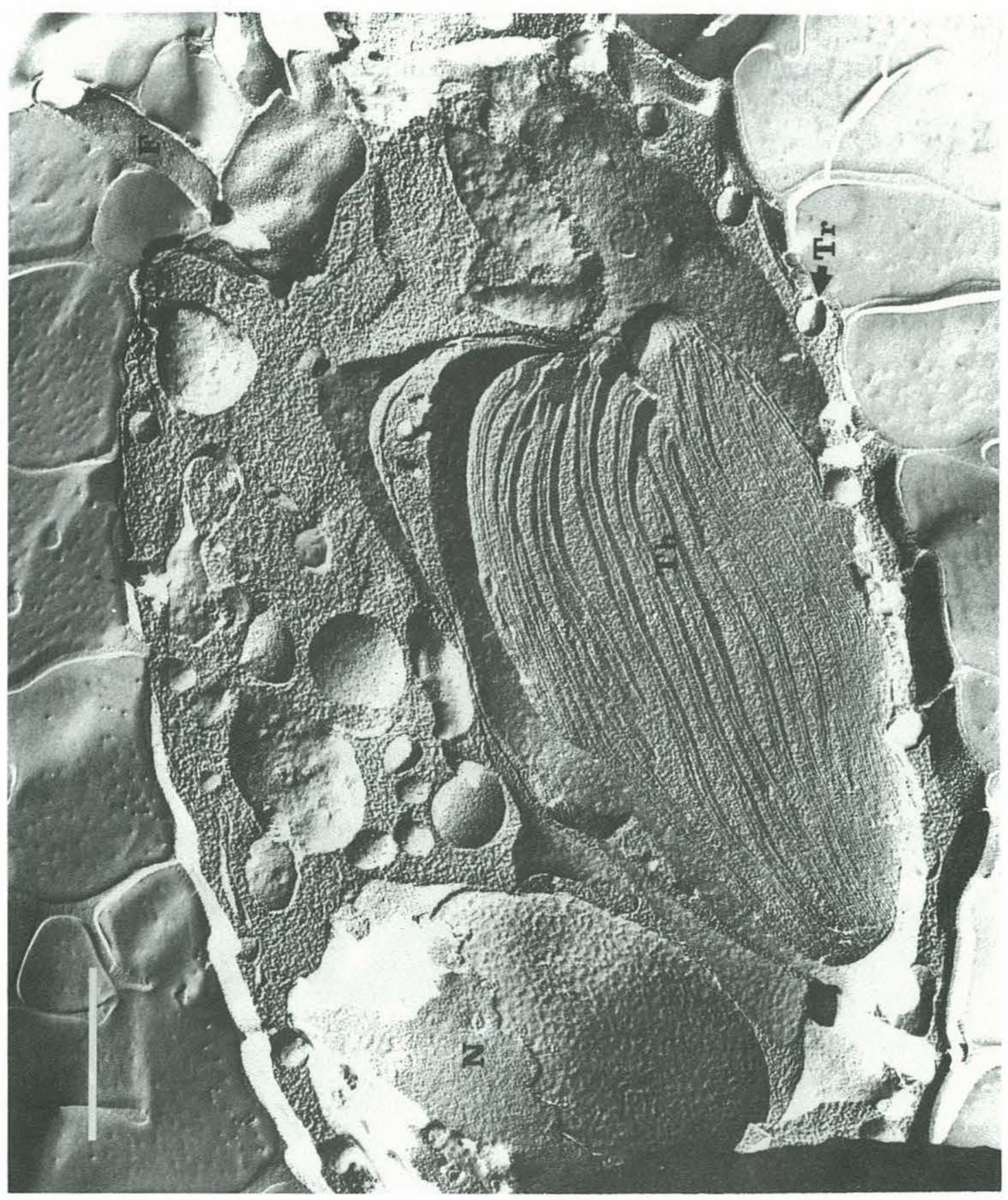


Figure 8. Freeze-fracture electron micrograph of $\underline{\mathrm{P}}$. salina showing the chloroplast envelope (C) and thylakoid membranes (Th). Scale bar $=1 \mu \mathrm{m}$. 


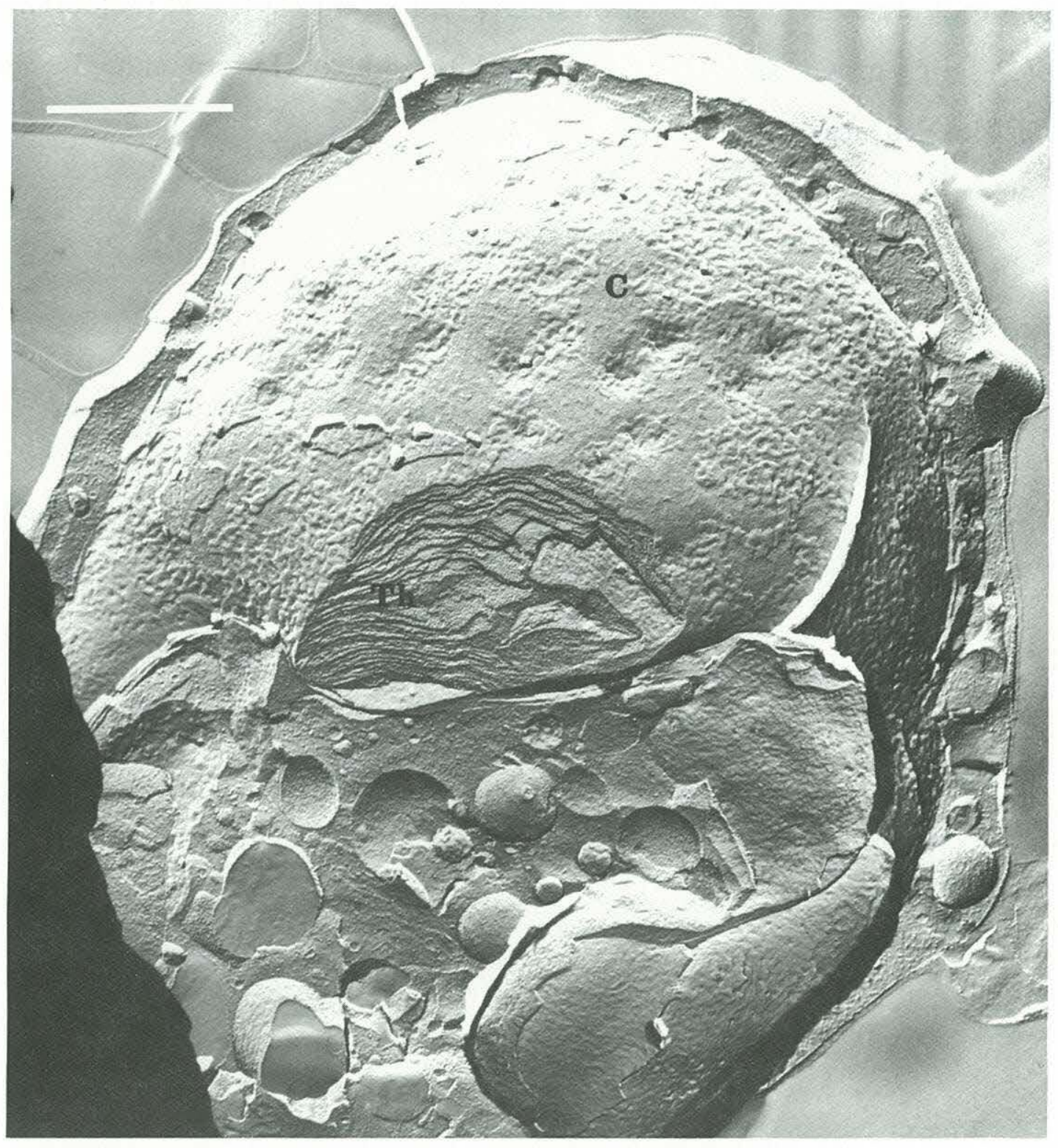


Figure 9. Freeze-fracture electron micrograph of the thylakoid membranes of $\underline{P}$ salina grown at the low light intensity without glycerol, showing the EFs and PFs faces. 


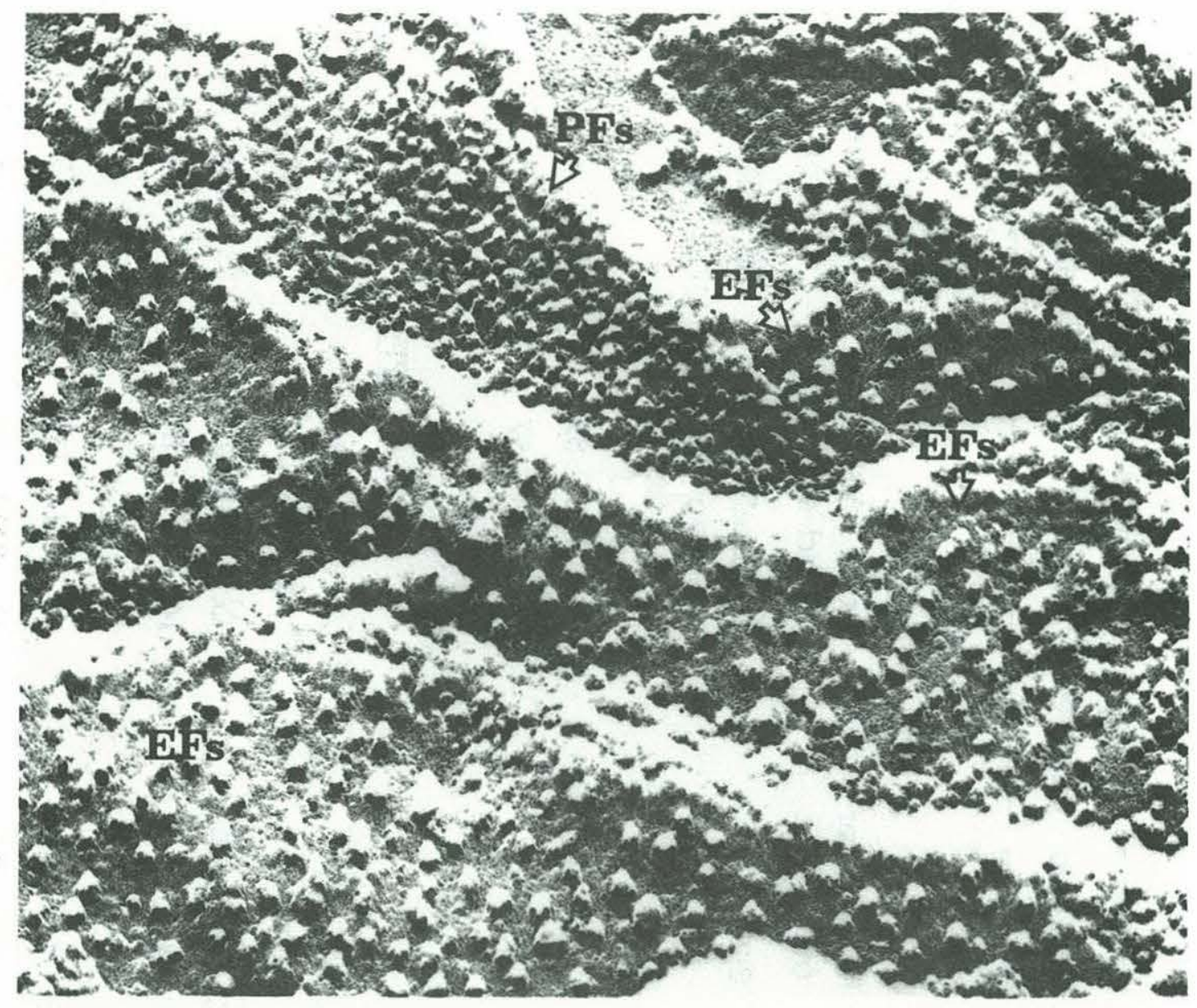

$0.1 \mu \mathrm{m}$ 
Table 3. Means and standard errors (SE) of areal densities and diameters of particles from the EFu, EFs, PFu, and $\mathrm{PFs}$ fracture faces of $\underline{\mathrm{P}} . \underline{\text { salina }}$ thylakoids as determined from freeze-fracture micrograph negatives.

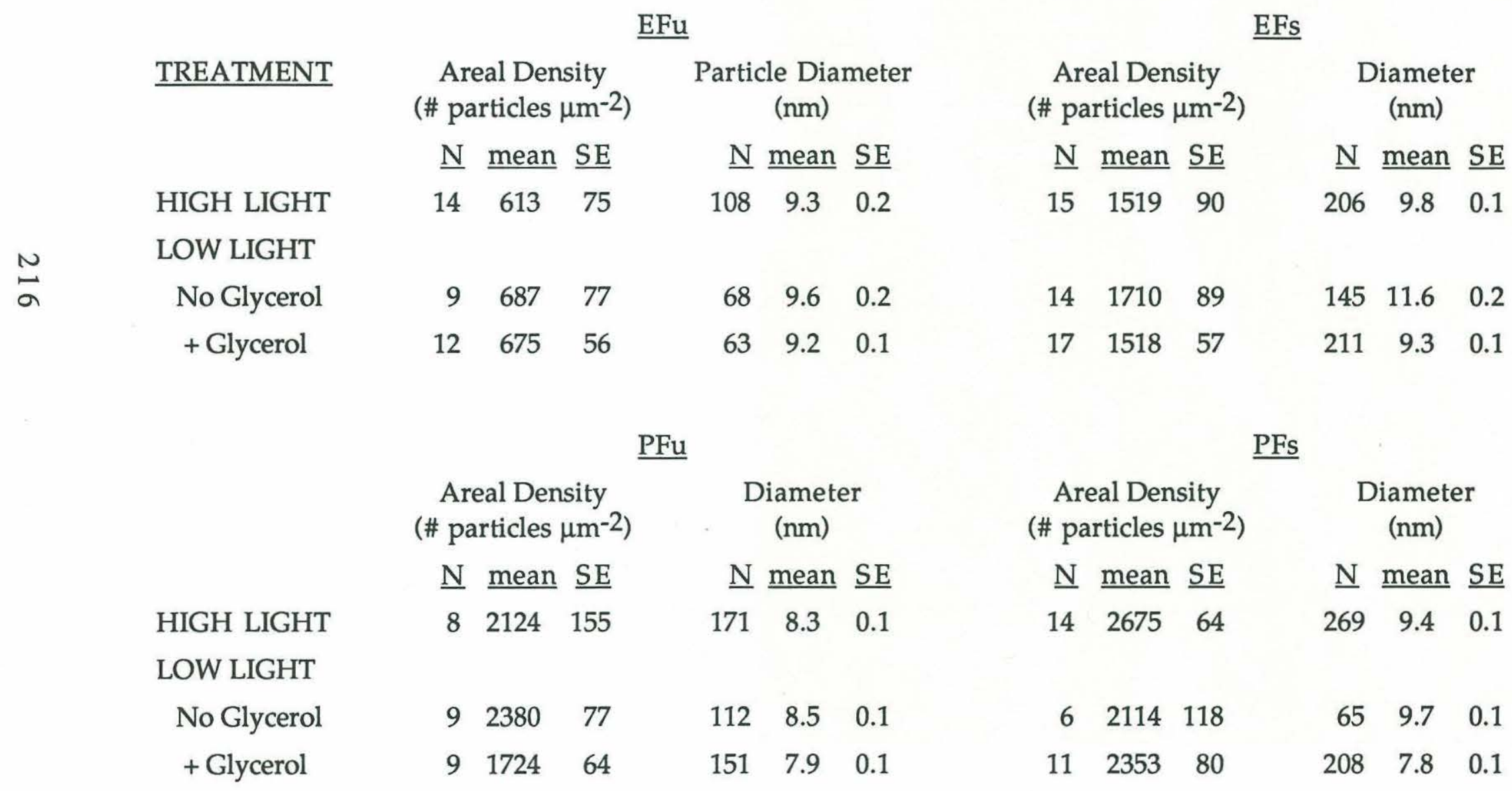


Figure 10. Freeze-fracture particle size histograms (normalized as $\%$ of

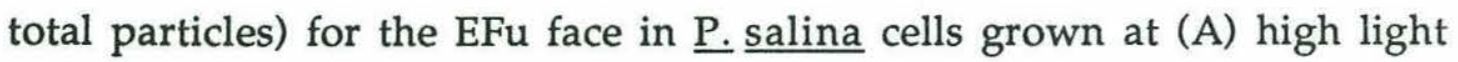
intensity, (B) low light intensity without glycerol, and (C) low light intensity with glycerol and for the EFs face in cells grown at (D) high light intensity, (E) low light intensity without glycerol, and (F) low light intensity with glycerol. Also shown are the mean particle diameter and standard error of the mean, SE (see Table 3). 
EFu
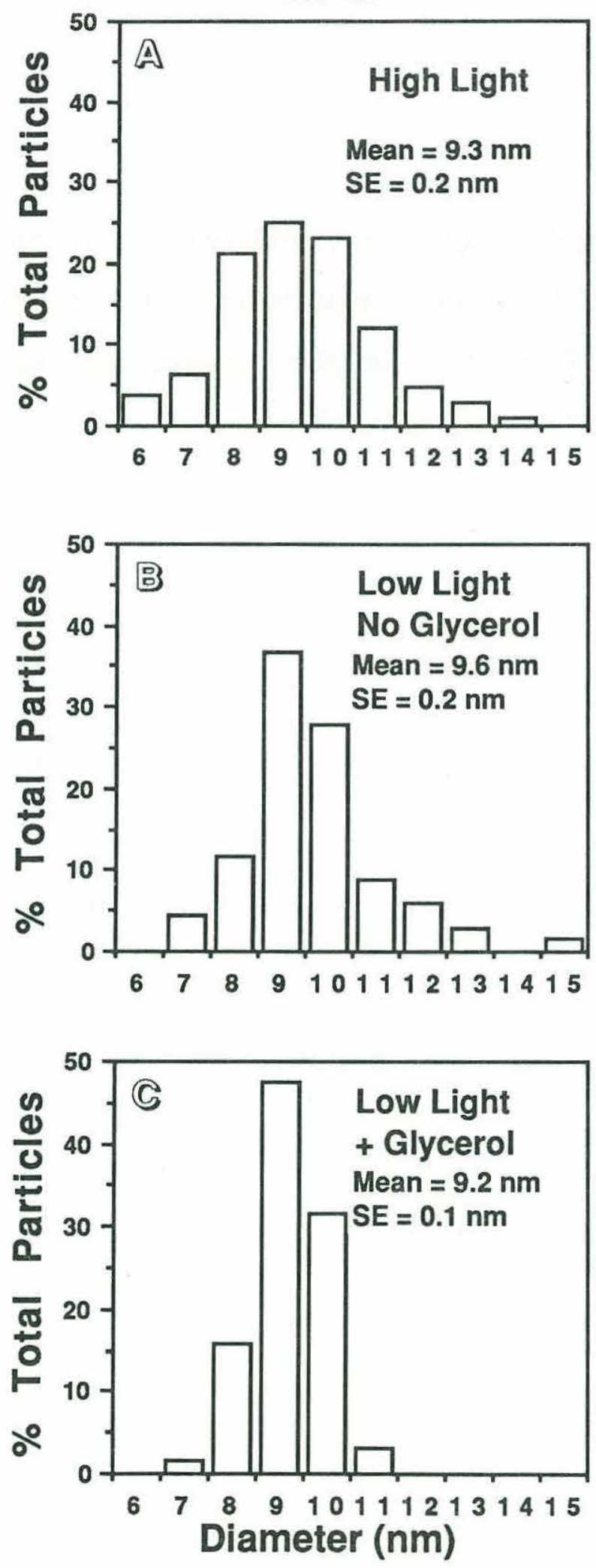

EFs
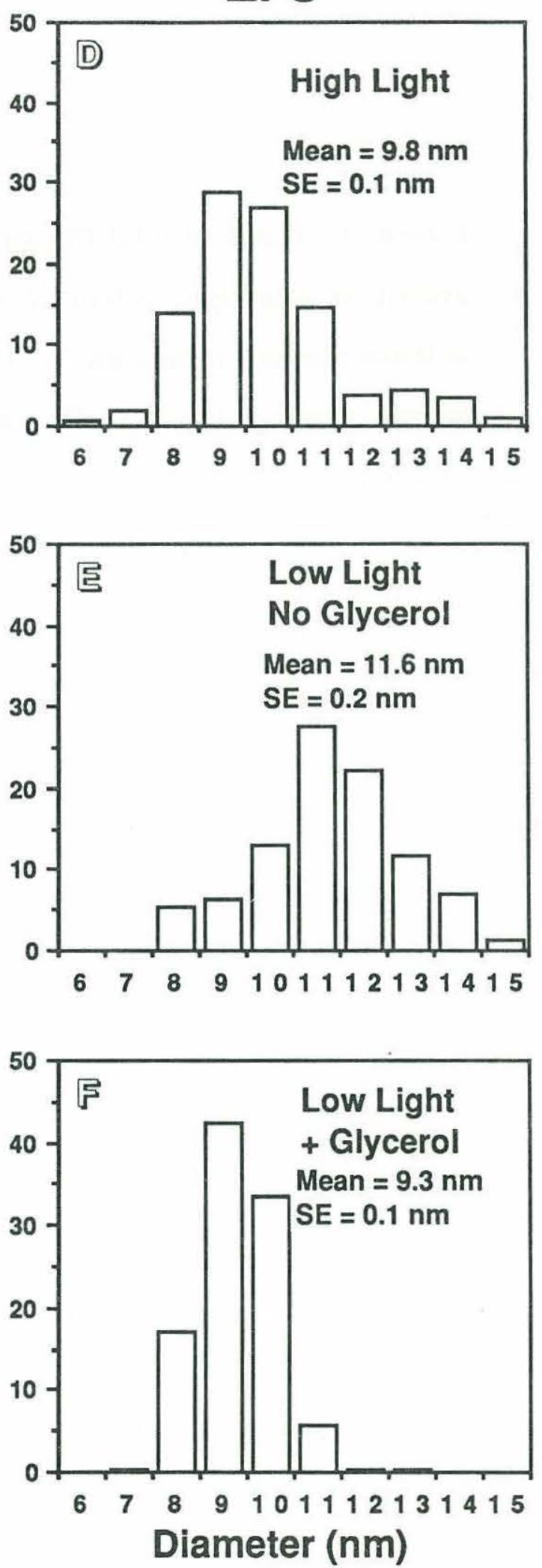
Figure 11. The \% of total EFs particles found in a specific size class in cells grown at low light intensity with glycerol or at high light intensity without glycerol minus the \% of EFs particles found in the same size class in cells grown at low light intensity without glycerol. 


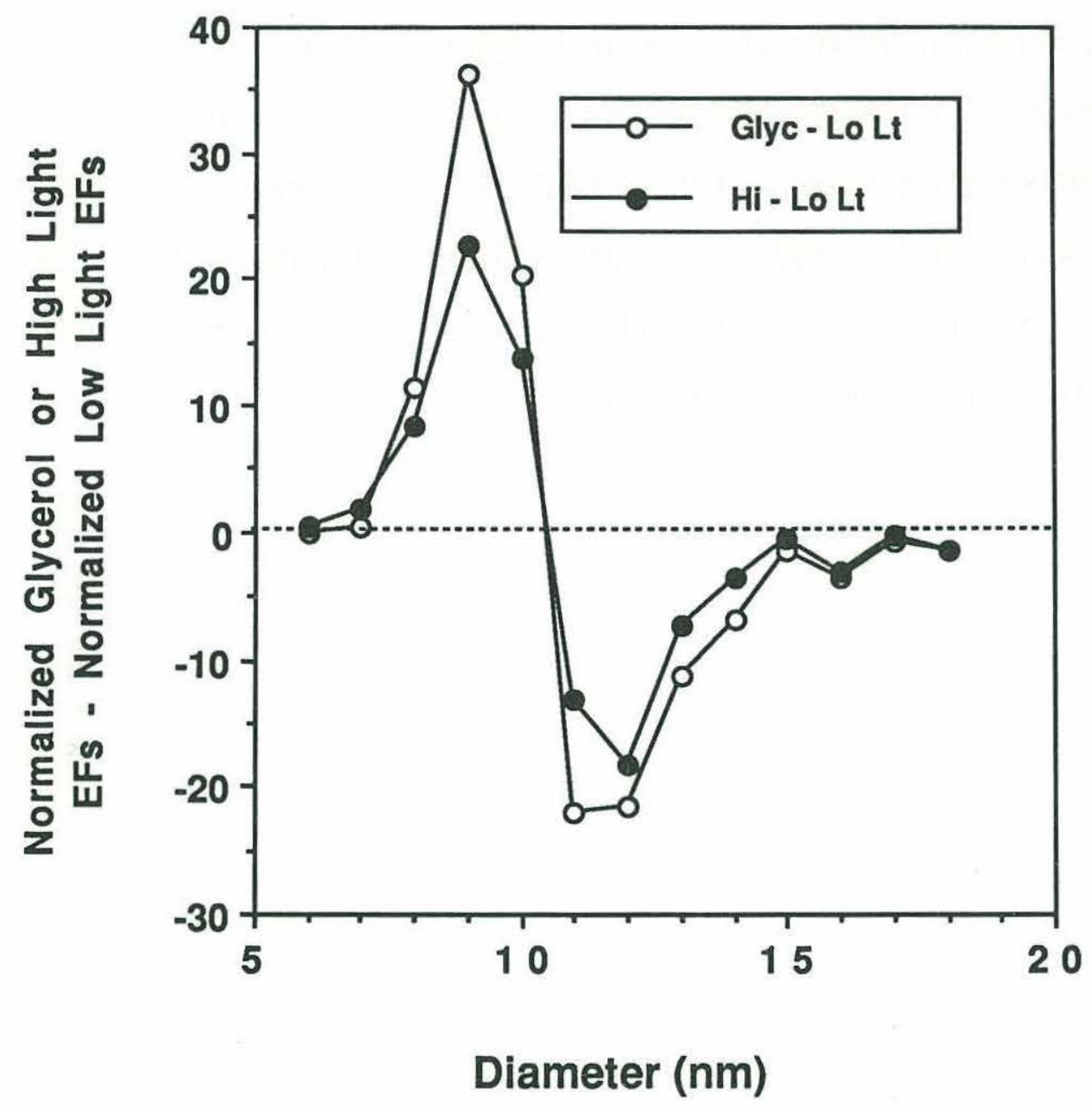


Figure 12. Freeze-fracture particle size histograms (normalized as $\%$ of

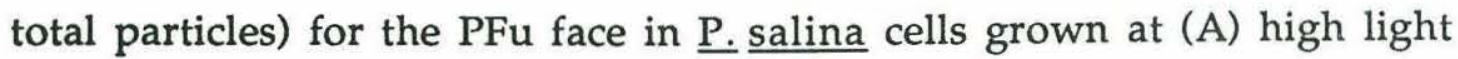
intensity, (B) low light intensity without glycerol, and (C) low light intensity with glycerol and for the PFs face in cells grown at (D) high light intensity, (E) low light intensity without glycerol, and (F) low light intensity with glycerol. Also shown are the mean particle diameter and standard error of the mean, SE (see Table 3). 

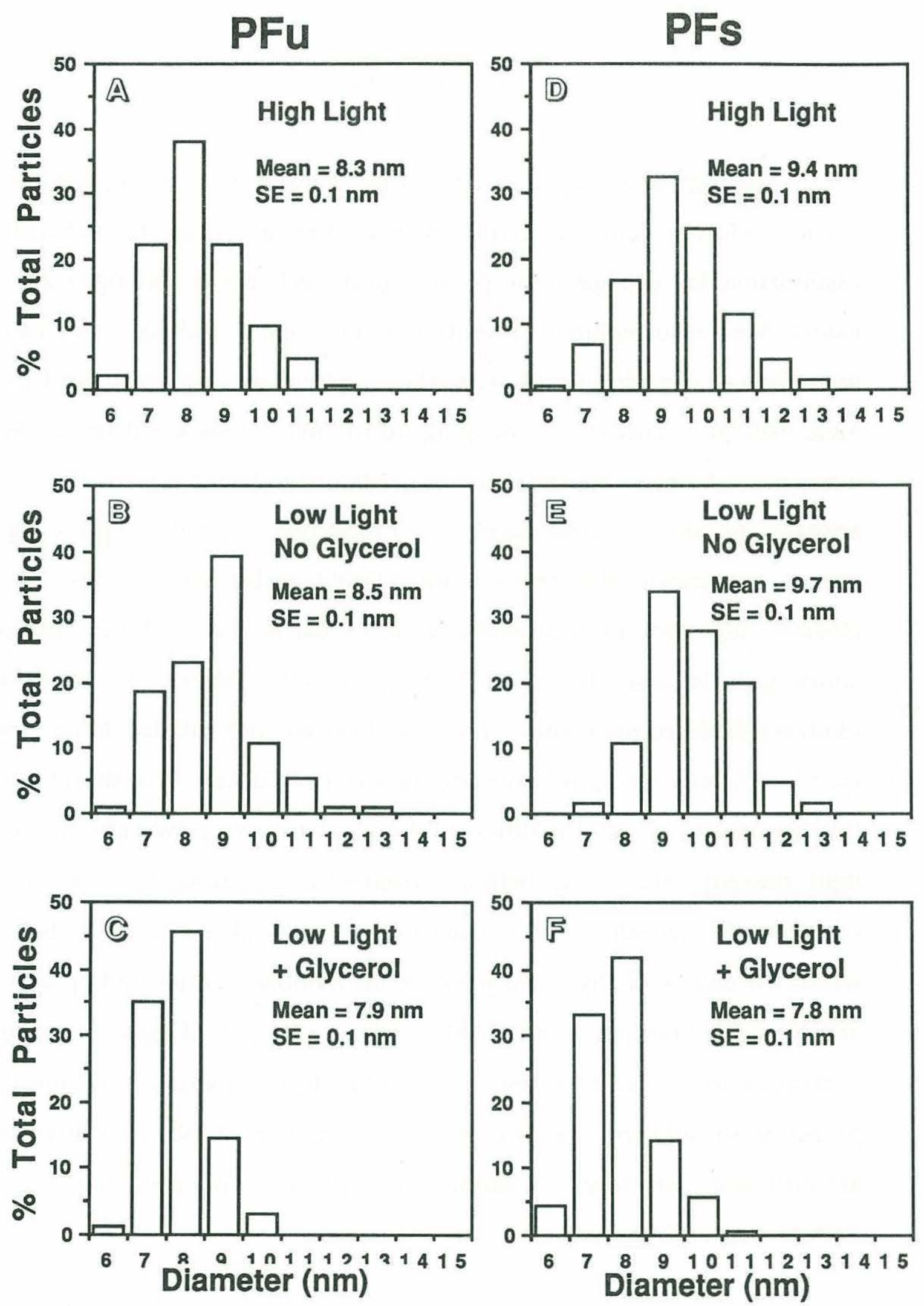


\section{DISCUSSION}

Although many algal species grown in culture can help meet their carbon and/or energy requirements through organic substrate assimilation, knowledge of the physiological mechanisms that algae use to switch from autotrophic to heterotrophic nutrition is lacking. Studies of the effects of organic substrates on algal pigment production suggest that algal cellular strategies for changing nutritional modes are diverse. For example, addition of assimilable organic compounds can repress, have no effect on, or enhance algal chlorophyll production, depending on the algal species and organic substrate examined (Shihira-Ishikawa and Hase 1964, Doemel and Brock 1971, Schwelitz et al. 1978a, Ellis et al. 1981). In this study, glycerol assimilation by $\underline{\text { P. salina }}$ caused a selective inhibition of photosynthetic components. It's hypothesized that this inhibition was specific towards the light-harvesting function of the cell. Consistent with this hypothesis, glycerol addition to $\underline{\underline{P}}$ salina cultures grown at a limiting light intensity enhanced growth and resulted in significantly lower (1) PE content cell-1, (2) cellular PE to chlorophyll a ratio, (3) mean cell thylakoid width, (4) degree of thylakoid packing, (5) number of thylakoids per cell, and (6) mean diameter of EFs (PSII) particles. That all of these properties decreased to a similar extent at a higher light intensity without the presence of glycerol further supports the hypothesis that glycerol assimilation selectively inhibits the synthesis of light-harvesting components in $\underline{\text { P. salina. }}$. 
Glycerol addition and increased light intensity resulted in significant decreases in cell PE content, chlorophyll a content, and PE to chlorophyll a ratio, but did not significantly affect the cell chlorophyll $\underline{c}$ content. Phycobiliproteins and chlorophyll a are light-harvesting pigments in cryptophytes, and therefore the lower concentrations of these pigments resulting from glycerol addition is consistent with the hypothesis that glycerol assimilation by $\underline{\underline{P}}$ salina leads to a loss of lightharvesting components. In cryptophytes, the light-harvesting function of chlorophyll $\underline{a}$ is relatively less than that of phycobiliproteins (Haxo and Fork 1959, Lichtlé et al. 1980). This is shown by an inverse relationship

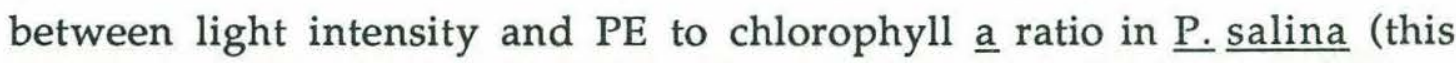
study) and other cryptophytes (Brown and Richardson 1968, Lichtlé et al. 1986, Thinh 1983). Glycerol addition to $\underline{P}$. salina also resulted in the selective loss of PE relative to chlorophyll $\underline{a}$, consistent with a reduction of the light-harvesting function of the cell.

The lack of an effect of light intensity on the chlorophyll $\underline{c}$ content in P. salina and some other cryptophytes (Faust and Gantt 1973, Lichtlé et al. 1986) is curious because, in various chromophytes, this pigment is important in light-harvesting and its concentration cell ${ }^{-1}$ varies inversely with light intensity (Falkowski and Owens 1980, Alberte et al. 1981, Kirk 1983, Haxo 1985). However, the functional role of chlorophyll $\underline{c}$ in lightharvesting is unclear in cryptophytes. Although chlorophyll $\underline{c}$ has been shown to efficiently transfer excitation energy to PSII-chlorophyll $\underline{\text { a }}$ in cryptophytes (Ingram and Hiller 1983, Bruce et al. 1986, Lichtlé et al. 1987, Rhiel et al. 1987), it is unknown whether, in vivo chlorophyll $\underline{\mathrm{c}}$ is an 
intermediary in the excitation energy transfer between phycobiliproteins and chlorophyll a. In other words, whether excitation energy transfer involves; a) a single pathway from phycobiliproteins to chlorophyll $\underline{c}$ to chlorophyll $\underline{\mathrm{a}}$ or b) two parallel pathways, from phycobiliproteins to chlorophyll $\underline{\text { a }}$ and from chlorophyll $\underline{c}$ to chlorophyll $\underline{\mathrm{a}}$, has not been definitively determined in cryptophytes. Indirect evidence suggests that excitation energy transfer may involve a single pathway in PE-containing cryptophytes. For instance, despite the greater spectral overlap between phycocyanin and chlorophyll $\underline{\mathrm{a}}$ than between $\mathrm{PE}$ and chlorophyll $\underline{\mathrm{a}}$ (MacColl and Berns 1978), Bruce et al. (1986) found that the transfer of energy from PE to chlorophyll a was faster in $\underline{P}$. salina and Cryptomonas ovata than the transfer from phycocyanin to chlorophyll a in Chroomonas pauciplastida. If chlorophyll $\underline{c}$ is an intermediary in energy transfer, then the rate-limiting step in the passage of light energy to PSII-chlorophyll $\underline{a}$ is the transfer from PE to chlorophyll $\underline{c}$. If this is the case, then the finding that glycerol addition decreased the cell PE, but not chlorophyll $\underline{c}$ content, is not inconsistent with the hypothesis that glycerol assimilation results in a selective decrease of light-harvesting components in $\underline{\underline{P}} \underline{\text { salina. }}$.

Increased light intensity and glycerol addition caused significant decreases in the mean thylakoid width, the number of thylakoid pairs per chloroplast distance, and the thylakoid area of $\underline{P}$ salina cells. Phycobiliproteins are contained within the thylakoid lumen of cryptophytes (Spear-Bernstein and Miller 1987, 1989, Rhiel et al. 1989). PE content varied directly with thylakoid width in $\underline{P}$ salina consistent with the pattern found in other cryptophytes (Faust and Gantt 1973, Lichtlé 
1979, Thinh 1983), although the ratio of phycobiliprotein content to thylakoid width varied widely between species. The decrease in thylakoid width caused by glycerol addition is in accordance with the results from extracted PE analysis and further supports the argument that glycerol assimilation leads to a reduction in the concentration of the major lightharvesting pigment in $\underline{P}$. salina cells.

The pairwise alignment of thylakoids observed in $\underline{P}$. salina is consistent with the arrangement found in other cryptophytes (Gibbs 1962, Kirk and Tilney-Bassett 1967). The overall packing of thylakoid pairs within the chloroplast varied inversely with light intensity in $\underline{P}$. salina, consistent with the pattern observed in Chroomonas sp. (Faust and Gantt 1973), but not Cryptomonas strain Lis (Thinh 1983). The specific function of thylakoid packing in cryptophytes is still not clear. Grana formation in chlorophytes and higher plants, however, is also inversely related to irradiance (Björkman and Ludlow 1972, Anderson 1982), and the packing of thylakoid pairs in cryptophytes may have an analogous function to the formation of grana. Although the reason for grana formation is controversial (Miller and Lyon 1985, 1986, Allen et al. 1986), it is generally accepted that this process leads to an enhancement of light-harvesting potential in the cell (Armond et al. 1976, Boardman et al. 1978, Larkum and Barrett 1983, Staehelin and Arntzen 1983). By analogy, thylakoid packing may function to improve the light-harvesting ability of $\underline{P}$. salina.

Alternatively, the functional adaptation of increasing thylakoid packing in response to low light availability may not be to bring thylakoids closer together, but to increase the total number of thylakoid membranes 
within the chloroplast. The number of thylakoids per chloroplast distance and the thylakoid area of $\underline{P}$. salina cells varied inversely with irradiance, resulting in more than twice as many thylakoids in cells grown under the low light intensity than under the high light intensity. An increase in thylakoid membranes should not only enhance light-scattering within the chloroplast (reviewed in Larkum and Barrett 1983) but provide a greater amount of absorbent surface area cell ${ }^{-1}$. Thus, increasing the cell thylakoid number should enhance its light-harvesting potential, especially in conjunction with an increase in PE content. The degree of thylakoid packing and the number of thylakoids per cell were significantly reduced by glycerol addition to $\underline{\underline{P}}$ salina, similar to the effect of increased light intensity (Table 2). By analogy to the effect of increased light intensity discussed above, the changes in thylakoid organization caused by glycerol suggest a loss of light-harvesting potential.

Knowledge of the effects of dissolved organic substrates on algal chloroplast ultrastructure is limited and comes primarily from research on chlorophytes; e. g., Euglena (Schwelitz et al. 1978b, Schuler et al. 1981, Vannini 1983), Chlorella (Shihira-Ishikawa and Hase 1964, Osafune and Hase 1975), and Chlamydobotris stellata (Wiessner and Amelunxen 1969a, b). The uptake of organic compounds inhibits the synthesis of specific portions of the photosynthetic apparatus in these algae. Although the mechanism of inhibition varied between species, organic substrate assimilation by these algae resulted in a greater separation of thylakoids and reductions in the degree of thylakoid stacking and cellular concentration of light-harvesting pigments. The results from this study 
on the effect of glycerol addition on chloroplast ultrastructure in $\underline{\text { P. }} \underline{\text { salina }}$ extend the above observations that algal thylakoid organization can be nutritionally regulated as well as photoregulated, and that organic substrate assimilation can result in a general depression of thylakoid membrane development.

The ratio of EFs to EFu particle density was always greater than two in this study. This is consistent with previous studies demonstrating a lateral heterogeneity in the location of EF particles along the thylakoid membrane in cryptophytes (Dwarte and Vesk 1983, Rhiel et al. 1985, SpearBernstein and Miller 1985, Lichtlé et al. 1986). EF particles have been linked to PSII complexes in chlorophytes and higher plants (Staehelin 1976, 1981, Miller and Cushman 1979). Because the densities and size distributions of EF particles in chromophytes approximate those of chlorophytes and higher plants, it is likely that EF particles in chromophytes also represent PSII complexes. The relatively greater density of EFs particles than EFu particles suggests that PSII complexes are preferentially located in stacked thylakoid regions in $\underline{\underline{P}} \underline{\text { salina }}$ and other cryptophytes.

PF particles were also unevenly distributed in stacked and unstacked regions but, whereas the PFs to PFu particle density ratio was less than one in the culture grown at the low light intensity without glycerol, this ratio was greater than one in the other cultures. Because the PF fracture faces probably include not only PSI complexes but other similarly-sized photosynthetic components (Staehelin and Arntzen 1983), it is impossible, from the data in this study, to determine whether 
differences in PF particle densities reflect lateral changes in PSI distribution. However, the patterns in PF particle distribution suggest that the lateral location of at least one photosynthetic component associated with the PF fracture face may be responsive to light and nutrient conditions.

Although the mean areal density of $\underline{P}$. salina EFs particles did not change with culture treatment, the mean diameter of EFs particles decreased with increased light intensity, and with glycerol addition at the low light intensity. Therefore, photoadaptation in $\underline{\text {. salina appears to }}$ involve changes in the size, but not number, of PSII units. This photoadaptive strategy is different from that demonstrated in Cryptomonas rufescens, in which increased irradiance caused a significant decrease in EFs particle density and increases in mean and modal EFs particle sizes (Lichtlé et al. 1986). Still another photoadaptive response was observed in Cryptomonas strain Lis. Based on growth irradiancedependent changes in the photosynthesis versus irradiance curve, Thinh (1983) suggested that Cryptomonas strain Lis photoadapts by adjusting both the number and size of photosynthetic units. Thus, several strategies for photoadaptation in cryptophytes appear to exist.

Although the EFs particle density of $\underline{P}$. salina did not change with increased light intensity or glycerol addition, there was a dramatic decrease in the number of 11-12 nm particles and increase in the number of $9 \mathrm{~nm}$ particles (Figs. 10,11). These results imply that $\underline{\underline{P}}$ salina cells respond to increased irradiance or glycerol assimilation by decreasing the diameter of existing EFs particles by 2-3 nm. In chlorophytes and higher plants, 
correlations between the size of EFs particles and number of chlorophyll a/b light-harvesting complexes (LHC) indicate that EFs particles consist of an $8 \mathrm{~nm}$ PSII core surrounded by varying numbers of 2-3 $\mathrm{nm}$ chlorophyll a/ $\underline{b}$ LHC's (reviewed in Staehelin 1986). The 2-3 nm decrease in EFs particle diameter observed in this study may have resulted from a loss of light-harvesting antennae around the $9 \mathrm{~nm}$ PSII core in $\underline{P}$. salina cells adapted to increased irradiance or glycerol addition.

In cryptophytes, two types of light-harvesting antennae transfer light energy to PSII; the chlorophyll $\underline{\mathrm{a}} / \underline{\mathrm{c}} \mathrm{LHC}$ and phycobiliproteins. The 2$3 \mathrm{~nm}$ decrease in the EFs particle diameter of $\underline{\mathbf{P}} \underline{\text { salina }}$ cells in response to increased irradiance or glycerol addition may be due to a loss of PE antenna from the PSII core. This conjecture is supported by the

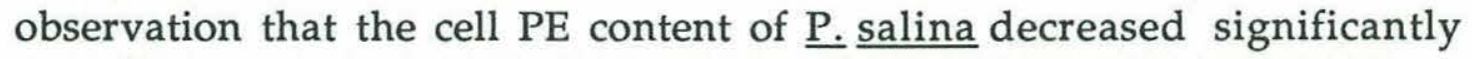
with increased light intensity or glycerol addition. Although PE is located within the cryptophyte thylakoid lumen, recent studies have demonstrated that at least a portion of the cell PE may be closely associated with the thylakoid membrane (Lichtlé et al. 1987, Ludwig and Gibbs 1989, Rhiel et al. 1989). Using sucrose density gradients, Lichtlé et al. (1987) isolated a photosynthetically-active subchloroplast fraction from Cryptomonas rufescens that was highly enriched in PE, xanthophylls, and PSII reaction centers. Although PSII reaction centers were also found associated with chlorophyll $\underline{\mathrm{a}} / \underline{\mathrm{c}}$ LHC's in another fraction, the amount of PSII activity in this fraction was relatively minor compared to the phycoerythin-associated fraction; i. e., most of the cell PSII reaction centers were probably associated with PE. Using negative staining electron 
microscopy, the authors observed that the PE in this fraction appeared as rod-shaped particles associated with thylakoid vesicles. It is possible, then, that cryptophyte EFs freeze-fracture particles are PSII cores surrounded by PE antennae, and that the size of EFs particles may depend on the amount of PE associated with the PSII core.

Lichtlé et al. (1987) also isolated a subchloroplast fraction from $\underline{C}$. rufescens containing only free PE. They hypothesized that different forms of PE exist in cryptophytes; those located in the thylakoid lumen (i. e., free $\mathrm{PE}$ ) and those associated with the thylakoid membrane (i. e., the PE complexed to the PSII reaction centers). Immunogold-labeling studies with cryptophytes have demonstrated that PE is labeled both in the center of the thylakoid lumen and in close association with the thylakoid membrane (Spear-Bernstein and Miller 1987, 1989, Ludwig and Gibbs 1989, Rhiel et al. 1989), consistent with this hypothesis. In $\underline{P}$ salina, increased light intensity and glycerol addition may have reduced not only the amount of lumenal PE (as indicated by the decrease in thylakoid width), but the amount of membrane-associated PE as well (as suggested by the decrease in EFs particle diameter).

An alternative explanation for the 2-3 nm decrease in EFs diameters is that chlorophyll $\underline{a} / \underline{c}$ LHC's are lost in response to increased light intensity or glycerol addition at the low light intensity. Although evidence is scarce, there are some similarities in the structure (Rhiel et al. 1987) and polypeptide composition (Lichtlé et al. 1987) of cryptophyte chlorophyll $\underline{a} / \underline{c}$ LHC and higher plant chlorophyll $\underline{a} / \underline{b}$ LHC. However, the function of chlorophyll $\underline{a} / \underline{c}$ LHC appears to be distinct in cryptophytes. 
Whereas a key regulatory factor in the control of excitation energy distribution in chlorophytes and higher plants is the phosphorylation state of the chlorophyll $\underline{a} / \underline{b}$ LHC, the regulation of light state transition in Cryptomonas ovata did not involve a phosphorylation event (Snyder and Biggins, 1987). Moreover, whereas the mechanism of excitation energy distribution in chlorophytes and higher plants depends on the migration of the chlorophyll $\underline{\mathrm{a}} / \underline{\mathrm{b}}$ LHC between photosystems, the mechanism in cryptophytes does not necessitate involvement of a mobile lightharvesting antenna, more closely resembling that of cyanobacteria and rhodophytes (reviewed in Biggins and Bruce, 1989). Rhiel et al. (1989) used immunogold-labeling to demonstrate that chlorophyll $\underline{a} / \underline{c}$ LHC was distributed evenly between stacked and unstacked thylakoid regions in Cryptomonas maculata. This contrasts with observations that chlorophyll a/b LHC is predominantly located in stacked thylakoid regions (Armond et al. 1976, Andersson and Anderson 1980, Vallon et al. 1986). In addition, the finding here that the cellular chlorophyll $\underline{c}$ content did not change with culture treatment in $\underline{P}$ salina provides further evidence that the decrease in EFs particle size was not related to a loss of chlorophyll $\underline{a} / \underline{c}$ LHC.

Because of the inability to differentiate PSI complexes from other particles on the PF fracture face, the decrease in the mean PF particle sizes caused by glycerol addition to $\underline{\underline{P}} \underline{\text { salina }}$ cells does not necessarily indicate a loss of PSI light-harvesting antennae. In fact, the finding that increasing the light intensity caused a significant decline in the cellular concentration of chlorophyll $\underline{\mathrm{a}}$, the major light-harvesting pigment of PSI in $\underline{\mathrm{P}} \underline{\underline{\text { salina }}}$ 
(Bruce et al. 1986), yet did not affect the mean PF particle diameters, argues against this possibility.

In summary, the pigment content and composition, thylakoid organization, and distribution and size of particles associated with the thylakoid membrane in $\underline{\text { P. salina }}$ were affected similarly by increased growth irradiance and glycerol addition at low irradiance. Increased light availability or organic substrate addition may each enhance the cell growth environment by providing a greater potential supply of carbon and/or energy. In each case, the limitation of light on growth may be to some extent relieved and, therefore, the need to invest biosynthetic energy in the light-harvesting machinery may be reduced. Although algal cellular regulatory mechanisms used in adapting to increased light availability are certainly distinct from those involved when shifting from autotrophic to heterotrophic nutrition, the results from this study indicate that $\underline{P} . \underline{\text { salina }}$ responds to each of these environmental changes by the loss of lightharvesting components. 


\section{ACKNOWLEDGEMENTS}

This work was supported by NSF Grants BSR-8620443 and BSR-8919447, Ocean Ventures Fund Grant 25/85.10 of the Woods Hole Oceanographic

Institution Education Program, and the Woods Hole Oceanographic Institution Education Program. 


\section{REFERENCES}

Alberte, R. S., Friedman, A. L., Gustafson, D. L., Rudnik, M. S. \& Lyman, H. 1981. Light-harvesting systems of brown algae and diatoms. Isolation and characterization of chlorophyll $\underline{a} / \underline{c}$ and chlorophyll

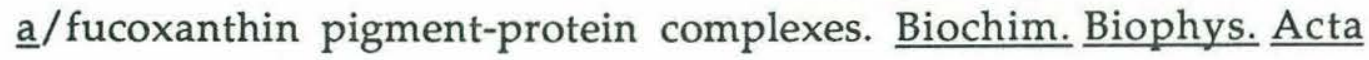
635:304-16.

Allen, J. F., Holmes, N. G., Mullineaux, C. W. \& Sanders, C. E. 1986. More

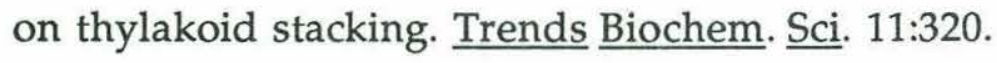

Anderson, J. M. 1982. The significance of grana stacking in chlorophyll $\underline{\mathrm{b}}-$ containing chloroplasts. Photobiochem. Photobiophys. 3:225-41.

Andersson, B. \& Anderson, J. M. 1980. Lateral heterogeneity in the distribution of chlorophyll-protein complexes of the thylakoid membrane of spinach chloroplast. Biochim. Biophys. Acta 593:427-40.

Antia, N. J., Cheng, J. Y. \& Taylor, F. J. R. 1969. The heterotrophic growth of a marine photosynthetic cryptomonad (Chroomonas salina). Proc. Int. Seaweed Symp. 6:17-29.

Antia, N. J., Kalley, J. P., McDonald, J. \& Bisalputra, T. 1973. Ultrastructure of the marine cryptomonad Chroomonas salina cultured under conditions of photoautotrophy and glycerol-heterotrophy. I. Protozool. 20:377-85.

Armond, P. A., Arntzen, C. J., Briantais, J. M. \& Venotte, C. 1976. Differentiation of chloroplast lamellae. I. Light harvesting efficiency and grana development. Arch. Biochem. Biophys. 175:400-18. 
Biggins, J. \& Bruce, D. 1989. Regulation of excitation energy transfer in organisms containing phycobilins. Photosynth. Res. 20:1-34.

Bisalputra, T. 1974. Plastids. In Stewart, W. D. P. [Ed.] Algal Physiology and Biochemistry. University of California Press, Berkeley, pp. 124-60.

Björkman, O. \& Ludlow, M. 1972. Characterization of the light climate on the floor of a Queensland rain forest. Carnegie Inst. Wash. $\underline{\text { Year }} \underline{\text { Book }}$ 71:85-94.

Boardman, N. K., Anderson, J. M. \& Goodchild, D. J. 1978. Chlorophyllprotein complexes and structure of mature and developing chloroplasts. Curr. Top. Bioenerg. 8:36-109.

Branton, D., Bullivant, S., Gilula, N. B., Karnovsky, M. J., Moor, H., Muhlethaler, K., Northcote, D. H., Packer, L., Satir, B., Satir, P., Speth, V., Staehelin, L. A., Steere, R. L. \& Weinstein, R. S. 1975. Freeze-etch nomenclature. Science 190:54.

Brown, T. E. \& Richardson, F. L. 1968. The effect of growth environment on the physiology of algae: light intensity. I. Phycol. 4:38-54.

Bruce, D., Biggins, J., Steiner, T. \& Thewalt, M. 1986. Excitation energy transfer in the cryptophytes. Fluorescence excitation spectra and picosecond time-resolved emission spectra of intact algae at $77 \mathrm{~K}$. Photochem. Photobiol. 44:519-25.

Dodge, J. D. 1979. The phytoflagellates: fine structure and phylogeny. In Levandowsky, M. \& Hutner, S. H. [Eds.] Biochemistry and Physiology of Protozoa, Vol. 1. Academic Press, New York, pp. 7-57.

Doemel, W. N. \& Brock, T. D. 1971. The physiological ecology of Cyanidium caldarium. I. Gen. Microbiol. 67:17-32. 
Dwarte, D. M. \& Vesk, M. 1982. Freeze-fracture thylakoid ultrastructure of representative members of chlorophyll $\underline{c}$ algae. Micron 13:325-6.

Dwarte, D. M. \& Vesk, M. 1983. A freeze-fracture study of cryptomonad thylakoids. Protoplasma 117:130-41.

Ellis, R., Moore, D. \& Shure, R. 1981. Characteristics of chlorophyll

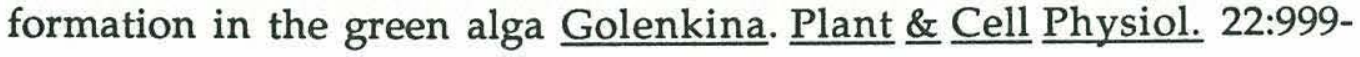
1009.

Falkowski, P. G. \& Owens, T. G. 1980. Light-shade adaptation. Two strategies in marine phytoplankton. Plant Physiol. 66:592-5.

Faust, M. A. \& Gantt, E. 1973. Effect of light intensity and glycerol on the growth, pigment composition, and ultrastructure of Chroomonas sp. L. Phycol. 9:489-95.

Gantt, E. 1979. Phycobiliproteins of Cryptophyceae. In Levandowski, M. \& Hutner, S. H. [Eds.] Biochemistry and Physiology of Protozoa, Vol. 2. Academic Press, New York, pp. 121-37.

Gibbs, S. P. 1962. The ultrastructure of the chloroplasts of algae. L. Ultrastruct. Res. 7:418-35.

Gibbs, S. P. 1970. The comparative ultrastructure of the algal chloroplast. Ann. N..$\underline{\text { Acad. Sci. }}$. 175:454-73.

Gibbs, S. P. 1981. The chloroplasts of some algal groups may have evolved from endosymbiotic eukaryotic algae. $\underline{\text { Ann. }} \underline{\text { N. }} . \underline{\text {. Acad. }}$ Sci. 361:193208.

Guard-Friar, D., Eisenberg, B. L., Edwards, M. R. \& MacColl, R. 1986. Immunochemistry on cryptomonad biliproteins. Plant Physiol. 80:3842. 
Guillard, R. R. L. 1975. Culture of phytoplankton for feeding marine invertebrates. In Smith, W. L. \& Chaney, M. H. [Eds.] Culture of Marine Invertebrate Animals. Plenum Press, New York, pp. 29-60.

Haxo, F. T. 1985. Photosynthetic action spectrum of the coccolithophorid, Emiliania huxleyi (Haptophyceae): 19'-hexanoyloxyfucoxanthin as antenna pigment. I. Phycol. 21:282-7.

Haxo, F. T. \& Fork, D. C. 1959. Photosynthetically active accessory pigments of cryptomonads. Nature 184:1051-2.

Holm-Hansen, O., Lorenzen, C. J., Holmes, R. W. \& Strickland, J. D. H. 1965. Fluorometric determination of chlorophyll. I. Cons., Cons. Perm. Int. Explor. Mer. 30:3-15.

Humphrey, G. F. 1979. Photosynthetic characterisitics of algae grown under constant illumination and light-dark regimes. I. Exp. Mar. Biol. Ecol. 40:63-70.

Ingram, K. \& Hiller, R. G. 1983. Isolation and characterization of a major chlorophyll $\underline{a} / \underline{c} 2$ light-harvesting protein from a Chroomonas species (Cryptophyceae). Biochim. Biophys. Acta 722:310-19.

Kirk, J. T. O. 1983. Light and Photosynthesis in Aquatic Environments. Cambridge Univ. Press, Cambridge, 401 pp.

Kirk, J. T. O. \& Tilney-Bassett, R. A. E. 1967. The Plastids. Their $\underline{\text { Chemistry }}$ Structure, Growth and Inheritance. W. H. Freeman and Company, London, $608 \mathrm{pp}$.

Larkum, A. W. D. \& Barrett, J. 1983. Light-harvesting processes in algae. Adv. Bot. Res. 10:1-219. 
Lewitus, A. J. \& Caron, D. A. 1990. Relative effects of nitrogen or phosphorus depletion and light intensity on the pigmentation, chemical composition, and volume of Pyrenomonas salina (Cryptophyceae). Mar. Ecol. Prog. Ser. 61:171-81.

Lichtlé, C. 1979. Effects of nitrogen deficiency and light of high intensity on Cryptomonas rufescens (Cryptophyceae). I. Cell and photosynthetic apparatus transformations and encystment. Protoplasma 101:283-99.

Lichtlé, C., Duval, J. C., Hauswirth, N. \& Spilar, A. 1986. Freeze fracture study of thylakoid organization of Cryptomonas rufescens (Cryptophyceae) according to illumination conditions. Photocbiohem. Photobiophys. 11:159-71.

Lichtlé, C., Duval, J. C. \& Lemoine, Y. 1987. Comparative biochemical, functional and ultrastructural studies of photosystem particles from a Cryptophycea: Cryptomonas rufescens; isolation of an active phycoerythrin particle. Biochim. Biophys. Acta 894:76-90.

Lichtlé, C., Jupin, H. \& Duval, J. C. 1980. Energy transfers from photosystem II to photosystem I in Cryptomonas rufescens (Cryptophyceae). Biochim. Biophys. Acta 591:104-12.

Lichtlé, C. \& Thomas, J. C. 1976. Étude ultrastructurale des thylacoïdes des algues à phycobiliproteines, comparaison des résultats obtenus par fixation classique et cryodécapage. Phycologia 15:393-404.

Ludwig, M. \& Gibbs, S. P. 1989. Localization of phycoerythrin at the lumenal surface of the thylakoid membrane in Rhodomonas lens. I. Cell Biol. 108:875-84. 
MacColl, R. \& Berns, D. S. 1978. Energy transfer studies on cryptomonad biliproteins. Photochem. Photobiol. 27:343-9.

MacColl, R., Berns, D. S. \& Gibbons, O. 1976. Characterization of cryptomonad phycoerythrin and phycocyanin. Arch. Biochem. Biophys. 177:265-75.

Miller, K. R. \& Cushman, R. A. 1979. A chloroplast membrane lacking photosystem II. Thylakoid stacking in the absence of the photosystem II particle. Biochim. Biophys. Acta 546:481-97.

Miller, K. R. \& Lyon, M. K. 1985. Do we really know why chloroplast membranes stack? Trends Biochem. Sci. 10:219-22.

Miller, K. R. \& Lyon, M. K. 1986. Reply from Miller and Lyon. Trends Biochem. Sci. 11:320.

Osafune, T. \& Hase, E. 1975. Some structural characteristics of the chloroplasts in the "glucose bleaching" and re-greening cells of Chlorella protothecoides. Biochem. Physiol. Pfl. 168:533-42.

Rhiel, E., Kunz, J. \& Wehrmeyer, W. 1989. Immunocytochemical localization of phycoerythrin-545 and of a chlorophyll $\underline{\mathrm{a}} / \underline{\mathrm{c}}$ light harvesting complex in Cryptomonas maculata (Cryptophyceae). $\underline{\text { Bot. }}$ Acta 102:46-53.

Rhiel, E., Mörschel, E. \& Wehrmeyer, W. 1985. Correlation of pigment deprivation and ultrastructural organization of thylakoid membranes in Cryptomonas maculata following nutrient deficiency. Protoplasma 129:62-73.

Rhiel, E., Mörschel, E. \& Wehrmeyer, W. 1985. Characterization and structural analysis of a chlorophyll $\underline{a} / \underline{c}$ light harvesting complex and 
of photosystem I particles isolated from thylakoid membranes of Cryptomonas maculata (Cryptophyceae). Eur. I. Biochem. 43:82-92.

Richardson, K., Beardall, J \& Raven, J. A. 1983. Adaptation of unicellular algae to irradiance: An analysis of strategies. New Phytol. 93:157-91.

Schuler, F., Brandt, P. \& Wiessner, W. 1981. Chloroplast reduction in Euglena gracilis by heterotrophic nutrition with glucose in the light. Protoplasma 106:317-28.

Schwelitz, F. D., Cisneros, P. L. \& Jagielo, J. A. 1978b. The effect of glucose on the biochemical and ultrastructural characteristics of developing Euglena chloroplasts. I. Protozool. 25:398-403.

Schwelitz, F. D., Cisneros, P. L., Jagielo, J. A., Comer, J. L. \& Butterfied, K. A. 1978a. The relationship of fixed carbon and nitrogen sources to the greening process in Euglena gracilis strain Z. I. Protozool. 25:257-61.

Shihira-Ishikawa, I. \& Hase, E. 1964. Nutritional control of cell pigmentation in Chlorella protothecoides with special reference to the degeneration of chloroplast induced by glucose. Plant $\underline{\&} \underline{\text { Cell }}$ Physiol. 5:227-40.

Snyder, U. K. \& Biggins, J. 1987. Excitation-energy redistribution in the cryptomonad alga Cryptomonas ovata. Biochim. Biophys. Acta 892:4855.

Spear-Bernstein, L. \& Miller, K. R. 1985. Are the photosynthetic membranes of cryptophyte algae inside out? Protoplasma 129:1-9.

Spear-Bernstein, L. \& Miller, K. R. 1987. Immunogold localization of the phycobiliprotein of a cryptophyte alga to the thylakoid space. $\underline{\text { In }}$ 


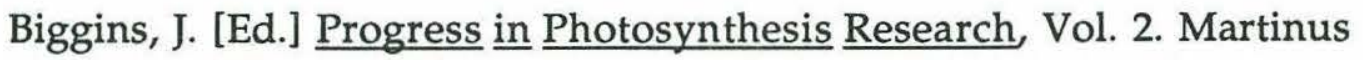
Nijhoff Publishers, Dordrecht, The Netherlands, pp. 309-12.

Spear-Bernstein, L. \& Miller, K. R. 1987. Unique localization of the phycobiliprotein light-harvesting pigment in the Cryptophyceae. I. Phycol. 25:412-19.

Spurr, A. R. 1969. A low-viscosity epoxy resin embedding medium for electron microscopy. I. Ultrastruct. Res. 26:31-42.

Staehelin, L. A. 1976. Reversible particle movements associated with unstacking and restacking of chloroplast membranes in vitro. I. Cell Biol. 71:136-58.

Staehelin, L. A. 1981. Freeze-fracture studies of green plant and Prochloron thylakoids. A status report. In Akoyunoglou, G. [Ed.] Encyclopedia of Plant Physiology Photosynthesis $\underline{\text { III. Structure and Molecular }}$ Organization of the Photosynthetic Apparatus. Balaban International Science Services, Philadelphia, Pa., pp. 3-14.

Staehelin, L. A. 1986. Chloroplast structure and supramolecular organization of photosynthetic membranes. In Staehelin, L. A. \& Arntzen, C. J. [Eds.] Encyclopedia of Plant Physiology Photosynthesis III. Photosynthetic Membranes and Light Harvesting Systems, Vol. 19. Springer-Verlag, Berlin, pp. 1-84.

Staehelin, L. A. \& Arntzen, C. J. 1983. Regulation of chloroplast membrane function: protein phosphorylation changes the spatial organization of membrane components. I. Cell Biol. 97:1327-37. 
Thinh, L.-V. 1983. Effect of irradiance on the physiology and ultrastructure of the marine cryptomonad, Cryptomonas strain Lis (Cryptophyceae). Phycologia 22:7-11.

Thinh, L.-V. 1988. Photoadaptation of photosynthesis in Cryptomonas Strain Lis. Photosynthetica 22:405-10.

Vallon, O., Wollman, F. A. \& Olive, J. 1986. Lateral distribution of the main complexes of the photosynthetic apparatus in Chlamydomonas reinhardtii and in spinach: an immunocytochemical study using intact thylakoid membranes and PSII enriched membrane preparations. Photobiochem. Photobiophys. 12:203-20.

Vannini, G. L. 1983. Degeneration and regeneration of chloroplasts in Euglena gracilis grown in the presence of acetate: ultrastructural evidence. I. Cell Sci. 61:413-22.

Wiessner, W. \& Amelunxen, F. 1969a. Beziehungen zwischen submikroskopischer Chloroplastenstruktur und Art der Kohlenstoffquelle unter phototrophen Ernährungsbedingungen bei Chlamydobotrys stellata. Arch. Mikrobiol. 66:14-24.

Wiessner, W. \& Amelunxen, F. 1969b. Umwandlungen der submikroskopischen Chloroplastenstruktur parallel zurVeränderung der stoffwechselphysiologischen Leistung von Chlamybobotris stellata. Arch. Mikrobiol. 67:357-69. 
Chapter 6.

Summary 


\section{SUMMARY}

By nature of their environment, phytoplankton can experience extreme variability in light and nutrient availability. The ability to use alternative sources of carbon, nitrogen, phosphorus, metabolic energy, reducing power, and other growth essentials obviously would enhance a phytoplankter's potential for growth and survival. The use of alternative resources, however, requires different metabolic pathways that, taken together, would involve expensive cellular investments in space and biosynthetic energy and materials. It's not surprising, therefore, that the acquisition of alternative carbon sources by some phytoplankton involves tradeoffs within the cell between the synthesis of components involved in the assimilation of organic carbon sources and those involved in photosynthesis; e. g., Chlorella protothecoides (Hase, 1971), Euglena gracilis (Monroy and Schwartzbach, 1984), Chlamydobotrys stellata (Wiessner, 1979), Cyanidium caldarium (Steinmüller and Zetsche, 1984), and Chlorogonium elongatum (Steinbi $\beta$ and Zetsche, 1986). This research shows that such tradeoffs also occur in Pyrenomonas salina and Poterioochromonas malhamensis adapting to changes in light and organic substrate availability, but that the mechanisms involved in switching between nutritional modes and the environmental control of these switches differ greatly between these species.

P. malhamensis has an exceptional heterotrophic capability and, when supplied with an organic substrate favorable for growth (e. g.,

glucose, bacteria), represses the development of its chloroplast such that 
the chlorophyll concentration cell ${ }^{-1}$ can be reduced dramatically. This study demonstrated that the inhibitory effect of organic substrates on chlorophyll production by $\underline{P}$. malhamensis varied with the type of organic substrate and was independent of the nitrogen concentration or carbon to nitrogen ratio of the culture medium. These results support Handa et al.'s (1981) hypothesis that glucose is a catabolite repressor of chloroplast development in $\underline{P}$. malhamensis, and indicate that glycerol and ethanol may also function in catabolite repression. Given the dominant role of heterotrophy in $\underline{P}$. malhamensis, catabolite repression would be a very efficient mechanism for controlling chloroplast development in this organism. For example, because glucose metabolism can support maximum growth rates of the alga even in the absence of light, photosynthesis is unnecessary for growth when glucose is available. The repression of chloroplast development under these conditions, therefore, would minimize the expenditure of cellular biosynthetic energy and materials on an organelle superfluous for growth.

$\underline{\text { P. malhamensis }}$ has an extremely limited capability for photoautotrophic growth. Even in the absence of organic substrates, when it's chloroplast is fully developed, $\underline{P}$. malhamensis can only attain a specific growth rate of 0.3 day $^{-1}$. Given the relatively minor contribution of photosynthesis to its overall nutrition, it's difficult to understand why this alga has retained the ability to synthesize a chloroplast. Photoautotrophic nutrition is presumably a mechanism to enhance $\underline{P}$. malhamensis's survival during periods when organic substrates are unavailable to the alga. An important finding from this research, 
however, indicates that chloroplast development in $\underline{P}$. malhamensis is controlled by more than simply the organic substrate concentration of the medium. The inhibitory effect of organic substrates on chlorophyll production by $\underline{P}$. malhamensis could be relieved even when organic substrate concentrations in the culture medium were very high. This relief apparently was related to excretory substance(s) produced by $\underline{P}$. malhamensis. The identity of these substance(s) and knowledge of their role in regulating cellular processes involved in autotrophy and heterotrophy in $\underline{P}$ malhamensis may prove valuable to our understanding of the relative importance of these nutritional modes to this chrysophyte (and possibly other phytoplankton) in nature.

Although a tradeoff between cellular components involved in organic substrate metabolism and photosynthesis also occurs in $\underline{P}$. salina, only selected components of the photosynthetic apparatus (i. e., those involved in light-harvesting) were reduced in response to organic substrate uptake by this cryptophyte. Because cellular carbon, energy, and/or reductant demands can be augmented by organic substrate catabolism, the ability to harvest light becomes less critical for growth when organic substrates are taken up by $\underline{P}$. salina. The reduction of the light-harvesting apparatus under these conditions appears to be an adaptive response to limit the production of cellular components that, with the utilization of organic compounds, become less essential for growth.

Although glycerol assimilation resulted in a loss of light-harvesting potential in $\underline{P}$. salina, the $\mathrm{CO}_{2}$ uptake rate cell-1 was not affected, even at a 
limiting light intensity. Thus, under these conditions, a fully operational Calvin cycle apparently is retained by $\underline{\mathbf{P}}$. salina and fueled by energy and reductants derived from glycerol catabolism. The maintenance of a fully functional photosynthetic system during organic substrate uptake by $\underline{P}$.

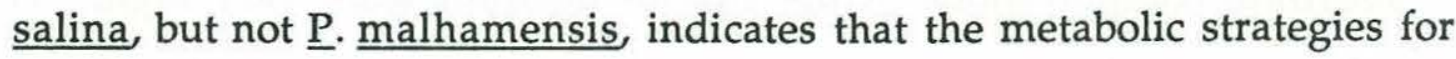
adapting to changes in nutritional mode are distinct in these algae, and these different strategies reflect their contrasting nutritional characteristics. Whereas the contribution of photosynthesis to the overall nutrition of $\underline{P}$. malhamensis was relatively minor, the dominant mode of carbon acquisition for growth in $\underline{P}$. salina was autotrophy. Unlike $\underline{P}$.

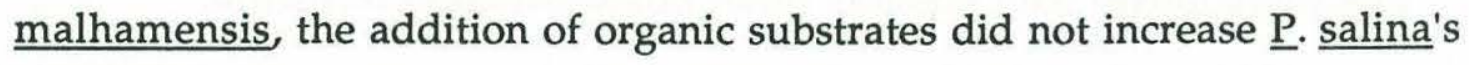
growth rate at saturating light intensities. Also, a major proportion of glycerol taken up by $\underline{\mathrm{P}}$. $\underline{\text { salina }}$ was incorporated into carbohydrate (starch) reserves. Therefore, analogous to the apparent use of photoautotrophy by $\underline{P}$. malhamensis as a survival mechanism during times when the availability organic substrates is limiting, $\underline{P}$. salina appears to use heterotrophy as a mechanism to enhance survival during periods when the availability of light is limiting.

\section{REFERENCES}

Handa, A. K., R. A. Bressan, H. Quader and P. Filner. 1981. Association of formation and release of cyclic AMP with glucose depletion and onset of chlorophyll synthesis in Poterioochromonas malhamensis. Plant Physiol. 68: 460-463. 
Hase, E. 1971. Studies on the metabolism of nucleic acid and protein associated with the processes of de- and re-generation of chloroplasts in Chlorella protothecoides. In: N. K. Boardman, A. W. Linnane, and R. M. Smillie (eds.) Autonomy and Biogenesis of Mitochondria and Chloroplasts. North-Holland, New York, pp. 434-446.

Monroy, A. F. and S. D. Schwartzbach. 1984. Catabolite repression of chloroplast development in Euglena. Proc. Natl. Acad. Sci. U. S. A. 81: 2786-2790.

Steinbi $\beta$, H. J. and K. Zetsche. 1986. Light and metabolic regulation of the synthesis of ribulose-1,5-bisphosphate carboxylase/oxygenase and the corresponding mRNAs in the unicellular alga Chlorogonium. Planta 167: 575-581.

Steinmüller, K. and K. Zetsche. 1984. Photo- and metabolite regulation of the synthesis of ribulose bisphosphate carboxylase/oxygenase and the phycobiliproteins in the alga Cyanidium caldarium. Plant Physiol. 76: 935-939.

Wiessner, W. 1979. Photoassimilation of organic compounds. In: M. Gibbs and E. Latzko (eds.) Photosynthesis II. Photosynthetic Carbon Metabolism and Related Processes, Encyclopedia of Plant Physiology Vol. 6. Springer-Verlag, Berlin, pp. 181-189. 